\title{
(a)
}

AUTARQUIA ASSOCIADA A UNIVERSIDADE DE SÃO PAULO

\section{DESENVOLVIMENTO E VALIDAÇÃO DE METODO PARA A EXTRAÇÃO E QUANTIFICAÇÃO DE COMPOSTOS FENÓLICOS EM SEDIMENTO. ESTUDO DE CASO: RESERVATÓRIO GUARAPIRANGA, SP}

\author{
GISELE ADAME
}

Dissertação apresentada como parte dos requisitos para obtenção do Grau de Mestre em Ciências na Área de Tecnologia Nuclear - Materiais

Orientadora:

Profa. Dra. Marycel Elena Barboza Cotrim 
INSTITUTO DE PESQUISAS ENERGÉTICAS E NUCLEARES

Autarquia associada à Universidade de São Paulo

\title{
DESENVOLVIMENTO E VALIDAÇÃO DE METODO PARA A EXTRAÇÃO E QUANTIFICAÇÃO DE COMPOSTOS FENÓLICOS EM SEDIMENTO. ESTUDO DE CASO: RESERVATÓRIO GUARAPIRANGA, SP
}

\author{
GISELE ADAME
}

Dissertação apresentada como parte dos requisitos para obtenção do Grau de Mestre em Ciências na Área de Tecnologia Nuclear - Materiais

Orientadora:

Profa. Dra. Marycel Elena Barboza Cotrim

Versão Corrigida

Versão Original disponivel no IPEN

São Paulo

2016 
Dedico este trabalho aos quatro grandes pilares da minha vida, Luci e Dorival, Ravindra Gopala das e Purushatraya Swami, sem os quais nada seria possível. 


\section{AGRADECIMENTOS}

À Dra. Marycel Elena Barboza Cotrim pela orientação e confiança em meu trabalho.

À Dra. Elâine Arantes Jardim Martins por toda contribuição ao trabalho, mas principalmente pelo carinho, amizade e por me ajudar a ser não só uma boa profissional como também uma pessoa melhor.

Ao Dr. Hélio Akira Furusawa, pela elaboração da planilha de validação e contribuições no início do projeto.

À Dra. Helena Miho Shihomatsu pelas contribuições feitas na disciplina Tópicos Especiais em Tecnologia Nuclear.

À Dra. Maria A. F. Pires pela disponibilização dos laboratórios e equipamentos.

Ao Instituto de Pesquisas Energéticas e Nucleares, IPEN-CNEN/SP, em especial ao Centro de Química e Meio Ambiente, CQMA, pela infraestrutura e oportunidade de desenvolver este trabalho.

À CAPES pela bolsa de estudos concedida.

À FAPESP pelo apoio financeiro para realização desta pesquisa.

Aos amigos Larissa, Raquel, Tarsila, Carlos, Karol, Juliana, Priscila pelo companheirismo, trabalho em equipe e momentos de descontração. Em especial à Juliana Otomo por todo suporte, paciência e disposição para ensinar.

A todos os funcionários e alunos do CQMA, pela convivência agradável e pela pronta disposição em ajudar todas as vezes que precisei.

À minha querida família, meus pais Luci e Dorival e minha tia do coração Edna, pelo apoio, carinho e suporte e ao meu marido Ravindra Gopala das, pela paciência e companheirismo. 
"O período de maior ganho em conhecimento e experiência é o período mais difícil da vida de alguém."

Dalai Lama 


\title{
DESENVOLVIMENTO E VALIDAÇÃO DE METODO PARA A EXTRAÇÃO E QUANTIFICAÇÃO DE COMPOSTOS FENÓLICOS EM SEDIMENTO. ESTUDO DE CASO: RESERVATÓRIO GUARAPIRANGA, SP
}

\author{
Gisele Adame
}

\section{RESUMO}

Compostos fenólicos vêm despertando preocupação nos últimos anos e incitando grande atenção em todo o mundo ao desenvolvimento de métodos de determinação e monitoramento contínuo no ambiente devido a sua elevada toxicidade e persistência no meio ambiente, principalmente no sedimento, que devido sua característica em acumular compostos faz desse um dos compartimentos mais importantes na avaliação do nível de contaminação de ecossistemas aquáticos continentais. Neste estudo foi desenvolvido um método analítico utilizando cromatografia a gás acoplada ao detector de espectrometria de massas (GC/MS) para a determinação de seis compostos fenólicos e foi avaliada a presença dos mesmos em amostras de sedimento do Reservatório Guarapiranga, um reservatório de usos múltiplos da água, destinado principalmente para abastecimento público de água potável da Região Metropolitana de São Paulo. Para garantir a reprodutibilidade do método de forma confiável atendendo aos objetivos e qualidade propostos, a metodologia desenvolvida foi submetida ao processo de validação, em que os parâmetros seletividade, linearidade, faixa de trabalho, limite de detecção, limite de quantificação, tendência/recuperação, precisão (repetitividade, precisão intermediária e reprodutibilidade) e robustez foram avaliados. A metodologia aqui proposta mostrou ser adequada para alcançar o objetivo de avaliar os compostos em estudo, e pela sua aplicação foi constatada a presença dos compostos fenol e 3-metilfenol no sedimento do reservatório. Nas amostras de sedimento coletadas em 2011, o fenol foi o composto encontrado com maior frequência, com alguns resultados acima do $L Q$, principalmente em pontos com maior influência urbana, em concentrações de 0,09 a 0,19 $\mathrm{g} \mathrm{g} \mathrm{g}^{-1}$. Também foi encontrado o 3-metilfenol com resultados acima do LQ em dois pontos de coleta, G-11 e G-13, nas concentrações de 0,10 e 0,19 $\mu \mathrm{g} \mathrm{g}^{-1}$ respectivamente. Já na coleta realizada em outubro de 2014, o composto 3-metilfenol foi quantificado em dois pontos de coleta, G-02 e G-07, nas concentrações de 0,07 e 0,08 $\mu \mathrm{g} \mathrm{g}^{-1}$ respectivamente, sendo detectado abaixo do $L Q$ em diversos pontos ao longo do reservatório. A presença destes compostos mesmo em baixas concentrações pode indicar uma contaminação decorrente de atividades industriais nas margens do reservatório e considerando-se que os compostos em sedimento com o tempo podem ser liberados na coluna d'água e causar contaminação na água de abastecimento este estudo fornece subsídios para revisão da legislação vigente que não estabelece limites para os compostos fenólicos na matriz de estudo. 


\title{
DEVELOPMENT AND VALIDATION METHOD FOR EXTRACTION AND QUANTIFICATION OF PHENOLICS COMPOUNDS IN SEDIMENT. CASE STUDY: RESERVOIR GUARAPIRANGA, SP
}

\author{
Gisele Adame
}

\begin{abstract}
Phenolic compounds are molecules with increased toxicity and persistence in the environment, mainly in the sediment. Furthermore, these molecules are capable of accumulate compounds, making them one of the most important at the evaluation of the contamination level on aquatic ecosystems in the continent. These features increased the preoccupation in the last years, inciting great attention around the globe about the development of methods to determine and continuously monitor these compounds in the environment. In this study, a new analytical methodology was developed using gas chromatography mass spectrometry system (GC/MS) at the determination and evaluation of six phenolic compounds in sediment samples of the Guarapiranga Reservoir, a water reservatory with multiple uses, intended primarily for public drinking water supply in the Metropolitan Region of São Paulo, Brazil. This methodology was submitted to the validation process, to ensure the reproducibility of the method in a trustworthy way, according to the objectives and quality proposed. Selectivity, linearity, working range, detection limit, quantification limit, trend/recovery, precision (repeatability, intermediate precision and reproducibility) and robustness are the parameters evaluated in this process. This methodology revealed itself adequate to achieve the goal of evaluating the compounds studied. Through this method, it was verified that the compounds phenol and 3-methylphenol are present at the reservoir's sediment. In sediment samples collected in 2011, phenol was the compound found most frequently, with some results above $L Q$, especially on points with greater urban influence, in concentrations from 0.09 to $0.19 \mu \mathrm{g} \mathrm{g}^{-1}$. It was also found 3-methylphenol with results above LQ on two collected points, G-11 and G-13 at concentrations of 0.10 and $0.19 \mu \mathrm{g} \mathrm{g}^{-1}$ respectively. In 2014, the 3-methyl phenol compound was quantified in two collected points, G-02 and G-07 at concentrations of 0.07 and $0.08 \mu \mathrm{g} \mathrm{g}^{-1}$ respectively, being detected below the $L Q$ at various points along the reservoir. The presence of these compounds, even in low concentrations, can indicate a contamination from industrial activities at the reservoir margin. Considering that these compounds in the sediment can, with time, be released in the water column and contaminate the water supply, this study provides subsidies for a review of the current legislation, that do not sets limits to the concentration of phenolic compounds on sediment matrix.
\end{abstract}




\section{SUMÁRIO}

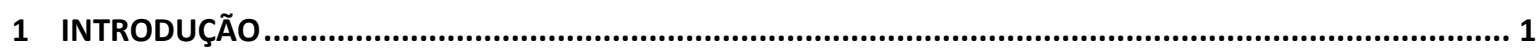

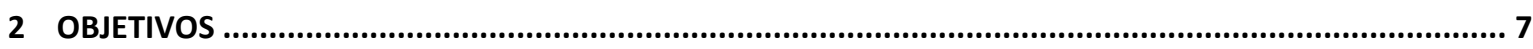

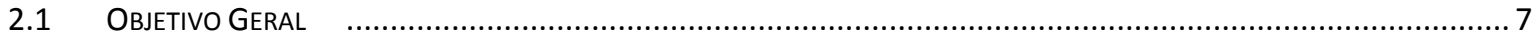

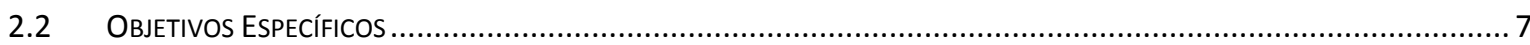

3 EMBASAMENTO TEÓRICO

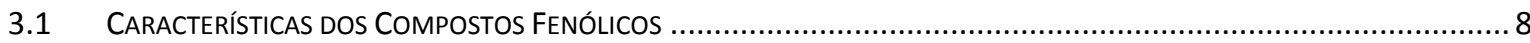

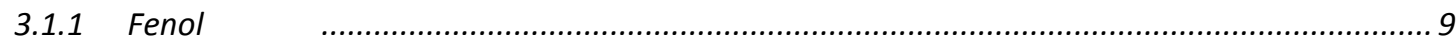

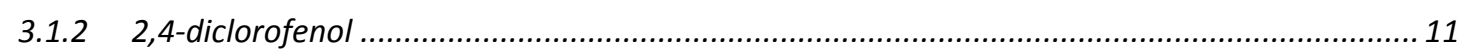

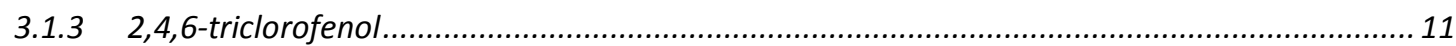

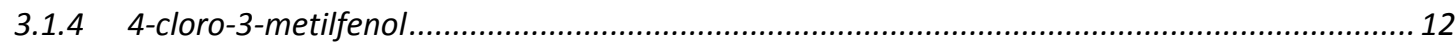

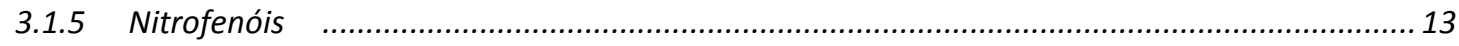

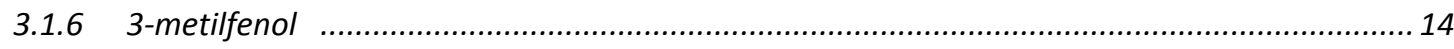

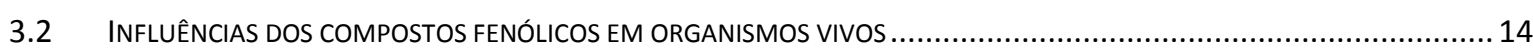

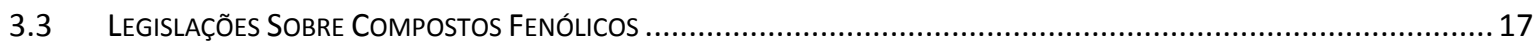

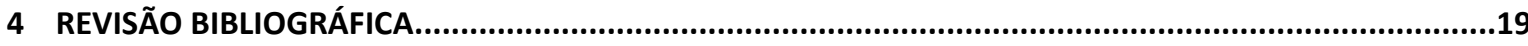

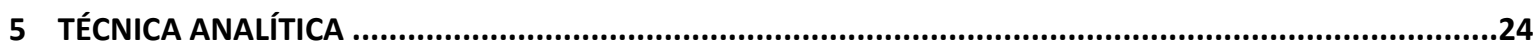

5.1 Metodologias EmpregadAs na Análise de Compostos Fenólicos ............................................................2

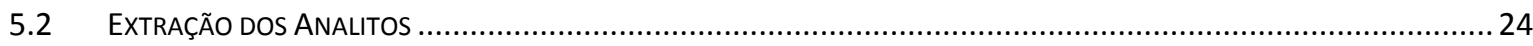

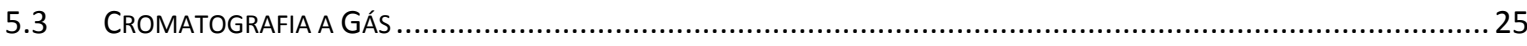

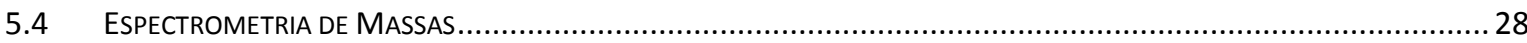

6 ÁREA DE ESTUDO

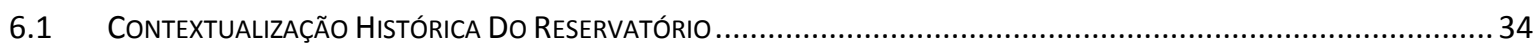

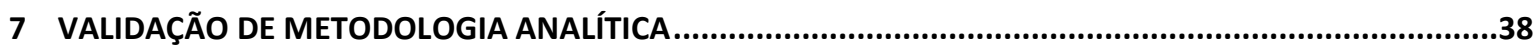

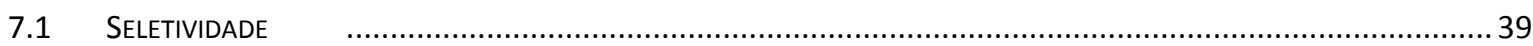

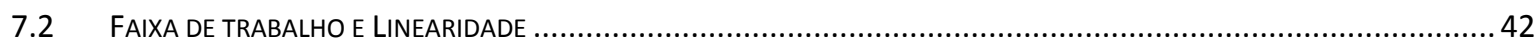

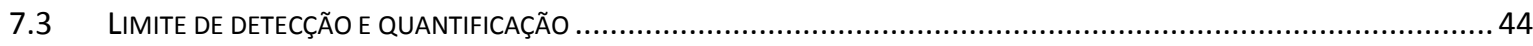

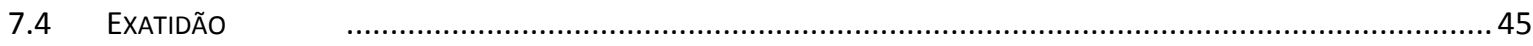

7.5 PRECISÃO

7.6 RECUPERAÇÃO

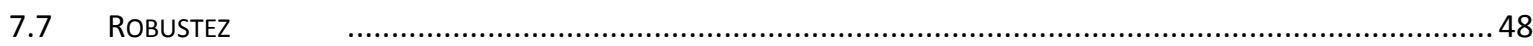

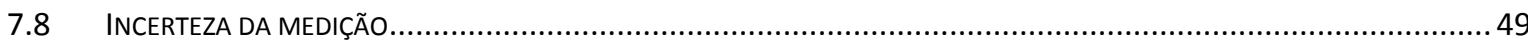


8 PARTE EXPERIMENTAL

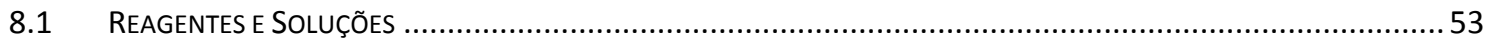

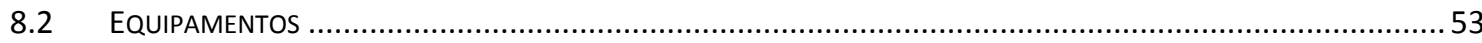

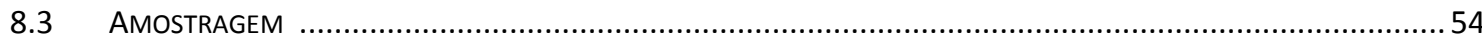

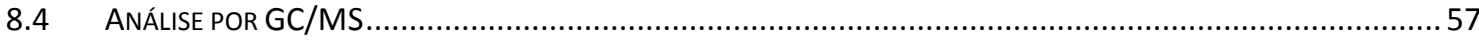

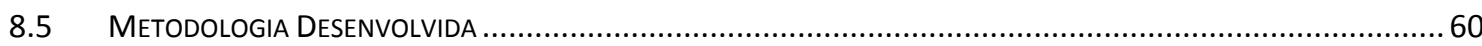

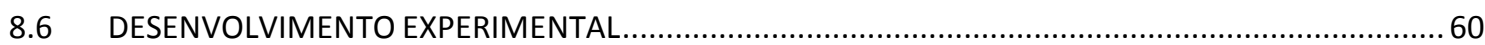

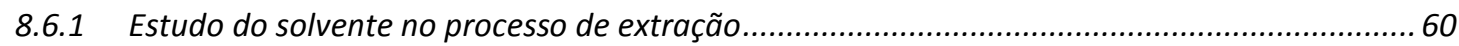

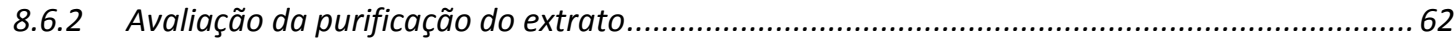

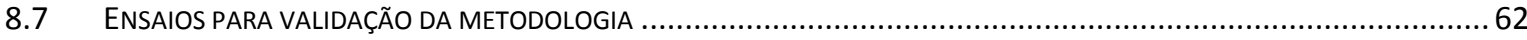

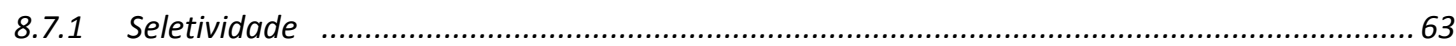

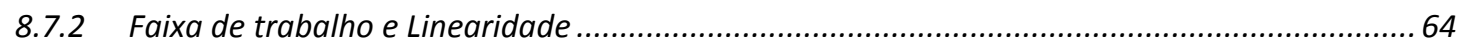

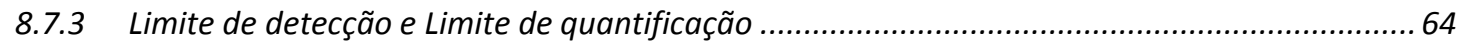

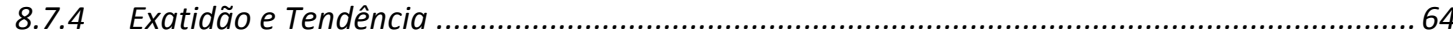

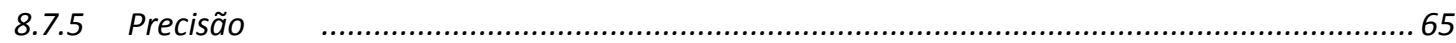

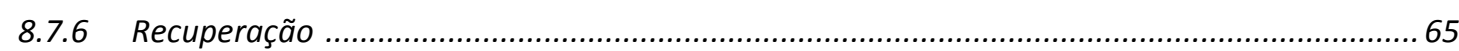

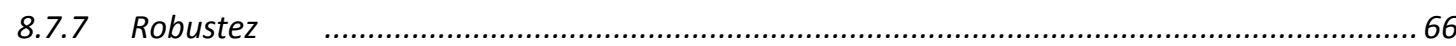

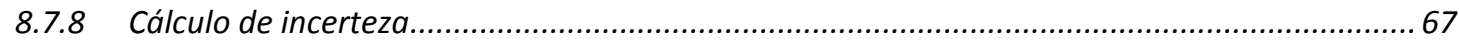

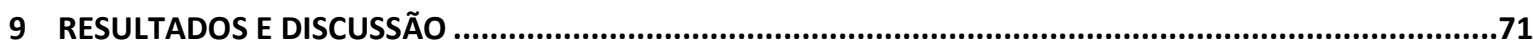

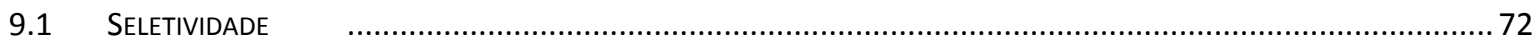

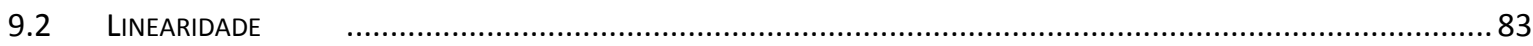

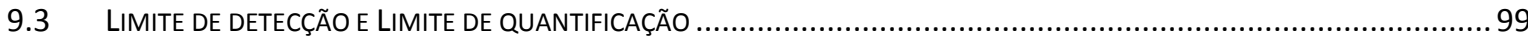

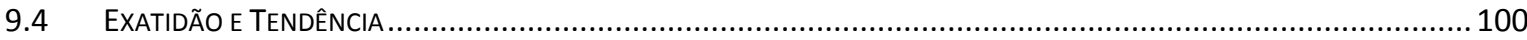

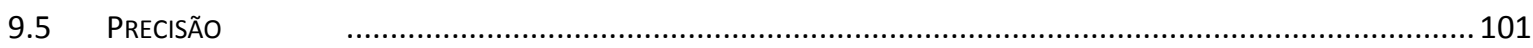

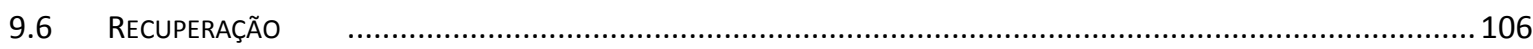

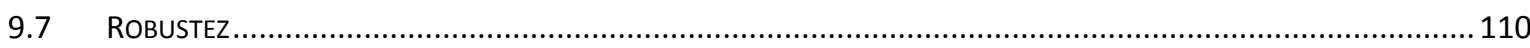

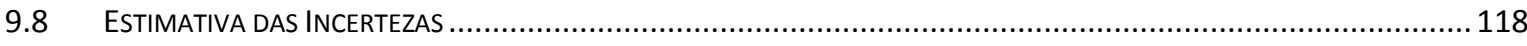

9.9 RESULTAdOS DA AVALIAÇÃo DAS AMOSTRAS DO RESERVATÓRIO GUARAPIRANGA .......................................... 121

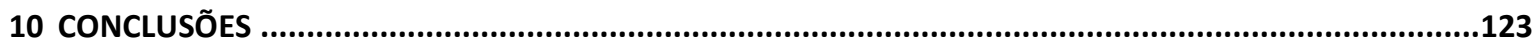

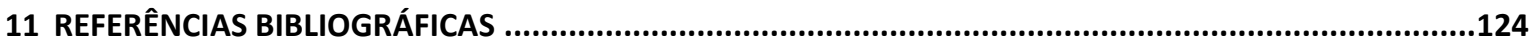

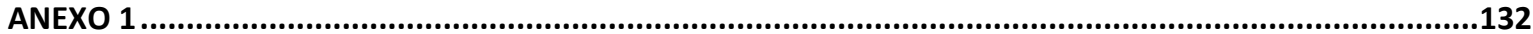




\section{LISTA DE TABELAS}

TABELA 1. Propriedades físico-químicas dos compostos fenólicos 09

TABELA 2. Planejamento fatorial saturado para avaliação da estimativa do erro da distribuição dos efeitos utilizando o algoritimo de Dong (pequenos experimentos). 49

TABELA 3. Identificação dos padrões analíticos utilizados 53

TABELA 4. Descrição dos pontos de coleta das amostras, coordenadas geográficas e registros de observações realizadas pela equipe de coleta 56

TABELA 5. Configuração do modo de aquisição SIM 59

TABELA 6. Concentrações das soluções de trabalho dos compostos estudados .... 59

TABELA 7. Relação dos solventes utilizados nos oito testes para extração de compostos fenólicos 60

TABELA 8. Faixas de concentrações do ensaio de recuperação 66

TABELA 9. Parâmetros nominais e suas variações selecionadas para o ensaio de robustez do método final. 66

TABELA 10. Resultados dos testes estatísticos $\mathrm{F}$ e $\mathrm{t}$ aplicados para avaliação da seletividade em extrato de sedimento (Matriz) e no solvente (sem matriz) e variância obtida $\left(\mathrm{s}^{2}\right)$ nos ensaios com e sem matriz do método final. Considerando $F_{\text {tabelado }}=4,28$ e $t_{\text {tabelado }}=2,179$, para 7 graus de liberdade $e$ $95 \%$ de confiança 78

TABELA 11. Resultados dos testes estatísticos $F$ e $t$ aplicados para avaliação da seletividade em extrato de sedimento (Matriz) e no solvente (sem matriz) e variância obtida $\left(\mathrm{s}^{2}\right)$ nos ensaios com e sem matriz do método SPE. Considerando $F_{\text {tabelado }}=4,28$ e $t_{\text {tabelado }}=2,179$, para 7 graus de liberdade $e$ $95 \%$ de confiança 80

TABELA 12. Valores obtidos com o teste t Student para intercepto para o método final. Onde $t_{\text {tabelado }}=2,179$, considerando 7 graus de liberdade e com $95 \%$ de confiança 
TABELA 13. Valores obtidos com o teste t Student para intercepto para o método SPE. Onde $t_{\text {tabelado }}=2,179$, considerando 7 graus de liberdade e com $95 \%$ de confiança...... 83

TABELA 14. Faixa de trabalho, equação da reta e coeficiente de determinação $\left(r^{2}\right)$ dos compostos estudados, obtidos pela adição padrão na matriz de extrato de sedimento do método final. 84

TABELA 15. Faixa de trabalho, equação da reta e coeficiente de determinação $\left(r^{2}\right)$ dos compostos estudados, obtidos pela adição padrão na matriz de extrato de sedimento do método SPE. 86

TABELA 16. Faixa de trabalho, equação da reta e coeficiente de determinação $\left(r^{2}\right)$ dos compostos estudados sem matriz 87

TABELA 17. Valores obtidos no Teste t-Student para a verificação do desvio da linearidade de cada ponto da curva de cada composto em matriz do método final. Sendo o valor tabelado de $t$ crítico para $8(n-1)$ graus de liberdade com $95 \%$ de confiança 2,365. 88

TABELA 18. Valores obtidos no Teste t-Student para a verificação do desvio da linearidade de cada ponto da curva de cada composto em matriz do método SPE. Sendo o valor tabelado de t crítico para $8(n-1)$ graus de liberdade com $95 \%$ de confiança 2,365 89

TABELA 19. Valores obtidos no Teste t-Student para a verificação do desvio da linearidade de cada ponto da curva de cada composto no ensaio sem matriz. Sendo o valor tabelado de t crítico para $8(n-1)$ graus de liberdade com $95 \%$ de confiança 2,365 . 89

TABELA 20. Valores de coeficiente de determinação e resultados do teste $F$ de regressão e de ajuste, porcentagem de variação explicada e máxima variação explicável para avaliação da linearidade do método final. 96

TABELA 21. Valores de coeficiente de determinação e resultados do teste $F$ de regressão e de ajuste, porcentagem de variação explicada e máxima variação explicável para avaliação da linearidade do método SPE 96

TABELA 22. Limites de detecção e limites de quantificação dos compostos avaliados no método final 100 
TABELA 23. Limites de detecção e limites de quantificação dos compostos avaliados no método SPE 100

TABELA 24. Valores de z Score obtidos para cada um dos compostos em ensaio com matriz no método final 101

TABELA 25. Valores de z Score obtidos para cada um dos compostos em ensaio com matriz no método SPE 101

TABELA 26. Coeficientes de variação (CV \%) para os compostos em três níveis de concentração no ensaio com matriz de extrato de sedimento no método final 102

TABELA 27. Coeficientes de variação (CV \%) para os compostos em três níveis de concentração no ensaio com matriz de extrato de sedimento no método SPE. 102

TABELA 28. Valores do limite de repetitividade ( $r$ ) para os compostos em três níveis de concentração no ensaio com matriz no método final 103

TABELA 29. Valores do limite de repetitividade ( $r$ ) para os compostos em três níveis de concentração no ensaio com matriz no método SPE 104

TABELA 30. Valores do limite de reprodutibilidade $(\mathrm{R})$ para os compostos em três níveis de concentração no ensaio com matriz no método final. 105

TABELA 31. Valores do limite de reprodutibilidade $(R)$ para os compostos em três níveis de concentração no ensaio com matriz no método SPE. 106

TABELA 32. Valores de recuperação obtidos para concentração baixa no método final. 107

TABELA 33. Valores de recuperação obtidos para concentração média no método final. 107

TABELA 34. Valores de recuperação obtidos para concentração alta no método final. 108

TABELA 35. Valores de recuperação obtidos para concentração baixa no método SPE. 108 
TABELA 36. Valores de recuperação obtidos para concentração média no método SPE 109

TABELA 37. Valores de recuperação obtidos para concentração alta no método SPE. 109

TABELA 38. Parâmetros nominais e suas variações selecionadas para o ensaio de robustez do método SPE 114

TABELA 39. Resultados dos cálculos de incertezas expandidas para os compostos estudados em matriz de extrato de sedimento, considerando-se um intervalo de concentração equivalente ao ponto médio da curva $\left(0,2 \mu \mathrm{g} \mathrm{g}^{-1}\right) \ldots \ldots .118$

TABELA 40. Contribuição da incerteza de cada grandeza de entrada no cálculo do mensurando no ensaio em matriz de sedimento para todos os compostos estudados, considerando-se intervalo de concentração equivalente ao ponto médio da curva. 119

TABELA 41. Resultados da análise da 1a coleta para os 6 compostos nas amostras de sedimento do Reservatório Guarapiranga 121

TABELA 42. Resultados da análise da $2^{\underline{a}}$ coleta para os 6 compostos nas amostras de sedimento do Reservatório Guarapiranga 122 


\section{LISTA DE FIGURAS}

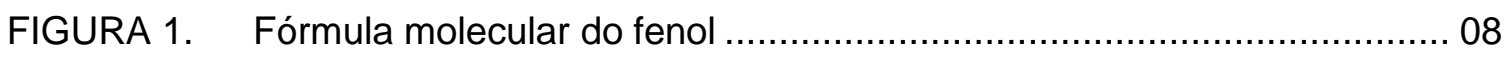

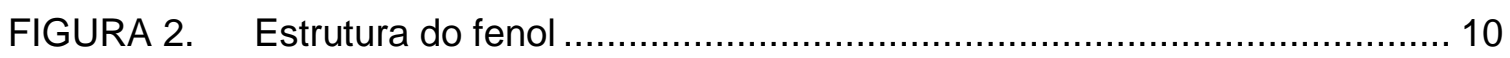

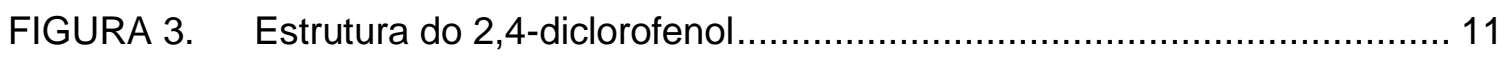

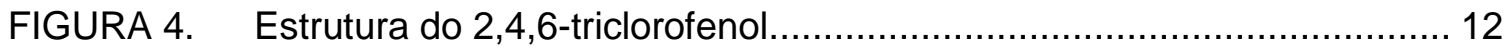

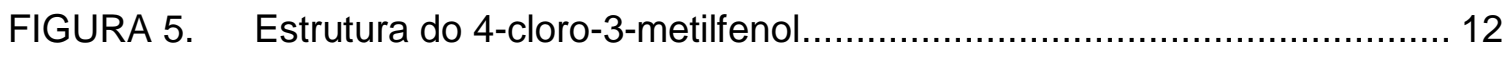

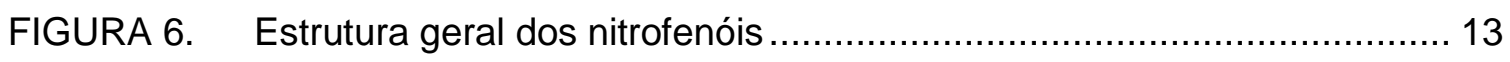

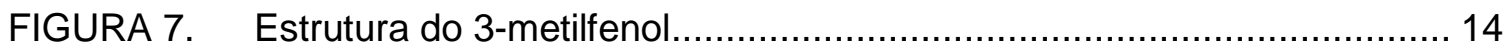

FIGURA 8. Resposta natural, efeito agonista e efeito antagonista dos interferentes endócrinos no organismo ........................................................... 16

FIGURA 9. Desenho esquemático da extração em cartucho SPE ......................... 25

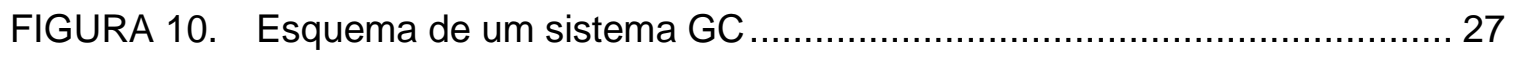

FIGURA 11. Limite da Bacia Hidrográfica do Alto Tietê ............................................ 32

FIGURA 12. Reservatório Guarapiranga ..................................................... 33

FIGURA 13. Mapa das bacias contribuintes, uso e ocupação do solo em torno do Reservatório Guarapiranga

FIGURA 14. Diagrama de Causa e Efeito da metodologia analítica para determinação de Fenóis em sedimento 51

FIGURA 15. Localização da represa Guarapiranga e a distribuição dos pontos de coleta. 55

FIGURA 16. Gráfico representativo da programação da temperatura..... 58

FIGURA 17. Comparação das áreas dos picos de cada um dos compostos extraídos com diferentes solventes.

FIGURA 18. Cromatograma de mistura de padrão com os 6 compostos estudados.. 73

FIGURA 19. Espectros de massa dos compostos fenol e 3-metilfenol. 74 
FIGURA 20. Espectros de massa dos compostos 2-nitrofenol e 2,4-diclorofenol ....... 75

FIGURA 21. Espectros de massa dos compostos 4-cloro-3-metilfenol e $2,4,6$-triclorofenol...................................................................... 76

FIGURA 22. Gráficos da seletividade representados pelas retas obtidas nos ensaios do método final, sem matriz e no método SPE. 82

FIGURA 23. Representação gráfica da linearidade para os compostos estudados no ensaio com matriz do método final 85

FIGURA 24. Representação gráfica da linearidade para os compostos estudados no ensaio com matriz do método SPE. 86

FIGURA 25. Representação gráfica da linearidade para os compostos estudados no ensaio sem matriz

FIGURA 26. Gráficos dos resíduos normalizados e absolutos para os compostos fenol e 3-metilfeno no ensaio com matriz do método final 90

FIGURA 27. Gráficos dos resíduos normalizados e absolutos para os compostos 2-nitrofenol,2,4-diclorofenol, 4-cloro-3-metilfenol e 2,4,6-triclorofenol no ensaio com matriz do método final 91

FIGURA 28. Gráficos dos resíduos normalizados e absolutos para os compostos fenol, 3-metilfenol, 2-nitrofenol e 2,4-diclorofenol no ensaio com matriz do método SPE 92

FIGURA 29. Gráficos dos resíduos normalizados e absolutos para os compostos 4-cloro-3-metilfenol e 2,4,6-triclorofenol no ensaio com matriz do método SPE 93

FIGURA 30. Gráficos dos resíduos normalizados e absolutos para os compostos fenol, 3-metilfenol, 2-nitrofenol e 2,4-diclorofenol no ensaio sem matriz 94

FIGURA 31. Gráficos dos resíduos normalizados e absolutos para os compostos 4-cloro-3-metilfenol e 2,4,6-triclorofenol no ensaio sem matriz 95

FIGURA 32. Gráficos da faixa de intervalo de confiança no ensaio com matriz para os seis compostos estudados na faixa de trabalho considerada do método final. 98 
FIGURA 33. Gráficos da faixa de intervalo de confiança no ensaio com matriz para os seis compostos estudados na faixa de trabalho considerada do método SPE. 99

FIGURA 34. Representação gráfica do teste de verificação de significância dos efeitos no ensaio de robustez em sedimento no método final 111

FIGURA 35. Gráficos de probabilidade normal e Rankit para os compostos fenol, 3-metilfenol, 2-nitrofenol e 2,4-diclorofenol no método final 113

FIGURA 36. Gráficos de probabilidade normal e Rankit para os compostos 4-cloro-3-metilfenol e 2,4,6-triclorofenol no método final. 114

FIGURA 37. Representação gráfica do teste de verificação de significância dos efeitos no ensaio de robustez em sedimento no método SPE 115

FIGURA 38. Gráficos de probabilidade normal e Rankit para os compostos fenol, 3-metilfenol, 2-nitrofenol e 2,4-diclorofenol no método SPE 116

FIGURA 39. Gráficos de probabilidade normal e Rankit para os compostos 4-cloro-3-metilfenol e 2,4,6-triclorofenol no método SPE 117

FIGURA 40. Representações gráficas das incertezas individuais envolvidas na análise dos compostos fenólicos em sedimento no método final 120 


\section{LISTA DE ABREVIATURAS}

ABNT Associação Brasileira de Normas Técnicas

ANA Agência Nacional das Águas

ANOVA Analysis of Variance

ANVISA Agência Nacional de Vigilância Sanitária

$\mathrm{APCl} \quad$ Atmospheric pressure chemical ionization

APPI Atmospheric Pressure Photoionization

ASE Accelerated Solvent Extraction

CETESB Companhia Ambiental do Estado de São Paulo

CF Detector de Faraday

CONAMA Conselho Nacional do Meio Ambiente

CNEM Comissão Nacional de Energia Nuclear

ESI Electrospray lonization

FAB Fast Atom Bombardment

FAPESP Fundação de Amparo à Pesquisa do Estado de São Paulo

FID Flame lonization Detector

GC Cromatografia a Gás

GC/MS Cromatógrafo a gás acoplados ao espectrômetro de massas

EC Comissão Europeia

ECD Electron-capture dissociation

EPA Agência de Proteção Ambiental Norte Americana

HPLC High Performance Liquid Chromatography

$\mathrm{ICH} \quad$ International Conference on Harmonization

INMETRO Instituto Nacional de Metrologia e Qualidade Instrumental

IPEN Instituto de Pesquisas Energéticas e Nucleares

IUPAC International Union of Pure and Applied Chemistry

LD Limite de Detecção 
LLE Extração Líquido-Líquido

LQ L Limite de Quantificação

MAE Microwave Assisted Extraction

MALDI Matrix-Assisted Laser Desorption/lonization

ME Detector Multiplicador De Elétrons

ME Margin of Error

MPO Enzimas Mieloperoxidases

MS Mass Spectrometry

SIM Selected Ion Monitoring

SMA Secretaria do Meio Ambiente do Estado de São Paulo

SME Simultaneous Margin of Error

SPE Solid Phase Extraction

SPME Solid Phase Microextraction

TCD Thermal Conductivity Detector

TOF Time of Flight

TSP Thermo-Spray lonization

USEPA United States Environmental Protection Agency 


\section{INTRODUÇÃO}

A água doce é essencial para a manutenção da vida de todos os seres vivos no planeta, sua disponibilidade não só em quantidade como também em qualidade é de extrema importância para a qualidade de vida das populações urbanas e rurais e fundamental para a economia de cada país. Apesar de sua importância, as águas continentais vêm sendo degradadas ao longo dos anos, devido ao mau gerenciamento dos recursos hídricos. O mau gerenciamento juntamente com o aumento da demanda está diretamente relacionado com a crise da água do século XXI (Tundisi, 2006; Tundisi, 2008).

O volume de água consumida pelas atividades humanas é de aproximadamente $6.000 \mathrm{~km} 3 /$ ano, várias são as atividades relacionadas a esse consumo direta ou indiretamente, tais como água para produção agrícola, irrigação e outras atividades para produção de alimentos, abastecimento público, produção de hidroeletricidade, recreação, turismo, pesca, aquicultura, transporte e navegação, mineração, etc. Além do consumo excessivo, a manipulação dos corpos d'água por meio da construção de reservatórios, canais e transposições, desmatamento de mata ciliar e remoção de áreas alagadas, alterou os ciclos hidrológicos gerando impactos complexos na qualidade e disponibilidade de água resultando em estresse hídrico em algumas regiões (Tundisi,2006).

O Brasil é um país privilegiado com relação aos seus recursos hídricos, tendo esse relevante papel ecológico, econômico, estratégico e social. Com aproximadamente $14 \%$ da água doce do Planeta Terra, porém apresenta sérios problemas de diagnóstico, avaliação estratégica e gestão de seus recursos hídricos, sendo que vários dos problemas ambientais relativos às águas na atualidade são de origem antrópica (Bicudo et al., 2010; Silva, 2013).

A gestão dos recursos hídricos no Brasil inicialmente era reduzida à avaliação quantitativa e voltada para fins de produção de energia hidrelétrica. Com a criação da Política Nacional de Recursos Hídricos (PNRH) pela Lei 9.433/97, a 
gestão dos recursos hídricos no país passou a avaliar também os aspectos qualitativos da água. Hoje o Sistema Nacional de Gerenciamento de Recursos Hídricos integra diversos órgãos, sendo eles Conselho Nacional de Recursos Hídricos, Agência Nacional das Águas, os Conselhos de Recursos Hídricos dos Estados e do Distrito Federal, os Comitês de Bacia Hidrográfica, os órgãos de governo cujas competências se relacionem com a gestão de recursos hídricos e as Agências de Água (Libânio, 2005; Tundisi, 2006).

Atividades industriais e despejo de águas residuárias sem tratamento causam grande impacto na qualidade da água. Com o aumento imprudente na produção e utilização de produtos químicos, verificado nas últimas décadas, observam-se problemas de poluição ambiental de maneira generalizada, não só no Brasil, mas praticamente em todas as partes do mundo. Os sistemas aquáticos são particularmente sensíveis aos poluentes por apresentarem cadeias alimentares mais longas, que podem favorecer fenômenos de biomagnificação, ou seja, de aumento na concentração entre dois níveis tróficos sucessivos (Bicudo et al., 2010; Kubota et al., 2001; Tundisi, 2006).

A proteção ambiental vem adquirindo importância fundamental na sociedade contemporânea, que tem cobrado mecanismos rápidos e eficientes de controle dos processos de contaminação ambiental. O último relatório da situação elaborado pela a ANA em 2013, aponta para reais progressos na gestão e no diagnóstico da situação das águas, porém ainda há necessidade avanços na análise estratégica dos recursos hídricos (Bicudo et al., 2010; Kubota et al., 2001).

A comunidade científica tem dado atenção à exposição humana a certos metais tóxicos, como $\mathrm{Hg}$ na forma de metilmercúrio, $\mathrm{Cd}$ e $\mathrm{Pb}$ que, mesmo em doses moderadas e contínuas, podem provocar efeitos tóxicos à saúde humana. Recentemente o problema de contaminação ambiental por micropoluentes orgânicos também está sendo investigado em sistemas aquáticos, sendo que um número considerável desses poluentes orgânicos possui estrutura fenólica. Entretanto, para ambientes tropicais existem poucas informações a respeito do comportamento e do destino final desta classe de substâncias (Bicudo et al., 2010; Kubota et al., 2001). 
Dentro desse contexto, é importante o desenvolvimento e adaptação de metodologias para determinação e quantificação dos diversos tipos de poluentes em diferentes matrizes ambientais.

Compostos fenólicos são um grupo de compostos comumente encontrados na natureza com estruturas fenólicas muito diversas, sendo este um termo coletivo para vários subgrupos de compostos fenólicos com nomenclatura variada entre si. A classificação destes compostos pode ser feita pela sua função biológica e pela sua estrutura de origem. Os subgrupos também podem diferir significativamente de acordo com a estabilidade, biodisponibilidade e funções fisiológicas relacionadas com a saúde humana (Silveira, 2013).

Encontram-se em ambientes aquáticos devido a decomposição natural de substâncias comuns no ambiente como as húmicas, ligninas e taninos. Porém, são compostos comuns também em efluentes industriais oriundos das atividades de produção de: plásticos, corantes, tintas, drogas, antioxidantes, polímeros sintéticos, resinas, pesticidas, detergentes, desinfetantes, refinaria de óleo e principalmente de papel e celulose. Sendo os compostos 2,4,6-triclorofenol; 2,4-diclorofenol; 3-metilfenol; 4-cloro-3-metilfenol; 2-nitrofenol, fenol e nitrobenzeno o grupo de contaminantes mais utilizados na indústria e, consequentemente, os fenóis mais encontrados nestes efluentes (Kleibohmer, 2001; Kubota et al., 2001; Silva, 2012).

Estes compostos vêm despertando preocupação nos últimos anos e incitando grande atenção em todo o mundo ao desenvolvimento de métodos de determinação e monitoramento contínuo no ambiente devido sua conhecida característica biorrecalcitrante e toxicidade aguda mesmo em pequenas concentrações, podendo afetar também o gosto e odor de águas potáveis e peixes (Kubota et al., 2001; Santana et al., 2009; Zhu, 2012; Medeiros, 2013).

Em função do alto potencial poluidor desses compostos, é permitida a presença de fenóis em corpos d'água em concentrações na faixa de $\mu \mathrm{g} \mathrm{L}^{-1}$ a ng L-1 (Medeiros, 2013). 
Muitos dos compostos fenólicos possuem efeitos tóxicos não só em seres humanos, mas também em animais e plantas, pois facilmente penetram na pele e membranas celulares, determinando um amplo espectro de genotoxicidade, mutagenicidade e efeitos hepatotóxicos, efeitos esses que os colocam na lista de substâncias perigosas e poluentes prioritários da EC (Comissão Europeia) e da EPA (Agência de Proteção Ambiental Norte Americana) (Kubota et al. 2001).

Embora boa parte dos trabalhos publicados em relação a determinação de compostos fenólicos em matrizes ambientais tiveram como foco a análise destes compostos em meio aquoso, alguns fenóis têm capacidade de transporte em água limitada e elevada tendência a serem adsorvidos e acumulados em matrizes sólidas como sedimento e solos. Esta tendência contribui para a persistência dos compostos fenólicos no ambiente em altas concentrações, representando uma ameaça em potencial à biota aquática e aos seres humanos (Peng et al.,2006; Santana, 2009).

A capacidade dos sedimentos em acumular compostos faz desse um dos compartimentos mais importantes na avaliação do nível de contaminação de ecossistemas aquáticos continentais, pois os compostos acumulados com o tempo podem ser liberados para a coluna d'água e tornando-se uma fonte de substâncias tóxicas. Sendo necessária, por este motivo, a quantificação precisa dos compostos fenólicos em sedimento para que seja possível a sua avaliação de risco (Esteves, 1998; Dornfeld, 2006; Gao et al., 2006; Santana, 2009).

O Reservatório Guarapiranga está localizado na Bacia Hidrográfica do Alto Tietê, no Estado de São Paulo. A área de drenagem do reservatório encontrase em Área de Proteção de Mananciais desde 1975, porém mesmo existindo critérios legais para a ocupação e uso do solo, é uma região submetida a grandes impactos em virtude de se tratar de uma área densamente povoada, na qual são desenvolvidas inúmeras atividades, resultando em baixa disponibilidade hídrica e deterioração de sua qualidade. Trata-se de um reservatório de usos múltiplos, destinado principalmente para abastecimento público de água potável, controle de enchentes, geração de energia e recreação. Dentre os impactos existentes na Bacia pode-se destacar a contribuição de esgotos domésticos, decorrente da 
expansão urbana da periferia em conjunto com a falta de investimento em saneamento básico da região. As águas do Reservatório Guarapiranga e seus afluentes encontram-se em deterioração progressiva, fazendo-se necessários cada vez mais estudos de monitoramento para garantir o uso sustentável destas águas e segurança sanitária para a população (Sant'Anna et al. 2008; Salim e Luchiari, 2014).

A determinação de micropoluentes em amostras ambientais constitui um desafio devido à complexidade das matrizes, baixas concentrações dos compostos alvo no ambiente, e necessidade de métodos cada vez mais sensíveis e precisos. Sendo assim, diversos métodos analíticos são utilizados para determinação desses analito e as técnicas mais utilizadas para a determinação quantitativa de compostos orgânicos, descritas na literatura, envolvem o uso de métodos cromatográficos, destacando-se a Cromatografia a Gás (Gas Chromatography, GC) e a Cromatografia Líquida de Alta Eficiência em fase reversa (High Performance Liquid Chromatography, HPLC). A cromatografia a gás e a cromatografia líquida, podem ser acopladas a diferentes detectores, entretanto, o detector por espectrometria de massas (MS, mass spectrometry) se sobressai por apresentar alta seletividade e sensibilidade, já que esta técnica tem a vantagem de fornecer informações precisas para a identificação de cada composto e somente quando a identificação qualitativa é bem estabelecida a informação quantitativa torna-se confiável, evitando-se o risco de gerar falsos resultados positivos. Por esse motivo o uso da técnica GC/MS vem sendo amplamente utilizada em avaliação ambiental e considerada uma técnica de referência para a determinação de compostos fenólicos (Petrovic et al., 2002; Vidal et al., 2002; Richardson, 2009; Silva, 2012).

Porém boas técnicas analíticas apenas não são suficientes para garantir a qualidade dos dados gerados e a confiabilidade dos resultados. Visando atender as exigências de órgãos nacionais e internacionais um novo método desenvolvido deve passar pelo processo denominado validação de ensaio químico. A validação busca demonstrar que a metodologia desenvolvida é adequada ao uso pretendido, além de assegurar a comparabilidade e rastreabilidade dos resultados. Apesar de não existir uma norma que padronize o processo de validação, no Brasil, as duas agências que regulamentam e fornecem guias para validar um ensaio são a 
ANVISA - Agência Nacional de Vigilância Sanitária e o INMETRO - Instituto Nacional de Metrologia e Qualidade Instrumental (Ribani, et al. 2004; Brito et al., 2009; Souza, 2011; Otomo; 2010, 2015).

É grande o volume de experimentos laboratoriais e cálculos estatísticos necessários para demonstrar a qualidade das medidas instrumentais envolvidas na validação de um método analítico. Neste estudo utilizou-se duas adaptações eletrônicas, a “Validação de Ensaios Químicos”, desenvolvida por Furusawa (2007), como ferramenta na etapa de validação do método e a "Estimativa da incerteza em ensaios químicos", desenvolvida por Martins (2010), para os cálculos de incerteza.

Este projeto de pesquisa está vinculado ao projeto temático da FAPESP intitulado "Reconstrução paleolimnológica da Represa Guarapiranga e diagnóstico da qualidade atual da água e dos sedimentos de mananciais da RMSP com vistas ao gerenciamento do abastecimento" sob a coordenação geral do Prof. Dr. Carlos Eduardo de Mattos Bicudo do Instituto de Botânica e por parte da instituição parceira IPEN-CNEN/SP, sob coordenação da Prof. ․ Dr.. Maria Aparecida Faustino Pires. O principal objetivo do projeto temático foi reconstituir o histórico de eutrofização e impactos antropogênicos da represa através da avaliação de sedimento, tanto do testemunho (perfil sedimentar) do reservatório como do sedimento superficial identificando os principais fatores desencadeadores do cenário atual. 


\section{OBJETIVOS}

\subsection{Objetivo Geral}

O principal objetivo deste trabalho foi desenvolver, validar e estabelecer metodologia analítica para a extração e quantificação de compostos fenólicos em sedimento.

\subsection{Objetivos Específicos}

Desenvolver, adaptar e validar metodologia analítica para a extração e quantificação dos compostos fenólicos: 2,4,6-triclorofenol; 2,4-diclorofenol; 2-nitrofenol; 3-metilfenol; 4-cloro-3-metilfenol; Fenol.

Aplicar a metodologia desenvolvida em amostras de sedimento da represa Guarapiranga, identificando e quantificando as substâncias presentes.

Avaliar a qualidade do sedimento da represa em relação aos compostos estudados. 


\section{EMBASAMENTO TEÓRICO}

\subsection{Características dos Compostos Fenólicos}

Os fenóis são compostos que apresentam em sua estrutura uma ou mais hidroxilas $(\mathrm{OH})$ ligadas diretamente a um anel aromático, conforme Figura 1 podendo apresentar ligações também com grupos clorados, nitrados, metilênicos e alquílicos (Santana et al., 2009; Silva, 2012; Medeiros, 2013).
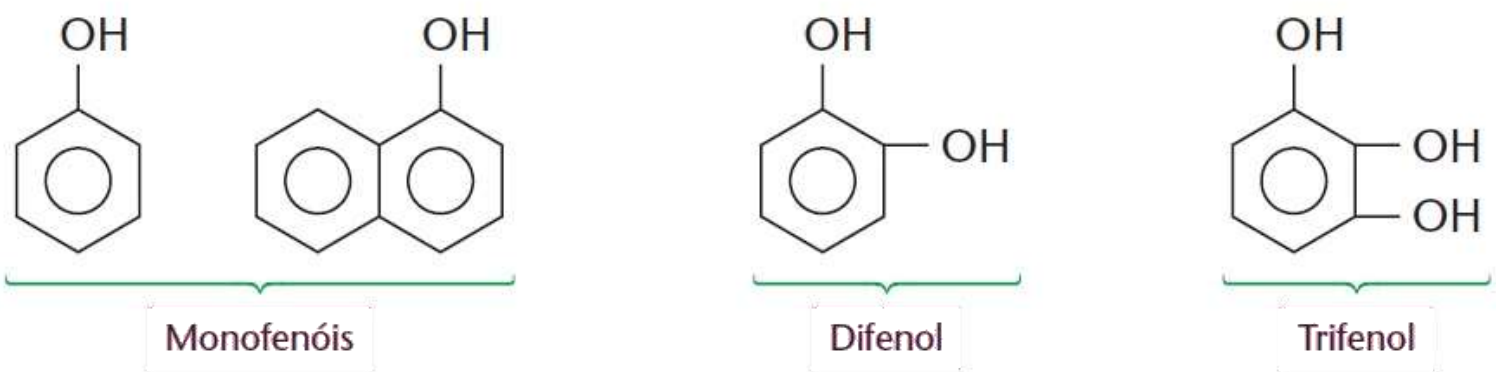

Figura 1. Fórmula molecular do fenol (Fonte: Feltre, 2005).

Fenóis complexos são encontrados na natureza, um exemplo é a lignina que é um composto de alto peso molecular, presente exclusivamente em vegetais superiores, sendo sua composição variável de acordo com o tipo de planta. O fenol comum, que é o representante mais simples, foi obtido inicialmente a partir do alcatrão da hulha, um tipo de carvão mineral. Ao longo do tempo vários processos industriais foram desenvolvidos para a obtenção do fenol, como hidrólise do clorobenzeno, hidrólise de sais de diazônio e oxidação do cumeno (Thomazelli, 2010; Feltre, 1974; Solomons, 2004).

O grupo dos fenóis é bastante heterogêneo de acordo com suas propriedades físico-químicas, porém são classificados de um modo geral como ácidos, principalmente os mais fortemente clorados (Kleibohmer, 2001).

Algumas propriedades físico-químicas dos fenóis estão apresentadas na TAB.1 
Tabela 1. Propriedades físico-químicas dos compostos fenólicos (Kleibohmer, 2001).

\begin{tabular}{llll}
\hline Composto & $\mathrm{pK}_{\mathrm{a}}$ & $\log \mathrm{P}$ & $\mathrm{S}\left(\mathrm{mg} \mathrm{L}^{-1}\right)$ \\
\hline Fenol & 9.99 & 1.46 & 82000 \\
2,4-Dimetilfenol & 10.5 & 2.42 & 4200 \\
2-Clorofenol & 8.52 & 2.29 & 23250 \\
3-Clorofenol & 8.97 & 2.64 & 22200 \\
4-Clorofenol & 9.37 & 2.53 & 2600 \\
2,3-Diclorofenol & 7.71 & 3.26 & 8200 \\
2,4-Diclorofenol & 7.9 & 3.2 & 5550 \\
2,5-Diclorofenol & 7.51 & 3.36 & - \\
2,6-Diclorofenol & 6.8 & 2.92 & 2650 \\
3,4-Diclorofenol & 8.6 & - & 9250 \\
3,5-Diclorofenol & 8.25 & 3.6 & 7400 \\
2,3,4-Triclorofenol & 7.00 & - & 915 \\
2,3,5-Triclorofenol & 6.43 & 3.85 & 770 \\
2,3,6-Triclorofenol & 5.8 & - & 590 \\
2,4,5-Triclorofenol & 6.72 & 4.02 & 650 \\
2,4,6-Triclorofenol & 6.00 & 3.67 & 710 \\
3,4,5-Triclorofenol & 7.55 & - & - \\
2,3,4,5-Tetraclorofenol & 5.64 & - & 165 \\
2,3,4,6-Tetraclorofenol & 5.22 & 4.24 & 180 \\
2,3,5,6-Tetraclorofenol & 5.02 & 5.02 & 100 \\
Pentaclorofenol & 4.74 & 5.85 & 18 \\
2-Nitrofenol & 7.21 & 1.78 & 2100 \\
3-Nitrofenol & 8.27 & - & - \\
4-Nitrofenol & 7.16 & 1.90 & 16000 \\
2,4-Dinitrofenol & 4.09 & 1.53 & 5600 \\
2-Metil-4,6-dinitrofenol & 4.34 & 2.12 & 100 \\
4-Cloro-3-metilfenol & 9.55 & 3.10 & 3850 \\
\hline
\end{tabular}

A solubilidade em água $\left(S, \mathrm{mg} \mathrm{L}^{-1}\right)$ é um dos fatores mais significantes no acúmulo e transporte dos compostos no ambiente, os fenóis possuem capacidade de formar fortes ligações de hidrogênio o que thes confere uma solubilidade em água modesta aos fenóis, que varia muito entre os diferentes compostos fenólicos. Outro parâmetro a ser considerado no estudo dos fenóis em diferentes matrizes ambientais é o logaritmo de coeficiente de partição octanol- 
água $(\log \mathrm{P})$, pois está diretamente relacionado com a tendência de alguns fenóis serem encontrados com mais frequência em uma determinada matriz, os compostos com valores mais elevados de log $\mathrm{P}$ encontram-se principalmente em solos, sedimentos ou lodos, enquanto fenóis com valores mais baixos são encontrados principalmente em reservatórios aquáticos (Kleibohmer, 2001; Medeiros, 2013; Solomons, 2004).

\subsubsection{Fenol}

Devido ao fato de o fenol ser precursor de outros compostos, tem vasto campo de aplicação e é utilizado na indústria química em processos de produção de compostos químicos (alquilfenóis, cresóis, xilenóis, resinas fenólicas, anilina e outros derivados), desinfetantes, loções anticépticas, explosivos, agrotóxicos e corantes. Também é formado na combustão do carvão de madeira, combustão de resíduos sólidos urbanos e como produto da exaustão dos combustíveis em automóveis (Michalowicz, 2007; Silva, 2012). Sua estrutura molecular é apresentada na FIG. 2.

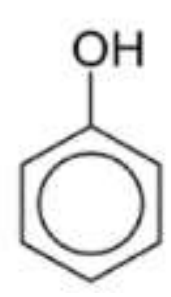

Figura 2. Estrutura do fenol.

Segundo a Agency for Toxic Substances and Disease Registry (ATSDR, 2008), a dose letal para a ingestão de fenóis é de $14 \mathrm{mg} \mathrm{kg}^{-1}$, porém o contato com a pele, por ser absorvido rapidamente, até mesmo em pequenas concentrações, pode levar à morte. A inalação dos vapores de fenol, quando aguda, causa dor de cabeça, nos músculos e fraqueza, além de provocar acúmulo desse nos rins, fígado, músculos e cérebro (Michalowicz, 2007; Silva, 2012). 


\subsubsection{2,4-diclorofenol}

Composto tóxico obtido pela cloração do fenol em presença de catalisadores. Utilizado principalmente como catalisador na produção de herbicidas. Ocorre no ambiente devido à atividade antrópica e também pode ser originado por degradação microbiana ou fotodegradação de pesticidas derivados de fenóis ou por cloração da água de abastecimento (DHHS, 1989). Sua estrutura molecular é apresentada na FIG. 3.

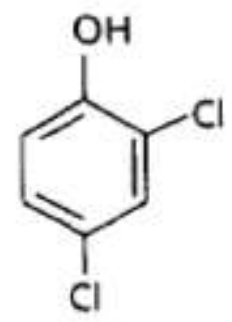

Figura 3. Estrutura do 2,4-diclorofenol.

Sendo assim, a exposição humana a esse composto se dá basicamente por atividades ocupacionais ou contato com pesticidas, tendo como principal via de contaminação o contato com a pele (DHHS, 1989).

Em contato com a pele provoca deterioração do tecido e, dependendo da concentração do composto e do tempo de exposição, pode levar à morte (DHHS, 1989).

\subsubsection{2,4,6-triclorofenol}

É um composto considerado de potencial carcinogênico pela USEPA e vem sendo utilizado principalmente como matéria prima de muitos pesticidas, conservante de madeira e fungicida de produtos têxteis. Sua estrutura molecular é apresentada na FIG. 4. 


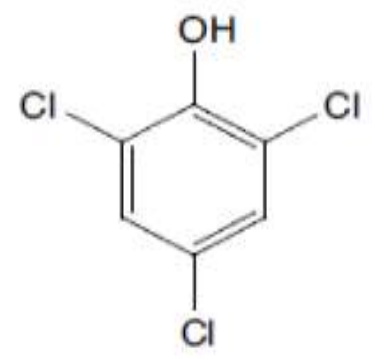

Figura 4. Estrutura do 2,4,6-triclorofenol.

Em seres humanos, a exposição do 2,4,6-TCP se dá principalmente devido às atividades ocupacionais, ocorrendo por inalação, ingestão e contato dérmico (DHHS, 2001).

\subsubsection{4-cloro-3-metilfenol}

Em 1968 seu uso foi registrado a primeira vez como um biocida, porém na indústria sua principal aplicação é como conservante de produtos orgânicos. Foi largamente utilizado como conservante em colas, na produção de tintas e adesivos industriais, teve sua aplicação estendida à indústria farmacêutica com o propósito de evitar a degradação por micro-organismos de compostos orgânicos presentes em cremes para o corpo, mas estudos demonstraram que o contato com a pele e olhos pode causar sérios danos à saúde (DHHS, 2008a). Sua estrutura molecular é apresentada na FIG. 5.

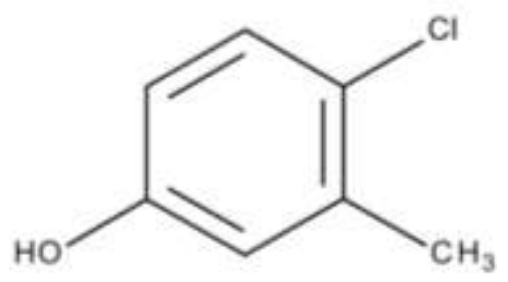

Figura 5. Estrutura do 4-cloro-3-metilfenol.

A possibilidade de ocorrer exposição por inalação é praticamente nula já que esse composto possui partículas que são dificilmente vaporizadas a temperatura ambiente (entre $20^{\circ} \mathrm{C}$ e $30^{\circ} \mathrm{C}$ ). A principal exposição ao composto 
relatada é a contaminação por ingestão. Apesar de não haver uma aplicação direta do composto em relação à produção de alimentos, a contaminação ocorre de maneira indireta já que o 4-cloro-3-metilfenol é utilizado em adesivos e embalagens de alimentos, podendo contaminar os mesmos (DHHS, 2008a).

Apesar de todo o perfil toxicológico, não há registros de contaminação de seres humanos pelo 4-cloro-3-metilfenol, podendo-se concluir que a maior exposição de seres humanos a esse composto é por atividades ocupacionais (DHHS, 2008a).

Apesar de todo o perfil toxicológico, não há registros de contaminação de seres humanos pelo 4-cloro-3-metilfenol, podendo-se concluir que a maior exposição de seres humanos a esse composto é por atividades ocupacionais (DHHS, 2008a).

\subsubsection{Nitrofenóis}

Os nitrofenóis, um dos grupos mais difundidos de compostos derivados do fenol, são largamente empregados em produções industriais e justamente por esse motivo, estão presentes no ambiente, pois a quantidade gerada por processos naturais representa uma parcela pequena. Naturalmente, os nitrofenóis são gerados pela reação de fenóis com nitritos presentes em água pela influência da radiação UV proveniente da luz do sol (Michalowicz, 2007).

Dos compostos pertencentes a esse grupo, o mais conhecido é o 4-nitrofenol, o qual é utilizado na fabricação de medicamentos, fungicidas, corantes e explosivos. A estrutura geral dos nitrofenóis é apresentada na FIG. 6.

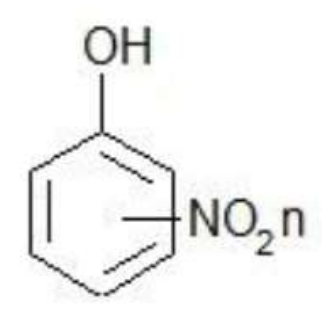

Figura 6. Estrutura geral dos nitrofenóis. 
Não possui toxicidade aguda em seres humanos, o modo como afeta a saúde depende do nível e tempo de exposição, porém deve-se sempre levar em conta a exposição ocupacional, que na maioria das vezes causa danos à saúde, já que o contato é de maneira direta e normalmente em altas concentrações (ATSDR, 1992).

\subsubsection{3-metilfenol}

O 3-metilfenol (m-cresol), assim como seus isômeros, é utilizado em escala industrial na produção de polímeros. Conhecido popularmente por creolina, além de ser utilizado na produção de polímeros, é largamente empregado como esmalte eletro isolante para fios de cobre utilizados na construção de motores elétricos e geradores (DHHS, 2008a). Sua estrutura molecular é apresentada na FIG. 7.

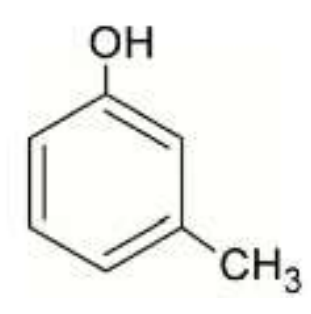

Figura 7. Estrutura do 3-metilfenol.

Estudos demonstram que o principal meio de exposição de seres humanos ao m-cresol é pela inalação do mesmo, porém, por ser facilmente degradado na atmosfera, não há relatos de contaminação de seres humanos devido à presença desse composto (DHHS, 2008a).

\subsection{Influências dos compostos fenólicos em organismos vivos}

Os compostos fenólicos podem ser absorvidos pelo organismo humano por inalação, via oral ou por via dérmica. Em ambientes aquáticos, portanto estes compostos podem ser ingeridos quando presentes em água destinada para abastecimento humano ou absorvidos pela pele quando presente em águas 
destinadas a lazer, sendo estes dois dos principais usos da água do Reservatório Guarapiranga (USEPA, 2002).

Estudos apontam que por via oral o fenol é rapidamente e completamente absorvido pelo organismo, porém independente da via de absorção este composto é amplamente distribuído por todos os tecidos do corpo, podendo ser encontrado em altas concentrações no fígado por ser um composto lipofílico. Trabalhos experimentais demonstraram que em doses baixas, de 85 a $98 \%$ do fenol absorvido é excretado em um período de 24 horas, sendo parte eliminado principalmente na urina de forma inalterada e parte excretado em forma conjugada com os ácidos glicurônico e sulfúrico. Sua meia-vida biológica dentro do organismo varia entre 5 a 12 horas (USEPA, 2002).

A excreção do fenol também pode ocorrer pelas fezes, suor e saliva, porém apesar de boa parte do fenol absorvido ser excretado, sua característica lipofílica contribui para a bioacumulação deste composto no organismo (Kleibohmer 2001; Peixe e Nascimento, 2008).

Quando absorvido pela medula, o fenol pode sofrer ação de enzimas mieloperoxidases (MPO), liberando quinonas reativas que podem ser reduzidas a hidroquinona. Esse processo de redução das quinonas reativas gera um estresse oxidativo no tecido, que pode posteriormente alterar o crescimento e diferenciação celular na medula (Peixe e Nascimento, 2008).

Os parâmetros pKa e log $P$ são importantes para comparar os efeitos tóxicos dos diferentes fenóis, pois o aumento da hidrofobicidade e log $\mathrm{P}$ juntamente com a diminuição do pKa resulta em uma maior facilidade de penetração dos compostos na célula, aumentando assim sua toxicidade. A hidrofobia pode ser um fator final quando se compara compostos com valores semelhantes de pKa (Michalowicz,2007).

O fenol apresenta de moderada a alta toxicidade em exposições agudas, sendo a dose letal estimada em humanos de $70 \mathrm{mg} \mathrm{kg}^{-1}$. É um composto agressivo 
à pele, podendo levar à irritação e sensibilização e ao aparecimento de lesões e necrose cutânea (USEPA, 2002; Peixe e Nascimento, 2008).

Para organismos aquáticos, os compostos fenólicos são altamente tóxicos em concentrações da ordem de partes por milhão. Os danos para estes organismos após exposição aos fenóis envolvem alterações em seus sistemas nervoso e circulatório, também já sido relatado casos de diminuição da taxa de reprodução e crescimento. As características organolépticas de peixes e mariscos também podem ser alteradas, causando prejuízos a atividades comerciais (Guerra, 2001).

Alguns compostos fenólicos, tais como alquilfenóis e bisfenol A, são considerados xenoestrógenos com capacidade de influenciar o sistema hormonal de organismos aquáticos e seres humanos, podendo ser denominados também como interferentes endócrinos. Interferentes endócrinos são substâncias químicas capazes de interagir com os receptores hormonais, modificando a resposta natural do organismo. A ação do interferente pode ser do tipo agonista, quando este imita a ação de um determinado hormônio, do tipo bloqueador, do tipo antagonista, quando o interferente impede a interação de um hormônio natural com seu respectivo receptor sem produzir uma resposta ao organismo ou pode ainda alterar as concentrações dos hormônios naturais por prejudicar a síntese, transporte, metabolismo e excreção dos mesmos. A ação dos interferentes endócrinos pode ser observada na FIG. 8 (Gao et al., 2006; Ghiselli e Jardim, 2007).
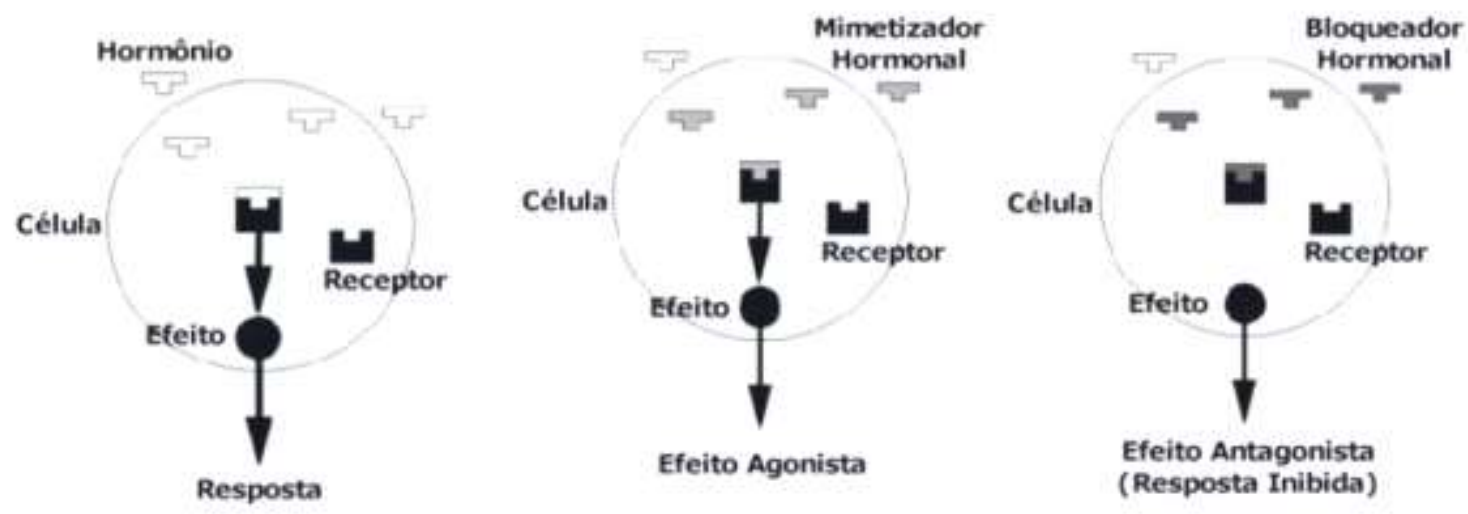

Figura 8. Resposta natural, efeito agonista e efeito antagonista dos interferentes endócrinos no organismo (Fonte: Ghiselli e Jardim, 2007). 


\subsection{Legislações Sobre Compostos Fenólicos}

Devido à grande quantidade de compostos derivados do fenol, o estabelecimento de limites individuais torna-se complexo. Em algumas legislações, são estabelecidos limites para a presença de fenóis totais ou para apenas um composto fenólico específico. No Brasil, os limites e normas ambientais são orientados ou regulamentados por meio de resoluções emitidas pelo Conselho Nacional do Meio Ambiente, CONAMA, que estabelece por meio da Resolução $357 / 2005$ o limite $3 \mu \mathrm{g} \mathrm{L}^{-1}$ de fenóis totais e $0,3 \mu \mathrm{g} \mathrm{L}^{-1}$ para 2,4-diclorofenol em águas classe 1. Limite de $2,4 \mu \mathrm{g} \mathrm{L}^{-1}$ para 2,4,6-triclorofenol em águas onde haja pesca ou cultivo de organismos para fins de consumo intensivo e de $10 \mathrm{\mu g} \mathrm{L}^{-1}$ para a presença de fenóis totais em água classe 3 , sendo considerados fenóis totais todas as substâncias que reagem com 4-aminoantipirina. A resolução CONAMA 430/2011, que complementa e altera a resolução 357/2005 estabelece $500 \mu \mathrm{g} \mathrm{L}^{-1}$ para fenóis totais em lançamento de efluentes. O ministério da saúde por meio da portaria 2914/2011 determina o limite apenas para a presença de pentaclorofenol em $9 \mu \mathrm{g} \mathrm{L}^{-1}$ e $200 \mu \mathrm{g} \mathrm{L}^{-1}$ de 2,4,6-triclorofenol em água para abastecimento. Em São Paulo, o decreto estadual 8.468 de 1976 estabelece limites para a presença de substâncias em água e, diferentemente do CONAMA, o limite para a presença de fenóis totais em água de abastecimento é de $1 \mu \mathrm{g} \mathrm{L}^{-1}$ em águas de classe $2 \mathrm{e}$ $5 \mu \mathrm{g} \mathrm{L} \mathrm{L}^{-1} \mathrm{em}$ águas de classe 3 (BRASIL, 2014a; BRASIL, 2014b; BRASIL, 2014c).

Embora a legislação vigente estabeleça limites apenas para corpos d'água, deixa claro que nos casos onde a metodologia analítica disponível for insuficiente para quantificar as concentrações dessas substâncias nas águas, os sedimentos e/ou biota aquática poderão ser investigados quanto à presença eventual dessas substâncias.

O documento de classificação de resíduos sólidos elaborado pela ABNT (2004) classifica alguns fenóis como resíduos perigosos de fontes específicas, decorrentes de atividades como preservação da madeira e produção de pesticidas, classificando-os como tóxicos. Este documento estabelece limites máximos para alguns compostos em extratos de ensaios de lixiviação, são estabelecidos os 
limites máximos tolerados de $200000 \mu \mathrm{g} \mathrm{L}^{-1}, 400000 \mu \mathrm{g} \mathrm{L}^{-1}, 20000 \mu \mathrm{g} \mathrm{L}^{-1}$ e $900 \mathrm{gg} \mathrm{L}^{-1}$ para cresóis totais ou parciais.

No Canadá, o documento que estabelece a Qualidade da Água e Diretrizes para a Proteção da Vida Aquática (1999), menciona relatos da presença de fenóis em sedimento, porém traz limite apenas para água, sendo de $4 \mu \mathrm{g} \mathrm{L}^{-1}$. Assim como documento da USEPA (1978) específico para Fenóis, estabelece limites claros somente para a concentração em água, que não deve exceder $3400 \mu \mathrm{g} \mathrm{L}^{-1}$ para a saúde humana, $1 \mu \mathrm{g} \mathrm{L}^{-1}$ para a prevenção de efeitos organolépticos que este composto possa provocar na água após processos de purificação e $3,4 \mu \mathrm{LL}^{-1}$ para a proteção da vida aquática.

A ênfase da monitoração de fenóis na Comunidade Europeia também é a monitoração destes compostos em água, estabelecendo os limites de concentração máxima permitida, para todos os tipos de fenóis em meio aquoso, o valor de $500 \mu \mathrm{g} \mathrm{L}^{-1}$ e $100 \mu \mathrm{g} \mathrm{L}^{-1}$ para fenóis individuais (Kubota, 2001). 


\section{REVISÃo BIBLIOGRÁFICA}

Muitos dos estudos que abordam a detecção de fenóis em sedimento, são em sua maioria estudos de compostos fenólicos resultantes da degradação da lignina no meio ambiente, tais como os feitos por Dupont et al. (2007), Louchouarn et al. (2010), Zocatelli et al. (2011), LV et al. (2012), Fu et al. (2014) e Pinto (2015). As estruturas destes compostos estão associadas a grupos específicos de organismos e os estudos relacionados a esses tipos específicos de fenóis são realizados para diversos fins, como marcadores geoquímicos, caracterização da origem orgânica em sedimentos, diferenciação da matéria orgânica de origem alóctone ou autóctone, estudo da dispersão de material terrestre em gradientes salinos e /ou estuarianos, etc (Thomazelli, 2010).

Encontram-se na literatura também, trabalhos referentes a determinação de compostos fenólicos em ambientes marinhos, como o realizado por Cardellicchio et al. (1997) que desenvolveu método analítico para análise destes compostos em água e sedimento marinho. Santana et al. (2005) desenvolveu método para a determinação dos compostos fenólicos somente em sedimento marinho utilizando micro-ondas na etapa de extração e purificação da amostra com micro extração em fase sólida. Ambos os métodos foram desenvolvidos para análise em cromatografia líquida de alta eficiência (HPLC).

Internacionalmente, muitos trabalhos vem sendo realizados ao longo dos anos, principalmente a partir do ano de 2000 , com o intuito de avaliar a presença dos compostos fenólicos não só de origem natural, mas também de origem antrópica em matriz ambiental, principalmente em reservatórios de água doce com finalidade de abastecimento para consumo humano. Alguns trabalhos de destaque são citados a seguir.

Kuch e Ballschmiter (2001) desenvolveu metodologia de extração de compostos fenólicos por extração em fase sólida (SPE) e análise por GC/MS em amostras de água potável e efluentes. $\mathrm{O}$ trabalho mostrou que estes compostos 
não são totalmente removidos no processo de tratamento de esgoto e podem ser encontrados em água potável.

Vidal et al. (2004) otimizou um método para a determinação de quinze compostos fenólicos em águas, sedimentos e biota (macroalgas) para análise por cromatografia líquida associada a espectrometria de massa. A etapa de preparação das amostras foi desenvolvida separadamente para cada tipo de matriz, utilizando micro extração em fase sólida para pré-concentração das amostras de água e extração por ultrassom para sedimento e biota com solventes específicos para cada matriz. Esta metodologia foi aplicada em amostras da região de Andaluzia na Espanha, identificando a presença de 4-clorofenol e 4-nitrofenol em concentrações maiores do que a permitida de acordo com a legislação da União Europeia para água potável.

Morales et al. (2005) avaliou a presença de compostos fenólicos em lamas provenientes de estações de tratamento de esgoto (ETE) e sedimentos. Seu método é baseado em extração por micro-ondas e análise por GC/MS. E verificou a presença dos compostos 2,4-diclorofenol, 2,4,6-triclorofenol e 2-(2,4-dichlorophenoxy)-5-chlorophenol (Triclosan) nas amostras de lama.

Diferente do método mais usual de extração em fase sólida, Saraji e Bakhshi (2005), utilizaram a técnica de micro extração em gota única (SDME) para a extração dos compostos fenólicos em água e análise por GC/MS, obtendo resultados satisfatórios.

Vermeulen et al. (2005) propõe um método com reação de derivatização utilizando anidrido acético para posterior extração líquido-líquido e análise por GC/MS, também para compostos fenólicos em água. $\mathrm{O}$ autor defende a extração líquido-líquido questionando a capacidade da extração em fase sólida quando há a necessidade de análise de grandes volumes de amostra.

Zhou et al. (2005) desenvolveu e aplicou metodologia para análise de seis compostos fenólicos em amostras de águas residuais de fábrica de coque e mostrou a contaminação por estes compostos, mesmo após o tratamento da água. 
Em sua metodologia foi utilizada microextração em fase sólida e análise por cromatografo a gás acoplado a detector por ionização de chama (GC/FID).

Kovacs et al. (2008) basearam sua metodologia para análise de 6 fenóis e 19 clorofenóis em água, na utilização do agente de derivatização trimetilsilil-N, $\mathrm{N}$-dimetilcarbamato (TMSDMC), que segundo o autor reage com os compostos fenólicos em temperatura ambiente e desse modo não são necessárias outras etapas no processo de derivatização que possam degradar os compostos de interesse. Neste método também é utilizada a extração em fase sólida seguida por análise em GC/MS.

Wu et al. (2012), utilizaram cromatografia de íons, com derivatização eletroquímica e acoplado a detector de fluorescência (IC / DE / DF). O método foi aplicado a amostras de águas residuais de uma fabrica de refinaria, constatando a presença de 4-metilfenol.

Zhang et al (2013), avaliaram a presença de fenóis considerados interferentes endócrinos endócrinos em sedimento superficial do Rio Shaying, o maior afluente do Rio Huaihe na China. Utilizou extração por ultrassom e análise por GC/MS. Foram encontrados os compostos nonilfenol, octilfenol e bisfenol A nas amostras de sedimento e esta contaminação foi relacionada à zona urbana de Zhengzhou considerada a principal fonte de contaminação.

Huang et al. (2015), desenvolveram método analítico, utilizando as técnica de extração acelerada por solvente (ASE), cromatografia de Permeação em Gel (GPC), extração em fase sólida (SPE) e análise por GC/MS, para a análise de fenóis considerados interferentes endócrinos em água, sedimento e amostras biológicas com objetivo de estudar a ocorrência, o destino e a bioacumulação destes compostos no ambiente.

A China se destaca em número de publicações relacionadas à determinação de compostos fenólicos em água e sedimento, como também em avaliar a bioacumulação, origem destes compostos e distribuição espacial, principalmente quando estes são considerados interferentes endócrinos. Além dos 
trabalhos já mencionados, destacam-se os trabalhos de Gao et al. (2011), Li et al. (2016) e Wang et al. (2016).

$\mathrm{Na}$ Hungria, um trabalho recente de Faludi et al. (2015), avaliou a presença de 26 compostos fenólicos na água e em partículas em suspensão do lago Lago Balaton. Alguns compostos foram encontrados exclusivamente adsorvidos nas partículas em suspensão, essas partículas podem sedimentar e gerar um acúmulo destes compostos no lago.

No Brasil existem poucos estudos que avaliam a presença de fenóis em matriz ambiental com o objetivo de identificar contaminações antrópicas e a maioria dos estudos existentes são voltados para a determinação destes compostos em água. Alguns trabalhos de destaque são citados a seguir.

Kubota et al. (2001) apresentam como alternativa aos métodos tradicionais, a determinação de compostos fenólicos utilizando biossensores amperométricos, uma vez que estes possibilitam um monitoramento continuo no próprio local de coleta de efluentes e outras matrizes ambientais, permitindo um aumento no número de análises e aumentando desse modo a confiabilidade do gerenciamento dos recursos hídricos.

Porto e Ethur (2009) investigaram a toxicidade da água da Bacia dos Rios Batuí-Icamaquã, no estado do Rio Grande do Sul e determinaram a presença de diversos elementos traço, incluindo a presença de fenóis em concentrações elevadas, quando comparadas com os valores máximos permitidos pela resolução no 357 do CONAMA - Conselho Nacional de Meio Ambiente.

O trabalho de Silva (2012) desenvolveu procedimento analítico para a determinação de compostos fenólicos em água subterrânea com extração em fase sólida e análise por GC/MS, porém o objetivo principal de seu trabalho foi o desenvolvimento de um software para automatizar o processo de estimativa da incerteza de medição pelo método descrito no Guia EURACHEM. 
Medeiros (2013) desenvolveu um método analítico para extração de compostos fenólicos com o objetivo de caracterizar e classificar resíduos sólidos, utilizando a técnica de micro extração em fase sólida no modo headspace e determinação por GC/MS. Neste estudo foi feito um teste de comparação do método desenvolvido com a tradicional extração líquido-líquido (LLE), mostrando que o novo método apresenta maior sensibilidade quando comparado com o método tradicional.

Apesar de muitos estudos realizados e em andamento no Reservatório Guarapiranga, poucos têm como foco principal a caracterização orgânica do sedimento. Otomo (2015) desenvolveu um método para determinação de interferentes endócrinos em água e sedimento deste reservatório. Entre os compostos analisados, verificou-se a ocorrência de fenóis como nonilfenol e bisfenol A neste compartimento, sendo que esta ocorrência pode ser associada à presença de indústrias localizadas na região do reservatório, segundo a autora.

Esse trabalho de mestrado consiste em uma continuidade das metodologias desenvolvidas pelo grupo de pesquisa do Centro de Química e Meio Ambiente do IPEN-CNEN/SP que serão úteis em trabalhos de pesquisa e desenvolvimento futuros e formação de pessoal especializado. 


\section{TÉCNICA ANALÍTICA}

\subsection{Metodologias Empregadas na Análise de Compostos Fenólicos}

A avaliação ambiental de compostos traço por química analítica está sujeita a dificuldades devido à complexidade das amostras e baixas concentrações das substâncias de interesse, sendo que a escolha das técnicas utilizadas nas etapas de um método analítico está intrinsecamente relacionada à qualidade do mesmo. A etapa de pré-tratamento da amostra para análise de compostos orgânicos em amostras sólidas é um passo crítico na análise de contaminantes por envolver diversos aspectos que podem interferir não só na qualidade como também na reprodutibilidade do método, tais como seletividade, recuperação do analito, toxicidade e volume dos solventes utilizados, custo e simplicidade de operação (Cotta et al., 2009; Souza, 2011).

\subsection{Extração dos Analitos}

Os métodos analíticos estabelecidos pela CFR - 6420 Standard Methods Committee para o preparo de amostras para determinação de compostos fenólicos em amostras ambientais, são a extração Soxhlet de analitos em amostras sólidas e a extração líquido-líquido (LLE) estabelecidos para amostras líquidas. Porém essas técnicas necessitam grande volume de solventes orgânicos que além de custo elevado não podem ser descartados no meio ambiente e que podem ser prejudiciais à saúde humana, além de ser necessário um longo tempo para análise. Por estas razões, nos últimos anos novas técnicas de extração vêm sendo estudadas. Técnicas que possibilitem análises mais rápidas, que envolvam pequenos volumes de solvente gerando deste modo menores volumes de resíduos e que sejam mais seletivas, já que a extração destes compostos de matrizes sólidas utilizando o método Soxhlet pode extrair também compostos indesejáveis para a análise (Santana, 2009; Medeiros, 2013).

Solventes polares são comumente utilizados para a extração de compostos fenólicos em matriz sólida, tais como metanol, acetona e acetonitrila. A utilização de solventes apolares para a extração de fenóis normalmente requer uma 
acidificação prévia da amostra. Santana (2009) relatou também a utilização de misturas de solventes polares e apolares.

Em substituição à tradicional extração Soxhlet para amostras no estado sólido, pode-se citar extração em fase sólida e micro extração em fase sólida (SPE e SPME), que utiliza colunas preenchidas com material adsorvente, por onde a amostra é percolada e posteriormente os analitos aprisionados na coluna são extraídos com uma pequena quantidade de solvente orgânico. A FIG. 9 esquematiza as etapas que constituem a extração em fase sólida: (1) condicionamento do cartucho, etapa necessária para a ativação do material adsorvente; (2) percolação da amostra, etapa em que os compostos que possuem afinidade com o material adsorvente ficam retidos; (3) clean-up, onde são removidos possíveis interferentes; (4) eluição dos analitos de interesse por meio de solvente orgânico adequado, concluindo o processo (Cotta, 2009; Santana, 2009; Otomo, 2010; Medeiros, 2013).

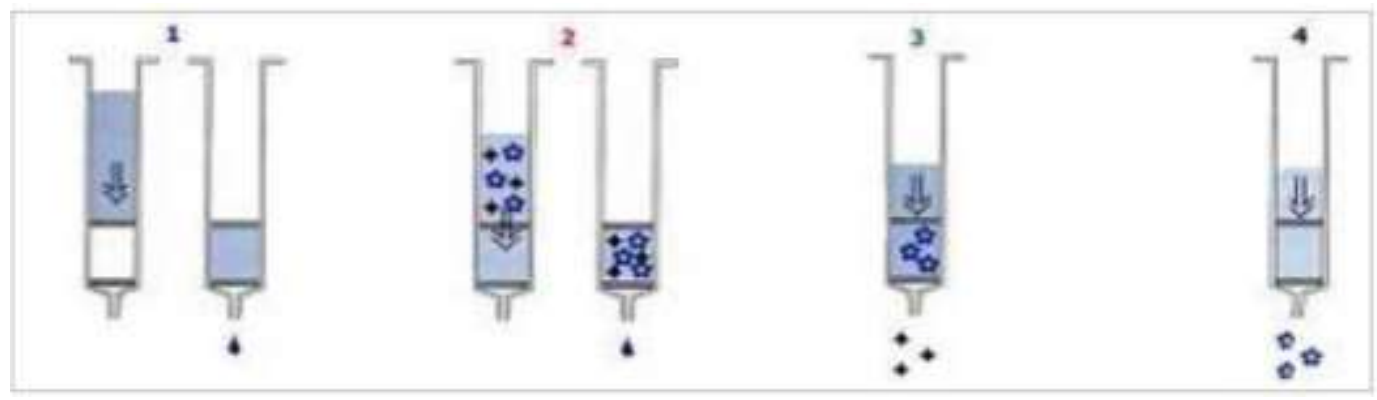

Figura 9. Desenho esquemático da extração em cartucho SPE.

A extração por energia de micro-ondas (MAE), também tem sido amplamente utilizada para compostos termicamente estáveis, pois sendo uma radiação não-ionizante provoca movimento molecular pela migração de íons e rotação dos dipolos, sem alterar as estruturas moleculares dos compostos estudados. Extração utilizando-se banho de ultrassom também é uma técnica convencional para extração de compostos fenólicos, pois pode ser realizada em um curto espaço de tempo curto e oferece boas recuperações (Cotta, 2009; Santana, 2009; Medeiros, 2013). 


\subsection{Cromatografia a Gás}

As técnicas mais utilizadas para a determinação quantitativa de compostos orgânicos, descritas na literatura, envolvem o uso de métodos cromatográficos, destacando-se a Cromatografia a Gás (Gas Chromatography, GC) e a Cromatografia Líquida de Alta Eficiência em fase reversa (High Performance Liquid Chromatography, HPLC) (Petrovic et al., 2002; Richardson, 2009).

Cromatografia é um método físico de separação de compostos existentes em uma mistura, no qual os componentes a serem separados são distribuídos em duas fases, denominadas fase estacionária, de grande área superficial e fase móvel, que consiste em um fluído que carrega a amostra através da coluna. Os diferentes métodos cromatográficos podem ser classificados, de acordo com seu mecanismo de separação, com a técnica empregada ou de acordo com o tipo da fase móvel utilizada. No caso da cromatografia a gás, este nome é utilizado por utilizar gás em sua fase móvel. O primeiro trabalho publicado na área da cromatografia a gás foi elaborado por Martim e James em 1952, cuja técnica foi desenvolvida ao longo da década de 1950 e aprimorada na década de 1960 com a utilização de computadores para monitorar os parâmetros experimentais. Esta é atualmente uma das principais técnicas utilizadas em laboratórios que realizam análises químicas, sendo uma das técnicas analíticas de melhor desempenho, podendo ainda ser combinada com diferentes sistemas de detecção (Lanças, 1993; Bonato et al., 1995; Otomo, 2010).

A cromatografia a gás, apesar de suas vantagens, deve ser utilizada apenas para compostos voláteis e termicamente estáveis. Caso os compostos utilizados não apresentem estas características é necessária uma etapa de derivatização da amostra, em que a estrutura da molécula passará por uma modificação a fim de torná-la apropriada. Compostos com grupos funcionais como $-\mathrm{COOH},-\mathrm{OH},-\mathrm{NH},-\mathrm{SH}$, são normalmente submetidos a esta etapa, devido à facilidade de formação de ponte de hidrogênio entre as moléculas e consequentemente diminuição da volatilidade (Bonato, 1995; HALKET, 2003). 
O sistema de cromatografia a gás é composto basicamente por cilindro para armazenamento do gás de arraste, injetor, coluna cromatográfica, forno, detector e registrador. Na FIG. 10 é apresentado o esquema de um sistema de cromatografia a gás.

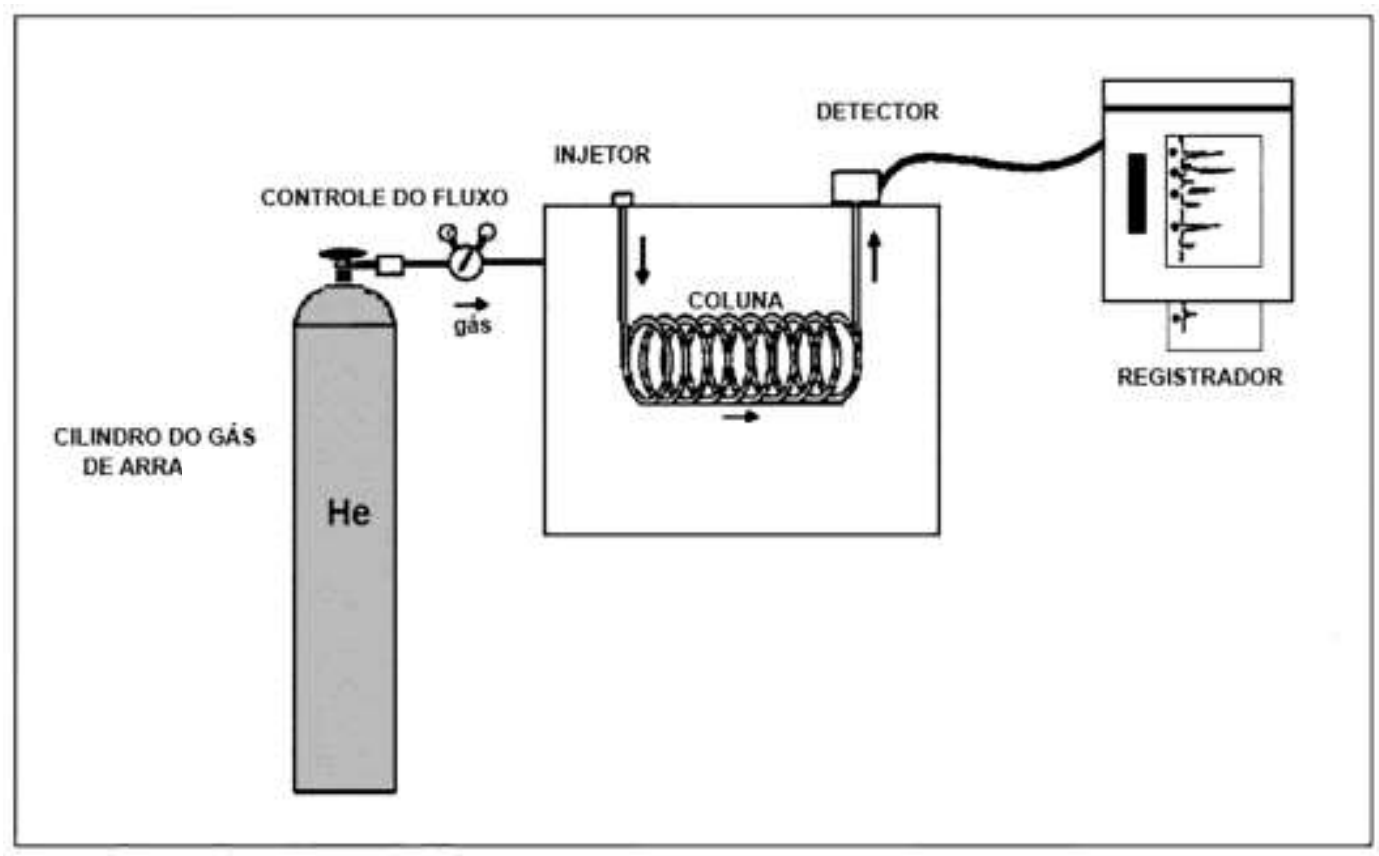

Figura 10. Esquema de um sistema GC (Fonte: adaptado de Lanças, 1993)

A fase móvel do cromatógrafo a gás é denominada gás de arraste, constituída de um gás inerte com elevada pureza, cuja finalidade é transportar as moléculas a serem separadas ao longo da coluna, sendo escolhido a partir do detector que será utilizado. A separação ocorre devido a adsorção diferencial dos compostos da mistura vaporizada sobre a superfície sólida. Moléculas com maior afinidade pela fase estacionária deslocam-se com menor velocidade e permanecem por mais tempo na coluna. A fase estacionária sólida é usualmente utilizada para a separação de substâncias apolares e de baixa massa molecular (Lanças, 1993; Otomo, 2010).

A injeção da amostra no equipamento é uma etapa crítica da análise para que se obtenham picos ideais. As condições de injeção, como volume da amostra e temperatura do injetor, dependem do estado físico da amostra. No caso de amostras líquidas, o ideal é que a temperatura do injetor esteja de 20 a $30{ }^{\circ} \mathrm{C}$ acima da temperatura de ebulição do componente mais volátil, para que ocorra 
completa e rápida volatilização. São injetados pequenos volumes de amostra utilizando micro seringa $(10 \mu \mathrm{L})$ e usualmente em análises em nível traço, utilizandose o modo splitless no qual todo o volume da amostra é direcionado à coluna (Lanças, 1993; Otomo, 2010; Souza, 2011).

As colunas podem ser confeccionadas a partir de diferentes materiais, como cobre, vidro, aço inoxidável, alumínio, etc. Podem ser classificadas em coluna empacotada, quando são preenchidas integralmente pelo material da fase estacionária e coluna capilar, onde a fase estacionária é depositada na parede interna do tubo na forma de um fino filme. A eficiência da coluna está diretamente relacionada às dimensões da mesma, tanto o diâmetro interno quanto 0 comprimento da coluna. As colunas do tipo empacotada possuem diâmetro interno maior (3-6 mm) em relação às colunas capilares $(0,1-0,5 \mathrm{~mm})$, se diferenciam também pelo comprimento. As empacotadas variam de 0,5 a $5 \mathrm{~m}$ de comprimento enquanto as capilares chegam até 100 m (Lanças, 1993; Bonato et al., 1995; Otomo, 2010).

O controle das temperaturas do injetor, coluna e detector também é um fator determinante da eficiência da análise cromatográfica. A temperatura da câmara de injeção deve ser suficiente para a completa vaporização da amostra de forma rápida para evitar perdas, porém controlada para que não haja decomposição térmica dos compostos estudados. Ao longo da coluna, deve ser estabelecida uma rampa de temperatura para facilitar a separação e otimizar o tempo de análise, com uma temperatura inicial baixa para a eluição de solutos com baixo ponto de ebulição e temperatura mais alta ao longo da coluna para a eluição de solutos com maior ponto de ebulição. A temperatura do detector, de um modo geral deve ser relativamente alta para evitar que a amostra condense e ocorra alargamento dos picos (Lanças, 1993; Otomo, 2010).

A cromatografia a gás é utilizada para separação de compostos orgânicos devido ao seu alto poder de resolução e capacidade de separar diversas substâncias em uma mesma análise. Porém a técnica identifica os compostos separados por comparação do tempo de retenção do composto na coluna com padrões, e para uma análise qualitativa e quantitativa com maior precisão, é 
necessária a utilização de detectores como técnica auxiliar. Existem diferentes tipos de sistemas de detecção em que a cromatografia pode ser combinada, sendo os mais utilizados: Detector por condutividade térmica (TCD), Detector por ionização de chama (FID), Detector por captura de elétrons (ECD) e Detector por espectrometria de massas (MS) (Lanças, 1993; Otomo, 2010; Souza, 2011).

\subsection{Espectrometria de Massas}

A cromatografia a gás (GC, gas chromatography) usada na determinação de analitos pode ser acoplada a diferentes detectores, entretanto, 0 detector por espectrometria de massas (MS, mass spectrometry) se sobressai aos demais por combinar as vantagens dos dois equipamentos, resultando em uma técnica com alta seletividade, eficiência de separação e obtenção de informação estrutural dos compostos em estudo, sendo ainda uma combinação simples uma vez que a necessidade de alto vácuo do espectrômetro de massas é compatível com as características de funcionamento do cromatógrafo a gás (Petrovic et al., 2002; Chiaradia,2008; Richardson, 2009).

O desenvolvimento da espectrometria de massas se iniciou com os experimentos de J.J. Thomsom em 1912 sobre raios catódicos, a partir das observações deste experimento desenvolveu-se uma das primeiras determinações da razão massa/carga (m/z) (Lanças, 2009).

O princípio da espectrometria de massas consiste na ionização de átomos e moléculas e sua identificação a partir da razão $\mathrm{m} / \mathrm{z}$ específica de cada composto. As trajetórias dos íons sob vácuo e diferentes combinações de campos elétricos e magnéticos são analisadas e desse modo é possível determinar as massas moleculares e identificar corretamente os analitos em estudo por meio da avaliação dos seus fragmentos de massas. Estes fragmentos são posteriormente separados e encaminhados para detecção e quantificação com o auxílio de software apropriado para efetuar os cálculos (Lanças, 2009; Otomo, 2010).

A ionização pode ser feita utilizando-se diversas técnicas de acordo com o tipo de amostra a ser analisada, como por exemplo fotoionização à pressão atmosférica (APPI), electrospray (ESI), ionização por dessorção a laser assistida 
por matriz (MALDI), ionização química à pressão atmosférica (APCI), ionização por impacto de elétrons, ionização por átomos rápidos (fast atom bombardment, FAB) e a ionização por spray aquecido (thermo-spray ionization, TSP) (Otomo, 2010; Souza, 2011).

A ionização por impacto de elétrons é a técnica mais antiga na formação de íons e também uma das mais empregadas sendo compatível com todos os tipos de analisadores de massas. O analito de interesse, em fase gasosa, é bombardeado por elétrons de alta energia de colisão, geralmente $70 \mathrm{eV}$, liberados de um filamento aquecido. A energia absorvida pela molécula ioniza o analito pela remoção de um elétron, resultando um íon com carga positiva. Para evitar colisões intermoleculares o processo de ionização é realizado em um meio com vácuo, com pressão menor que $10^{-2} \mathrm{~Pa}$. A energia de colisão constante permite a obtenção de espectros de massas reprodutíveis, que podem ser constituídos por todos os íons produzidos ou apenas por íons de interesse selecionados (Lanças, 2009; Otomo, 2010; Souza, 2011).

Os íons gerados são direcionados para o analisador de massas, que os separa de acordo com sua razão $\mathrm{m} / \mathrm{z}$. A escolha do analisador de massas mais apropriado deve ser feita considerando-se a aplicação, o desempenho desejado e o custo. Os analisadores de massas podem ser baseados em setores elétricos ou magnéticos, utilizados para medições de razão isotópica, massa exata e análises orgânicas, este tipo de analisador apesar de apresentar alta resolução e exatidão de massas têm um alto custo e complexidade para operação e manutenção. Há ainda o analisador por tempo de voo (time of flight, TOF), que também apresenta alta resolução e é utilizado normalmente para análise desde pequenas a macromoléculas (Lanças, 2009; Souza, 2011).

O analisador de massas do tipo quadrupolo é atualmente o mais utilizado por ser relativamente simples de operar com um custo menor em comparação aos outros. É formado por quatro hastes metálicas, arranjadas em pares e carregadas eletricamente com cargas opostas. Os íons com relação $\mathrm{m} / \mathrm{z}$ que estejam em ressonância com o campo elétrico aplicado atravessarão o quadrupolo com trajetória estável atingindo o detector, os demais serão desviados da trajetória 
central e eliminados pelo vácuo. Para aumentar a eficiência deste tipo de analisador, aumentando sua detectabilidade, diminuindo ruídos e gerando informações estruturais mais significativas dos analitos, é utilizado um arranjo de três quadrupolos em série, denominado triplo quadrupolo (Chiaradia,2008; Souza, 2011).

Os detectores são responsáveis por registrar a carga induzida quando um íon atinge sua superfície gerando um espectro de massas em função da razão $\mathrm{m} / \mathrm{z}$ dos íons detectados, as principais características que um bom detector deve apresentar são resposta a uma ampla faixa de massas, ruído baixo, alta estabilidade, detecção simultânea e resposta rápida. Os dois principais tipos utilizados são detector de Faraday ou copo de Faraday (CF), constituído em um copo fabricado em metal que capta partículas carregadas em baixa pressão cuja corrente é medida e tida como base para quantificar os íons. E o detector tipo multiplicador de elétrons (ME), pode ser montado com diferentes geometrias e por catodos de materiais que apresentem como característica principal a perda de elétrons quando atingidos por um íon. Desse modo é gerada uma cascata de elétrons em quantidade proporcional à quantidade de íons que chegam ao detector, esse processo gera uma amplificação da corrente elétrica detectada, melhorando desta forma a eficiência do sistema de detecção (Lanças, 2009; Souza, 2011).

A aquisição dos dados em espectrometria de massas pode ser feita no modo SIM, selecionando-se íons específicos, normalmente os íons de maior intensidade já conhecidos para cada composto em estudo, sendo esta a melhor alternativa quando o objetivo é a quantificação. E no modo SCAN, em que é feita uma varredura em faixa pré-determinada de íons, utilizado em análises qualitativas de misturas complexas e/ou desconhecidas (Otomo,2010; Souza, 2011). 


\section{6 ÁREA DE ESTUDO}

O Reservatório Guarapiranga está localizado na Bacia Hidrográfica do Alto Tietê e sub-bacia Guarapiranga, no Estado de São Paulo, que inclui a Região Metropolitana de São Paulo. Sua bacia abrange $631 \mathrm{~km}^{2}$ distribuídos entre as cidades de Embu (41 km²), Embu-Guaçu (162 km²), Itapecerica da Serra (183km²), porções menos extensas dos municípios de Juquitiba, São Lourenço da Serra, Cotia e a cidade de São Paulo $\left(211 \mathrm{~km}^{2}\right)$. Tendo como principais tributários na margem direita os Rios Bonito, das Pedras, Parelheiros, Córregos Tanquinho e São José e na margem esquerda: Rios Embu-mirim, Embu-Guaçu e Córregos Guaravirutuba, Itupú e Mombaça (FIG. 11). A maior parte de seu território está inserido na área de abrangência da Reserva da Biosfera do Cinturão Verde da Cidade de São Paulo (Whately \& Cunha 2006; Silva, 2013; Pompeo, 2013).

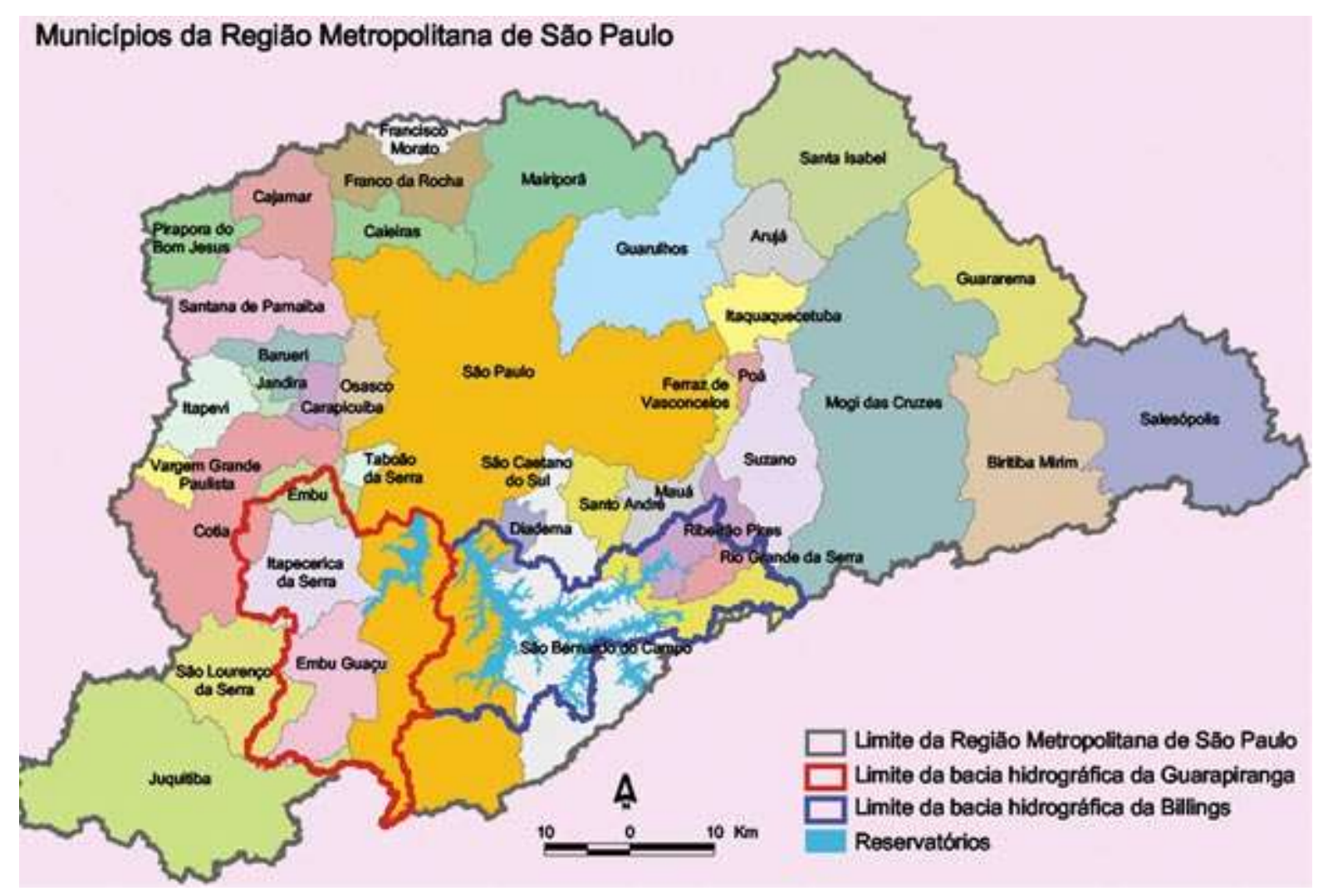

Figura 11. Limite da Bacia Hidrográfica do Alto Tietê.

A represa Guarapiranga situa-se a uma altitude de $742 \mathrm{~m}$, apresenta uma área de aproximadamente $36 \mathrm{~km}^{2}$ com tempo de retenção da água de 185 dias, profundidades média de $6 \mathrm{~m}$ e máxima de $13 \mathrm{~m}$ e capacidade de volume total 
de $253 \times 10^{6} \mathrm{~m}^{3}$ (FIG. 12). O regime de precipitação da bacia é caracterizado por um período chuvoso, entre outubro e março e um período seco, entre abril e setembro. É considerado atualmente o segundo maior reservatório produtor da RMSP, atendendo cerca de 4 milhões de habitantes, sendo que 95\% da população atendida reside no Município de São Paulo e 5\% no município de Taboão da Serra (Silva, 2013, Pompeo, 2013, Otomo, 2015).

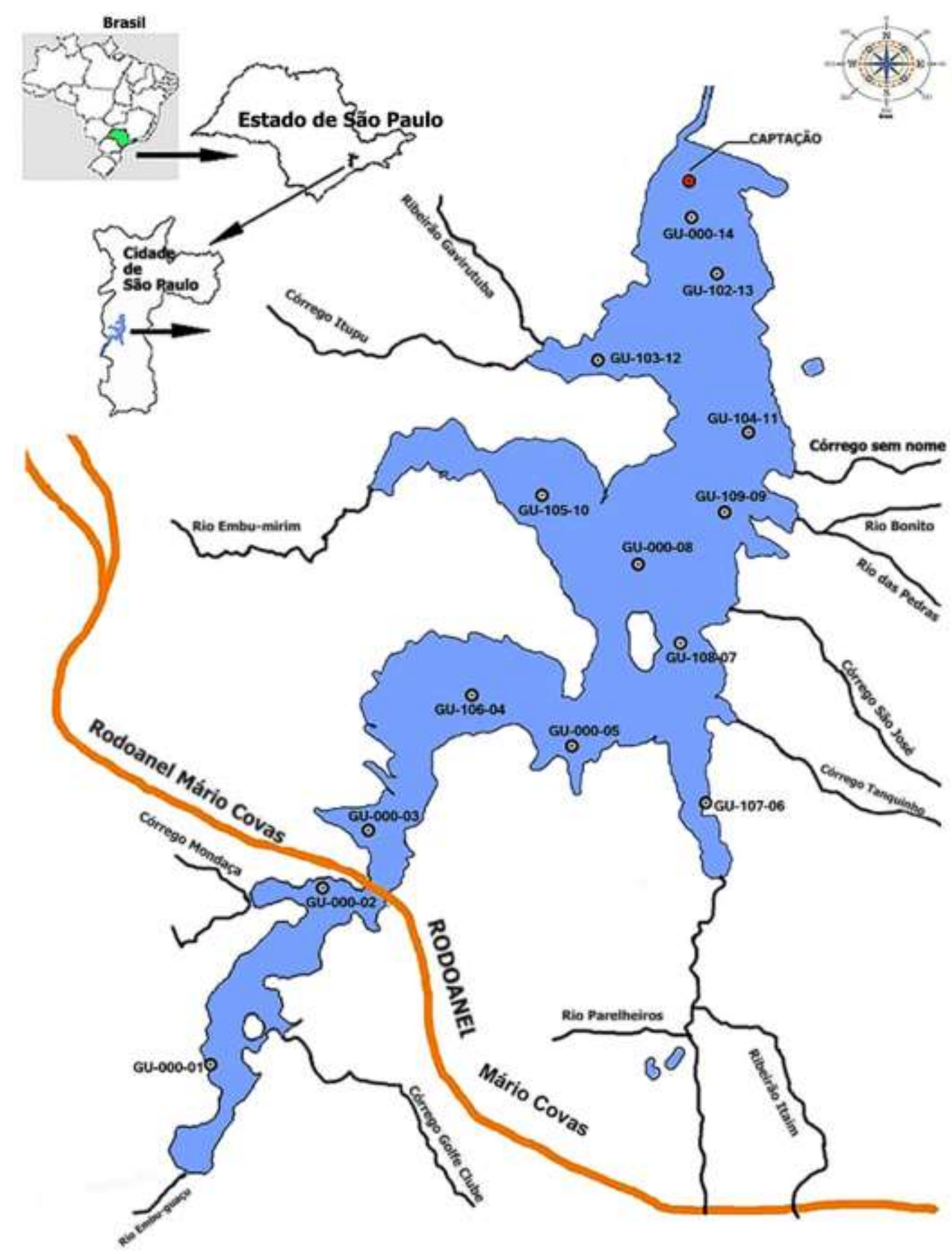

Figura 12. Reservatório Guarapiranga 


\subsection{Contextualização Histórica Do Reservatório}

A construção do Reservatório Guarapiranga foi iniciada em 1906, pela empresa The São Paulo Tramway Light and Power Co., cujo objetivo era geração e distribuição de energia elétrica, por meio da regularização da vazão do Rio Tietê, melhorando desse modo a capacidade de geração de energia na Usina de Santana de Parnaíba que tinha sua produção comprometida em períodos de estiagem da região (Sabesp,2008).

Com a construção concluída no ano de 1909, o reservatório começou a exercer diferentes funções das inicialmente propostas. Inicialmente, a população da região foi atraída por seu potencial recreativo, e dessa forma novas atividades econômicas na região foram geradas, como a criação de bares, clubes náuticos, hotéis e consequente valorização imobiliária da região (Borelli, 2006; Sabesp,2008).

No ano de 1925, após período crítico da estiagem no estado de São Paulo, a utilização de suas águas para abastecimento público começou a ser discutida, sendo considerado na década de 1950 o principal sistema produtor para abastecimento público de água da capital paulista. Além da aprovação de projeto, também no ano de 1925, que permite o encaminhamento de suas águas para o canal do Rio Pinheiros, seguindo até o Reservatório Billings com o objetivo de alimentar as turbinas de uma usina de geração de energia elétrica em Cubatão. Transformando desse modo o Reservatório Guarapiranga em um reservatório de usos múltiplos da água, sendo utilizado até os dias de hoje, principalmente para abastecimento de água potável, controle de enchentes, geração de energia e recreação (Sabesp,2008; Sant'Anna et al. 2008).

Com o crescimento da cidade e expansão de empresas e indústrias, a ocupação das margens do reservatório se fez de forma desordenada e com carência de saneamento básico e planejamento urbano, em áreas que seriam posteriormente definidas como áreas de proteção ambiental. A região do reservatório se tornou então densamente povoada, ficando consequentemente submetida a grandes impactos ambientais, resultando em baixa disponibilidade 
hídrica e deterioração de sua qualidade. Dentre os impactos existentes na Bacia pode-se destacar a contribuição de esgotos domésticos (Borelli, 2006; Sant'Anna et al. 2008).

Somente em meados da década 1970, começaram a surgir medidas de proteção dos mananciais. Primeiramente com a criação do Plano de Controle de Poluição das Águas para o Estado de São Paulo, organizado em decorrência do Decreto-Lei no 50.592, de 29/10/1968 e contemplava a Bacia do Guarapiranga com um plano de controle da poluição próprio. Em 1971, por resolução da Secretaria de Serviços e Obras Públicas do Estado foi constituído um grupo de trabalho cuja finalidade foi "coordenar e acompanhar as providências necessárias ao desenvolvimento de um programa destinado ao controle de poluição das águas da Bacia do Guarapiranga, compreendendo as obras necessárias e outras atividades correlatas". Também nesta década foi criada a Legislação de Proteção aos Mananciais, composta pelas leis estaduais 898/75 e 1.172//76 com o objetivo de ordenar a expansão da mancha urbana, estabelecendo critérios legais para ocupação e uso do solo e delimitar as áreas de mananciais a serem protegidas (Borellli, 2006; Sabesp,2008).

As leis criadas em 1971 foram eficientes para conter a atividade industrial na Bacia, porém não foram suficientes para controlar ocupação irregular das margens do reservatório, devido à queda no valor de mercado dos terrenos, favorecendo a proliferação de loteamentos irregulares na região. Então em 1997, foi promulgada a Lei Estadual 9.866, que não só estabelece princípios de proteção dos mananciais, como também reconhece a existência da ocupação irregular na área e determina o princípio de recuperação das áreas degradadas. Em 2006, foi aprovada a Lei Específica da Área de Proteção e Recuperação da Guarapiranga Lei Estadual no 12.233, que define áreas, instrumentos e ações para a recuperação ambiental da Bacia. Entre as principais abordagens desta lei, destaca-se a definição de três categorias de áreas de intervenção, sendo áreas de restrição à ocupação, áreas de ocupação dirigida e áreas de recuperação ambiental (Borelli, 2006; Sabesp, 2008). 
Segundo Andrade et al. (2015) a região da Bacia ainda se encontra em crescente urbanização com característica periférica e dispersa, sendo constituída essencialmente por residências e de forma subordinada por comércios e indústrias. Essas áreas residenciais encontram-se em diferentes estágios de ocupação, sendo $60 \%$ destas já consolidadas e nas áreas restantes ainda se encontram terrenos passíveis de ocupação, com malha viária extensa e distribuída por toda a bacia contribuindo para tal ocupação. No entorno do reservatório que inclui os municípios de Embu, Itapecerica da Serra e São Paulo, o crescimento demográfico é tão intenso que já se pode notar uma tendência de conturbação entre os municípios, fato que pode ser agravado com o funcionamento do Rodoanel Metropolitano Mário Covas.

O uso e ocupação do solo em torno do Reservatório Guarapiranga e a densidade populacional em 5 bacias contribuintes, de acordo com estudo realizado por Andrade e colaboradores (2015), pode ser observado na FIG. 13, na qual é apresentada a divisão e a localização dessas bacias junto à represa. A área de contribuição A envolve as bacias dos córregos Santa Rita e Embu-Guaçu, enquanto que a área de contribuição B consiste da bacia do córrego Embu Mirim. 


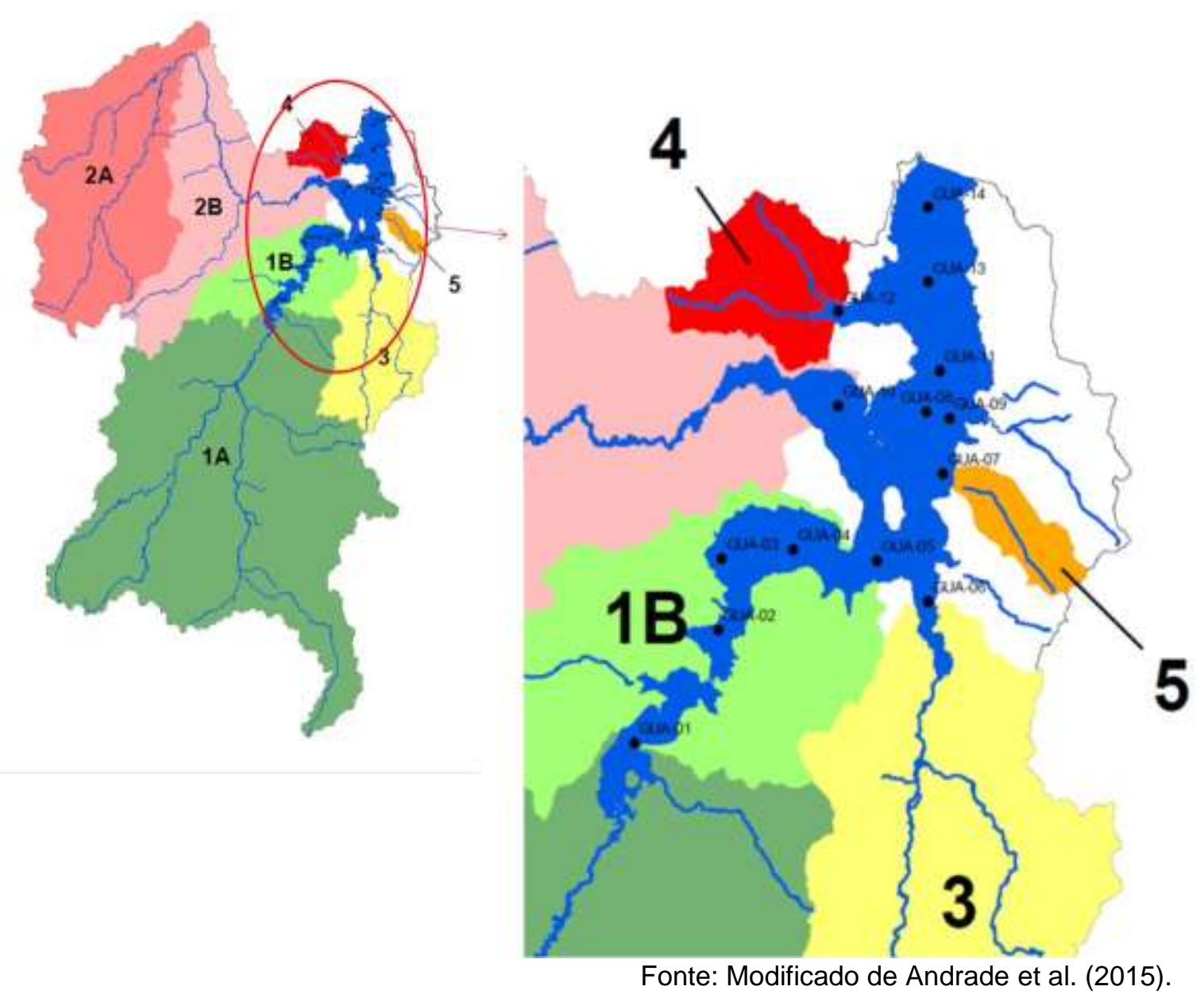

Figura 13. Mapa das bacias contribuintes, uso e ocupação do solo em torno do Reservatório Guarapiranga.

As bacias 4 e 5, embora sejam menores, possuem elevada densidade demográfica e essa população está muito próxima das margens da represa. A bacia 4 é a mais densamente ocupada e bem próxima ao ponto mais crítico (G103-12) (Andrade et al., 2015; Otomo, 2015). 


\section{VALIDAÇÃO DE METODOLOGIA ANALÍTICA}

A validação é uma etapa de extrema importância no desenvolvimento da metodologia analítica, pois garante a reprodutibilidade do método de forma confiável atendendo aos objetivos e qualidade propostos. Esta etapa vem sendo cada vez mais exigida ao longo dos anos, pois dados analíticos gerados de forma não confiável pode conduzir a decisões desastrosas e a prejuízos financeiros muitas vezes irreparáveis. O processo de validação consiste em uma série de ensaios analíticos, seguidos por tratamento estatístico dos resultados sempre comparando com valores de referência (Brito, 2009; Ribani et al. 2004).

Os laboratórios devem validar métodos totalmente novos, criados/desenvolvidos pelo próprio laboratório, métodos não normalizados, métodos normalizados usados fora do escopo para o qual foi desenvolvido ou métodos normalizados que sofreram modificações ou ampliações para objetivos específicos. Todas as etapas da validação do método devem ser devidamente registradas e documentadas para garantir a rastreabilidade do mesmo. No Brasil, a ANVISA (Agência Nacional de Vigilância Sanitária) e o INMETRO (Instituto Nacional de Metrologia, Normalização e Qualidade Industrial) são os órgãos brasileiros com autoridade para verificar a competências dos laboratórios de ensaio, por meio de resoluções e guias inspiradas em diretrizes da ICH (International Conference on Harmonization) e do grupo EURACHEM, estabelecem dessa forma as diretrizes para uma validação segura e confiável (INMETRO).

A Resolução ANVISA RE nº899, 29/05/2003, determinou a publicação do "Guia para validação de métodos analíticos e bioanalíticos", voltado para pesquisas farmacêuticas. Em 2003 o INMETRO publicou a primeira versão do documento DOQ-CGCRE-008, o qual vem sendo atualizado periodicamente, destinado a avaliadores e especialistas na área de laboratórios de ensaio.

As metodologias desenvolvidas com uso de técnicas cromatográficas, especialmente, exigem procedimentos de validação, pois envolvem metodologias complexas para utilização em monitoramentos que dizem respeito a aspectos 
essenciais na sociedade como saúde pública, monitoramento ambiental, comércio exterior e controle de qualidade de produção (Ribani, 2004).

Para a validação da metodologia desenvolvida neste trabalho, foi utilizado como referência o documento INMETRO DOQ-CGCRE-008 de 4 julho de 2011 e para os cálculos estatísticos uma ferramenta desenvolvida por Furusawa (2007), também baseada neste documento. De acordo com este documento do INMETRO, os parâmetros recomendados para avaliação são seletividade, linearidade, faixa de trabalho e faixa linear, limite de detecção, limite de quantificação, tendência/recuperação, precisão (repetitividade, precisão intermediária e reprodutibilidade) e robustez, além de sugerir a avaliação das incertezas associadas. Essas incertezas foram estimadas com base no guia Eurachem (2012), e fazendo uso de uma planilha eletrônica desenvolvida por Martins (2010), também baseada no Eurachem.

\subsection{Seletividade}

Método seletivo é aquele onde os picos dos compostos de interesse podem ser identificados, de forma inequívoca, mesmo com a presença de interferentes na matriz em estudo. A seletividade é o primeiro parâmetro que deve ser avaliado, pois garantindo-se boa seletividade, os demais parâmetros como linearidade, exatidão e precisão podem ser avaliados com maior segurança. Este parâmetro deve também ser reavaliado não só no decorrer de todo o processo de validação, mas também em análises posteriores. Como sugerido pela IUPAC o termo seletividade será usado no lugar do termo especificidade para evitar confusão desnecessária, já que o método desenvolvido tem por objetivo produzir resposta para vários compostos químicos, com características em comum (Ribani, et al. 2004).

A seletividade pode ser avaliada com o uso de branco da amostra com adição de padrões ou materiais de referência, porém devido à dificuldade de se obter tais amostras completamente isentas do analito de interesse, é comum o uso de detectores modernos, como o espectrômetro de massas, que possibilita a 
identificação exata do composto de interesse, mesmo usando-se uma matriz com interferentes (Ribani, et al. 2004).

Além da análise do cromatograma, a seletividade pode também ser avaliada por meio de testes estatísticos. Para avaliação da interferência da matriz na precisão do método utiliza-se o teste $\mathrm{F}$ (Snedecor) de homogeneidade das variâncias nas medidas de adição padrão nas soluções com e sem matriz, com número estatisticamente significativo de replicatas $(n=7)$, O cálculo é feito utilizando a equação 1, e a comparação com um valor de referências ( F $_{\text {Tabelado), }}$ com $95 \%$ de confiança e (n-1) graus de liberdade.

$$
F=\frac{s_{1}^{2}}{s_{2}^{2}}
$$

Onde:

$\mathrm{F}=\mathrm{F}_{\text {calculado }}$

$s_{1}^{2}=$ maior variância;

$s_{2}^{2}=$ menor variância.

Se a matriz tem efeito sobre a precisão do método o valor de $F_{\text {calculado }}$ será maior que o valor de FTabelado.

É também recomendado o teste $\mathrm{t}$ (Student) de significância das diferenças das médias, aplicado nos dois grupos de soluções (com e sem matriz) de acordo com a equação 2. Nesse teste, se a matriz afeta as medidas do ensaio, o valor de tcalculado será maior que o valor de trabelado.

$$
t_{\text {calculado }}=\frac{\left|\overline{x_{1}}-\overline{x_{2}}\right|}{\sqrt{\frac{s_{1}^{2}}{n_{1}}+\frac{s_{2}^{2}}{n_{2}}}}
$$

Onde:

$\overline{x_{1}}$ e $\overline{x_{2}}=$ diferença da média das replicatas de cada nível de concentração com e sem matriz;

$s_{1}^{2}$ e $s_{2}^{2}=$ variância das replicatas nas soluções com e sem matriz;

$n_{1}$ e $n_{2}=$ tamanho do conjunto de soluções utilizados, com e sem matriz. 
No caso do teste t, a definição do grau de liberdade depende do resultado obtido com o teste $F$. Sendo $F_{\text {calculado }}<F_{\text {Tabelado, }} 0$ grau de liberdade é obtido pela distribuição de Student considerando $\left(\mathrm{n}_{1}+\mathrm{n}_{2}-2\right)$ graus de liberdade e a confiança desejada (normalmente $95 \%$ ), e sendo $\mathrm{F}_{\text {calculado }}>\mathrm{F}_{\text {Tabelado }} \mathrm{o}$ grau de liberdade é calculado pela equação 3.

$$
v=\frac{\left(\frac{s_{1}^{2}}{n_{1}}+\frac{s_{2}^{2}}{n_{2}}\right)}{\frac{\left(\frac{s_{1}^{2}}{n_{1}}\right)^{2}}{n_{1}+1}+\frac{\left(\frac{s_{2}^{2}}{n_{2}}\right)^{2}}{n_{2}+2}}-2
$$

A fim de comparar as curvas analíticas, com matriz e sem matriz, a seletividade pode também ser avaliada pelo teste t de Inclinação e Paralelismo e pelo teste do Intercepto, utilizando-se as equações 4 e 5 respectivamente. Curvas com a mesma inclinação indica que não há influência da matriz na determinação dos compostos estudados (Ribani, 2004; Furusawa, 2007; INMETRO, 2011).

$$
t=\frac{b 1-b 2}{\sqrt{S_{x y}} \sqrt{\frac{1}{\sum\left(X_{1 i}-\bar{X}\right)^{2}}+\frac{1}{\sum\left(X_{2 i}-\bar{X}\right)^{2}}}}
$$

Onde:

b1 = b da equação da reta do ensaio com matriz;

b2 $=$ b da equação da reta do ensaio sem matriz;

$$
t=\frac{a 1-a 2}{\overline{S_{x y}} \sqrt{\frac{1}{n_{1}}+\frac{\bar{x}_{1}^{2}}{\sum\left(X_{1 i}-\bar{X}_{1}\right)^{2}}+\frac{1}{n_{1}}+\frac{\bar{x}_{2}^{2}}{\sum\left(X_{2 i}-\bar{X}_{2}\right)^{2}}}}
$$

Onde:

a1 = a da equação da reta do ensaio com matriz; a2 = a da equação da reta do ensaio sem matriz; 
Para ambas as equações (4 e 5), pode-se considerar a equação 6 :

$$
\bar{S}_{x y}=\sqrt{\frac{\left(n_{1}-2\right) S_{y 1 x 1}^{2}+\left(n_{2}-2\right) S_{y 2 x 2}^{2}}{n_{1}+n_{2}-4}}
$$

\subsection{Faixa de trabalho e Linearidade}

Faixa de trabalho corresponde ao intervalo entre valores mínimo e máximo de concentrações em que o método quantitativo pode ser aplicado, fornecendo resultados confiáveis. O valor mínimo pode ser determinado de acordo com o limite de quantificação e o valor máximo, geralmente é estabelecido de acordo com a capacidade de resposta do sistema de medição. Os valores mais esperados, devem sempre que possível estar no centro da faixa. (INMETRO, 2010)

A linearidade é o parâmetro que demonstra se o método é capaz de fornecer resultados com proporção direta às concentrações dos compostos em estudo, dentro de uma determinada faixa de trabalho. Este parâmetro torna possível mensurar por meio de curvas analíticas um analito em uma matriz cuja concentração é desconhecida (Leite, 2008; Otomo, 2010).

A relação matemática que correlaciona o sinal medido com a concentração do composto de interesse na matriz de estudo, pode ser expressa como uma equação de reta denominada curva analítica, onde no eixo $x$, por exemplo, têm-se concentrações e no eixo y as repostas medidas. Na confecção da curva analítica, as concentrações do eixo $\mathrm{x}$ devem ser previamente determinadas de acordo com o que se espera obter na amostra em estudo, objetivando uma variação em torno de $20 \%$ em relação ao valor estimado para o composto a ser mensurado, sendo necessário no mínimo cinco níveis de concentração e quantidade de replicatas o mais próximo possível da utilizada em laboratório (Leite, 2008; Ribani, 2004). A equação da reta pode ser observada na equação 7.

$$
y=a x+b
$$


Onde:

$y=$ resposta medida ou sinal analítico;

$\mathrm{x}=$ concentração do analito;

$\mathrm{a}=$ coeficiente angular, expressa a inclinação da curva;

$\mathrm{b}=$ coeficiente linear, expressa a intersecção da curva ao eixo.

Para indicar o quanto a reta obtida a partir de pontos experimentais é adequada como modelo matemático para um estudo de caso específico, utiliza-se com frequência a equação da regressão linear obtida pelo método dos mínimos quadrados. Este método garante que a função que melhor se ajusta a um determinado conjunto de dados seja utilizada, pois minimiza a soma dos quadrados das diferenças entre os valores Tabelados e os valores obtidos pela aproximação (INMETRO, 2010).

Para verificar a ausência de valores discrepantes, utiliza-se também a análise de resíduos avaliada de acordo com o teste $\mathrm{t}$ (Student), de acordo com a equação 8 , que calcula as variâncias e os desvios padrão de cada nível de concentração. Utilizam-se também os gráficos de resíduos e probabilidade normalizada.

$$
t_{\text {calculado }}=\frac{\text { Resíduo }}{\frac{S_{r}}{\sqrt{n}}}
$$

Onde:

Resíduo = $\left|X_{\text {medido }}-X_{\text {calculado }}\right|$;

$\mathrm{S}_{\mathrm{r}}=$ desvio padrão dos resíduos;

$\mathrm{N}=$ número de pontos.

O valor obtido, tcalculado de cada ponto, é comparado ao valor Tabelado, considerando-se (n-1) graus de liberdade, no intervalo de confiança desejado. Se o tcalculado for menor ou igual ao trabelado, o ponto é considerado pertencente à curva e a faixa de trabalho a qual ele pertence é linear.

A partir dos pontos experimentais, a qualidade de uma curva analítica é avaliada principalmente pelo coeficiente de determinação $\left(\mathrm{r}^{2}\right)$. $\mathrm{O}$ coeficiente de determinação é o quadrado do coeficiente de correlação de Pearson e expressa a 
relação entre x e y. Este coeficiente deve estar o mais próximo de 1, pois quanto mais próximo deste valor maior é o ajuste do modelo, indicando desta forma a menor dispersão do conjunto de pontos experimentais e incerteza possíveis. Para que uma curva analítica possa ser utilizada para quantificação é recomendado um valor próximo de 1 . Um valor acima de 0,90 indica uma correlação muito forte (Ribani, 2004; Leite, 2008; Otomo, 2010; Mukaka, 2012).

Como alternativa o INMETRO (2003; 2010; 2011) sugere o uso da análise de variância (ANOVA) para avaliar a linearidade. A análise de variância é realizada pelo teste $\mathrm{F}$ de regressão que avalia a adequação do modelo adotado aos dados obtidos e o teste $\mathrm{F}$ de ajuste que verifica o quanto esse modelo se ajusta ao conjunto de dados obtidos. Essa análise também avalia a porcentagem de variação explicada em relação à porcentagem máxima de variação explicável, ou seja, o quanto de variação pode ser explicada dentro da porcentagem explicável pelo ajuste aplicado ao método (Furusawa, 2007; Otomo, 2010; INMETRO, 2011).

\subsection{Limite de detecção e quantificação}

Limite de detecção (LD) é o menor valor detectado do composto em estudo com confiabilidade e precisão aceitável, porém não necessariamente quantificado. Esse parâmetro é muito importante para amostras com baixos níveis de analito, como análise de traços (INMETRO, 2011; Ribani, 2004).

A metodologia para calcular o limite de detecção pode variar uma vez que esse parâmetro também varia com o tipo da amostra O INMETRO sugere algumas metodologias para o cálculo, mas de um modo geral recomenda um mínimo de sete replicatas da menor concentração da curva analítica, sendo o valor de $t$ unilateral tabelado para $(n-1)$ graus de liberdade no intervalo de confiança escolhida, multiplicado pelo desvio padrão amostral, como mostra a equação 9.

$$
L D=t_{(n-1,1-\alpha)} \cdot(S)
$$

Onde:

$\mathrm{S}$ = desvio padrão das 7 replicatas da menor concentração; 
$\mathrm{t}=$ valor da abscissa $\mathrm{t}($ Student) para $(1-\alpha) \times 100 \%$ nível de confiança e $(\mathrm{n}-1)$ graus de liberdade.

O limite de quantificação (LQ) representa a menor concentração do analito que pode ser quantificada com confiabilidade aceitável, correspondendo normalmente ao padrão de calibração de menor concentração, utilizando-se um determinado procedimento experimental. Sendo recomendado que seja a concentração mais baixa da curva para análise em nível traço (INMETRO, 2011; Ribani, 2004).

O LQ pode ser determinado experimentalmente ou considerando-se a soma da média dos valores do branco mais 5,6 ou 10 vezes o desvio-padrão amostral dos brancos, conforme equação 10.

$$
L Q=\bar{X}+(5,6 \text { ou } 10) . S
$$

Onde:

$\mathrm{X}=$ média das replicatas da menor concentração da curva analítica;

$S=$ desvio padrão das replicatas da menor concentração da curva analítica.

É recomendável também tanto para o LD quanto para o $L Q$, que cada analito seja expresso na unidade apropriada de acordo com o método analítico em validação e que a matriz da amostra seja especificada (INMETRO, 2011).

\subsection{Exatidão}

O parâmetro exatidão representa o grau de concordância entre os resultados encontrados em um ensaio específico e um valor de referência aceito como verdadeiro. A exatidão é considerada dentro de limites pré-definidos, podendo ser limites estreitos em valores de concentração elevados ou mais amplos para amostras em níveis traço. Os métodos comumente utilizados para a avaliação deste parâmetro têm como base materiais de referência certificado, comparação de métodos, adição padrão, ensaios de recuperação. Os resultados podem ser 
avaliados pelo índice z (z Score) conforme equação 11 (Ribani, 2004; INMETRO, 2010).

$$
Z=\frac{\left(X_{\text {laboratório }}-X_{\text {verdadeiro }}\right)}{S}
$$

Onde:

$X_{\text {laboratório }}$ valor obtido pelo laboratório;

$X_{\text {verdadeiro }}=$ valor aceito como verdadeiro;

$\mathrm{S}=$ desvio padrão do conjunto de valores do ensaio de proficiência.

O seguinte critério é usado para a avaliação do valor de z obtido:

$|z| \leq 2$, o resultado é satisfatório;

$2<|\mathbf{z}|<3$, o resultado é questionável;

$|z| \geq 3$, o resultado é insatisfatório.

\subsection{Precisão}

Precisão é o parâmetro que expressa a dispersão de resultados entre ensaios independentes, repetidos de uma mesma amostra, amostras semelhantes ou padrões, sob condições determinada, ou seja, é a avaliação da dispersão dos valores em amostras medidas em replicatas. Normalmente avaliada em termos de desvio-padrão (DP) e desvio padrão relativo (DPR), também conhecido como coeficiente de variação (equação 12). Em métodos que avaliam elementos em nível traço é aceito desvio padrão relativo de até $20 \%$ em função da complexidade da amostra de estudo, sendo que aumentando-se o número de replicatas é possível melhorar a precisão (Ribani, 2004; Otomo, 2010).

$$
\operatorname{DPR}(\%)=\frac{S}{X} X 100
$$

Onde:

$\mathrm{S}=$ desvio padrão;

$\mathrm{X}=$ concentração média determinada. 
Segundo guia de orientação sobre validação do INMETRO (2011) a precisão é normalmente determinada para circunstâncias específicas de medição, sendo comum expressá-la por meio da repetitividade, precisão intermediária e da reprodutibilidade.

Repetitividade: representa a concordância entre os resultados de medições sucessivas de um mesmo método nas mesmas condições de repetitividade: mesmo procedimento de medição, mesmo operador, mesmo local e todas as repetições no menor intervalo de tempo possível. O ensaio para determinação da repetitividade pode ser feito por meio da análise de padrões, material de referência ou adição do analito a branco da amostra, em várias concentrações na faixa de trabalho (Ribani, 2004; INMETRO, 2011).

A avaliação dos resultados pode ser feita utilizando o cálculo do limite de repetitividade, $r$, conforme equação 13. O valor de $r$ permite verificar se há diferença significativa entre as análises realizadas. Caso a diferença entre valores das replicatas seja maior que $r$, algum valor deve ser descartado (Otomo, 2010).

$$
r=t_{(n-1,1-\propto)} \cdot \sqrt{2} . S
$$

Onde:

$\mathrm{t}(\mathrm{n}-1,1-\alpha)=$ valor estatística $\mathrm{t}$ de Student para $\mathrm{n}-1$ graus de liberdade no intervalo de confiança estabelecido.

$\mathrm{S}=$ desvio padrão para as $\mathrm{n}$ replicatas executadas.

Precisão intermediária: diz respeito à precisão frente ao efeito das variações dentro do laboratório em que o método será aplicado, devido a eventos como diferentes dias ou diferentes analistas ou diferentes equipamentos ou uma combinação destes fatores. Sendo então, possível verificar se o método fornecerá os mesmos resultados dentro do mesmo laboratório. O resultado da precisão intermediária pode ser expresso através da estimativa do desvio padrão relativo (RSD) (Ribani,2004; INMETRO, 2011). 
Reprodutibilidade: representa o grau de concordância entre os resultados de medições de uma mesma amostra, efetuadas em condições variadas, como mudança de operador, local ou equipamentos. Permite avaliar o desempenho do método em relação aos dados de validação obtidos por meio de comparação interlaboratorial. O limite de reprodutibilidade pode ser calculado do mesmo modo que o limite de repetitividade (Ribani, 2004; INMETRO 2011).

\subsection{Recuperação}

Calculando-se a recuperação, é possível verificar a eficiência do método, pois este parâmetro mede quanto do composto de interesse presente ou adicionado na amostra é possível de ser extraído e quantificado pela metodologia proposta. Pode ser estimada pela análise de amostras fortificadas com concentrações conhecidas dos compostos estudados (Spike), em pelo menos três concentrações (baixa, média e alta) na faixa de concentração esperada para os compostos de interesse. Segundo o INMETRO (2011), este procedimento pode ser limitado, pois o analito adicionado não está necessariamente na mesma forma que a presente na amostra, podendo gerar avaliações superestimadas da recuperação (Ribani, 2004).

A recuperação pode ser calculada de acordo com a equação 14.

$$
\text { Recuperação }(\%)=\left(\frac{C_{1}-C_{2}}{C 3}\right) \times 100
$$

Onde:

$\mathrm{C}_{1}$ = concentração do analito na amostra fortificada;

$\mathrm{C}_{2}=$ concentração do analito no branco da amostra não fortificada;

$\mathrm{C}_{3}=$ concentração real do analito adicionada à amostra fortificada.

Os resultados da recuperação podem diferir substancialmente em altas e baixas concentrações, pois de um modo geral a dispersão dos resultados aumenta com a diminuição da concentração. Os intervalos de recuperação aceitáveis de recuperação para análise de resíduos estão entre 70 e 120\%, com precisão de até $\pm 20 \%$. Dependendo da complexidade analítica e da amostra, este valor pode ser de 50 a 120\%, com precisão de até \pm 15\% (Ribani, 2004). 


\subsection{Robustez}

A robustez mede a sensibilidade que um método apresenta frente a pequenas variações, medindo assim sua confiabilidade em condições normais de operação. As variações introduzidas no ensaio de robustez refletem as alterações que podem ocorrer em diferentes situações, como quando um método é transferido para outro laboratório, analista ou equipamento (Ribani, 2004; Brito, 2009).

Segundo O DOQ-CGCRE-008 do INMETRO (2011), para a determinação da robustez pode ser aplicado o teste de Youden, que consiste na seleção de 7 variáveis que exerçam influência significativa sobre o método, essas variáveis são arranjadas por combinação fatorial resultando em 8 ensaios distintos (Tab. 2). Esse teste permite avaliar não só a robustez do método, como também ordenar a influência de cada uma das variações nos resultados finais, permitindo verificar quais variáveis devem ser melhor monitoradas para não influenciar negativamente os resultados obtidos pelo método (Otomo, 2010).

Tabela 2. Planejamento fatorial saturado para avaliação da estimativa do erro da distribuição dos efeitos utilizando o algoritimo de Dong (pequenos experimentos)

\begin{tabular}{ccccccccc}
\hline \multirow{2}{*}{$\begin{array}{c}\text { Valor do } \\
\text { Fator }\end{array}$} & \multicolumn{7}{c}{ Combinação Ensaiada } \\
\cline { 2 - 9 } & A & 2 & 3 & 4 & 5 & 6 & 7 & 8 \\
\hline A ou a & A & A & A & A & a & a & a & A \\
B ou b & B & B & b & b & B & B & b & B \\
C ou C & C & C & C & C & C & c & C & C \\
D ou d & D & D & d & d & d & d & D & D \\
E ou e & E & e & E & e & e & E & e & E \\
F ou f & F & f & f & F & F & $f$ & $f$ & F \\
G ou g & G & g & g & G & g & G & G & G \\
Resultado & S & t & u & v & w & $x$ & $y$ & z \\
\hline
\end{tabular}

Os resultados obtidos em cada ensaio combinado podem ser mais facilmente interpretados pela análise dos gráficos de robustez, probabilidade normalizada e Rankit (Otomo, 2010). 


\subsection{Incerteza da medição}

A estimativa da incerteza de medição têm sido uma ferramenta útil para suprir a necessidade de fornecer precisão aos resultados obtidos a partir de um método específico, exigência essa que vem crescendo ao longo dos últimos anos tratando-se de química analítica.

A incerteza da medição é definida, segundo o Guia Eurachem (2002), como: "Um parâmetro associado ao resultado de uma medição, que caracteriza a dispersão que poderiam ser razoavelmente atribuídas ao mensurado". O conhecimento da incerteza de medição dos dados gerados por um determinado método, implica em uma confiança maior nesses resultados.

Os componentes da estimativa da incerteza da medição podem ser classificados como incertezas do Tipo A, em que são calculados com base na análise estatística dos resultados obtidos após medições sucessivas, sendo desse modo os desvios padrão experimentais. $E$ incertezas do Tipo $B$, onde os valores são baseados em outras informações, como por exemplo, certificados de fabricantes, materiais de referência, dados de manuais entre outros.

Este item está diretamente ligado à qualidade laboratorial, uma vez que na prática a incerteza pode provir de diversas fontes, como amostragem, efeitos da matriz e interferência, procedimento de medição, variação aleatória e aproximações incorporadas ao método.

Cada grandeza de entrada é denominada um componente de incerteza e cada um desses componentes pode ser composto por diversos outros fatores os quais devem ser combinados a fim de se obter a contribuição de cada fonte. A incerteza total, denominada, incerteza total padronizada, $u_{c}(y)$, é determinada pela lei de propagação de incerteza, a partir do conjunto da incerteza individual de cada fonte expressa em desvio padrão, denominada incerteza padronizada u(xi).

Para obter um alto nível de confiança, pode-se ampliar o intervalo por meio do cálculo da incerteza expandida (U). Para calcular a incerteza expandida, multiplica-se $u_{c}(y)$ por um fator de abrangência $k$, de acordo com o nível de 
confiança desejado, por exemplo para um nível de confiança de 95\% com número de graus efetivos tendendo a infinito, o fator de abrangência utilizado é 1,96. $\mathrm{Na}$ prática costuma-se usar o fator k=2 (Guia Eurachem, 2002).

\subsubsection{Diagrama de Causa e Efeito (Espinha de Peixe ou Ishikawa)}

Para estimar a incerteza da medição inicialmente foi feito o Diagrama de Causa e Efeito (Ishikawa ou Espinha de peixe) que permite agrupar e visualizar de forma sistêmica as principais fontes de incerteza. A partir da elaboração do diagrama é possível avaliar todas as incertezas envolvidas no cálculo. O diagrama para a metodologia proposta é apresentado na FIG. 14.

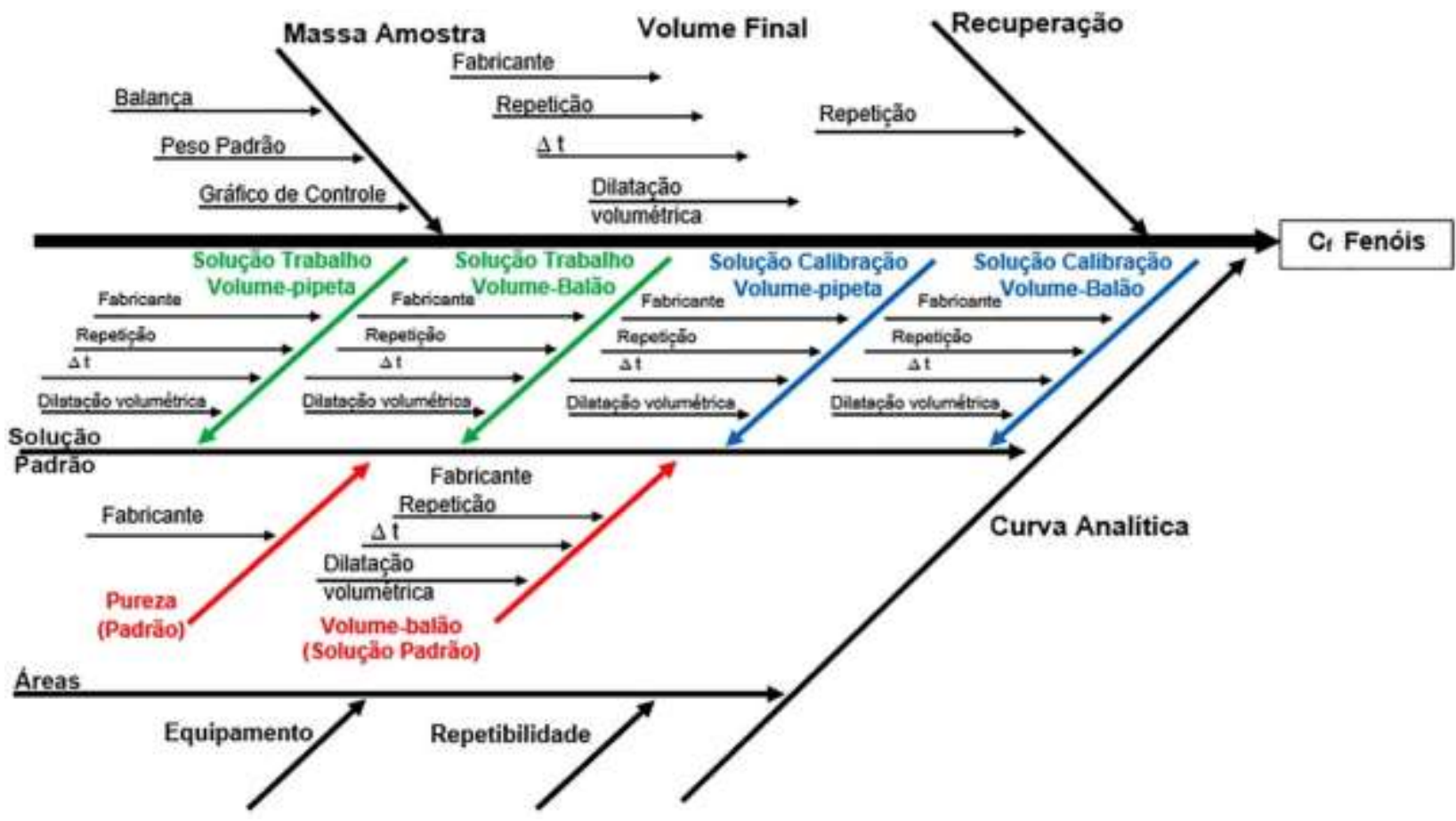

Figura 14. Diagrama de Causa e Efeito da metodologia analítica para determinação de Fenóis em sedimento.

Conforme pode ser observado no diagrama da FIG. 8, as principais fontes de incerteza identificadas para este método foram as associadas à curva de calibração, ao fator de recuperação do analito, ao volume final e à massa da amostra. As grandezas de entrada envolvidas no cálculo da incerteza da curva analítica são a preparação da solução padrão obtida do fornecedor, as diluições 
das soluções de calibração e as incertezas associadas à área de resposta de cada analito.

Nesse caso, a incerteza combinada final referente ao método pode ser calculada a partir da combinação das incertezas individuais para cada grandeza de entrada, de acordo com a equação 15.

$$
\mu_{C}\left(C_{\text {fenóis }}\right)=\sqrt{\left(\frac{\mu\left(C_{\text {curva }}\right)}{C_{\text {curva },}}\right)^{2}+\left(\frac{\mu\left(V_{f}\right)}{V_{f}}\right)^{2}+\left(\frac{\mu\left(m_{\text {amostra }}\right)}{m_{\text {amostra }}}\right)^{2}+\left(\frac{\mu(R)}{R}\right)^{2}}
$$

Onde:

$\mu \mathrm{C}$ curva = incerteza associada à concentração obtida pela curva analítica;

CCurva = concentração obtida pela curva analítica;

$\mu \mathrm{V}_{f}=$ incerteza associada ao volume final

$\mathrm{V}_{\mathrm{f}}=$ volume final;

$\mu \mathrm{m}_{\mathrm{amostra}}=$ incerteza associada à massa de amostra;

mamostra = massa de amostra;

$\mu \mathrm{R}=$ incerteza associada à recuperação do método;

$\mathrm{R}=$ recuperação do método;

Para o resultado final da medição, a Incerteza Expandida $(\mu \mathrm{E})$ é o componente que fornece um intervalo mais provável onde o mensurando se encontra.

$$
\mu_{E\left(C_{\text {fenóis }}\right)}=\mu_{C\left(C_{f}\right) . K}
$$

Onde:

$\mu_{C\left(C_{f}\right)}=$ incerteza combinada da concentração de fenóis;

$K=$ fator de abrangência.

Porém, as incertezas parciais são calculadas a partir das incertezas individuais das grandezas de entrada para cada uma das fontes identificadas, e serão apresentadas no item 8.7 Desta dissertação. 


\section{PARTE EXPERIMENTAL}

\subsection{Reagentes e Soluções}

- Água ultrapura (tipo 1) de baixa condutância;

- Metanol (MeOH), Acetona, Diclorometano, Acetonitrila, n-Hexano e Acetato de Etila;

- Padrões de referência com certificado de pureza dos compostos: 2,4,6-triclorofenol; 2,4-diclorofenol; 2-nitrofenol; 3-metilfenol; 4-cloro-3-metilfenol; Fenol.

- Solução de Nitro sulfônica.

Todos os reagentes e solventes utilizados são de grau analítico, cromatográfico ou compatível. Para as curvas analíticas e desenvolvimento da metodologia foram utilizados padrões analíticos de procedência SPEX CertiPrep, a pureza e a nomenclatura IUPAC são apresentadas na TAB. 3.

Tabela 3. Identificação dos padrões analíticos utilizados.

\begin{tabular}{llll}
\hline Nomenclatura IUPAC & Número CAS & $\begin{array}{l}\text { Fórmula } \\
\text { Molecular }\end{array}$ & Pureza \\
\hline Fenol & $108-95-2$ & $\mathrm{C}_{6} \mathrm{H}_{6} \mathrm{O}$ & $99 \%$ \\
3-metilfenol & $108-39-4$ & $\mathrm{C}_{7} \mathrm{H}_{8} \mathrm{O}$ & $99 \%$ \\
2-nitrofenol & $88-75-5$ & $\mathrm{C}_{6} \mathrm{H}_{5} \mathrm{NO}_{3}$ & $98 \%$ \\
2,4-diclorofenol & $120-83-2$ & $\mathrm{C}_{6} \mathrm{H}_{4} \mathrm{Cl}_{2} \mathrm{O}$ & $99 \%$ \\
4-cloro-3-metilfenol & $59-50-7$ & $\mathrm{C}_{7} \mathrm{H}_{7} \mathrm{ClO}$ & $99 \%$ \\
2,4,6-triclorofenol & $88-06-2$ & $\mathrm{C}_{6} \mathrm{H}_{3} \mathrm{Cl}_{3} \mathrm{O}$ & $98 \%$ \\
\hline
\end{tabular}

\subsection{Equipamentos}

Para o desenvolvimento deste trabalho foram utilizados os seguintes equipamentos: 
- Cromatógrafo a gás, Shimadzu - GC 2010 Plus, equipado com coluna DB-5, acoplado ao detector de espectrometria de massas, Shimadzu - QP 2010 SE, microprocessador de dados com o programa GCMS Solution, Shimadzu; injetor automático AOC-20i;

- Sistema de filtração a vácuo, com membranas de 0,45 $\mu \mathrm{m}$;

- Banho de ultrassom, $40 \mathrm{mHz}$, marca Limp Sonic;

- Compressor/aspirador (Dia pump), modelo 089 cal, marca FANEM;

- Centrífuga de bancada, marca Nova Técnica;

- Vidraria básica de laboratório analítico: béqueres, erlenmeyers, balões volumétricos, provetas, seringas, pipetas, etc.

As vidrarias utilizadas foram todas lavadas com detergente neutro, descontaminadas com solução nitro sulfônica, enxaguadas com água purificada por osmose reversa, em seguida com água ultrapura (tipo 1) e posteriormente secas.

\subsection{Amostragem}

A rede de amostragem foi selecionada em parceria com os membros do projeto temático, sendo representantes do Centro de Integração e Gerenciamento de Informação da Coordenadoria de Planejamento Ambiental (SMA), Instituto de Pesquisas Energéticas e Nucleares (IPEN) e Instituto de Botânica de São Paulo, de modo a avaliar a heterogeneidade da qualidade ecológica da represa Guarapiranga. Foram definidos 14 pontos sob influência de aportes de nutrientes dos tributários, principalmente dos rios Embu-Guaçu (ponto GU-01) e Embu-Mirim (ponto GU-10), sendo três pontos de monitoramento da SABESP e quatro pontos de monitoramento da CETESB apresentados. Os pontos de amostragem estão apresentados na FIG. 15 e suas respectivas coordenadas geográficas e detalhes ambientais podem ser observados na TAB. 4. 


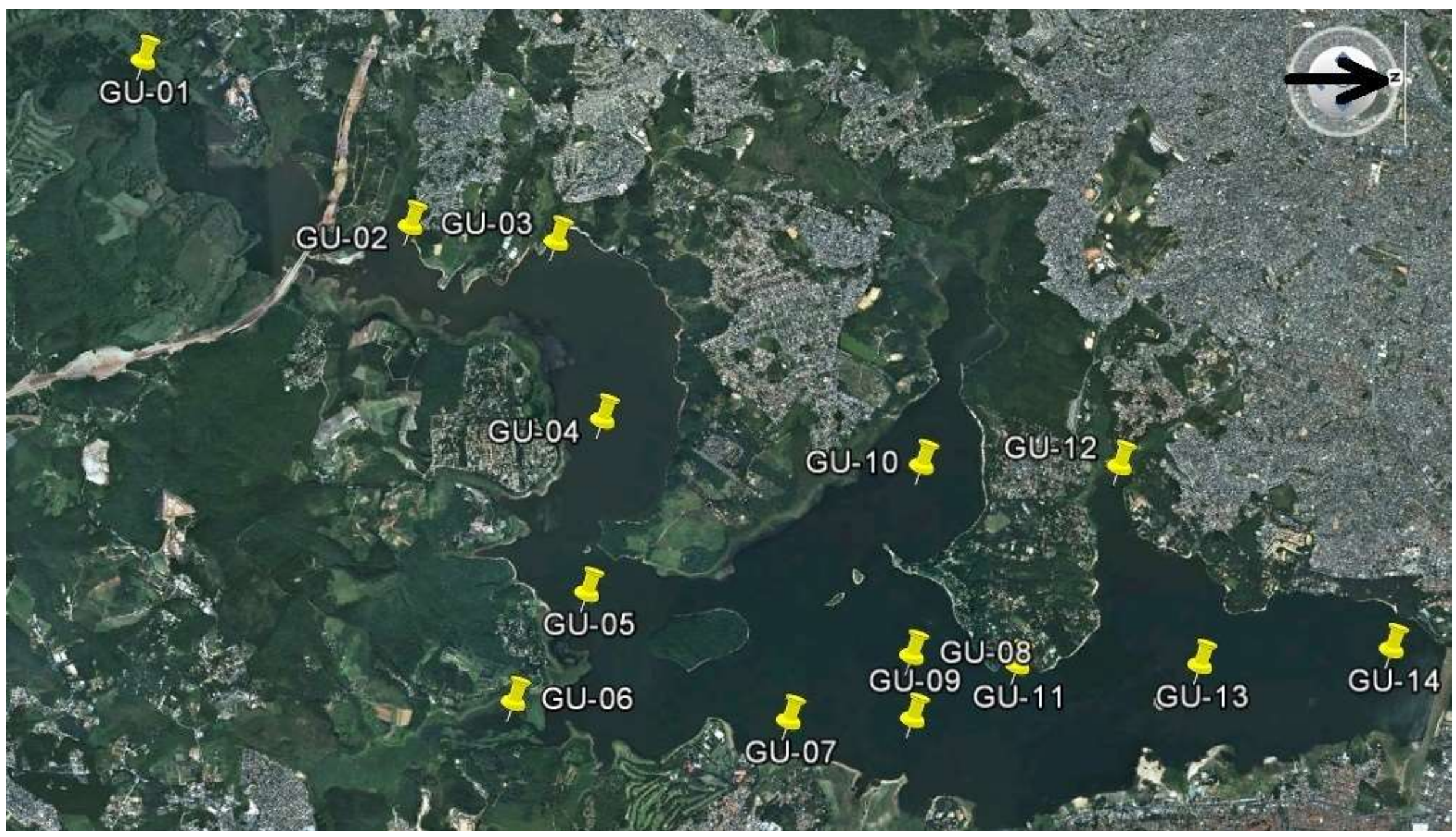

Figura 15. Localização da represa Guarapiranga e a distribuição dos pontos de coleta. 
Tabela 4. Descrição dos pontos de coleta das amostras, coordenadas geográficas e registros de observações realizadas pela equipe de coleta.

\begin{tabular}{|c|c|c|c|}
\hline $\begin{array}{c}\text { Ponto de } \\
\text { amostragem }\end{array}$ & $\begin{array}{l}\text { Local de } \\
\text { amostragem } \\
\text { (no mapa) }\end{array}$ & Coordenadas & Observações \\
\hline GU000-01 & GU-01 & $\begin{array}{l}23^{\circ} 46^{\prime} 496^{\prime \prime} \mathrm{S} \\
46^{\circ} 47^{\prime} 220^{\prime \prime} \mathrm{W}\end{array}$ & $\begin{array}{l}\text { Influência do rio Embu-Guaçu. } \\
\text { Local mais protegido com duas espécies de } \\
\text { macrofitas. }\end{array}$ \\
\hline GU000-02 & GU-02 & $\begin{array}{l}23^{\circ} 45^{\prime} 295^{\prime \prime} \mathrm{S} \\
46^{\circ} 46^{\prime} 187^{\prime \prime} \mathrm{W}\end{array}$ & $\begin{array}{l}\text { Influência do Córrego Mombaça (esgoto) } \\
\text { Urbanização desordenada. Com bolhas de } \\
\text { gás na superfície. }\end{array}$ \\
\hline GU000-03 & GU-03 & $\begin{array}{l}23^{\circ} 44^{\prime} 522 " \mathrm{~S} \\
46^{\circ} 46^{\prime} 136^{\prime \prime} \mathrm{W}\end{array}$ & Com cheiro de esgoto e banco de Salvinia. \\
\hline GU106-04 & GU-04 & $\begin{array}{l}23^{\circ} 44^{\prime} 446^{\prime \prime} \mathrm{S} \\
46^{\circ} 45^{\prime} 258^{\prime \prime} \mathrm{W}\end{array}$ & $\begin{array}{l}\text { Próximo à estação de monitoramento em } \\
\text { tempo real da Sabesp. }\end{array}$ \\
\hline GU000-05 & GU-05 & $\begin{array}{l}23^{\circ} 44^{\prime} 575^{\prime \prime S} \\
46^{\circ} 44^{\prime} 242^{\prime \prime} \mathrm{W}\end{array}$ & Entre a Ilha da Formiga e o Solo Sagrado. \\
\hline GU107-06 & GU-06 & $\begin{array}{l}23^{\circ} 45^{\prime} 012^{\prime \prime} \mathrm{S} \\
46^{\circ} 43^{\prime} 615^{\prime \prime} \mathrm{W}\end{array}$ & $\begin{array}{l}\text { Várzea da Transposição do Taquacetuba } \\
\text { (encerrada em 2009). }\end{array}$ \\
\hline GU108-07 & GU-07 & $\begin{array}{l}23^{\circ} 43^{\prime} 647^{\prime \prime} \mathrm{S} \\
46^{\circ} 43^{\prime} 423^{\prime \prime} \mathrm{W}\end{array}$ & $\begin{array}{l}\text { Entre a saída do Córrego Tanquinho e o } \\
\text { Córrego São José. }\end{array}$ \\
\hline GU000-08 & GU-08 & $\begin{array}{l}23^{\circ} 42^{\prime} 969 " \mathrm{~S} \\
46^{\circ} 43^{\prime} 612^{\prime \prime} \mathrm{W}\end{array}$ & Floração de cianobactérias (Dia ensolarado). \\
\hline GU109-09 & GU-09 & $\begin{array}{l}23^{\circ} 43^{\prime} 046^{\prime \prime} \mathrm{S} \\
46^{\circ} 43^{\prime} 340^{\prime \prime} \mathrm{W}\end{array}$ & $\begin{array}{l}\text { Próximo à saída do Rio das Pedras e Rio } \\
\text { Bonito. Apresentava uma floração. }\end{array}$ \\
\hline GU105-10 & GU-10 & $\begin{array}{l}43^{\circ} 42^{\prime} 899^{\prime \prime S} \\
46^{\circ} 44^{\prime} 687^{\prime \prime} \mathrm{W}\end{array}$ & $\begin{array}{l}\text { Ponto que sofre influência do Rio Embu-Mirim. } \\
\text { Cianobactérias. Entre a antena e o Heliporto. }\end{array}$ \\
\hline GU108-11 & GU-11 & $\begin{array}{l}23^{\circ} 42^{\prime} 534^{\prime \prime} \mathrm{S} \\
46^{\circ} 43^{\prime} 449^{\prime \prime} \mathrm{W}\end{array}$ & Ponto próximo ao Córrego sem nome. \\
\hline GU103-12 & GU-12 & $\begin{array}{l}23^{\circ} 41^{\prime} 885^{\prime \prime} \mathrm{S} \\
46^{\circ} 44^{\prime} 673^{\prime \prime} \mathrm{W}\end{array}$ & $\begin{array}{l}\text { Próximo às saídas do Córrego Itupu e do } \\
\text { Ribeirão Guavirutuba. Cheiro forte de esgoto } \\
\text { próximo à estação de remoção de nutrientes. }\end{array}$ \\
\hline GU102-13 & GU-13 & $\begin{array}{l}23^{\circ} 41^{\prime} 580^{\prime \prime} \mathrm{S} \\
46^{\circ} 43^{\prime} 573^{\prime \prime} \mathrm{W}\end{array}$ & $\begin{array}{c}\text { Cheiro forte. Ponto com aplicação de } \\
\text { Algicida. }\end{array}$ \\
\hline GU000-14 & GU-14 & $\begin{array}{l}23^{\circ} 40^{\prime} 782^{\prime \prime} \mathrm{S} \\
46^{\circ} 43^{\prime} 559^{\prime \prime} \mathrm{W}\end{array}$ & $\begin{array}{l}\text { Em frente à captação de água. Entre o late } \\
\text { Clube e o começo do parque Guarapiranga. } \\
\text { Pode ter sofrido influência da aplicação de } \\
\text { algicida. Algas com aparência esbranquiçada. }\end{array}$ \\
\hline
\end{tabular}


As amostras de sedimento foram coletadas conforme recomendação do guia de coletas da CETESB \& ANA (2011) com o auxílio de um amostrador de sedimento tubular de gravidade (tipo Kajak), nos períodos de agosto de 2011 e outubro de 2014, entretanto nesta última coleta, não foi possível amostrar todos os 14 pontos, sendo coletados apenas os pontos G000-01, G000-02, G000-03, G106-04, G108-07, G000-08, G109-09, G105-10, G108-11.

\subsection{Análise por GC/MS}

Foi estudada a separação e identificação de cada um dos compostos a serem quantificados e estabelecidas todas as condições de análise no equipamento inicialmente partindo de um método cromatográfico encontrado em literatura, porém foram necessárias adaptações para que os compostos fossem adequadamente separados.

Para verificar as condições cromatográficas que melhor se aplicavam ao estudo dos compostos fenólicos, foram realizados testes com a injeção de uma solução padrão mista contendo todos os compostos, no modo SCAN, com intervalo de varredura 50 a $300 \mathrm{~m} / \mathrm{z}$, primeiramente para identificar os tempos de retenção de cada composto. Após esta etapa, foram realizados novos testes com a injeção do padrão no modo SIM com variações na rampa de temperatura e fluxo da coluna para estudar o comportamento de cada composto. Os parâmetros explorados foram: temperatura do injetor, rampa de temperatura do forno da coluna, temperatura da interface, fluxo total do gás de arraste pela coluna e fluxo na coluna. A partir desses ensaios foram estabelecidas as seguintes condições para esse método de análise:

- Temperatura do Injetor: $280^{\circ} \mathrm{C}$;

- Temperatura da Interface: $300^{\circ} \mathrm{C}$;

- Fluxo da Coluna: 2,0 mL $\mathrm{min}^{-1}$;

- Fluxo Total: $28 \mathrm{~mL} \mathrm{~min}^{-1}$;

- Tempo total da corrida: 10,88 minutos. 
Foi empregada a coluna capilar RTX5MS (29,6 $\mathrm{m} \times 0,25 \mathrm{~mm}$ d.i.). Foi estabelecido um tempo de corte do solvente em 4 minutos. A programação da temperatura do forno teve início em $50 \stackrel{\circ}{\mathrm{C}}$ a qual foi mantida por 2 minutos. Foi elevada a $150 \stackrel{\circ}{\circ}$ por uma rampa de $50 \stackrel{\circ}{-}$ min $^{-1}$ mantendo essa temperatura por 4 minutos. Por fim, a temperatura foi elevada a $300^{\circ} \mathrm{C}$ por uma rampa de $80 \stackrel{\circ}{\circ}$ min $^{-1}$ mantendo essa temperatura por 1 minuto FIG 16.

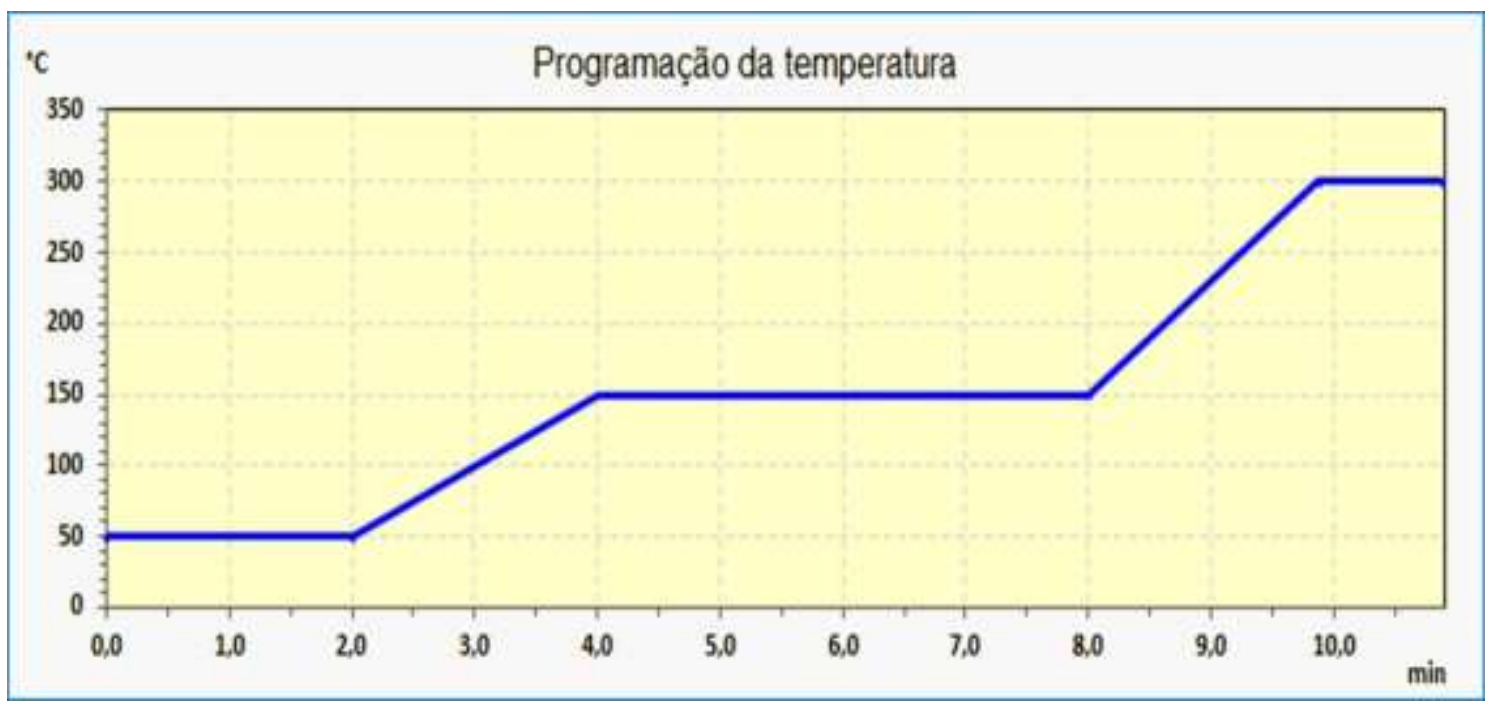

Figura 16. Gráfico representativo da programação da temperatura.

A configuração do modo de aquisição Single lon Monitoring, SIM, incluindo as relações massa/carga $(\mathrm{m} / \mathrm{z})$ características dos analitos, o intervalo de monitoramento dos fragmentos e os tempos de retenção encontram-se na TAB. 5. 
Tabela 5. Configuração do modo de aquisição SIM.

\begin{tabular}{cccc}
\hline Composto & $\begin{array}{c}\text { Intervalo de tempo } \\
\text { (min.) }\end{array}$ & $\begin{array}{c}\text { TR } \\
(\text { min. })\end{array}$ & Ílons monitorados (m/z) \\
\hline Fenol & $4,00-4,60$ & 4,32 & $65,66,94^{\star}$ \\
3-metilfenol & $4,60-5,05$ & 4,85 & $77,79,107,108^{*}$ \\
2-nitrofenol & $5,05-5,90$ & 5,30 & $65,81,109,139^{\star}$ \\
2,4-diclorofenol & $5,05-5,90$ & 5,56 & $63,97,161^{*}, 163$ \\
4-cloro-3-metilfenol & $5,90-6,70$ & 6,13 & $77,107,141^{\star}, 143$ \\
2,4,6-triclorofenol & $6,70-8,00$ & 7,40 & $131,195^{*}, 197,199$ \\
\hline
\end{tabular}

* Íons de maior intensidade

Os padrões analíticos foram preparados a partir de uma solução mista contendo todos os compostos estudados $\left(2000 \mu \mathrm{g} \mathrm{mL} \mathrm{m}^{-1}\right)$ em estado líquido. $A$ solução de trabalho dos compostos estudados foi obtida diluindo-se a solução inicial para uma concentração de $40 \mu \mathrm{g} \mathrm{mL}^{-1}$ em metanol e posteriormente diluída novamente para uma concentração de $1,00 \mu \mathrm{g} \mathrm{mL}^{-1}$ também em metanol.

Os níveis de concentração da curva analítica foram preparados a partir da solução de trabalho por meio de diluições no momento da injeção a fim de evitar possíveis interferentes ou a evaporação dos compostos. $\mathrm{Na}$ TAB. 6 são apresentadas as concentrações utilizadas na curva analítica para cada composto.

Tabela 6. Concentrações das soluções, $\mu \mathrm{g} \mathrm{mL}^{-1}$, de trabalho dos compostos estudados.

\begin{tabular}{cccccc}
\hline Fenol & 3-metilfenol & 2-nitrofenol & $\begin{array}{c}2,4- \\
\text { diclorofenol }\end{array}$ & $\begin{array}{c}\text { 4-cloro-3- } \\
\text { metilfenol }\end{array}$ & $\begin{array}{c}2,4,6- \\
\text { triclorofenol }\end{array}$ \\
\hline 0,03 & 0,03 & 0,03 & 0,03 & 0,03 & 0,03 \\
0,05 & 0,05 & 0,05 & 0,05 & 0,05 & 0,05 \\
0,10 & 0,10 & 0,10 & 0,10 & 0,10 & 0,10 \\
0,15 & 0,15 & 0,15 & 0,15 & 0,15 & 0,15 \\
0,20 & 0,20 & 0,20 & 0,20 & 0,20 & 0,20 \\
0,25 & 0,25 & 0,25 & 0,25 & 0,25 & 0,25 \\
0,30 & 0,30 & 0,30 & 0,30 & 0,30 & 0,30 \\
0,50 & 0,50 & 0,50 & 0,50 & 0,50 & 0,50 \\
\hline
\end{tabular}




\subsection{Metodologia Desenvolvida}

O procedimento de extração dos compostos estudados desenvolvido e otimizado foi definido da seguinte maneira: em um erlenmeyer de $125 \mathrm{~mL}$ foi pesado $1 \mathrm{~g}$ de sedimento previamente liofilizado e adicionado $20 \mathrm{~mL}$ de solução de acetona e metanol na proporção de 1:1. Essa mistura foi submetida a banho de ultrassom por 30 minutos. Após a extração todo o conteúdo do erlenmeyer foi transferido para um tubo tipo falcon de polipropileno e centrifugado por 20 minutos a $2500 \mathrm{rpm}$. O sobrenadante foi filtrado em sistema de filtração a vácuo com membrana de PTFE $0,45 \mu \mathrm{m}$ e posteriormente submetido a secagem parcial com uso de rotoevaporador a temperatura de $50^{\circ} \mathrm{C}$, seguido de secagem em fluxo suave de nitrogênio, até aproximadamente $0,5 \mathrm{~mL}$. Por fim o volume foi retomado a $1 \mathrm{~mL}$ com solução de acetona e metanol na proporção de 1:1 e analisado por GC/MS.

\subsection{DESENVOLVIMENTO EXPERIMENTAL}

\subsubsection{Estudo do solvente no processo de extração}

Para a definição do solvente a ser utilizado no processo de extração dos compostos fenólicos em sedimento, foram realizados oito testes com diferentes combinações de solventes (TAB. 7) estipulados a partir da literatura, sendo que com o teste 3 não foi possível a observação de picos.

Tabela 7. Relação dos solventes utilizados nos oito testes para extração de compostos fenólicos.

\begin{tabular}{cc}
\hline Teste & Solventes utilizados \\
\hline 1 & Acetona:MeOH $-1: 1$ \\
2 & Acetona:n-Hexano - 1:1 \\
3 & Acetona:MeOH - 6:4 \\
4 & Acetona:Acetonitrila:MeOH - 1:1:1 \\
5 & Acetato de etila \\
6 & Acetato de etila:MeOH - 6:4 \\
7 & Acetona:MeOH - 4:6 \\
8 & $\mathrm{MeOH}$ \\
\hline
\end{tabular}


Comparando os resultados obtidos em cada teste (FIG. 17), optou-se pela combinação dos solventes Acetona:MeOH na proporção de 1:1 (Teste 1) por ter sido essa a melhor mistura para extração de todos os compostos em um só experimento.

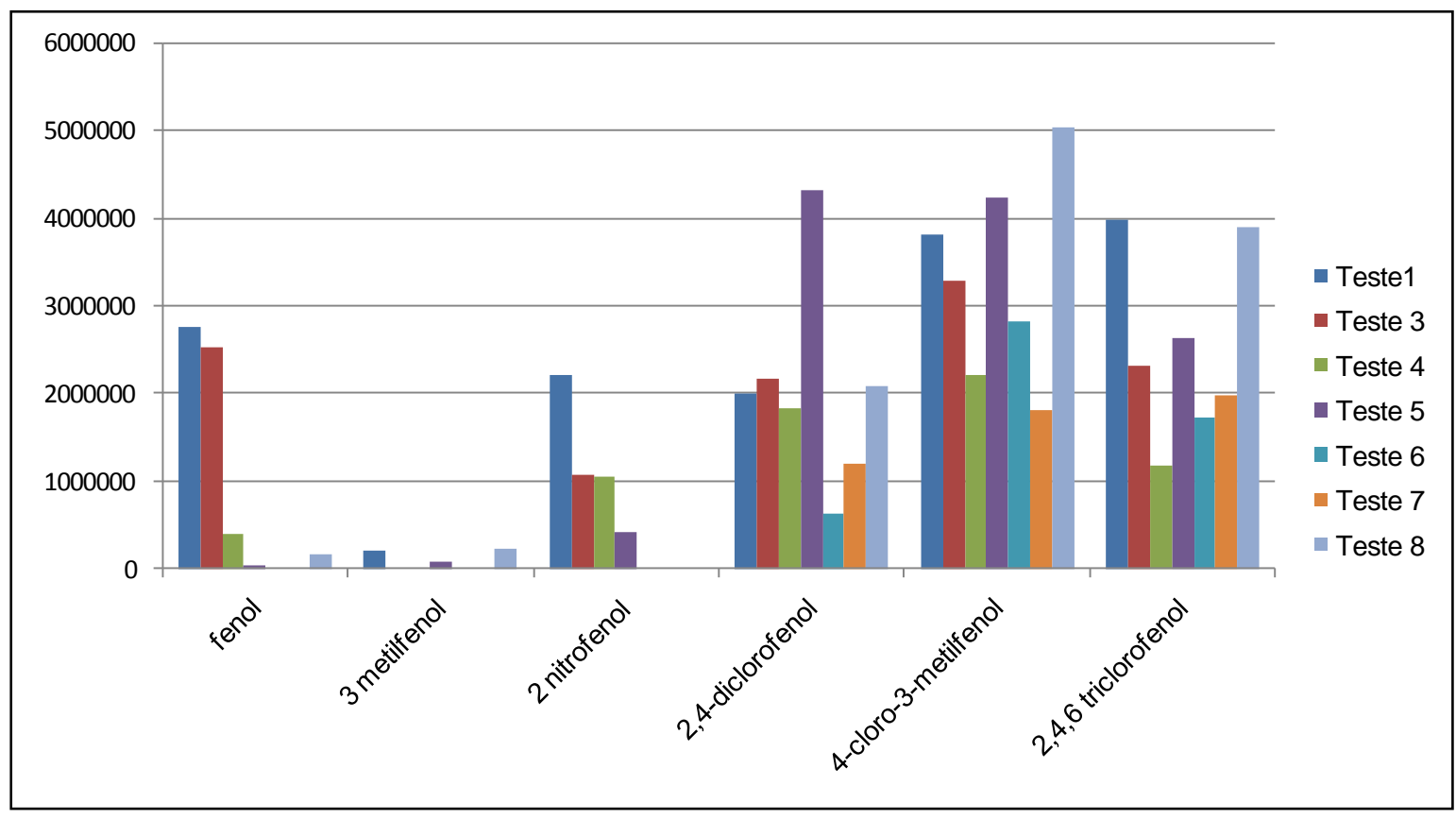

Figura 17. Comparação das áreas dos picos de cada um dos compostos extraídos com diferentes solventes.

Para definição da metodologia de extração foram realizados os ensaios iniciais para definição dos melhores solventes, tempos de extração e derivatização. Em seguida foi realizado um primeiro ensaio de robustez, a fim de otimizar o método. Foram avaliados os seguintes parâmetros: Massa de sedimento; Tempo de agitação no shaker para a fortificação do sedimento; Mistura e proporção dos solventes selecionados; Tempo no ultrassom para a extração; Uso ou não do rotoevaporador e Tempo entre derivatização e injeção.

Este primeiro ensaio de robustez, foi importante para se estabelecer o ajuste de alguns parâmetros. Dos parâmetros previamente avaliados, foram estabelecidas algumas alterações.

Nos estudos preliminares foram realizados testes para avaliar a necessidade de se derivatizar os compostos e os melhores resultados foram 
obtidos sem derivatização, sendo, portanto, descartada esta etapa do procedimento. Alguns destes parâmetros foram utilizados já para o método com purificação por SPE.

A etapa de concentração por rotoevaporação se mostrou muito eficaz, principalmente para os compostos fenol, 2-nitrofenol e 3-metilfenol.

Foi estabelecida a acidificação do extrato a pH 3 para a eluição no SPE e a mistura de DCM:MeOH (1:1) para a dessorção dos compostos retidos. O tempo de extração no ultrassom foi otimizado inicialmente para 50 e depois para 30 minutos, visto que um tempo maior não altera significativamente a extração e a massa de amostra foi estabelecida em $1 \mathrm{~g}$, pois um aumento na quantidade não teve efeito significativo, além de contribuir para um possível aumento na concentração de outros compostos no extrato.

\subsubsection{Avaliação da purificação do extrato}

A metodologia de extração foi inicialmente adaptada a partir dos métodos desenvolvidos por Silva (2012) e Otomo (2015), sendo utilizados cartuchos SPE $\mathrm{C}_{18}$ na etapa de purificação da amostra. Porém, ao iniciar os ensaios de validação, verificou-se que os resultados de recuperação não foram satisfatórios para quatro dos seis compostos (Fenol, 3-metilfenol, 2-nitrofenol e 2,4-diclorofenol). O procedimento experimental foi então reavaliado ao longo de testes sucessivos. Os resultados são apresentados no item 9 desta dissertação.

Foram feitos testes para purificação utilizando-se duplo cartucho SPE $\mathrm{C}_{18}$ e cartuchos Strata-x, além de avaliação apenas submetendo a amostra a filtração à vácuo com membrana 0,45 $\mu \mathrm{m}$. Após a análise dos resultados optou-se pela utilização do sistema de filtração à vácuo com membrana 0,45 $\mu \mathrm{m}$ após a extração em ultrassom.

\subsection{Ensaios para validação da metodologia}

Neste trabalho, pelo fato de não haver um sedimento padrão com as caraterísticas desejadas e isento dos analitos de interesse, foi utilizado o sedimento 
coletado no ponto G000-01 em 2011, por ser considerado o mais limpo e livre da presença de interferentes nos tempos de retenção estudados.

A partir do método de preparação da amostra e análise apresentado no item 8.5 desta dissertação, a validação foi realizada seguindo a orientação do INMETRO, estabelecida no documento DOQ-CGCRE-008 (INMETRO, 2011) intitulado "Orientação sobre validação de métodos analíticos" e para os cálculos estatísticos utilizou-se a planilha "Ensaios de Validação Química" desenvolvida por Furusawa (2007) com base neste mesmo documento. Os parâmetros avaliados foram: seletividade, linearidade, limites de detecção e quantificação, exatidão, precisão, robustez e recuperação, conforme recomendado para análise de elementos traço (INMETRO, 2011).

Para a avaliação destes parâmetros os ensaios foram realizados por meio de adição dos padrões em solução com matriz e sem matriz (somente com solvente). Conforme já citado, para os ensaios com matriz, foi utilizado um sedimento da própria área estudada (ponto G-000-01) por ocasião da primeira coleta em 2011, por ser considerado o mais limpo. Foram utilizados oito níveis de concentrações, conforme apresentado anteriormente na TAB. 6.

\subsubsection{Seletividade}

A seletividade foi inicialmente avaliada a partir de cromatogramas obtidos por injeção da solução mista de padrão dos compostos estudados e observando-se o comportamento de separação dos picos.

Além da análise visual, a interferência da matriz na precisão do método foi avaliada por meio o teste $\mathrm{F}$ (Snedecor) de homogeneidade das variâncias nas medidas de adição padrão nas soluções sem matriz e na matriz de extrato do sedimento, com um número estatisticamente significativo de replicatas $(n=7)$, utilizando a equação 1 do item 7.1 desta dissertação. 
Foi realizado o teste $\mathrm{t}$ (Student) de significância das diferenças das médias, também aplicado nos dois grupos de soluções (com e sem matriz) de acordo com a equação 2 do item 7.1 desta dissertação.

O grau de liberdade foi obtido pela distribuição de Student considerandose $\left(n_{1}+n_{2}-2\right)$ graus de liberdade e 95\%, calculado pela equação 3 do item 7.1 desta dissertação.

A seletividade foi também avaliada pelo teste $t$ de Inclinação e Paralelismo e pelo teste do Intercepto, utilizando-se as equações 4 e 5 respectivamente do item 7.1 desta dissertação e considerando a equação 6 desse mesmo item.

\subsubsection{Faixa de trabalho e Linearidade}

A linearidade foi avaliada utilizando-se o coeficiente de determinação $\left(R^{2}\right)$ obtido pelo cálculo da regressão linear das curvas analíticas elaboradas para cada composto na matriz com oito níveis de concentração.

Além do coeficiente de determinação, a linearidade foi também utilizada a análise de variância (ANOVA), como recomendado pelo DOQ-CGCRE-008 do INMETRO. A análise de variância foi realizada pelo teste $F$ de regressão que avalia a adequação do modelo adotado aos dados obtidos é significativo e pelo teste $\mathrm{F}$ de ajuste que verifica o quanto esse modelo se ajusta ao conjunto de dados obtidos. Foi ainda avaliada a porcentagem de variação explicada em relação à porcentagem máxima de variação explicável, ou seja, o quanto de variação pôde ser explicada dentro da porcentagem explicável pelo ajuste aplicado ao método (Furusawa, 2007; Otomo, 2010; INMETRO, 2011).

\subsubsection{Limite de detecção e Limite de quantificação}

O limite de detecção (LD) foi obtido pela multiplicação do desvio padrão das replicatas $(n=7)$ da concentração mais baixa das curvas analíticas de cada composto pelo valor de t (Student) tabelado considerando 95\% de confiança, de acordo com a equação 9 do item 7.3 desta dissertação. 
O limite de quantificação (LQ) foi obtido pela média das medidas das replicatas $(n=7)$ também da concentração mais baixa das curvas analíticas de cada composto mais cinco vezes o desvio padrão dessas replicatas, de acordo com a equação 10 do item 7.3 desta dissertação.

\subsubsection{Exatidão e Tendência}

Este parâmetro foi avaliado por meio do índice z Score, calculado pela equação 11 do item 7.4, onde o valor de z deve permanecer menor que 2 para ser considerado satisfatório e é considerado questionável, mas ainda aceitável, quando se encontra entre 2 e 3, sendo insatisfatório os valores acima de 3 (Furusawa, 2007; Otomo, 2015; INMETRO, 2011).

\subsubsection{Precisão}

Este parâmetro foi avaliado por meio dos valores de limite de repetitividade, limite de reprodutibilidade e por meio do coeficiente de variação obtidos a partir de injeções sucessivas de sete replicatas em três níveis de concentrações (consideradas, baixa, média e alta) para cada um dos compostos. Essas injeções foram realizadas em dias diferentes pelo mesmo analista, utilizando o mesmo procedimento e mesmo equipamento e os cálculos foram realizados de acordo com as equações 12 e 13 do item 7.5 desta dissertação.

\subsubsection{Recuperação}

Conforme já citado no item 7.6 desta dissertação, o documento DOQ-CGCRE-008 do INMETRO recomenda que o ensaio de recuperação seja realizado em pelo menos três faixas de concentrações conhecidas da mistura padrão nas amostras. Os valores das concentrações da solução padrão selecionadas para este estudo encontram-se na TAB. 8, concentrações estas adicionadas na matriz antes da extração, seguida pela determinação da concentração dos analitos adicionados após todas as etapas do método. O cálculo de recuperação foi realizado segundo a equação 14 do item 7.6 desta dissertação. 
Tabela 8. Faixas de concentrações do ensaio de recuperação

\begin{tabular}{cccc}
\hline \multirow{2}{*}{ Composto } & \multicolumn{3}{c}{ Concentração $\mu \mathrm{L} \mathrm{L}^{-1}$} \\
\cline { 2 - 4 } & Baixa & Média & Alta \\
\hline Fenol & 0,05 & 0,10 & 0,20 \\
3-metilfenol & 0,05 & 0,10 & 0,20 \\
2-nitrofenol & 0,05 & 0,10 & 0,20 \\
2,4-diclorofenol & 0,05 & 0,10 & 0,20 \\
4-cloro-3-metilfenol & 0,05 & 0,10 & 0,20 \\
2,4,6-triclorofenol & 0,05 & 0,10 & 0,20 \\
\hline
\end{tabular}

\subsubsection{Robustez}

Para a avaliação do parâmetro robustez foram selecionados sete fatores com influência direta sobre o método proposto, relacionados na TAB 9. Os cálculos foram feitos com auxílio da planilha elaborada por Furusawa (2007), que segue a metodologia proposta por Vander Heyden et al. (2001), utilizando-se um planejamento fatorial das sete variáveis combinadas em oito experimentos. Os oito experimentos foram executados de acordo com as combinações da TAB. 2 do teste de Youden descrito no item 7.7 desta dissertação, onde as letras maiúsculas indicam os valores nominais dos parâmetros, e as minúsculas, suas variações (Ribani, 2004).

Tabela 9. Parâmetros nominais e suas variações selecionadas para o ensaio de robustez do método final.

\begin{tabular}{c|cc|cc}
\hline Parâmetro & \multicolumn{2}{|c|}{ Nominal } & \multicolumn{2}{c}{ Variação } \\
\hline Massa da Amostra & A & $1 \mathrm{~g}$ & a & $2 \mathrm{~g}$ \\
Volume Solvente & B & $20 \mathrm{~mL}$ & $\mathrm{~b}$ & $10 \mathrm{~mL}$ \\
Tempo Ultrassom & $\mathrm{C}$ & $30 \mathrm{~min}$ & $\mathrm{C}$ & $50 \mathrm{~min}$ \\
Secagem Total & $\mathrm{D}$ & $\mathrm{NÃO}$ & $\mathrm{d}$ & $\mathrm{SIM}$ \\
Temperatura Injetor & $\mathrm{E}$ & $280^{\circ}$ & $\mathrm{e}$ & $260^{\circ}$ \\
Temperatura Interface & $\mathrm{F}$ & $300^{\circ}$ & $\mathrm{f}$ & $280^{\circ}$ \\
Voltagem Detector $(\mathrm{kV})$ & $\mathrm{G}$ & Absolute & $\mathrm{g}$ & 0.4 \\
\hline
\end{tabular}




\subsubsection{Cálculo de incerteza}

A incerteza da medição foi avaliada seguindo as orientações do Guia Eurachem, utilizando uma adaptação eletrônica elaborada por Martins (2010), baseada no documento EURACHEM/CITAC Guide (2000). Conforme já citado no item 7.8 desta dissertação, as grandezas de entrada que mais influenciam na determinação de compostos fenólicos em sedimento pelo método desenvolvido, foram as incertezas associadas à curva analítica, as incertezas associadas à massa da amostra, ao volume final e à recuperação.

\subsubsection{Incerteza associada à curva analítica}

Para o cálculo das incertezas associadas à curva analítica, consideramse as incertezas da preparação da solução padrão, diluições para preparação das soluções de trabalho e de calibração e as incertezas associadas às respostas do equipamento (área dos picos). O cálculo é realizado por meio do método de Kragten, que se baseia inteiramente no método proposto pelo ISO GUM pela resolução de forma numérica das derivadas parciais (INMETRO, 2012; Machado et al., 2013).

\subsubsection{1-Incerteza associada à solução padrão}

A solução padrão utilizada neste trabalho, foi obtida de fornecedor em ampolas de $1 \mathrm{~mL}$, contendo a mesma concentração inicial $(2000 \mu \mathrm{g} \mathrm{mL})$ para todos os compostos estudados. Admitindo-se uma distribuição retangular, o valor da incerteza emitido pelo fornecedor em certificado, referente à pureza dos compostos fenólicos, foi dividido por $\sqrt{3}$. Como o padrão é líquido, foram consideradas as incertezas referentes à pureza do padrão e ao volume do balão.

Associadas ao volume do balão ( $\mu$ vol. balão) foram consideradas as incertezas vinculadas à informação do fabricante, repetições, variação de temperatura e coeficiente de dilatação do vidro, de acordo com a equação 17.

$$
\mu_{C(\text { sol.padrão. })}=C_{\text {sol_inicial }} \sqrt{\left(\frac{\mu P}{\sqrt{3}}\right)^{2}+\left(\frac{\mu\left(V_{10}\right)}{V_{10}}\right)^{2}}
$$




\subsubsection{Incerteza associada à solução de trabalho e às soluções de calibração}

Para os cálculos associados à solução de trabalho, foram considerados como fontes de incerteza, o volume do balão volumétrico utilizado na diluição da solução padrão e a incerteza relacionada à pureza da solução padrão inicial. Para o volume foram consideradas as informações emitidas pelo fornecedor do balão, as repetições durante as verificações da vidraria, a variação de temperatura e coeficiente de dilatação. Para o cálculo da incerteza combinada das soluções de trabalho são consideradas as incertezas de cada uma das diluições, conforme equação 18.

$$
\mu_{\text {Vbalão }}=\sqrt{\left(\mu_{\text {fabricante }}\right)^{2}+\left(\mu_{\text {repe }}\right)^{2}+\left(\mu_{\Delta t}\right)^{2}+\left(\mu_{\text {coef.dilatação }}\right)^{2}}
$$

Onde:

$\mu_{\text {fabricante }}=$ incerteza do volume informada pelo fabricante;

$\mu_{\text {repe }}=$ incerteza real referente à carta controle para 10 replicatas;

$\mu_{\Delta t}=$ incerteza referente à variação de temperatura;

$\mu_{\text {coef.dilatação }}=$ incerteza referente à dilatação do balão em relação ao $\Delta t$.

A incerteza combinada da preparação da solução de trabalho foi calculada pela equação 19 .

$$
\mu_{\text {Csoluçãotrabalho }}=\sqrt{\left(\mu_{\text {pureza padrão }}\right)^{2}+\left(\mu_{\text {vol.Balão }}\right)^{2}}
$$

Após a obtenção das incertezas associadas à solução de trabalho, o mesmo procedimento é repetido para obtenção das incertezas associadas a cada uma das cinco soluções de calibração. A estimativa da incerteza combinada da preparação das soluções de trabalho considera as incertezas de atribuídas às diluições, de acordo com a equação 20. 


$$
\mu_{C(\text { sol.trab })}=C_{\text {sol.trab }} \sqrt{\left(\frac{\mu\left(V_{\text {sol.esta }}\right)}{V_{\text {sol estr }}}\right)^{2}+\left(\frac{\mu\left(V_{f}\right)}{V_{f}}\right)^{2}+\left(\frac{\mu\left(C_{\text {sol.estg }}\right)}{C_{\text {sol estg }}}\right)^{2}}
$$

Onde:

$\mathrm{C}_{\text {sol.trab. }}=$ concentração da solução de trabalho;

$\mu \mathrm{V}_{\text {sol.estq }}=$ incerteza do volume pipetado da solução estoque padrão para preparação da solução de trabalho;

$\mathrm{V}_{\text {sol.estq }}=$ volume pipetado da solução estoque padrão para preparação da solução de trabalho;

$\mu \mathrm{V}_{\mathrm{f}}=$ incerteza do volume final da solução de trabalho;

$\mathrm{V}_{\mathrm{f}}=$ volume final da solução mista de trabalho;

$\mu \mathrm{C}_{\text {sol.esta }}=$ incerteza da solução de calibração para cada ponto;

$\mathrm{C}_{\text {sol.esta }}=$ concentração da solução de calibração para cada composto.

\subsubsection{3-Incerteza associada à resposta do equipamento}

Para o cálculo da incerteza associada ao equipamento, foram avaliadas as áreas dos picos dos cromatogramas, considerando a combinação das incertezas da repetitividade e as incertezas da resolução do equipamento. O valor da incerteza para a repetitividade de injeção no equipamento de cromatografia a gás é calculado de acordo com a equação 21 .

$$
\mu_{\text {repetitividade }}=\frac{s}{\sqrt{n}}
$$

Onde:

$\mathrm{S}=$ desvio padrão das medições;

$\mathrm{n}=$ número de injeções realizadas.

A incerteza proveniente da resolução do equipamento é um valor calculado pela divisão do valor da resolução do GC/MS a meia altura base do pico cromatográfico por raiz de 3, considerando-se uma distribuição retangular (Martins el al., 2014). A resolução do equipamento foi calculada de acordo com a equação 22 e a incerteza do equipamento de acordo com a equação 23. 


$$
R=\frac{\Delta T r}{W_{b 2}+W_{b 1}}
$$

Onde:

$\Delta T r=$ Diferença entre os tempos de retenção de dois picos adjacentes;

$W_{b 2}$ e $W_{b 1}=$ Largura da base de cada pico.

$$
\mu_{\text {equip }}=\frac{\operatorname{Re} c}{\sqrt{3}}
$$

Onde:

$\operatorname{Rec}=$ resolução do equipamento a meia altura base do pico cromatográfico.

\subsubsection{Incerteza associada ao volume final}

Após a preparação da amostra, o volume da solução é retomado para $1 \mathrm{~mL}$ com o solvente da extração para posterior análise em GC/MS. Sendo a esse volume final associada uma incerteza que envolve a incerteza declarada pelo fabricante da vidraria utilizada, a incerteza proveniente da repetitividade e as incertezas provenientes da variação de temperatura e do coeficiente de dilatação, conforme demonstrado na equação 18.

\subsubsection{Incerteza associada à massa da amostra}

Associada à massa de sedimento pesada inicialmente para o processo de extração dos compostos de interesse, consideram-se as incertezas referentes ao gráfico de controle, ao peso padrão de calibração da balança e a incerteza associada ao erro percentual da última casa da balança de acordo com a equação 24.

$$
\mu_{\left(m_{\text {amostra }}\right)}=\sqrt{\left(\mu_{\text {gráfico controle }}\right)^{2}+\left(\mu_{\text {peso padrão }}\right)^{2}+\left(\mu_{\text {balança }}\right)^{2}}
$$




\subsubsection{Incerteza associada à recuperação}

A incerteza associada à recuperação é calculada de acordo com a equação 25.

$$
\mu(\boldsymbol{R})=\boldsymbol{R} \sqrt{\left(\frac{\mu\left(C_{\text {real }}\right)}{C_{\text {real }}}\right)^{2}+\left(\frac{\mu\left(C_{\text {encontrada }}\right)}{C_{\text {encontrada }}}\right)^{2}}
$$

Onde:

$\mathrm{R}$ = valor da recuperação;

$\mu($ Creal $)$ = incerteza da solução padrão adicionada;

Creal = concentração da solução padrão adicionada;

$\mu($ Cencontrada $)=$ incerteza da concentração obtida;

Cencontrada $=$ concentração encontrada.

\subsubsection{Incerteza combinada e expandida}

A incerteza combinada de todas as incertezas padrão do procedimento analítico foi calculada de acordo com a equação 15 e a incerteza expandida conforme a equação 16, ambas apresentadas no item 7.8.1 desta dissertação. 


\section{RESULTADOS E DISCUSSÃO}

Neste capítulo são apresentados os resultados obtidos nos testes estatísticos aplicados na validação do método analítico final desenvolvido para a determinação de compostos fenólicos em sedimento e os resultados dos testes analíticos do método inicialmente proposto utilizando cartucho para extração em fase sólida (SPE). Os parâmetros avaliados, como já mencionados anteriormente, foram: seletividade, linearidade, limite de detecção e quantificação, exatidão, precisão, robustez, recuperação e cálculo de incerteza.

Os resultados obtidos pela aplicação do método para a quantificação destes compostos nas amostras coletadas no Reservatório Guarapiranga também estão apresentados neste capítulo.

\subsection{Seletividade}

A seletividade foi inicialmente avaliada com a injeção da solução padrão dos compostos estudados em concentração conhecida e observando-se o comportamento de separação dos picos.

Embora a sensibilidade para os compostos estudados seja baixa, com o método cromatográfico foi possível identificar separadamente cada um dos 6 compostos, como pode ser observado no cromatograma representado na FIG. 18, referente à mistura de padrões com todos os compostos (na faixa de concentração de $0,05 \mu \mathrm{g} \mathrm{mL}-1$ ). 


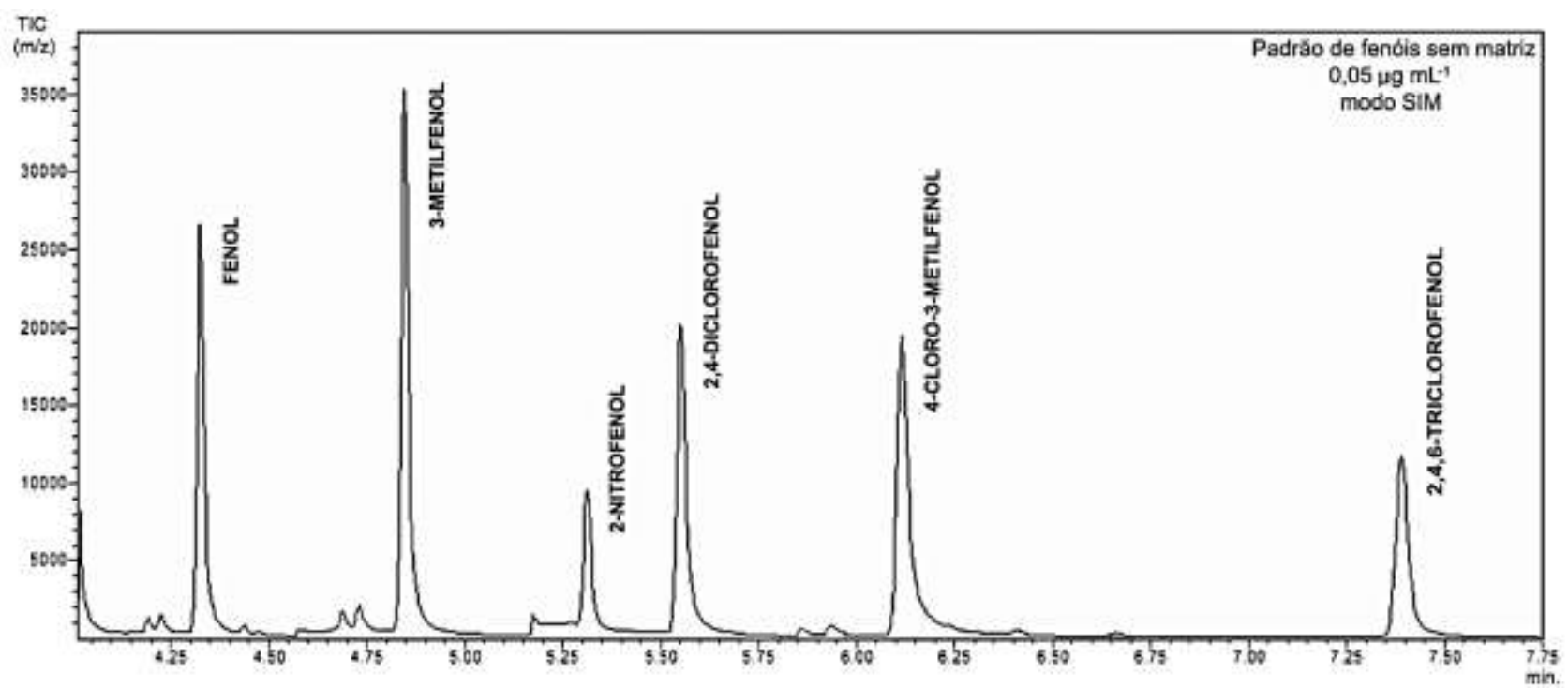

Figura 18. Cromatograma de mistura de padrão com os 6 compostos estudados.

Nas FIG. 19, 20 e 21 são também apresentados os espectros de massa dos compostos estudados, onde podem ser observadas as identificações de cada composto e suas respectivas confirmações pela biblioteca do espectrômetro de massas. 


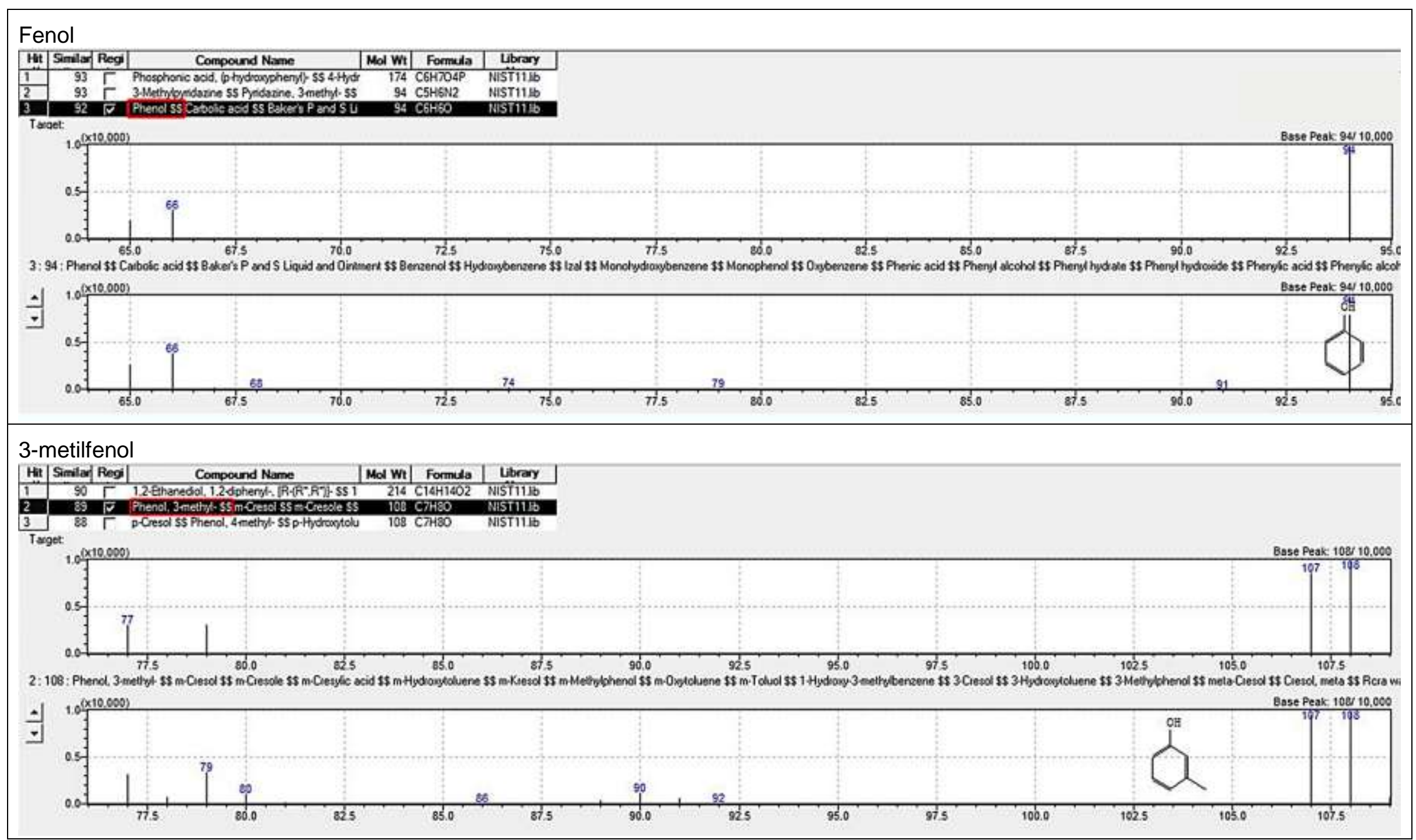

Figura 19. Espectros de massa dos compostos fenol e 3-metilfenol. 


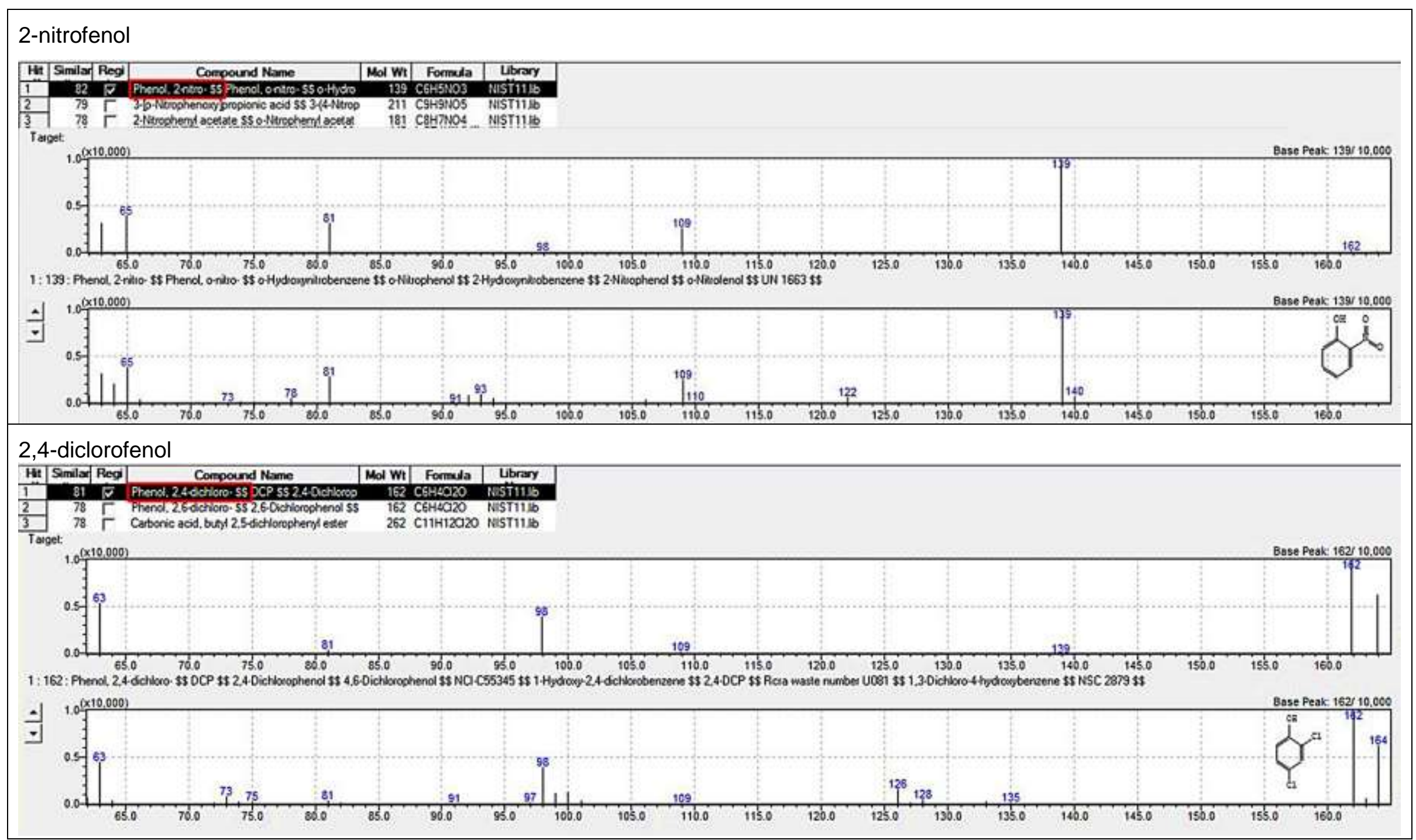

Figura 20. Espectros de massa dos compostos 2-nitrofenol e 2,4-diclorofenol. 


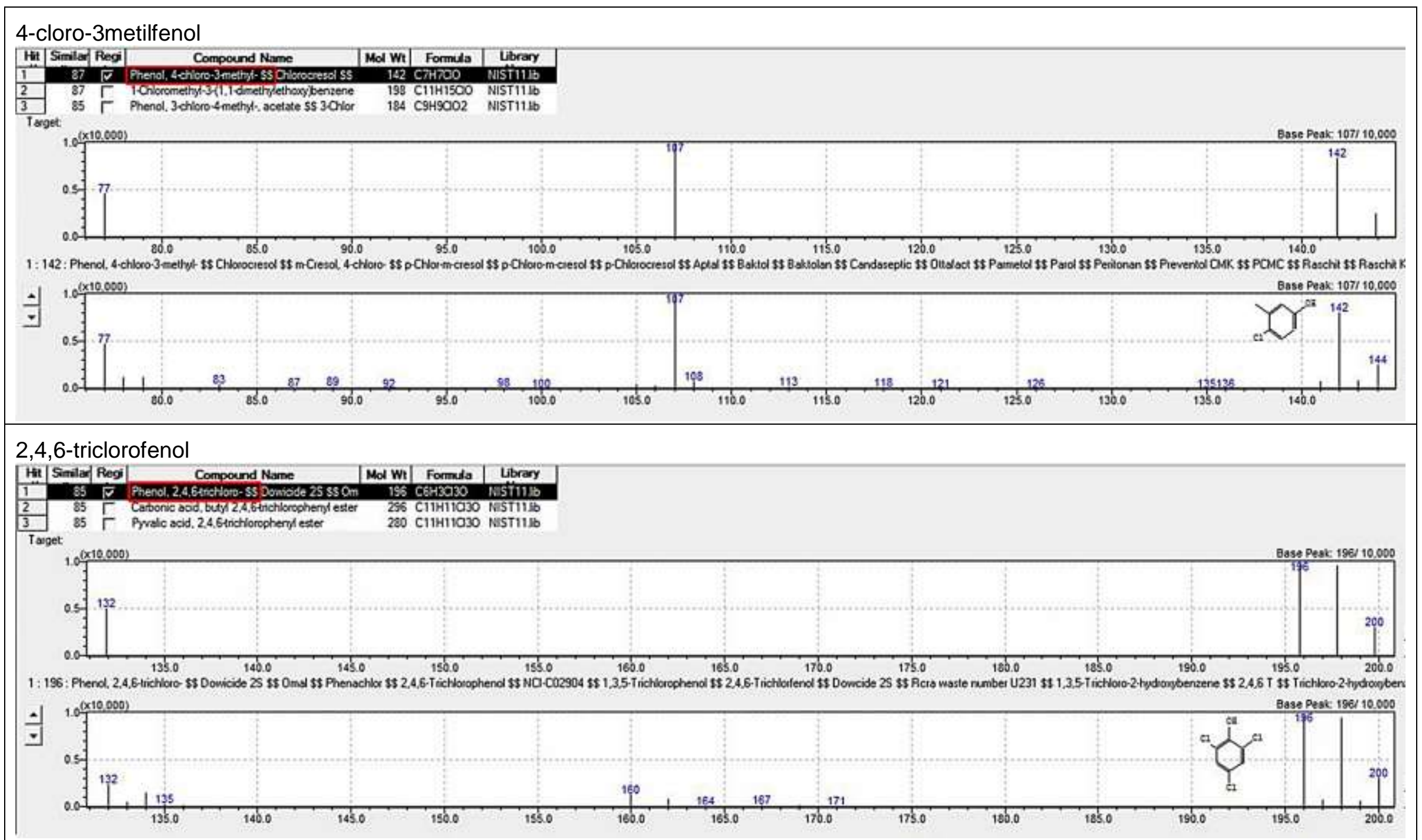

Figura 21. Espectros de massa dos compostos 4-cloro-3-metilfenol e 2,4,6-triclorofenol. 
Além da análise visual, é importante também uma análise estatística para avaliar a seletividade. A interferência da matriz na precisão do método foi avaliada com os testes $F$ (Snedecor) de homogeneidade das variâncias nas medidas de adição padrão nas soluções sem matriz (somente nos solventes) e na matriz de extrato do sedimento, com um número estatisticamente significativo de replicatas $(n=7)$ e 95\% de confiança e o teste t (Student) de significância das diferenças das médias, também aplicado nos dois grupos de soluções (com e sem matriz). Os resultados obtidos pela análise estatística dos testes $F$ e $t$ foram comparados com os valores Tabelados assim como os dados das variâncias $\left(\mathrm{s}^{2}\right)$ e podem ser observados na TAB. 10, obtidos nos ensaios sem matriz e com matriz método final. 
Tabela 10. Resultados dos testes estatísticos F e t aplicados para avaliação da seletividade em extrato de sedimento (Matriz) e no solvente (sem matriz) e variância obtida (s2) nos ensaios com e sem matriz do método final. Considerando $F_{\text {Tabelado }}=4,28$ e tTabelado $=2,179$, para 7 graus de liberdade e $95 \%$ de confiança.

\begin{tabular}{|c|c|c|c|c|c|c|c|c|c|}
\hline \multicolumn{10}{|c|}{ Fenol - Concentração - $\mu \mathrm{g} \mathrm{mL}^{-1}$} \\
\hline & [ ] & 0,03 & 0,05 & 0,1 & 0,15 & 0,2 & 0,25 & 0,3 & 0,5 \\
\hline $\begin{array}{l}\text { Sem } \\
\text { Matriz }\end{array}$ & s2 & $1,7 \mathrm{E}+07$ & $2,1 \mathrm{E}+07$ & $1,3 \mathrm{E}+08$ & $3,6 \mathrm{E}+08$ & $4,2 \mathrm{E}+08$ & $2,0 \mathrm{E}+09$ & $8,0 \mathrm{E}+07$ & $9,2 \mathrm{E}+09$ \\
\hline \multirow{3}{*}{$\begin{array}{l}\text { Com } \\
\text { Matriz }\end{array}$} & s2 & $2,8 \mathrm{E}+08$ & $1,3 \mathrm{E}+08$ & $9,8 \mathrm{E}+08$ & $1,7 \mathrm{E}+09$ & $4,4 \mathrm{E}+09$ & $3,6 \mathrm{E}+09$ & $3,7 \mathrm{E}+10$ & $1,5 \mathrm{E}+10$ \\
\hline & Fcalc & 16,5 & 6,3 & 7,3 & 4,7 & 10,4 & 1,8 & 462,6 & 1,7 \\
\hline & tcalc & 1,3 & 5,3 & 8,6 & 5,7 & 4,5 & 6,2 & 5,3 & 16,1 \\
\hline \multicolumn{10}{|c|}{ 3-metilfenol - Concentração - $\mu \mathrm{g} \mathrm{mL^{-1 }}$} \\
\hline & [ ] & 0,03 & 0,05 & 0,1 & 0,15 & 0,2 & 0,25 & 0,3 & 0,5 \\
\hline $\begin{array}{l}\text { Sem } \\
\text { Matriz }\end{array}$ & s2 & $1,3 \mathrm{E}+07$ & $3,5 \mathrm{E}+07$ & $1,4 \mathrm{E}+08$ & $4,1 \mathrm{E}+08$ & $4,8 \mathrm{E}+07$ & $6,8 \mathrm{E}+08$ & $2,1 \mathrm{E}+08$ & $2,2 \mathrm{E}+09$ \\
\hline \multirow{3}{*}{$\begin{array}{l}\text { Com } \\
\text { Matriz }\end{array}$} & s2 & $8,5 \mathrm{E}+08$ & $2,8 \mathrm{E}+08$ & $1,4 \mathrm{E}+09$ & $2,6 \mathrm{E}+09$ & $3,1 \mathrm{E}+09$ & $5,2 \mathrm{E}+09$ & $3,6 \mathrm{E}+10$ & $7,8 \mathrm{E}+09$ \\
\hline & Fcalc & 63,6 & 8,2 & 9,7 & 6,4 & 64,2 & 7,6 & 175,0 & 3,6 \\
\hline & tcalc & 2,4 & 0,4 & 1,0 & 1,8 & 3,5 & 2,1 & 0,5 & 7,2 \\
\hline \multicolumn{10}{|c|}{ 2-nitrofenol - Concentração - $\mu \mathrm{g} \mathrm{mL^{-1 }}$} \\
\hline & [ ] & 0,03 & 0,05 & 0,1 & 0,15 & 0,2 & 0,25 & 0,3 & 0,5 \\
\hline $\begin{array}{c}\text { Sem } \\
\text { Matriz }\end{array}$ & s2 & $1,4 \mathrm{E}+07$ & $1,2 \mathrm{E}+07$ & $2,5 \mathrm{E}+07$ & $2,3 \mathrm{E}+07$ & $5,8 \mathrm{E}+07$ & $8,8 \mathrm{E}+07$ & $4,9 \mathrm{E}+07$ & $3,3 \mathrm{E}+08$ \\
\hline \multirow{3}{*}{$\begin{array}{l}\text { Com } \\
\text { Matriz }\end{array}$} & s2 & $1,2 \mathrm{E}+09$ & $6,9 \mathrm{E}+07$ & $3,4 \mathrm{E}+08$ & $5,9 \mathrm{E}+08$ & $1,1 \mathrm{E}+09$ & $5,6 \mathrm{E}+08$ & $1,1 \mathrm{E}+10$ & $8,3 \mathrm{E}+09$ \\
\hline & Fcalc & 82,6 & 5,9 & 13,5 & 26,1 & 18,5 & 6,3 & 228,2 & 25,1 \\
\hline & tcalc & 4,3 & 8,3 & 6,5 & 9,9 & 12,9 & 19,6 & 6,1 & 18,3 \\
\hline \multicolumn{10}{|c|}{ 2,4diclorofenol - Concentração - $\mu \mathrm{g} \mathrm{mL}^{-1}$} \\
\hline & [ ] & 0,03 & 0,05 & 0,1 & 0,15 & 0,2 & 0,25 & 0,3 & 0,5 \\
\hline $\begin{array}{l}\text { Sem } \\
\text { Matriz }\end{array}$ & s2 & $1,6 \mathrm{E}+07$ & $2,0 \mathrm{E}+07$ & $1,8 \mathrm{E}+07$ & $3,3 E+08$ & $7,8 \mathrm{E}+08$ & $3,7 \mathrm{E}+08$ & $6,0 \mathrm{E}+08$ & $1,3 \mathrm{E}+09$ \\
\hline \multirow{3}{*}{$\begin{array}{l}\text { Com } \\
\text { Matriz }\end{array}$} & s2 & $4,1 \mathrm{E}+09$ & $1,1 \mathrm{E}+07$ & $3,9 \mathrm{E}+08$ & $5,3 E+08$ & $3,6 \mathrm{E}+09$ & $3,2 \mathrm{E}+09$ & $1,7 \mathrm{E}+10$ & $7,3 \mathrm{E}+09$ \\
\hline & Fcalc & 260,1 & 0,6 & 21,7 & 1,6 & 4,6 & 8,7 & 23,0 & 5,5 \\
\hline & tcalc & 3,2 & 1,6 & 2,9 & 4,2 & 4,8 & 3,8 & 3,2 & 7,9 \\
\hline
\end{tabular}


Continuação TABELA 10

\begin{tabular}{|c|c|c|c|c|c|c|c|c|c|}
\hline \multicolumn{10}{|c|}{ 4-cloro-3-metilfenol - Concentração - $\mu \mathrm{g} \mathrm{mL}{ }^{-1}$} \\
\hline & [ ] & 0,03 & 0,05 & 0,1 & 0,15 & 0,2 & 0,25 & 0,3 & 0,5 \\
\hline $\begin{array}{c}\text { Sem } \\
\text { Matriz }\end{array}$ & s2 & $6,5 \mathrm{E}+06$ & $8,5 \mathrm{E}+05$ & $1,3 \mathrm{E}+07$ & $6,9 \mathrm{E}+06$ & $3,2 \mathrm{E}+07$ & $6,4 \mathrm{E}+07$ & $3,6 \mathrm{E}+07$ & $5,0 \mathrm{E}+08$ \\
\hline \multirow{3}{*}{$\begin{array}{l}\text { Com } \\
\text { Matriz }\end{array}$} & s2 & $1,0 \mathrm{E}+08$ & $4,9 \mathrm{E}+07$ & $5,5 \mathrm{E}+08$ & $1,5 \mathrm{E}+09$ & $3,6 \mathrm{E}+09$ & $3,0 \mathrm{E}+09$ & $1,2 \mathrm{E}+10$ & $3,0 \mathrm{E}+09$ \\
\hline & Fcalc & 16,0 & 57,7 & 41,8 & 224,1 & 111,1 & 46,1 & 344,7 & 6,0 \\
\hline & tcalc & 14,0 & 19,8 & 7,9 & 9,0 & 9,4 & 9,8 & 6,8 & 17,7 \\
\hline \multicolumn{10}{|c|}{ 2,4,6-triclorofenol - Concentração - $\mu \mathrm{g} \mathrm{mL}-1$} \\
\hline & [ ] & 0,03 & 0,05 & 0,1 & 0,15 & 0,2 & 0,25 & 0,3 & 0,5 \\
\hline $\begin{array}{l}\text { Sem } \\
\text { Matriz }\end{array}$ & s2 & $1,6 \mathrm{E}+07$ & $1,5 \mathrm{E}+06$ & $2,2 \mathrm{E}+07$ & $1,5 \mathrm{E}+07$ & $2,3 \mathrm{E}+07$ & $2,6 \mathrm{E}+07$ & $7,3 \mathrm{E}+07$ & $7,3 E+08$ \\
\hline \multirow{3}{*}{$\begin{array}{l}\text { Com } \\
\text { Matriz }\end{array}$} & s2 & $6,1 \mathrm{E}+08$ & $8,7 \mathrm{E}+06$ & 1,7E+08 & $1,8 \mathrm{E}+08$ & $7,1 \mathrm{E}+08$ & $9,0 \mathrm{E}+08$ & $3,4 \mathrm{E}+09$ & $5,1 \mathrm{E}+08$ \\
\hline & Fcalc & 38,5 & 5,9 & 7,7 & 12,2 & 31,7 & 34,9 & 47,1 & 0,7 \\
\hline & tcalc & 3,0 & 2,1 & 1,5 & 4,9 & 4,2 & 4,5 & 3,7 & 7,3 \\
\hline
\end{tabular}

A matriz é tida como interferente na precisão do método, quando em ambos os testes estatísticos os valores calculados são maiores que os valores Tabelados. Como pode-se observar nos resultados apresentados na TAB 10, ambos os testes confirmaram que a matriz interfere na precisão do método para a maioria dos compostos em grande parte dos níveis de concentração, como fenol, 2-nitrofenol, 2,4-diclorofenol, 4-cloro-3-metilfenol, 2,4,6-triclorofenol. Somente o composto 3-metilfenol não apresentou o mesmo comportamento, apresentando resultado de tcalc menor que o valor de tab em cinco dos oito níveis de concentração avaliados, mostrando que, por este teste, o comportamento deste composto em matriz de extrato de sedimento é semelhante quando o mesmo está presente em solução somente de solventes. Porém avaliando os resultados do teste $F$, o valor calculado para todos os pontos foi maior que o tabelado, o que indica que a matriz interfere. A diferença nos resultados para esses dois testes apenas comprova a necessidade de se utilizar mais de um teste estatístico para se ter certeza de uma correta avaliação. 
Os resultados obtidos pela análise estatística dos testes $\mathrm{F}$ e $\mathrm{t}$ assim como os dados das variâncias $\left(\mathrm{s}^{2}\right)$ obtidos nos ensaios sem matriz e com matriz no método SPE, podem ser observados na TAB. 11.

Tabela 11. Resultados dos testes estatísticos F e t aplicados para avaliação da seletividade em extrato de sedimento (Matriz) e no solvente (sem matriz) e variância obtida $\left(s^{2}\right)$ nos ensaios com e sem matriz do método SPE. Considerando $\mathrm{F}_{\text {Tabelado }}=4,28$ e $\mathrm{t}_{\mathrm{Tabelado}}=2,179$, para 7 graus de liberdade e $95 \%$ de confiança.

\begin{tabular}{|c|c|c|c|c|c|c|c|c|c|}
\hline \multicolumn{10}{|c|}{ Fenol - Concentração - $\mu \mathrm{g} \mathrm{mL^{-1 }}$} \\
\hline & {[]} & 0,03 & 0,05 & 0,1 & 0,15 & 0,2 & 0,25 & 0,3 & 0,5 \\
\hline $\begin{array}{l}\text { Sem } \\
\text { Matriz }\end{array}$ & s2 & 1,7E+07 & $2,1 \mathrm{E}+07$ & $1,3 \mathrm{E}+08$ & $3,6 \mathrm{E}+08$ & $4,2 \mathrm{E}+08$ & $2,0 \mathrm{E}+09$ & $8,0 \mathrm{E}+07$ & $9,2 \mathrm{E}+09$ \\
\hline \multirow{3}{*}{$\begin{array}{l}\text { Com } \\
\text { Matriz }\end{array}$} & s2 & $1,8 \mathrm{E}+08$ & $4,5 E+08$ & $8,3 E+09$ & $1,9 E+08$ & $1,2 E+10$ & $2,3 E+09$ & $2,4 \mathrm{E}+10$ & $4,9 E+10$ \\
\hline & $\mathrm{F}_{\text {calc }}$ & 10,5 & 21,2 & 62,0 & 0,5 & 27,5 & 1,1 & 301,3 & 5,3 \\
\hline & $\mathrm{t}_{\text {calc }}$ & 19,1 & 29,4 & 21,1 & 118,5 & 35,1 & 87,4 & 45,6 & 53,6 \\
\hline \multicolumn{10}{|c|}{ 3-metilfenol - Concentração - $\mu \mathrm{g} \mathrm{mL^{-1 }}$} \\
\hline & [ ] & 0,03 & 0,05 & 0,1 & 0,15 & 0,2 & 0,25 & 0,3 & 0,5 \\
\hline $\begin{array}{c}\text { Sem } \\
\text { Matriz }\end{array}$ & s2 & $1,3 \mathrm{E}+07$ & $3,5 \mathrm{E}+07$ & $1,4 \mathrm{E}+08$ & $4,1 \mathrm{E}+08$ & $4,8 \mathrm{E}+07$ & $6,8 \mathrm{E}+08$ & $2,1 \mathrm{E}+08$ & $2,2 \mathrm{E}+09$ \\
\hline \multirow{3}{*}{$\begin{array}{l}\text { Com } \\
\text { Matriz }\end{array}$} & s2 & $2,9 \mathrm{E}+07$ & $8,5 \mathrm{E}+07$ & $3,8 E+08$ & $1,5 \mathrm{E}+09$ & $1,3 \mathrm{E}+09$ & $3,9 E+09$ & $3,0 \mathrm{E}+09$ & $1,3 \mathrm{E}+10$ \\
\hline & $\mathrm{F}_{\text {calc }}$ & 2,2 & 2,5 & 2,7 & 3,7 & 28,0 & 5,7 & 14,4 & 5,8 \\
\hline & $\mathrm{t}_{\text {calc }}$ & 6,3 & 28,9 & 38,5 & 24,8 & 40,7 & 27,4 & 48,1 & 38,8 \\
\hline \multicolumn{10}{|c|}{ 2-nitrofenol - Concentração - $\mu \mathrm{g} \mathrm{mL^{-1 }}$} \\
\hline & [ ] & 0,03 & 0,05 & 0,1 & 0,15 & 0,2 & 0,25 & 0,3 & 0,5 \\
\hline $\begin{array}{c}\text { Sem } \\
\text { Matriz }\end{array}$ & s2 & $1,4 \mathrm{E}+07$ & $1,2 \mathrm{E}+07$ & $2,5 E+07$ & $2,3 E+07$ & $5,8 E+07$ & $8,8 E+07$ & $4,9 E+07$ & $3,3 E+08$ \\
\hline \multirow{3}{*}{$\begin{array}{l}\text { Com } \\
\text { Matriz }\end{array}$} & s2 & $2,3 \mathrm{E}+07$ & $8,7 \mathrm{E}+07$ & $7,8 \mathrm{E}+07$ & $4,4 \mathrm{E}+08$ & $9,6 \mathrm{E}+08$ & $2,9 \mathrm{E}+08$ & 1,7E+09 & 1,7E+09 \\
\hline & $\mathrm{F}_{\text {calc }}$ & 1,7 & 7,4 & 3,1 & 19,3 & 16,6 & 3,3 & 35,3 & 5,2 \\
\hline & $\mathrm{t}_{\text {calc }}$ & 5,4 & 10,8 & 26,5 & 22,2 & 16,8 & 37,1 & 27,8 & 50,2 \\
\hline \multicolumn{10}{|c|}{ 2,4diclorofenol - Concentração - $\mu \mathrm{g} \mathrm{mL} \mathrm{m}^{-1}$} \\
\hline & [ ] & 0,03 & 0,05 & 0,1 & 0,15 & 0,2 & 0,25 & 0,3 & 0,5 \\
\hline $\begin{array}{c}\text { Sem } \\
\text { Matriz }\end{array}$ & s2 & $1,6 \mathrm{E}+07$ & $2,0 \mathrm{E}+07$ & $1,8 \mathrm{E}+07$ & $3,3 \mathrm{E}+08$ & $7,8 \mathrm{E}+08$ & $3,7 \mathrm{E}+08$ & $6,0 \mathrm{E}+08$ & $1,3 \mathrm{E}+09$ \\
\hline \multirow{3}{*}{$\begin{array}{l}\text { Com } \\
\text { Matriz }\end{array}$} & s2 & $4,2 \mathrm{E}+08$ & $1,6 \mathrm{E}+08$ & $9,2 \mathrm{E}+08$ & $5,4 \mathrm{E}+08$ & $8,4 \mathrm{E}+08$ & $1,3 E+09$ & 1,7E+09 & $1,3 \mathrm{E}+10$ \\
\hline & $\mathrm{F}_{\text {calc }}$ & 27,0 & 7,8 & 50,3 & 1,6 & 1,1 & 3,6 & 2,7 & 9,6 \\
\hline & $\mathrm{t}_{\text {calc }}$ & 5,4 & 10,8 & 26,5 & 22,2 & 16,8 & 37,1 & 27,8 & 50,2 \\
\hline
\end{tabular}


Continuação TABELA 11.

\begin{tabular}{|c|c|c|c|c|c|c|c|c|c|}
\hline \multicolumn{10}{|c|}{ 4-cloro-3-metilfenol - Concentração - $\mu \mathrm{g} \mathrm{mL} \mathrm{m}^{-1}$} \\
\hline & [] & 0,03 & 0,05 & 0,1 & 0,15 & 0,2 & 0,25 & 0,3 & 0,5 \\
\hline $\begin{array}{c}\text { Sem } \\
\text { Matriz }\end{array}$ & $s^{2}$ & $6,5 \mathrm{E}+06$ & $8,5 \mathrm{E}+05$ & $1,3 \mathrm{E}+07$ & $6,9 \mathrm{E}+06$ & $3,2 \mathrm{E}+07$ & $6,4 \mathrm{E}+07$ & $3,6 \mathrm{E}+07$ & $5,0 \mathrm{E}+08$ \\
\hline \multirow{3}{*}{$\begin{array}{l}\text { Com } \\
\text { Matriz }\end{array}$} & $s^{2}$ & $6,8 \mathrm{E}+06$ & $2,9 \mathrm{E}+07$ & $1,6 \mathrm{E}+08$ & $4,9 \mathrm{E}+07$ & $2,0 \mathrm{E}+08$ & $4,1 \mathrm{E}+08$ & $4,8 \mathrm{E}+08$ & $3,1 \mathrm{E}+09$ \\
\hline & $\mathrm{F}_{\text {calc }}$ & 1,1 & 33,8 & 12,1 & 7,1 & 6,2 & 6,4 & 13,5 & 6,2 \\
\hline & $t_{\text {calc }}$ & 0,5 & 19,7 & 22,1 & 50,7 & 36,3 & 27,0 & 44,0 & 30,9 \\
\hline \multicolumn{10}{|c|}{ 2,4,6-triclorofenol - Concentração - $\mu \mathrm{g} \mathrm{mL}$} \\
\hline & [ ] & 0,03 & 0,05 & 0,1 & 0,15 & 0,2 & 0,25 & 0,3 & 0,5 \\
\hline $\begin{array}{c}\text { Sem } \\
\text { Matriz }\end{array}$ & $s^{2}$ & $1,6 \mathrm{E}+07$ & $1,5 \mathrm{E}+06$ & $2,2 \mathrm{E}+07$ & $1,5 \mathrm{E}+07$ & $2,3 \mathrm{E}+07$ & $2,6 \mathrm{E}+07$ & $7,3 E+07$ & $7,3 E+08$ \\
\hline \multirow{3}{*}{$\begin{array}{l}\text { Com } \\
\text { Matriz }\end{array}$} & $\mathrm{s}^{2}$ & $2,4 E+07$ & $3,8 E+07$ & $2,0 E+08$ & $5,6 \mathrm{E}+07$ & $4,5 E+08$ & $7,1 E+08$ & $2,4 \mathrm{E}+09$ & $9,4 \mathrm{E}+08$ \\
\hline & $F_{\text {calc }}$ & 1,5 & 25,5 & 9,1 & 3,8 & 19,8 & 27,2 & 32,5 & 1,3 \\
\hline & $\mathrm{t}_{\text {calc }}$ & 14,5 & 26,2 & 22,6 & 57,1 & 27,8 & 30,0 & 21,3 & 45,6 \\
\hline
\end{tabular}

Para o método SPE também se observa a interferência da matriz tanto pelo teste $\mathrm{F}$ (Snedecor) como para o teste $\mathrm{t}$ (Student) para todos os compostos.

A diferença de comportamento dos diferentes compostos em diferentes matrizes pode ser observada comparando-se as diferentes inclinações das retas na FIG. 22. 

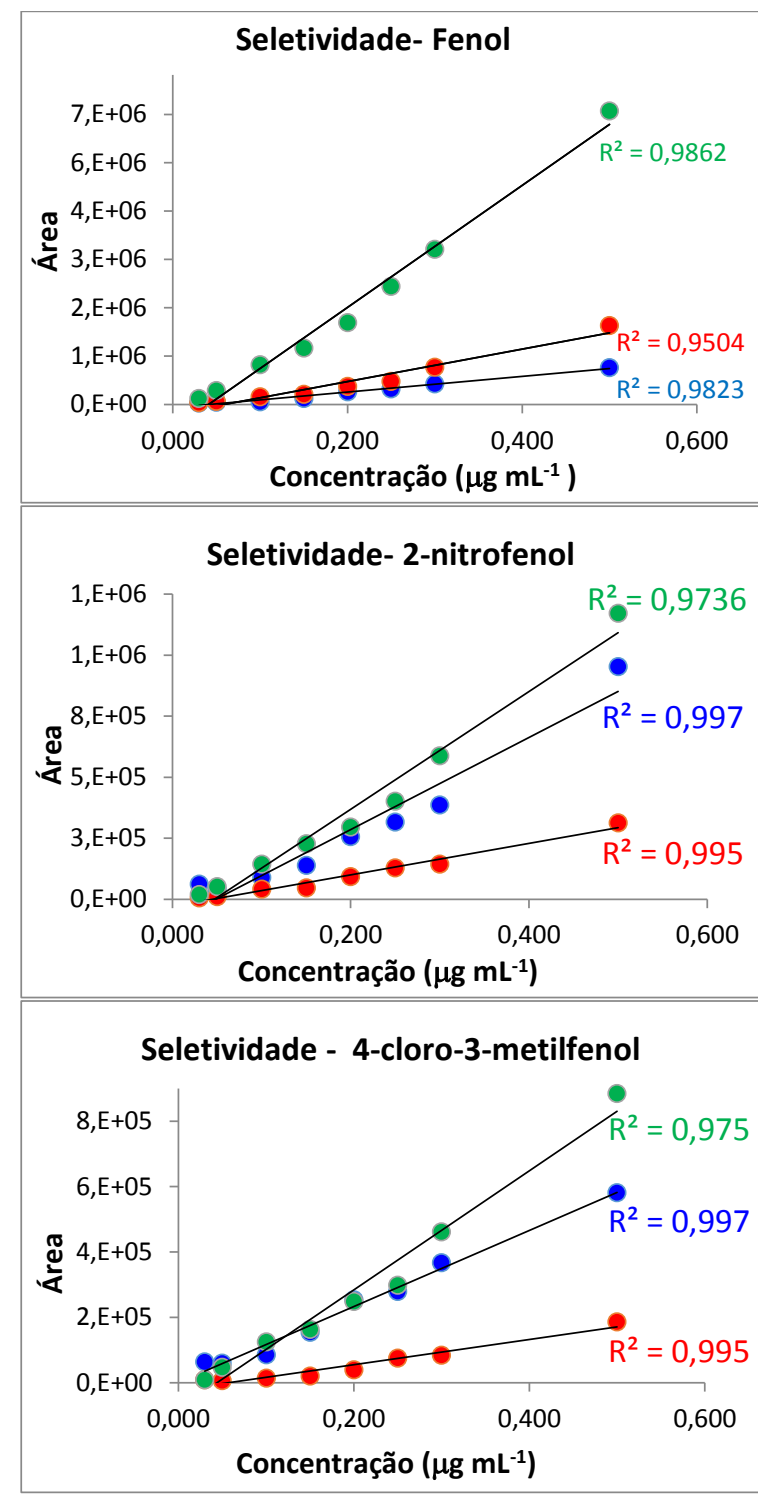
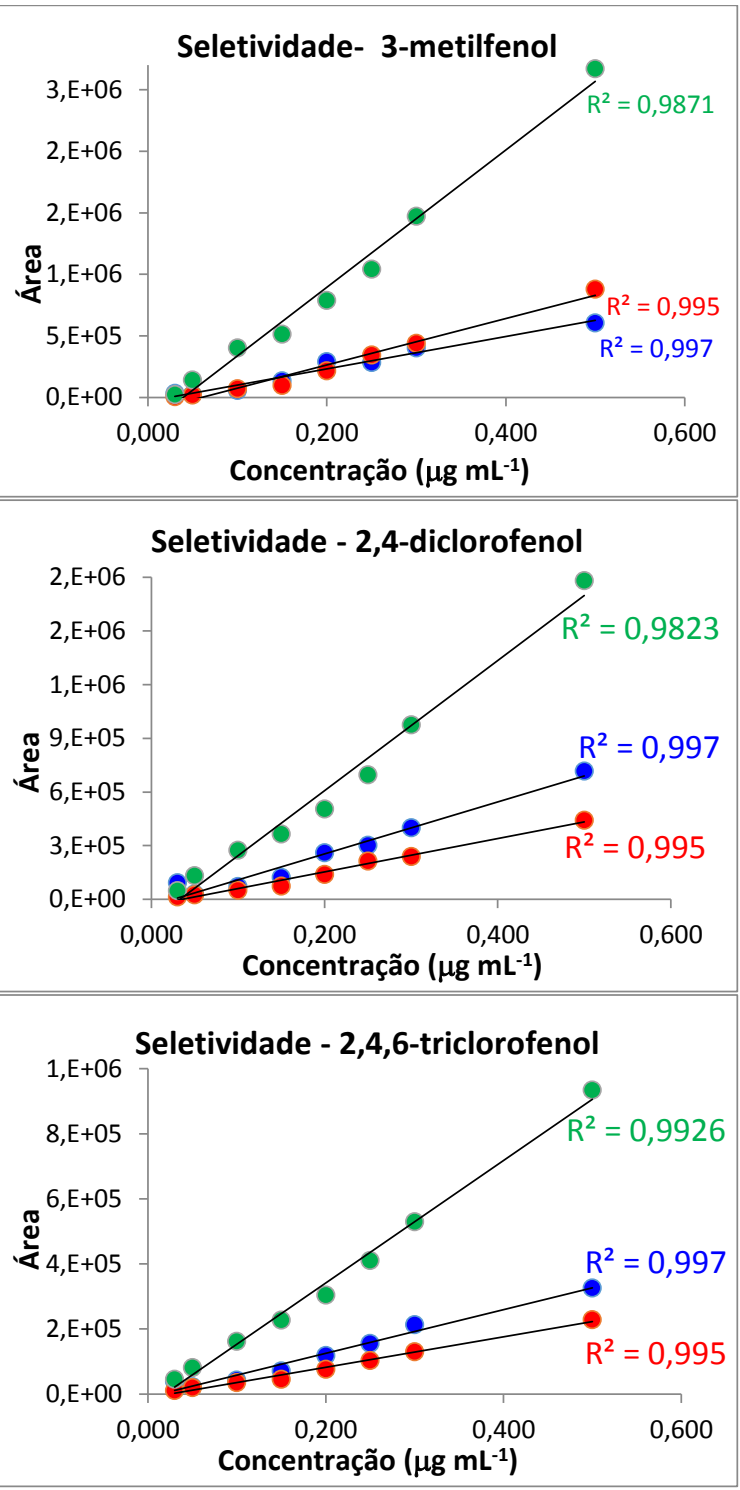

Legenda: ๑ Método Final $\bullet$ Sem matriz $\bigcirc$ Método SPE

Figura 22. Gráficos da seletividade representados pelas retas obtidas nos ensaios do método final, sem matriz e no método SPE.

Estatisticamente a inclinação das retas com matriz e sem matriz foi avaliada pelo teste $t$ de inclinação e paralelismo e pelo teste do intercepto, pois curvas com a mesma inclinação indicam que não há influência da matriz na determinação dos compostos estudados (Ribani, 2004; Furusawa, 2007; INMETRO, 2011). Pelos resultados obtidos pode-se observar que as retas possuem inclinações estatisticamente diferentes para todos os compostos e as inclinações e os interceptos são estatisticamente diferentes como observado na TAB. 12 para o método final e na TAB. 13 para o método SPE. 
Tabela 12. Valores obtidos com o teste t Student para intercepto para o método final. Onde t tabelado $=2,179$, considerando 7 graus de liberdade e com $95 \%$ de confiança.

\begin{tabular}{c|c}
\hline Composto & Teste de Intercepto \\
\hline Fenol & 710 \\
\hline 3-metilfenol & 531 \\
\hline 2-nitrofenol & 456 \\
\hline 2,4-diclorofenol & 27 \\
\hline 4-cloro-3-metilfenol & 209 \\
\hline 2,4,6-triclorofenol & 27 \\
\hline
\end{tabular}

Tabela 13. Valores obtidos com o teste t Student para intercepto para o método SPE. Onde tTabelado $=2,179$, considerando 7 graus de liberdade e com $95 \%$ de confiança.

\begin{tabular}{c|c}
\hline Composto & Teste de Intercepto \\
\hline Fenol & 969 \\
\hline 3-metilfenol & 451 \\
\hline 2-nitrofenol & 559 \\
\hline 2,4-diclorofenol & 469 \\
\hline 4-cloro-3-metilfenol & 453 \\
\hline 2,4,6-triclorofenol & 178 \\
\hline
\end{tabular}

Ambos os métodos foram considerados seletivos para os testes com e sem matriz. Porém, devido à influência da matriz sobre grande parte dos compostos estudados, os demais parâmetros da validação foram baseados nos ensaios com matriz a fim de minimizar as interferências da mesma nas medições.

\section{$9.2 \quad$ Linearidade}

A linearidade foi inicialmente avaliada utilizando-se o coeficiente de determinação $\left(r^{2}\right)$ obtido pelo cálculo da regressão linear das curvas analíticas elaboradas para cada composto na matriz com oito níveis de concentração, 
utilizando os valores de todas as sete replicatas, além da análise de resíduos por meio do teste $t$ (Student) e dos gráficos de resíduos e probabilidade normalizada. Nas TAB. 14, 15 e 16 estão apresentadas as faixas de trabalho de cada um dos compostos, assim como a equação das retas e seus respectivos coeficientes de determinação obtidos pelas curvas analíticas confeccionadas na matriz de estudo do método final, na matriz de estudo do método SPE e sem matriz. Pode-se observar também nas FIG. 23, 24 e 25 as representações gráficas da linearidade nos dois ensaios.

Tabela 14. Faixa de trabalho, equação da reta e coeficiente de determinação $\left(r^{2}\right)$ dos compostos estudados, obtidos pela adição padrão na matriz de extrato de sedimento do método final.

\begin{tabular}{ccccc}
\hline \multirow{2}{*}{ Composto } & \multicolumn{5}{c}{ Faixa de trabalho $\left(\mu \mathrm{g} \mathrm{mL}^{-1}\right)$} \\
\cline { 2 - 5 } & mínima & máxima & Equação da Reta & $\mathrm{r}^{2}$ \\
\hline Fenol & 0,03 & 0,5 & $\mathrm{y}=2 \mathrm{E}+06 \mathrm{x}-72719$ & 0,98 \\
3-metilfenol & 0,03 & 0,5 & $\mathrm{y}=1 \mathrm{E}+06 \mathrm{x}-304$ & 0,97 \\
2-nitrofenol & 0,03 & 0,5 & $\mathrm{y}=2 \mathrm{E}+06 \mathrm{x}-91262$ & 0,94 \\
2,4-diclorofenol & 0,03 & 0,5 & $\mathrm{y}=1 \mathrm{E}+06 \mathrm{x}-36736$ & 0,96 \\
4-cloro-3-metilfenol & 0,03 & 0,5 & $\mathrm{y}=1 \mathrm{E}+06 \mathrm{x}+621,0$ & 0,98 \\
2,4,6-triclorofenol & 0,03 & 0,5 & $\mathrm{y}=67070 \mathrm{x}-8753$ & 0,97 \\
\hline
\end{tabular}




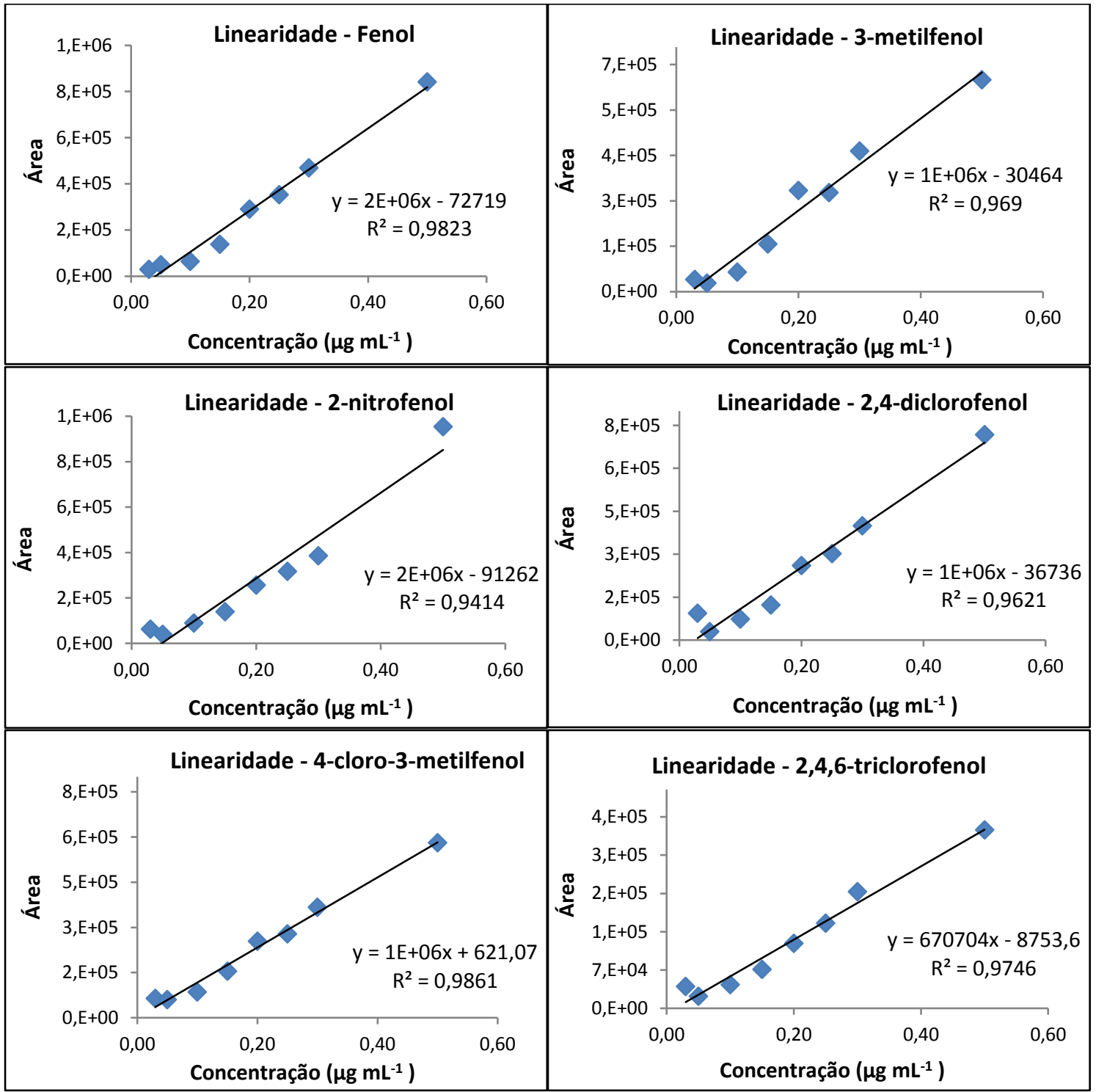

Figura 23. Representação gráfica da linearidade para os compostos estudados no ensaio com matriz do método final. 
Tabela 15. Faixa de trabalho, equação da reta e coeficiente de determinação $\left(r^{2}\right)$ dos compostos estudados, obtidos pela adição padrão na matriz de extrato de sedimento do método SPE.

\begin{tabular}{ccccc}
\hline Composto & \multicolumn{4}{c}{ Faixa de trabalho $\left(\mu \mathrm{g} \mathrm{mL}^{-1}\right)$} \\
\hline & mínima & máxima & Equação da reta & $\mathrm{R}^{2}$ \\
\hline Fenol & 0,03 & 0,5 & $\mathrm{y}=1 \mathrm{E}+07 \mathrm{x}-567688$ & 0,99 \\
3-metilfenol & 0,03 & 0,5 & $\mathrm{y}=6 \mathrm{E}+06 \mathrm{x}-219012$ & 0,99 \\
2-nitrofenol & 0,03 & 0,5 & $\mathrm{y}=2 \mathrm{E}+06 \mathrm{x}-113030$ & 0,97 \\
2,4-diclorofenol & 0,03 & 0,5 & $\mathrm{y}=4 \mathrm{E}+06 \mathrm{x}-119836$ & 0,98 \\
4-cloro-3-metilfenol & 0,03 & 0,5 & $\mathrm{y}=2 \mathrm{E}+06 \mathrm{x}-79996$ & 0,97 \\
2,4,6-triclorofenol & 0,03 & 0,5 & $\mathrm{y}=2 \mathrm{E}+06 \mathrm{x}-34792$ & 0,99 \\
\hline
\end{tabular}

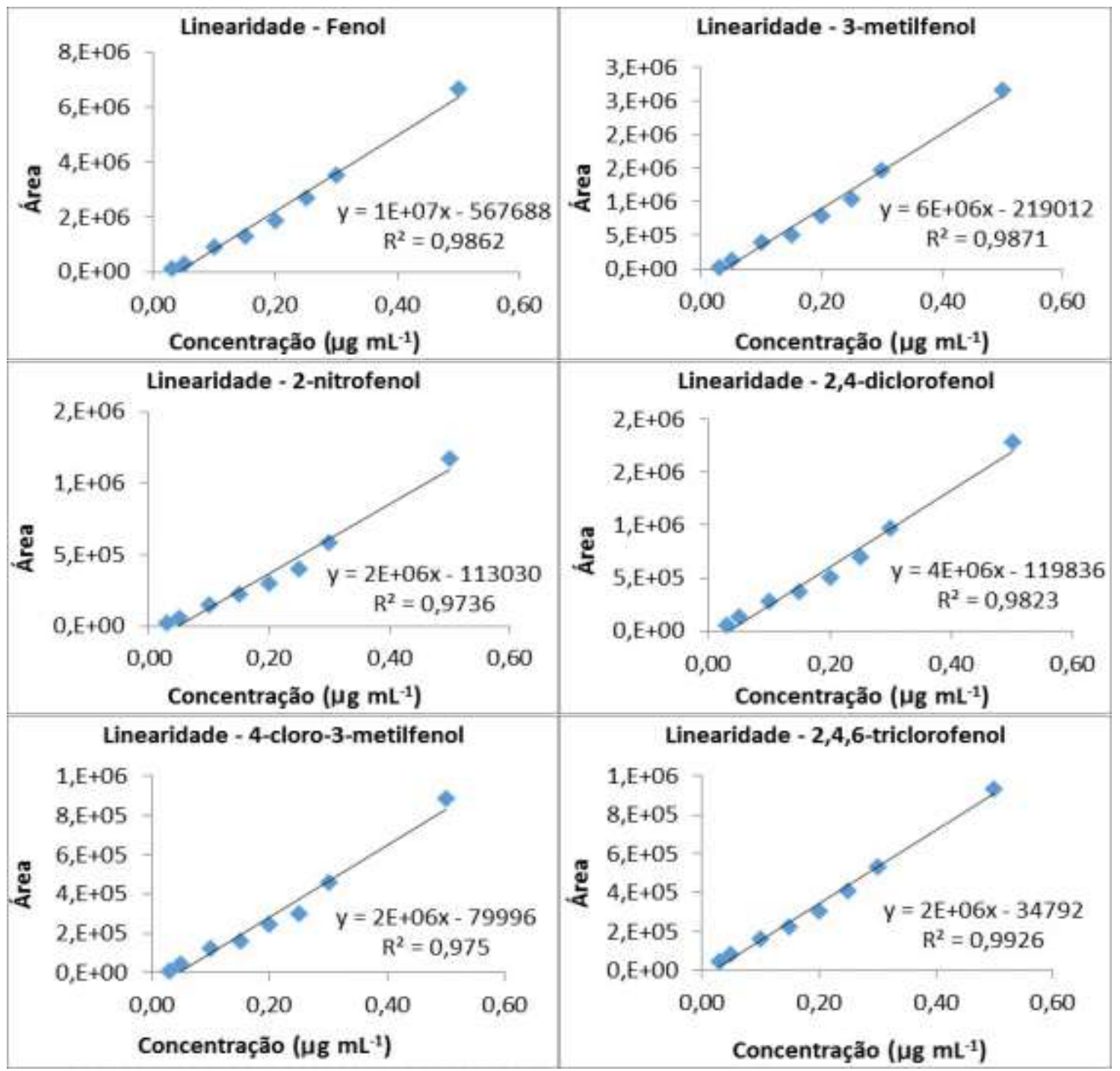

Figura 24. Representação gráfica da linearidade para os compostos estudados no ensaio com matriz do método SPE. 
Tabela 16. Faixa de trabalho, equação da reta e coeficiente de determinação $\left(r^{2}\right)$ dos compostos estudados sem matriz.

\begin{tabular}{ccccc}
\hline \multirow{2}{*}{ Composto } & \multicolumn{4}{c}{ Faixa de trabalho $\left(\mu \mathrm{gL}^{-1}\right)$} \\
\cline { 2 - 5 } & mínima & máxima & Equação da reta & $\mathrm{R}^{2}$ \\
\hline Fenol & 0,03 & 0,5 & $\mathrm{y}=4 \mathrm{E}+06 \mathrm{x}-216469$ & 0,95 \\
3-metilfenol & 0,03 & 0,5 & $\mathrm{y}=2 \mathrm{E}+06 \mathrm{x}-112590$ & 0,97 \\
2-nitrofenol & 0,03 & 0,5 & $\mathrm{y}=6444444 \mathrm{x}-28552$ & 0,98 \\
2,4-diclorofenol & 0,03 & 0,5 & $\mathrm{y}=931662 \mathrm{x}-33175$ & 0,99 \\
4-cloro-3- & & & & \\
metilfenol & 0,03 & 0,5 & $\mathrm{y}=385587 \mathrm{x}-21837$ & 0,95 \\
2,4,6-triclorofenol & 0,03 & 0,5 & $\mathrm{y}=468239 \mathrm{x}-11214$ & 0,99 \\
\hline
\end{tabular}

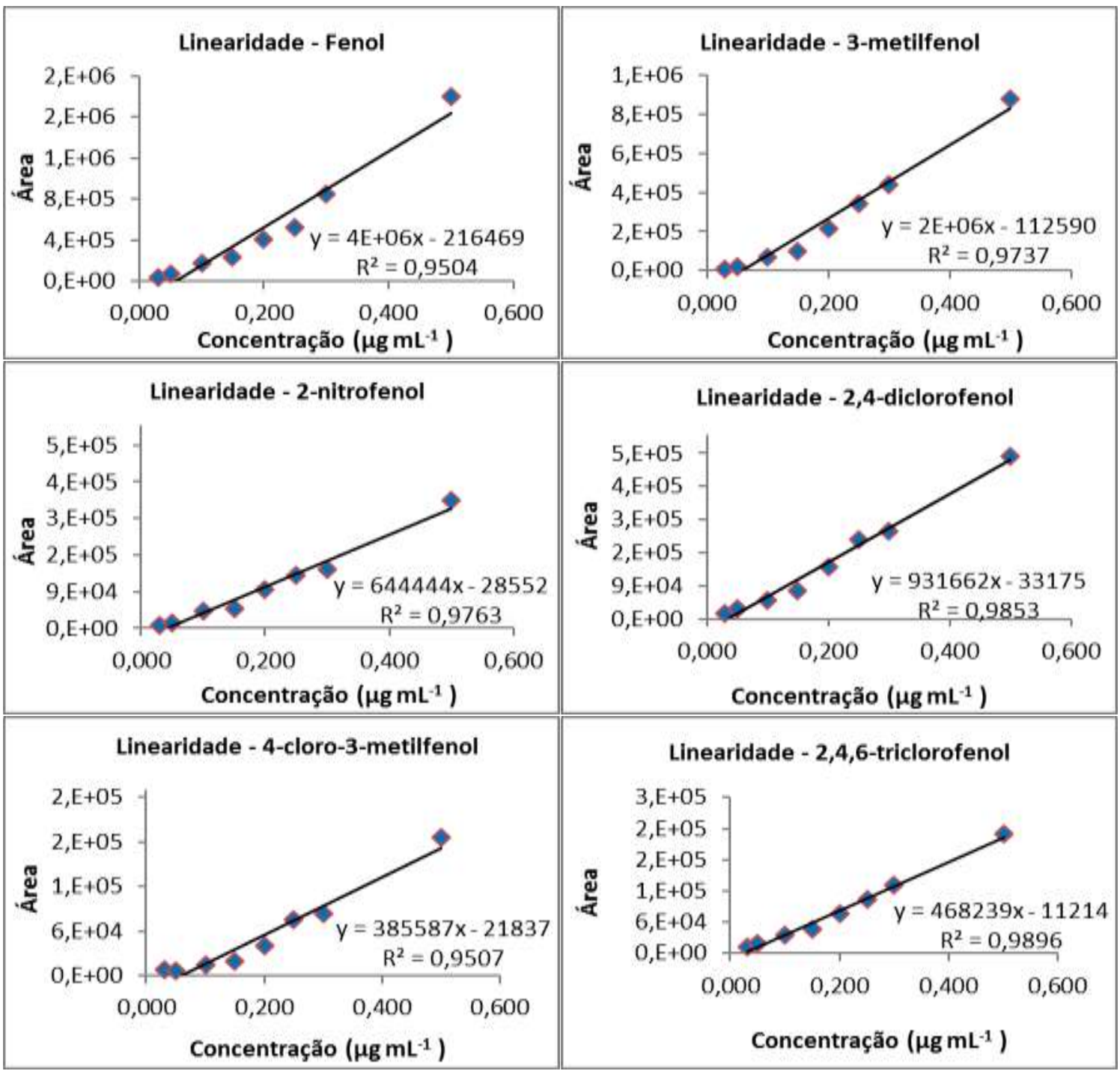

Figura 25. Representação gráfica da linearidade para os compostos estudados no ensaio sem matriz. 
Apesar de a representação gráfica mostrar alguns pontos discrepantes, principalmente nas concentrações baixas para praticamente todos os compostos e para as altas e baixas dos compostos 2-nitrofenol e 2,4-diclorofenol, os valores de coeficiente de correlação obtidos para cada composto superaram o valor recomendado de 0,90. É importante ressaltar que nenhum valor de replicata foi descartado.

$\mathrm{Na}$ análise dos resíduos, realizada pelo teste $\mathrm{t}$ (Student), os resultados dos valores de tcalculado obtidos nos cálculos estatísticos para os seis compostos nos oito níveis de concentração em matriz do método final, em matriz do método SPE e sem matriz são apresentados nas TAB. 17, 18 e 19. Os valores de t calculados acima do valor $t$ Tabelado ( $\left.t_{t a b}=2,365\right)$, para $8(n-1)$ graus de liberdade com $95 \%$ de confiança, indicam que o ponto não pertence à reta de regressão.

Tabela 17. Valores obtidos no Teste t-Student para a verificação do desvio da linearidade de cada ponto da curva de cada composto em matriz do método final. Sendo o valor Tabelado de t crítico para $8(n-1)$ graus de liberdade com 95\% de confiança igual a 2,365.

\begin{tabular}{|c|c|c|c|c|c|c|c|c|c|}
\hline \multirow{2}{*}{ Fenol } & $\mu \mathrm{g} \mathrm{mL}^{-1}$ & 0,03 & 0,05 & 0,10 & 0,15 & 0,20 & 0,25 & 0,30 & 0,5 \\
\hline & $t_{c a l c}$ & 3,791 & 2,536 & 3,197 & 4,345 & 0,569 & 1,597 & 0,525 & 1,718 \\
\hline \multirow{2}{*}{ 3-metilfenol } & $\mu \mathrm{g} \mathrm{mL}^{-1}$ & 0,03 & 0,05 & 0,10 & 0,15 & 0,20 & 0,25 & 0,30 & 0,5 \\
\hline & $t_{\text {calc }}$ & 2,047 & 0,822 & 3,530 & 2,384 & 4,471 & 1,149 & 3,002 & 1,634 \\
\hline \multirow{2}{*}{ 2-nitrofenol } & $\mu \mathrm{g} \mathrm{mL}^{-1}$ & 0,03 & 0,05 & 0,10 & 0,15 & 0,20 & 0,25 & 0,30 & 0,5 \\
\hline & $t_{\text {calc }}$ & 3,826 & 1,462 & 0,292 & 2,027 & 1,115 & 2,439 & 3,427 & 4,012 \\
\hline \multirow{2}{*}{ 2,4-diclorofenol } & $\mu \mathrm{g} \mathrm{mL}^{-1}$ & 0,03 & 0,05 & 0,10 & 0,15 & 0,20 & 0,25 & 0,30 & 0,5 \\
\hline & tcalc & 5,578 & 0,393 & 2,228 & 3,722 & 0,405 & 1,540 & 0,064 & 1,837 \\
\hline \multirow{2}{*}{ 4-cloro-3-metilfenol } & $\mu \mathrm{g} \mathrm{mL}^{-1}$ & 0,03 & 0,05 & 0,10 & 0,15 & 0,20 & 0,25 & 0,30 & 0,5 \\
\hline & tcalc & 3,812 & 0,110 & 4,265 & 2,799 & 2,728 & 1,698 & 2,255 & 0,142 \\
\hline \multirow{2}{*}{ 2,4,6-triclorofenol } & $\mu \mathrm{g} \mathrm{mL}^{-1}$ & 0,03 & 0,05 & 0,10 & 0,15 & 0,20 & 0,25 & 0,30 & 0,5 \\
\hline & $t_{\text {calc }}$ & 4,789 & 0,489 & 2,614 & 3,475 & 1,126 & 0,537 & 3,516 & 0,064 \\
\hline
\end{tabular}


Tabela 18. Valores obtidos no Teste t-Student para a verificação do desvio da linearidade de cada ponto da curva de cada composto em matriz do método SPE. Sendo o valor Tabelado de t crítico para $8(n-1)$ graus de liberdade com 95\% de confiança 2,365.

\begin{tabular}{|c|c|c|c|c|c|c|c|c|c|}
\hline \multirow[b]{2}{*}{ Fenol } & $\mu \mathrm{g} \mathrm{mL}^{-1}$ & 0,03 & 0,05 & 0,1 & 0,15 & 0,2 & 0,25 & 0,3 & 0,5 \\
\hline & $t_{\text {calc }}$ & $\begin{array}{c}3,25 \\
0\end{array}$ & $\begin{array}{c}2,10 \\
9\end{array}$ & $\begin{array}{c}0,91 \\
6\end{array}$ & $\begin{array}{c}2,61 \\
3\end{array}$ & $\begin{array}{c}3,85 \\
0\end{array}$ & $\begin{array}{c}2,46 \\
2\end{array}$ & $\begin{array}{c}0,78 \\
8\end{array}$ & $\begin{array}{c}3,43 \\
8\end{array}$ \\
\hline \multirow[b]{2}{*}{ 3-metilfenol } & $\mu g \mathrm{~mL}^{-1}$ & 0,03 & 0,05 & 0,1 & 0,15 & 0,2 & 0,25 & 0,3 & 0,5 \\
\hline & tcalc & $\begin{array}{c}2,17 \\
4\end{array}$ & $\begin{array}{c}2,34 \\
9\end{array}$ & $\begin{array}{c}1,84 \\
8\end{array}$ & $\begin{array}{c}2,96 \\
8\end{array}$ & $\begin{array}{c}3,11 \\
4\end{array}$ & $\begin{array}{c}3,82 \\
8\end{array}$ & $\begin{array}{c}0,56 \\
2\end{array}$ & $\begin{array}{c}2,97 \\
8\end{array}$ \\
\hline \multirow[b]{2}{*}{ 2-nitrofenol } & $\mu \mathrm{gL}^{-1}$ & 0,03 & 0,05 & 0,1 & 0,15 & 0,2 & 0,25 & 0,3 & 0,5 \\
\hline & $t_{\text {calc }}$ & $\begin{array}{c}2,78 \\
2\end{array}$ & $\begin{array}{c}2,11 \\
0\end{array}$ & $\begin{array}{c}0,74 \\
1\end{array}$ & $\begin{array}{c}0,96 \\
9\end{array}$ & $\begin{array}{c}3,34 \\
7\end{array}$ & $\begin{array}{c}4,02 \\
1\end{array}$ & $\begin{array}{c}1,02 \\
5\end{array}$ & $\begin{array}{c}3,72 \\
9\end{array}$ \\
\hline \multirow[b]{2}{*}{ 2,4-diclorofenol } & $\mu \mathrm{g} \mathrm{mL}^{-1}$ & 0,03 & 0,05 & 0,1 & 0,15 & 0,2 & 0,25 & 0,3 & 0,5 \\
\hline & tcalc & $\begin{array}{c}2,26 \\
9\end{array}$ & $\begin{array}{c}2,69 \\
9\end{array}$ & $\begin{array}{c}1,21 \\
2\end{array}$ & $\begin{array}{c}2,21 \\
7\end{array}$ & $\begin{array}{c}3,82 \\
7\end{array}$ & $\begin{array}{c}3,50 \\
6\end{array}$ & $\begin{array}{c}0,17 \\
7\end{array}$ & $\begin{array}{c}3,19 \\
5\end{array}$ \\
\hline \multirow[b]{2}{*}{ 4-cloro-3-metilfenol } & $\mu \mathrm{g} \mathrm{mL}^{-1}$ & 0,03 & 0,05 & 0,1 & 0,15 & 0,2 & 0,25 & 0,3 & 0,5 \\
\hline & tcalc & $\begin{array}{c}2,18 \\
5\end{array}$ & $\begin{array}{c}2,28 \\
4\end{array}$ & $\begin{array}{c}1,39 \\
4\end{array}$ & $\begin{array}{c}1,89 \\
8\end{array}$ & $\begin{array}{c}2,26 \\
9\end{array}$ & $\begin{array}{c}4,84 \\
5 \\
\end{array}$ & $\begin{array}{c}0,28 \\
0\end{array}$ & $\begin{array}{c}3,42 \\
9\end{array}$ \\
\hline \multirow[b]{2}{*}{ 2,4,6-triclorofenol } & $\mu \mathrm{g} \mathrm{mL}^{-1}$ & 0,03 & 0,05 & 0,1 & 0,15 & 0,2 & 0,25 & 0,3 & 0,5 \\
\hline & $t_{\text {calc }}$ & $\begin{array}{c}2,74 \\
9 \\
\end{array}$ & $\begin{array}{c}2,49 \\
4\end{array}$ & $\begin{array}{c}0,92 \\
6 \\
\end{array}$ & $\begin{array}{c}2,30 \\
1 \\
\end{array}$ & $\begin{array}{c}4,20 \\
9 \\
\end{array}$ & $\begin{array}{c}2,82 \\
7 \\
\end{array}$ & $\begin{array}{c}0,05 \\
0 \\
\end{array}$ & $\begin{array}{c}3,21 \\
8 \\
\end{array}$ \\
\hline
\end{tabular}

Tabela 19. Valores obtidos no Teste t-Student para a verificação do desvio da linearidade de cada ponto da curva de cada composto no ensaio sem matriz. Sendo o valor Tabelado de $t$ crítico para 8 ( $n-1)$ graus de liberdade com $95 \%$ de confiança 2,365.

\begin{tabular}{llllcccccc}
\hline \multirow{2}{*}{ Fenol } & $\mu \mathrm{g} \mathrm{mL}^{-1}$ & 0,03 & 0,05 & 0,1 & 0,15 & 0,2 & 0,25 & 0,3 & 0,5 \\
\cline { 2 - 10 } & $\mathrm{t}_{\text {calc }}$ & 3,190 & 2,339 & 0,422 & 2,274 & 2,515 & 3,983 & 0,872 & 3,693 \\
\hline \multirow{2}{*}{ 3-metilfenol } & $\mu \mathrm{mL}^{-1}$ & 0,03 & 0,05 & 0,1 & 0,15 & 0,2 & 0,25 & 0,3 & 0,5 \\
\cline { 2 - 10 } & $\mathrm{t}_{\text {calc }}$ & 3,609 & 2,255 & 0,351 & 4,009 & 2,768 & 0,813 & 0,667 & 2,745 \\
\hline \multirow{2}{*}{ 2-nitrofenol } & $\mu \mathrm{gL} \mathrm{m}^{-1}$ & 0,03 & 0,05 & 0,1 & 0,15 & 0,2 & 0,25 & 0,3 & 0,5 \\
\cline { 2 - 10 } & $\mathrm{t}_{\text {calc }}$ & 2,979 & 1,617 & 1,238 & 3,811 & 1,239 & 0,631 & 3,798 & 3,645 \\
\hline \multirow{2}{*}{ 2,4-diclorofenol } & $\mu \mathrm{mL}^{-1}$ & 0,03 & 0,05 & 0,1 & 0,15 & 0,2 & 0,25 & 0,3 & 0,5 \\
\cline { 2 - 10 } & $\mathrm{t}_{\text {calc }}$ & 2,911 & 1,855 & 1,245 & 4,414 & 1,739 & 2,282 & 1,044 & 1,394 \\
\hline \multirow{2}{*}{ 4-cloro-3- } & $\mu \mathrm{mL}^{-1}$ & 0,03 & 0,05 & 0,1 & 0,15 & 0,2 & 0,25 & 0,3 & 0,5 \\
\hline metilfenol & $\mathrm{t}_{\text {calc }}$ & 3,827 & 1,902 & 0,503 & 3,277 & 3,172 & 0,173 & 1,992 & 3,041 \\
\hline \multirow{2}{*}{ 2,4,6-triclorofenol } & $\mu \mathrm{gL} \mathrm{m}^{-1}$ & 0,03 & 0,05 & 0,1 & 0,15 & 0,2 & 0,25 & 0,3 & 0,5 \\
\cline { 2 - 9 } & $\mathrm{t}_{\text {calc }}$ & 2,974 & 2,491 & 0,233 & 4,671 & 2,191 & 0,857 & 0,403 & 2,083 \\
\hline
\end{tabular}


Pode-se observar nas TAB. 17, 18 e 19 que alguns pontos apresentaram valores de tcalculado acima do valor crítico, indicando que estes pontos não pertencem a reta de regressão da curva analítica. Entretanto os valores de coeficiente de correlação linear ( $r$ ) obtidos para cada uma das retas foi satisfatório, sendo a recomendação do INMETRO (2003) que este valor seja maior que 0,90 e para todas as curvas foram obtidos valores de $\mathrm{r}^{2}$ maiores que 0,95 , desse modo optouse por considerar esses pontos na quantificação das amostras estudadas.

A análise dos resíduos também foi avaliada por meio dos gráficos de distribuição espacial dos resíduos absolutos em função das concentrações e a distribuição dos resíduos em função da probabilidade normalizada apresentados nas FIG. 26 e 27 para os ensaios com matriz do método final, nas FIG. 28 e 29 para os ensaios com matriz do método SPE e nas FIG. 30 e 31 no ensaio sem matriz respectivamente (Furusawa, 2007).

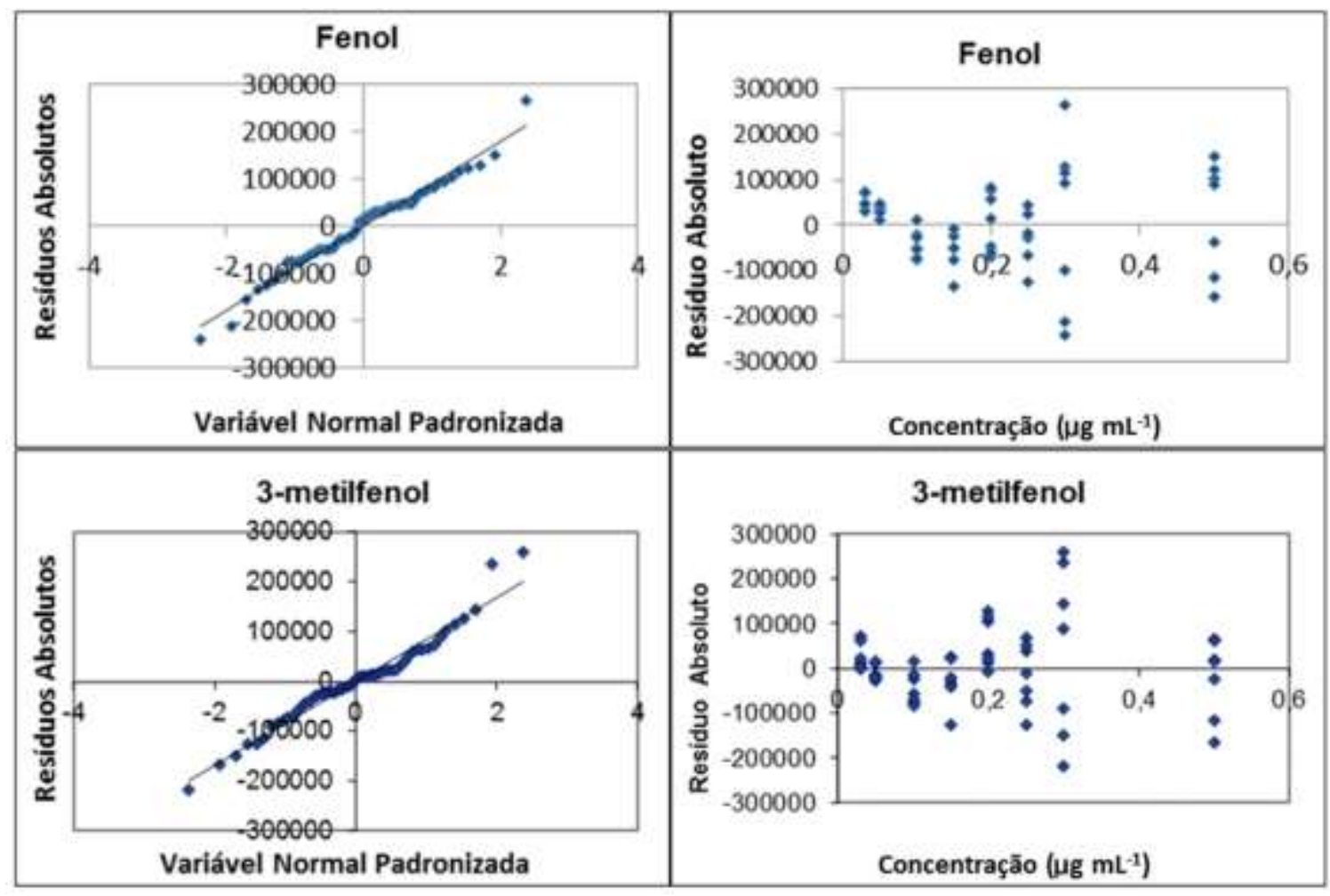

Figura 26. Gráficos dos resíduos normalizados e absolutos para os compostos fenol e 3-metilfeno no ensaio com matriz do método final. 


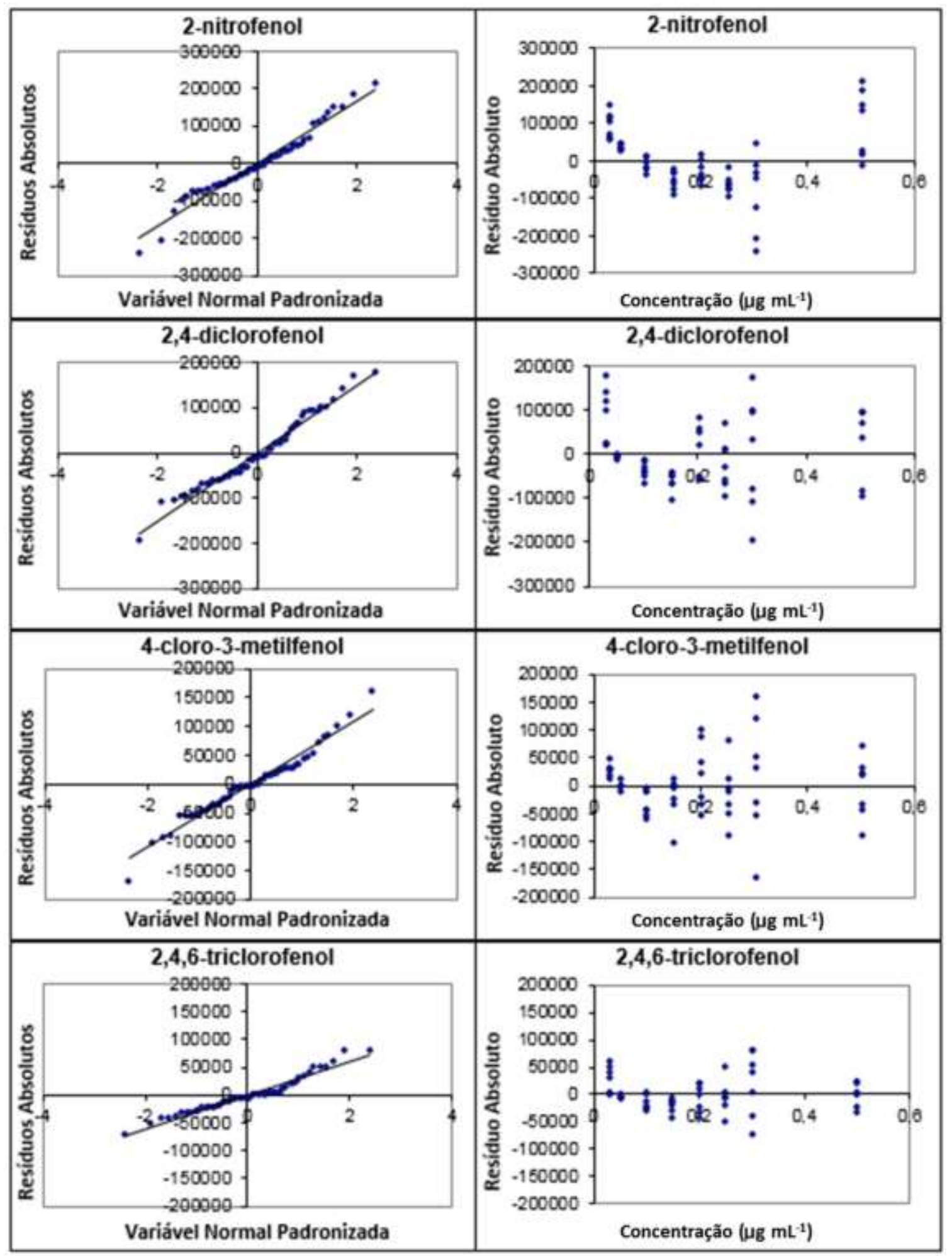

Figura 27. Gráficos dos resíduos normalizados e absolutos para os compostos 2-nitrofenol,2,4-diclorofenol, 4-cloro-3-metilfenol e 2,4,6-triclorofenol no ensaio com matriz do método final. 


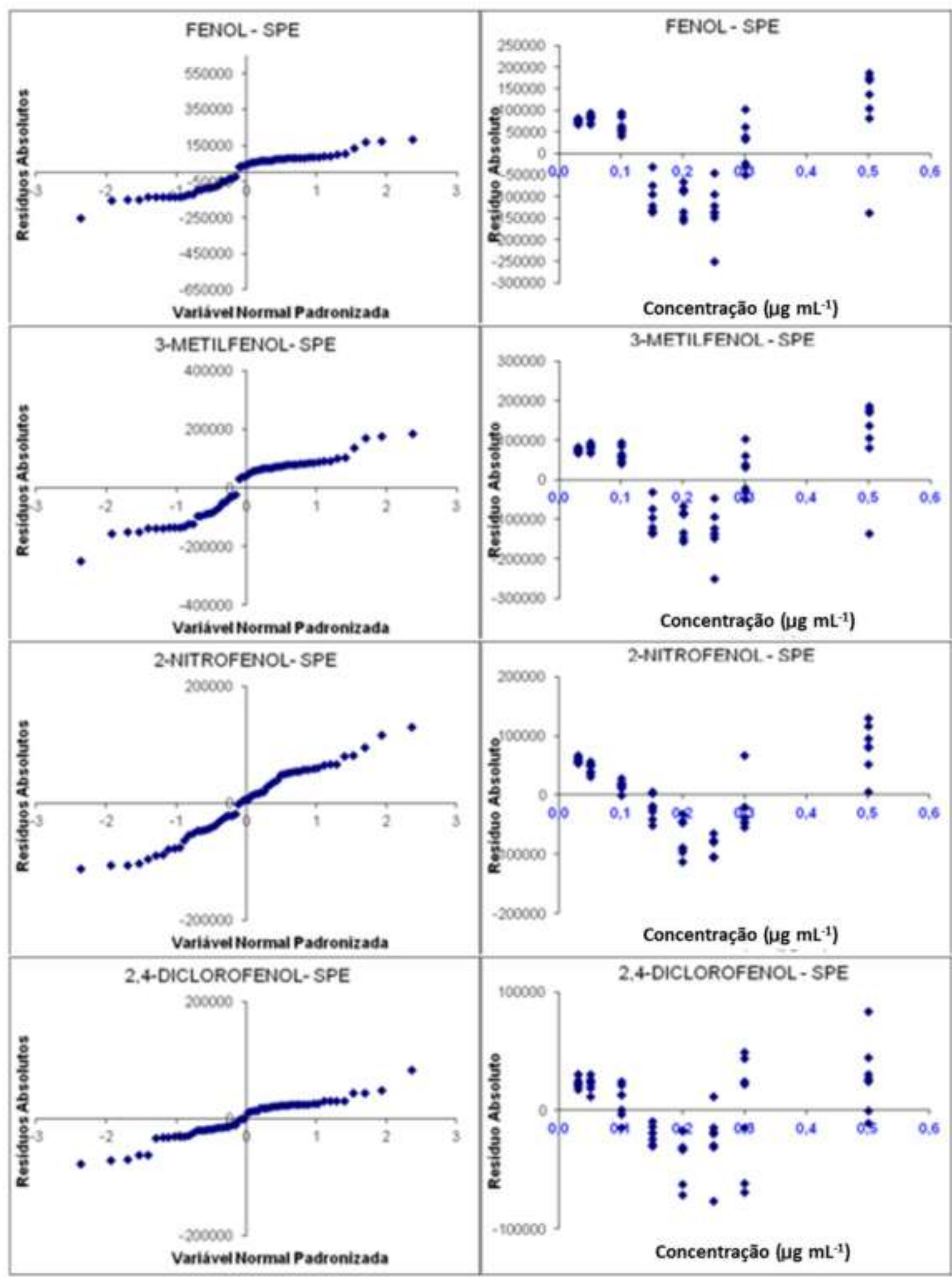

Figura 28. Gráficos dos resíduos normalizados e absolutos para os compostos fenol, 3-metilfenol, 2-nitrofenol e 2,4-diclorofenol no ensaio com matriz do método SPE. 


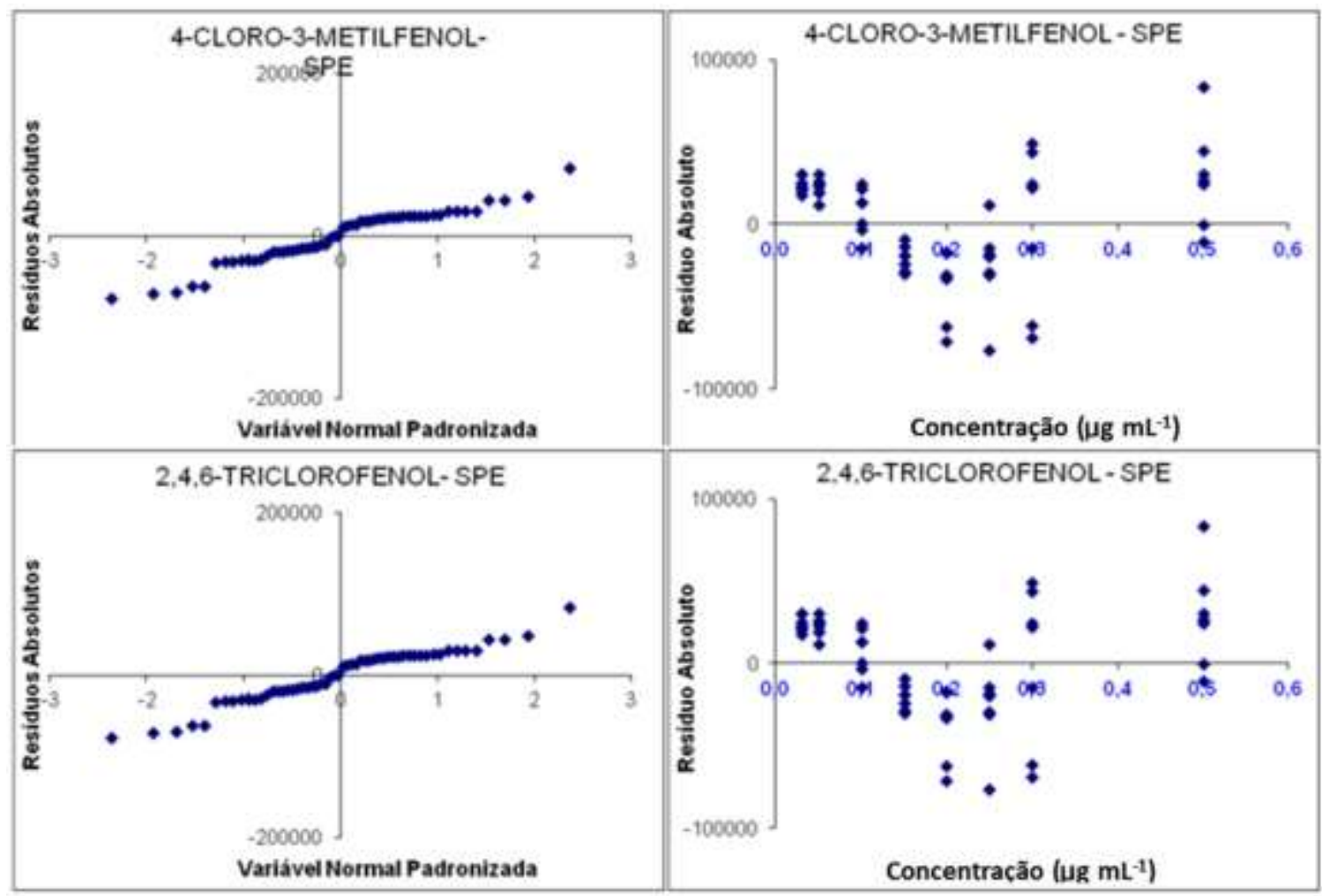

Figura 29. Gráficos dos resíduos normalizados e absolutos para os compostos 4-cloro-3-metilfenol e 2,4,6-triclorofenol no ensaio com matriz do método SPE. 


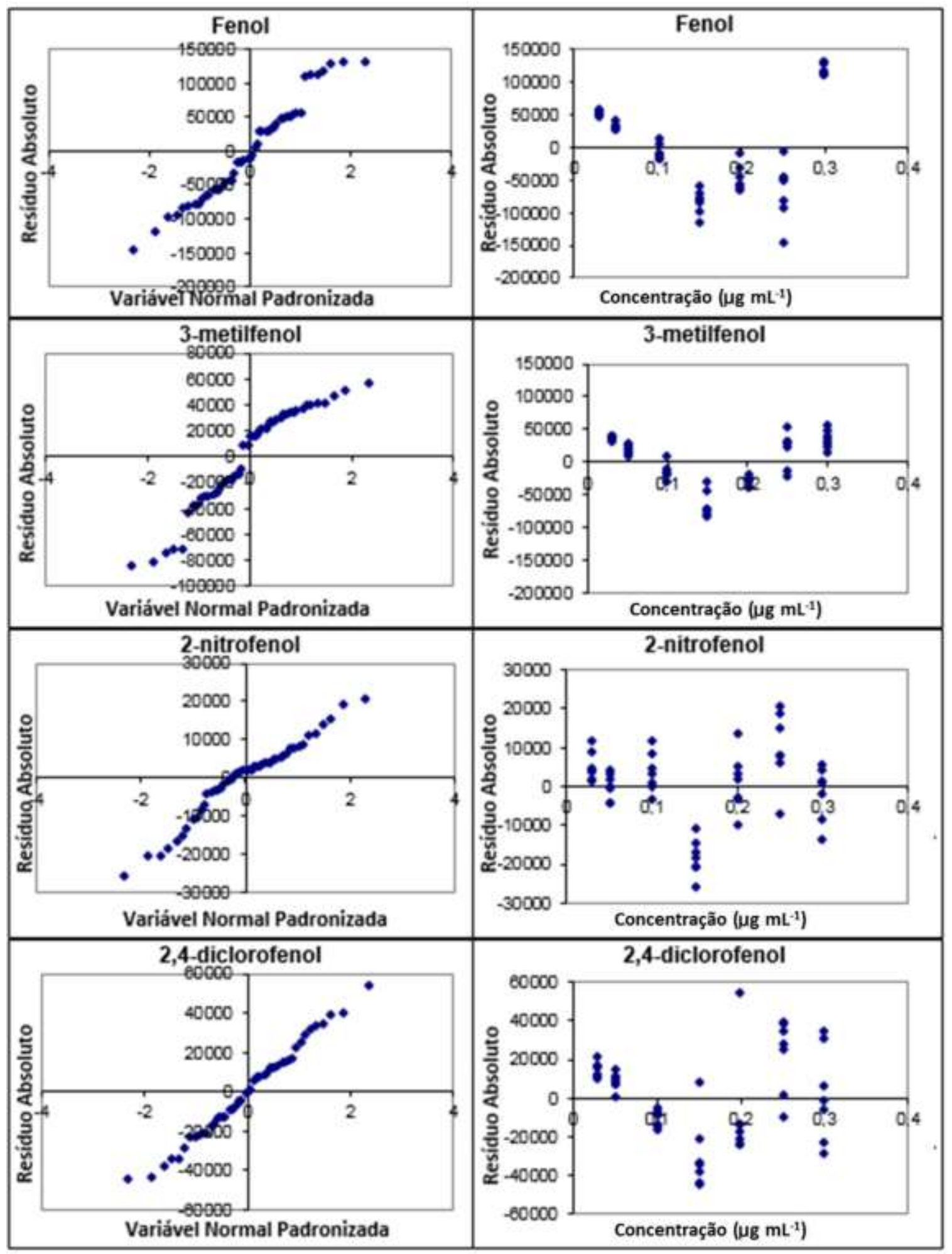

Figura 30. Gráficos dos resíduos normalizados e absolutos para os compostos fenol, 3-metilfenol, 2-nitrofenol e 2,4-diclorofenol no ensaio sem matriz. 


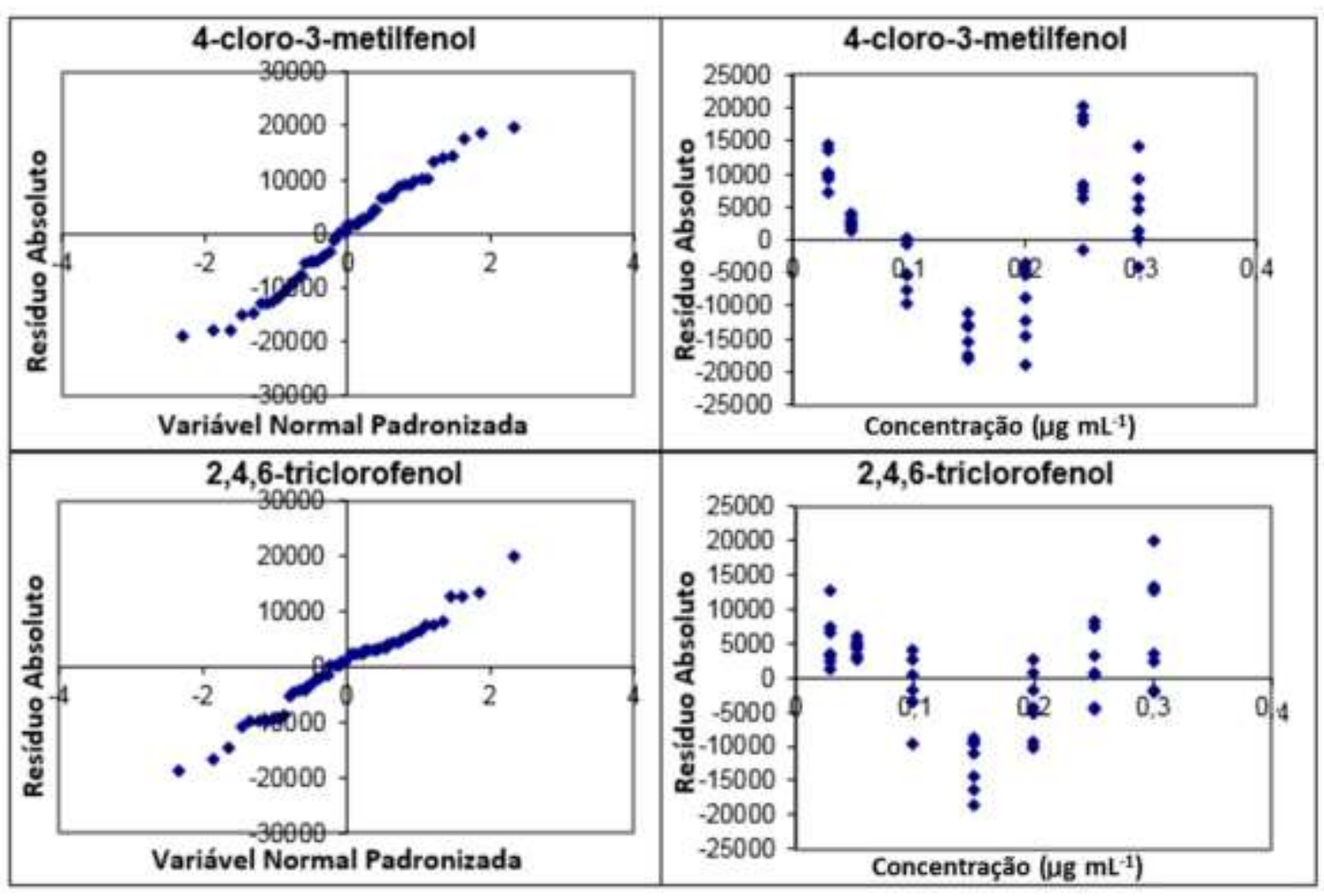

Figura 31. Gráficos dos resíduos normalizados e absolutos para os compostos 4-cloro-3-metilfenol e 2,4,6-triclorofenol no ensaio sem matriz.

Nos gráficos de resíduos nos três ensaios, para todos os compostos estudados, pode-se observar uma maior flutuação, seja positiva ou negativa, nas concentrações mais altas, embora esses valores não ultrapassem $15 \%$ da área total. Pela análise do gráfico de probabilidade normalizada nota-se que a maioria dos pontos está distribuída no intervalo de -2 a +2 , ou seja, dentro de \pm 2 desvios padrão, com 95\% de confiança. Observa-se ainda, que a distribuição se aproxima de uma reta, sem grandes tendências que depreciem o comportamento linear.

Além da avaliação da linearidade pelos resíduos, foi também utilizada a análise de variância (ANOVA), como recomendado pelo Guia de Validação do INMETRO cujos resultados são apresentados nas TAB. 20 e 21. A partir do teste $F$ de regressão é avaliado se a adequação do modelo adotado aos dados obtidos é significativa, mostrando se o modelo linear se ajusta ao conjunto de dados obtidos, considerando $95 \%$ de confiança. $A$ análise do teste $F$ de ajuste permite verificar o quanto esse modelo se ajusta ao conjunto de dados obtidos, considerando o mesmo limite de confiança. Ainda foi avaliada a porcentagem de variação explicada 
em relação à porcentagem máxima de variação explicável, ou seja, o quanto de variação pôde ser explicada dentro da porcentagem explicável pelo ajuste aplicado ao método (Furusawa, 2007; Otomo, 2010; INMETRO, 2011).

Tabela 20. Valores de coeficiente de determinação e resultados do teste $F$ de regressão e de ajuste, porcentagem de variação explicada e máxima variação explicável para avaliação da linearidade do método final.

\begin{tabular}{|c|c|c|c|c|}
\hline \multirow[b]{2}{*}{ Composto } & \multicolumn{2}{|c|}{$F_{\text {calculado }}$} & \multirow{2}{*}{$\begin{array}{c}\text { \% de } \\
\text { variação } \\
\text { explicada }\end{array}$} & \multirow{2}{*}{$\begin{array}{c}\text { \% máxima de } \\
\text { variação } \\
\text { explicável } \\
\end{array}$} \\
\hline & $\begin{array}{c}\text { Regressão } \\
\mathrm{F}_{1,14,95 \% \text { tab. }}=4,49\end{array}$ & $\begin{array}{c}\text { Ajuste } \\
F_{6,8,95 \% \text { tab }=3,29}\end{array}$ & & \\
\hline Fenol & 1105 & 6,97 & 98 & 100 \\
\hline 3-metilfenol & 583 & 6,75 & 97 & 99 \\
\hline 2-nitrofenol & 354 & 70,62 & 96 & 100 \\
\hline 2,4-diclorofenol & 497 & 7,18 & 97 & 99 \\
\hline 4-cloro-3-metilfenol & 911 & 1,72 & 98 & 99 \\
\hline 2,4,6-triclorofenol & 510 & 2,15 & 97 & 99 \\
\hline
\end{tabular}

Tabela 21. Valores de coeficiente de determinação e resultados do teste $F$ de regressão e de ajuste, porcentagem de variação explicada e máxima variação explicável para avaliação da linearidade do método SPE.

\begin{tabular}{|c|c|c|c|c|}
\hline \multirow[b]{2}{*}{ Composto } & \multicolumn{2}{|c|}{$F_{\text {calculado }}$} & \multirow{2}{*}{$\begin{array}{c}\text { \% de } \\
\text { variação } \\
\text { explicada }\end{array}$} & \multirow{2}{*}{$\begin{array}{c}\text { \% máxima } \\
\text { de variação } \\
\text { explicável }\end{array}$} \\
\hline & $\begin{array}{c}\text { Regressão } \\
F_{2,13,95 \% \text { tab. }}=3,81\end{array}$ & $\begin{array}{c}\text { Ajuste } \\
\mathrm{F}_{5,8,95 \% \text { tab }=3,69}\end{array}$ & & \\
\hline Fenol & 450 & 50,02 & 99 & 100 \\
\hline 3-metilfenol & 484 & 99,83 & 99 & 100 \\
\hline 2-nitrofenol & 230 & 70,55 & 97 & 100 \\
\hline 2,4-diclorofenol & 323 & 18,30 & 98 & 100 \\
\hline 4-cloro-3-metilfenol & 229 & 25,95 & 97 & 100 \\
\hline 2,4,6-triclorofenol & 778 & 15,43 & 99 & 100 \\
\hline
\end{tabular}

De acordo com os resultados obtidos pelo teste de regressão, a regressão foi significativa para todos os compostos, uma vez que os valores de $F$ calculados foram superiores ao valor $F$ Tabelado $\left(F_{\text {tab }}=4,49\right)$, o que significa que para o modelo de regressão adotado, os dados obtidos possuem comportamento linear. 
Os resultados do teste de ajuste mostram que houve falta de ajuste para quatro dos seis compostos estudados no método final, com valores de $F_{\text {calculado }}>F_{\text {Tabelado }}\left(F_{\text {tab }}=3,29\right)$, indicando uma maior dispersão dos pontos ou que apesar da equação ser adequada, existem pontos fora da curva. Porém, os resultados da porcentagem de variação explicada foram próximos aos valores de porcentagem de variação explicável, além de terem permanecido acima de $90 \%$, demonstrando que as variações foram explicadas satisfatoriamente pelo modelo de regressão adotado e o mesmo se ajusta aos dados.

Na FIG. 32 são apresentados os intervalos de confiança para cada composto nas faixas de trabalho consideradas no método final e na FIG. 33 os intervalos de confiança do método SPE, sendo os resultados que se encontram dentro desta faixa considerados estatisticamente aceitáveis.

Como pode ser observado para todos os compostos, perde-se confiança nos resultados no limite superior da curva, onde os limites se afastam da média proposta pela curva analítica, portanto deve-se estabelecer nova curva mais próxima a esses limites quando for necessária a quantificação nesses intervalos. Para os compostos 2-nitrofenol e 2,4-diclorofenol no método final, os limites são mais afastados do que para os demais compostos em praticamente toda a faixa de trabalho. Isso ocorre devido à dificuldade de se trabalhar com esses dois compostos, portanto a incerteza para estes é maior e qualquer concentração quando comparados aos demais compostos estudados, devendo-se ter um maior critério na avaliação para que não sejam considerados falsos positivos. 

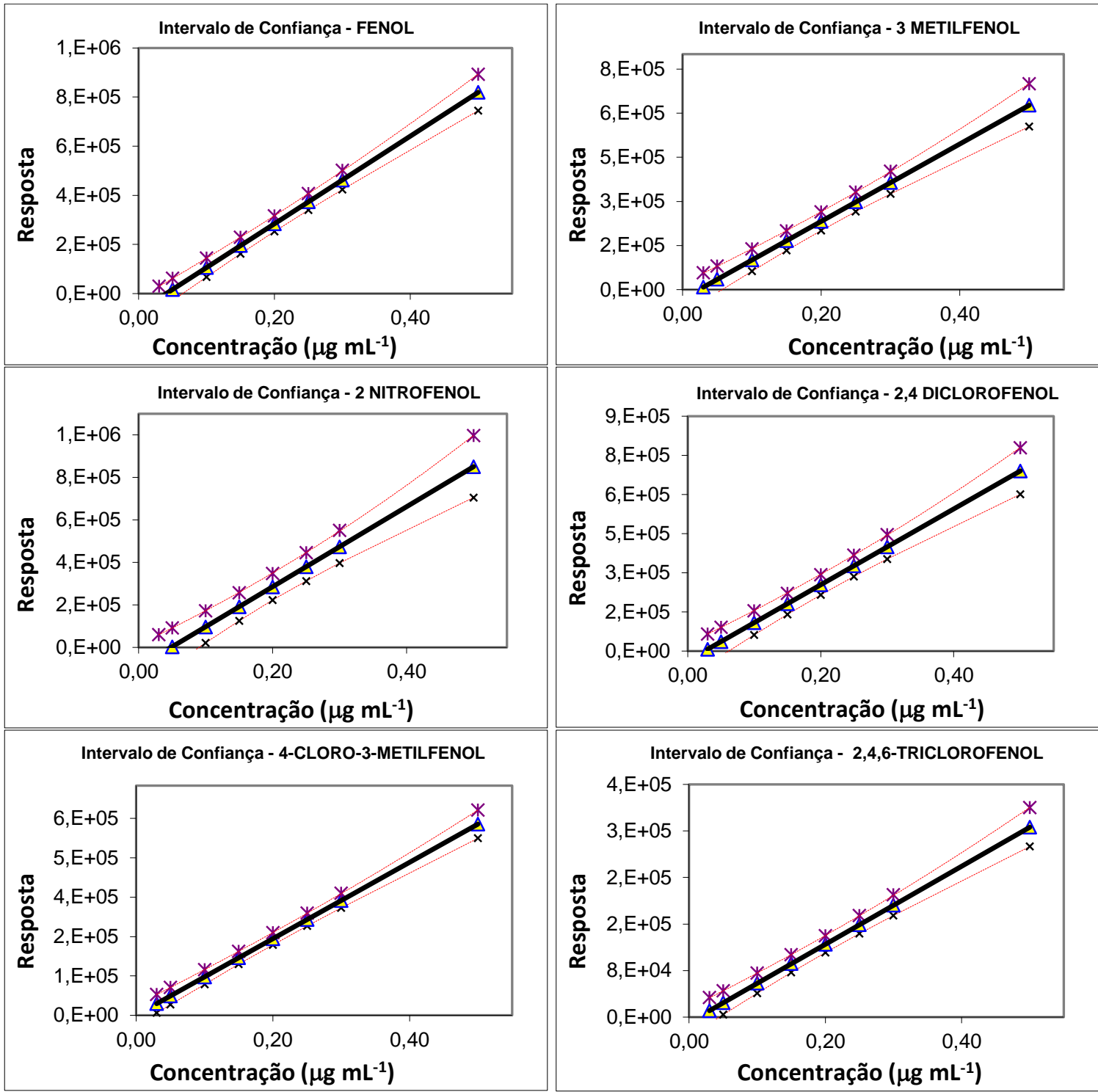

Figura 32. Gráficos da faixa de intervalo de confiança no ensaio com matriz para os seis compostos estudados na faixa de trabalho considerada do método final. 

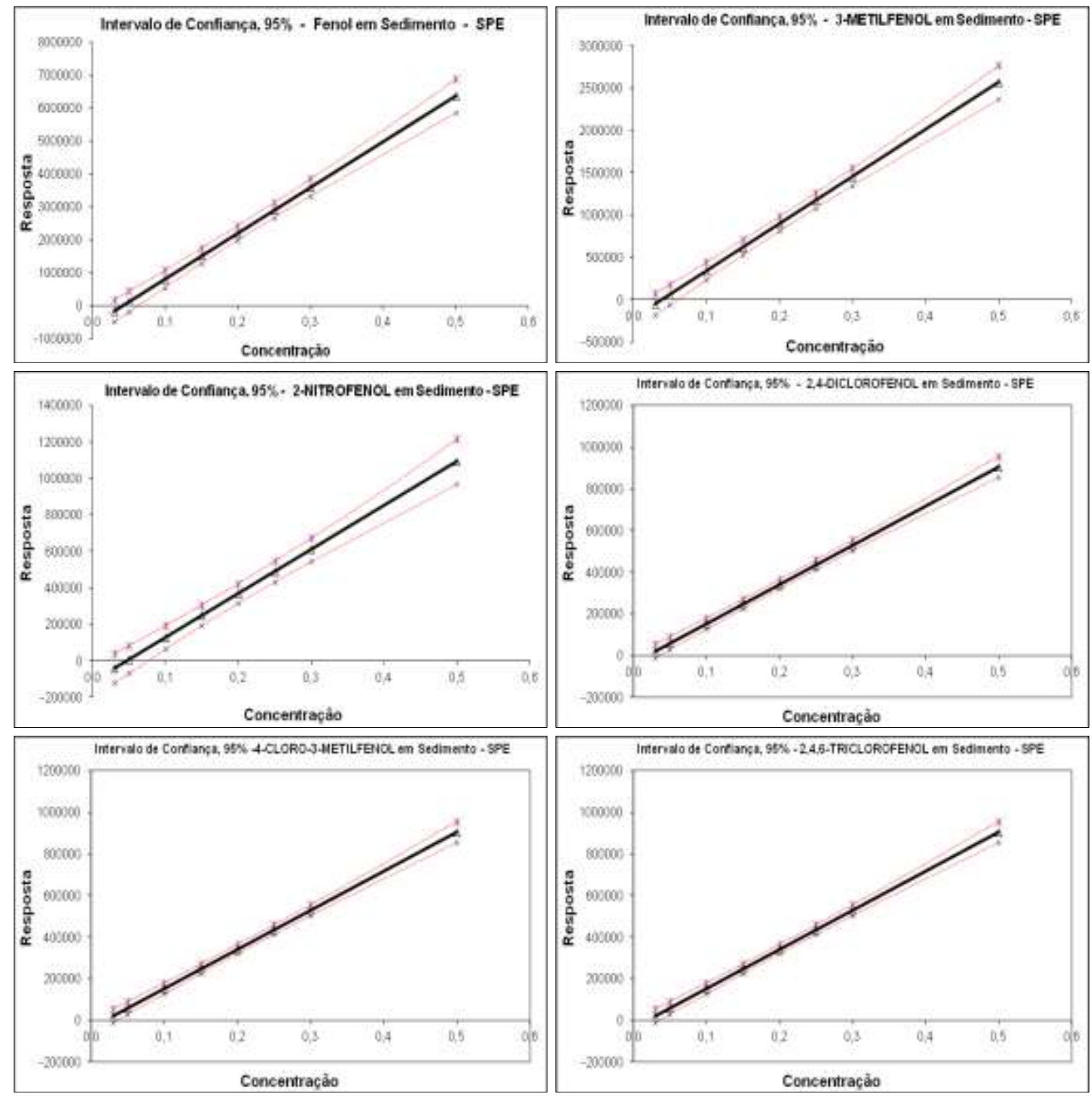

Figura 33. Gráficos da faixa de intervalo de confiança no ensaio com matriz para os seis compostos estudados na faixa de trabalho considerada do método SPE.

Considerando-se todos os estudos estatísticos utilizados para avaliar este parâmetro, observou-se que ambos os métodos apresentaram linearidade satisfatória para todos os compostos estudados.

\subsection{Limite de detecção e Limite de quantificação}

Na TAB. 22 estão apresentados os valores de LD e LQ obtidos para cada composto para o método final e na TAB. 23 estão apresentados os valores de LD 
e LQ para o método SPE, sendo que cada um apresenta sensibilidade distinta no equipamento.

Tabela 22. Limites de detecção e limites de quantificação dos compostos avaliados no método final.

\begin{tabular}{ccc}
\hline Composto & $\mathrm{LD}\left(\mu \mathrm{g} \mathrm{g}^{-1}\right)$ & $\mathrm{LQ}\left(\mu \mathrm{g} \mathrm{g}^{-1}\right)$ \\
\hline Fenol & 0,020 & 0,081 \\
3-metilfenol & 0,012 & 0,069 \\
2-nitrofenol & 0,021 & 0,081 \\
2,4-diclorofenol & 0,008 & 0,056 \\
4-cloro-3-metilfenol & 0,026 & 0,085 \\
2,4,6-triclorofenol & 0,010 & 0,049 \\
\hline
\end{tabular}

Tabela 23. Limites de detecção e limites de quantificação dos compostos avaliados no método SPE.

\begin{tabular}{ccc}
\hline Composto & $\mathrm{LD}\left(\mu \mathrm{g} \mathrm{g}^{-1}\right)$ & $\mathrm{LQ}\left(\mu \mathrm{g} \mathrm{g}^{-1}\right)$ \\
\hline Fenol & 0,003 & 0,038 \\
3-metilfenol & 0,003 & 0,035 \\
2-nitrofenol & 0,004 & 0,037 \\
2,4-diclorofenol & 0,025 & 0,078 \\
4-cloro-3-metilfenol & 0,005 & 0,043 \\
2,4,6-triclorofenol & 0,005 & 0,046 \\
\hline
\end{tabular}

\subsection{Exatidão e Tendência}

Os valores de z Score obtidos no ensaio com matriz no método final e no método SPE estão apresentados nas TAB. 24 e 25, demonstrando que todos os valores estão dentro do limite satisfatório, com exceção do 2,4-diclorofenol no método final e 2,4,6-triclorofenol no método SPE, ambos para baixas concentrações. 
Tabela 24. Valores de z Score obtidos para cada um dos compostos em ensaio com matriz no método final.

\begin{tabular}{cccc}
\hline \multirow{2}{*}{ Composto } & \multicolumn{3}{c}{ Valores de z Score nas } \\
& Baixa & Média & Alta \\
\cline { 2 - 4 } & 1,22 & 0,28 & 0,04 \\
Fenol & 0,31 & 0,33 & 0,20 \\
3-metilfenol & 1,06 & 0,08 & 0,83 \\
2-nitrofenol & 3,22 & 0,78 & 0,01 \\
2,4-diclorofenol & 1,32 & 0,02 & 0,15 \\
4-cloro-3-metilfenol & 1,02006 & 0,35 \\
2,4,6-triclorofenol & 0,70 & 0,06 &
\end{tabular}

Tabela 25. Valores de z Score obtidos para cada um dos compostos em ensaio com matriz no método SPE.

\begin{tabular}{cccc}
\hline & \multicolumn{3}{c}{ Valores de $z$ Score nas concentrações: } \\
\cline { 2 - 4 } Composto & Baixa & Média & Alta \\
\hline Fenol & 0,89 & 0,28 & 0,39 \\
3-metilfenol & 0,96 & 0,85 & 0,31 \\
2-nitrofenol & 0,49 & 0,49 & 0,52 \\
2,4-diclorofenol & 0,29 & 2,32 & 0,37 \\
4-cloro-3-metilfenol & 1,25 & 1,32 & 0,4 \\
2,4,6-triclorofenol & 2,34 & 0,65 & 0,93 \\
\hline
\end{tabular}

\subsection{Precisão}

Este parâmetro foi avaliado por meio do coeficiente de variação e dos valores de limite de repetitividade e limite de reprodutibilidade, a partir de 7 replicatas de três níveis de concentrações (baixa, média e alta) para cada um dos compostos.

Nas TAB. 26 e 27 são expressos os coeficientes de variação (CV) de sete replicatas para os compostos estudados, em três níveis de concentrações, nos ensaios com matriz de extrato de sedimento no método final e no método SPE. 
Praticamente todos os compostos apresentaram coeficiente de variação abaixo de $20 \%$, porcentagem máxima de referência para análise de traços (Ribani, 2004).

Tabela 26. Coeficientes de variação (CV \%) para os compostos em três níveis de concentração no ensaio com matriz de extrato de sedimento no método final.

\begin{tabular}{cccc}
\hline \multirow{2}{*}{ Composto } & \multicolumn{3}{c}{ Coeficiente de Variação (\%) } \\
& Baixa & Média & Alta \\
\hline Fenol & 8 & 6 & 5 \\
3-metilfenol & 9 & 0 & 4 \\
2-nitrofenol & 6 & 6 & 6 \\
2,4-diclorofenol & 17 & 16 & 8 \\
4-cloro-3-metilfenol & 6 & 9 & 8 \\
2,4,6-triclorofenol & 8 & 5 & 4 \\
\hline
\end{tabular}

Tabela 27. Coeficientes de variação (CV \%) para os compostos em três níveis de concentração no ensaio com matriz de extrato de sedimento no método SPE.

\begin{tabular}{cccc}
\hline \multirow{2}{*}{ Composto } & \multicolumn{3}{c}{ Coeficiente de Variação (\%) } \\
& Baixa & Média & Alta \\
\hline Fenol & 4 & 1 & 3 \\
3-metilfenol & 4 & 6 & 4 \\
2-nitrofenol & 10 & 8 & 3 \\
2,4-diclorofenol & 28 & 6 & 6 \\
4-cloro-3-metilfenol & 8 & 4 & 6 \\
2,4,6-triclorofenol & 9 & 3 & 3 \\
\hline
\end{tabular}

Nas TAB. 28 e 29 são apresentados os limites de repetitividade (r) para cada composto nas soluções das concentrações consideradas, bem como as médias dos desvios padrão entre as replicatas. 
Tabela 28. Valores do limite de repetitividade (r) para os compostos em três níveis de concentração no ensaio com matriz no método final.

\begin{tabular}{|c|c|c|c|c|}
\hline \multirow{3}{*}{ Fenol } & $\mu \mathrm{g} \mathrm{mL}^{-1}$ & 0,15 & 0,20 & 0,25 \\
\hline & $\bar{S}_{\text {replicatas }}$ & 0,010 & 0,010 & 0,010 \\
\hline & $r$ & 0,028 & 0,028 & 0,028 \\
\hline \multirow{3}{*}{ 3-metilfenol } & $\mu \mathrm{g} \mathrm{mL}^{-1}$ & 0,15 & 0,20 & 0,25 \\
\hline & $\bar{S}_{\text {replicatas }}$ & 0,010 & 0,000 & 0,010 \\
\hline & $r$ & 0,028 & 0,000 & 0,028 \\
\hline \multirow{3}{*}{ 2-nitrofenol } & $\mu \mathrm{g} \mathrm{mL}^{-1}$ & 0,15 & 0,20 & 0,25 \\
\hline & $\bar{S}_{\text {replicatas }}$ & 0,007 & 0,012 & 0,015 \\
\hline & $r$ & 0,021 & 0,033 & 0,041 \\
\hline \multirow{3}{*}{ 2,4-diclorofenol } & $\mu \mathrm{g} \mathrm{mL}^{-1}$ & 0,15 & 0,20 & 0,25 \\
\hline & $\bar{S}_{\text {replicatas }}$ & 0,020 & 0,030 & 0,021 \\
\hline & $r$ & 0,055 & 0,084 & 0,058 \\
\hline \multirow{3}{*}{ 4-cloro-3-metilfenol } & $\mu \mathrm{g} \mathrm{mL}^{-1}$ & 0,15 & 0,20 & 0,25 \\
\hline & $\bar{S}_{\text {replicatas }}$ & 0,007 & 0,015 & 0,021 \\
\hline & $r$ & 0,019 & 0,041 & 0,058 \\
\hline \multirow{3}{*}{ 2,4,6-triclorofenol } & $\mu \mathrm{g} \mathrm{mL}^{-1}$ & 0,15 & 0,20 & 0,25 \\
\hline & $\bar{S}_{\text {replicatas }}$ & 0,010 & 0,010 & 0,010 \\
\hline & $r$ & 0,028 & 0,028 & 0,028 \\
\hline
\end{tabular}


Tabela 29. Valores do limite de repetitividade ( $r$ ) para os compostos em três níveis de concentração no ensaio com matriz no método SPE.

\begin{tabular}{|c|c|c|c|c|}
\hline \multirow{3}{*}{ Fenol } & $\mu g \mathrm{~mL}^{-1}$ & 0,03 & 0,15 & 0,5 \\
\hline & S replicatas & 0,003 & 0,021 & 0,060 \\
\hline & $r$ & 0,008 & 0,058 & 0,167 \\
\hline \multirow{3}{*}{ 3-metilfenol } & $\mu \mathrm{g} \mathrm{mL}^{-1}$ & 0,15 & 0,20 & 0,25 \\
\hline & S replicatas & 0,010 & 0,000 & 0,010 \\
\hline & r & 0,028 & 0,000 & 0,028 \\
\hline \multirow{3}{*}{ 2-nitrofenol } & $\mu \mathrm{g} \mathrm{mL}^{-1}$ & 0,15 & 0,20 & 0,25 \\
\hline & S replicatas & 0,008 & 0,032 & 0,064 \\
\hline & $r$ & 0,021 & 0,091 & 0,180 \\
\hline \multirow{3}{*}{ 2,4-diclorofenol } & $\mu \mathrm{g} \mathrm{mL}^{-1}$ & 0,15 & 0,20 & 0,25 \\
\hline & S replicatas & 0,022 & 0,025 & 0,121 \\
\hline & $r$ & 0,062 & 0,070 & 0,338 \\
\hline \multirow{3}{*}{ 4-cloro-3-metilfenol } & $\mu \mathrm{g} \mathrm{mL}^{-1}$ & 0,15 & 0,20 & 0,25 \\
\hline & S replicatas & 0,007 & 0,018 & 0,144 \\
\hline & $r$ & 0,019 & 0,051 & 0,404 \\
\hline \multirow{3}{*}{ 2,4,6-triclorofenol } & $\mu \mathrm{g} \mathrm{mL}^{-1}$ & 0,15 & 0,20 & 0,25 \\
\hline & S replicatas & 0,011 & 0,016 & 0,066 \\
\hline & r & 0,029 & 0,045 & 0,184 \\
\hline
\end{tabular}

Nas TAB. 30 e 31 são apresentados os limites de reprodutibilidade (R) para cada composto nas soluções das concentrações consideradas, assim como as médias dos desvios padrão entre as replicatas. 
Tabela 30. Valores do limite de reprodutibilidade $(R)$ para os compostos em três níveis de concentração no ensaio com matriz no método final.

\begin{tabular}{|c|c|c|c|c|}
\hline \multirow{3}{*}{ Fenol } & $\mu \mathrm{g} \mathrm{mL}^{-1}$ & 0,15 & 0,20 & 0,25 \\
\hline & $\bar{S}_{\text {replicatas }}$ & 0,054 & 0,043 & 0,052 \\
\hline & $\mathrm{R}$ & 0,153 & 0,120 & 0,147 \\
\hline \multirow{3}{*}{ 3-metilfenol } & $\mu \mathrm{g} \mathrm{mL}^{-1}$ & 0,15 & 0,20 & 0,25 \\
\hline & $\bar{S}_{\text {replicatas }}$ & 0,013 & 0,010 & 0,006 \\
\hline & $\mathrm{R}$ & 0,036 & 0,027 & 0,018 \\
\hline \multirow{3}{*}{ 2-nitrofenol } & $\mu \mathrm{g} \mathrm{mL}^{-1}$ & 0,15 & 0,20 & 0,25 \\
\hline & $\bar{S}_{\text {replicatas }}$ & 0,014 & 0,017 & 0,015 \\
\hline & $\mathrm{R}$ & 0,040 & 0,047 & 0,042 \\
\hline \multirow{3}{*}{ 2,4-diclorofenol } & $\mu \mathrm{g} \mathrm{mL}^{-1}$ & 0,15 & 0,20 & 0,25 \\
\hline & $\bar{S}_{\text {replicatas }}$ & 0,009 & 0,009 & 0,011 \\
\hline & $\mathrm{R}$ & 0,024 & 0,025 & 0,030 \\
\hline \multirow{3}{*}{ 4-cloro-3-metilfenol } & $\mu g \mathrm{~mL}^{-1}$ & 0,15 & 0,20 & 0,25 \\
\hline & $\bar{S}_{\text {replicatas }}$ & 0,157 & 0,090 & 0,103 \\
\hline & $\mathrm{R}$ & 0,438 & 0,251 & 0,289 \\
\hline \multirow{3}{*}{ 2,4,6-triclorofenol } & $\mu \mathrm{g} \mathrm{mL^{-1 }}$ & 0,15 & 0,20 & 0,25 \\
\hline & $\bar{S}_{\text {replicatas }}$ & 0,004 & 0,003 & 0,007 \\
\hline & $\mathrm{R}$ & 0,010 & 0,009 & 0,019 \\
\hline
\end{tabular}


Tabela 31. Valores do limite de reprodutibilidade (R) para os compostos em três níveis de concentração no ensaio com matriz no método SPE.

\begin{tabular}{ccccc}
\hline \multirow{3}{*}{ Fenol } & $\mu \mathrm{g} \mathrm{mL}^{-1}$ & 0,03 & 0,15 & 0,50 \\
\cline { 2 - 5 } & $\mathrm{S}_{\text {replicatas }}$ & 0,002 & 0,001 & 0,043 \\
& $\mathrm{R}$ & 0,006 & 0,004 & 0,121 \\
\hline \multirow{3}{*}{ 3-metilfenol } & $\mu \mathrm{g} \mathrm{mL}^{-1}$ & 0,15 & 0,20 & 0,25 \\
\cline { 2 - 5 } & $\mathrm{S}_{\text {replicatas }}$ & 0,002 & 0,014 & 0,036 \\
& $\mathrm{R}$ & 0,006 & 0,038 & 0,101 \\
\hline \multirow{3}{*}{ 2-nitrofenol } & $\mu \mathrm{g} \mathrm{mL}^{-1}$ & 0,15 & 0,20 & 0,25 \\
\cline { 2 - 5 } & $\mathrm{S}_{\text {replicatas }}$ & 0,004 & 0,015 & 0,036 \\
& $\mathrm{R}$ & 0,010 & 0,042 & 0,100 \\
\hline \multirow{3}{*}{ 2,4-diclorofenol } & $\mu \mathrm{g} \mathrm{mL}-1$ & 0,15 & 0,20 & 0,25 \\
\cline { 2 - 5 } & $\mathrm{S}_{\text {replicatas }}$ & 0,011 & 0,011 & 0,064 \\
& $\mathrm{R}$ & 0,030 & 0,032 & 0,180 \\
\hline & $\mu \mathrm{g} \mathrm{mL}-1$ & 0,15 & 0,20 & 0,25 \\
\cline { 2 - 5 } & $\mathrm{S}_{\text {replicatas }}$ & 0,005 & 0,009 & 0,101 \\
& $\mathrm{R}$ & 0,014 & 0,024 & 0,282 \\
\hline \multirow{3}{*}{ 2,4,6-triclorofenol 3-metilfenol } & $\mu \mathrm{g} \mathrm{mL}{ }^{-1}$ & 0,15 & 0,20 & 0,25 \\
\cline { 2 - 5 } & $\mathrm{S}_{\text {replicatas }}$ & 0,007 & 0,007 & 0,017 \\
& $\mathrm{R}$ & 0,020 & 0,019 & 0,047 \\
\hline
\end{tabular}

Avaliando os resultados obtidos, para todos os compostos a média do desvio padrão das replicatas foi menor que os limites de repetibilidade e reprodutibilidade calculados e a diferença entre as replicatas não foi maior que os limites estabelecidos para nenhum dos compostos. Portanto pode-se considerar que o método é preciso (Ribani, 2004; Furusawa, 2007).

\subsection{Recuperação}

Foram adicionadas três concentrações do padrão na matriz antes da extração, seguida pela determinação da concentração do analito adicionado após todas as etapas do método. Para considerar o método adequado à análise proposta a recuperação deve estar na faixa de 70 a $120 \%$, com precisão em torno de $20 \%$, 
ou ainda entre 50 e 120\%, com precisão em torno de 15\% quando matriz é complexa (Ribani, 2004; Furusawa, 2007; INMETRO, 2011).

Os valores de recuperação obtidos no método final se encontraram na faixa de 70 a 100\% indicando uma adequada recuperação do método desenvolvido, como se pode observar nas TAB. 32, 33, 34, para as concentrações baixa, média e alta respectivamente.

Tabela 32. Valores de recuperação obtidos para concentração baixa no método final.

\begin{tabular}{cccc}
\hline Compostos & $\begin{array}{c}\text { Concentração } \\
\text { adicionada } \\
\mu g^{-1}\end{array}$ & $\begin{array}{c}\text { Concentração } \\
\text { recuperada } \\
\mu g g^{-1}\end{array}$ & $\begin{array}{c}\text { Recuperação } \\
\%\end{array}$ \\
\hline Fenol & 0,0495 & 0,0429 & 87 \\
3-metilfenol & 0,0495 & 0,0460 & 93 \\
2-nitrofenol & 0,0490 & 0,0426 & 87 \\
2,4-diclorofenol & 0,0495 & 0,0490 & 99 \\
4-cloro-3-metilfenol & 0,0495 & 0,0407 & 82 \\
2,4,6-triclorofenol & 0,0490 & 0,0404 & 82 \\
\hline
\end{tabular}

Tabela 33. Valores de recuperação obtidos para concentração média no método final.

\begin{tabular}{cccc}
\hline Compostos & $\begin{array}{c}\text { Concentração } \\
\text { adicionada } \\
\mu g g^{-1}\end{array}$ & $\begin{array}{c}\text { Concentração } \\
\text { recuperada } \\
\mu g ~ g^{-1}\end{array}$ & $\begin{array}{c}\text { Recuperação } \\
\%\end{array}$ \\
\hline Fenol & 0,0990 & 0,0933 & 94 \\
3-metilfenol & 0,0990 & 0,0965 & 97 \\
2-nitrofenol & 0,0980 & 0,0814 & 83 \\
2,4-diclorofenol & 0,0990 & 0,0997 & 100 \\
4-cloro-3-metilfenol & 0,0990 & 0,0912 & 92 \\
2,4,6-triclorofenol & 0,0980 & 0,0966 & 99 \\
\hline
\end{tabular}


Tabela 34. Valores de recuperação obtidos para concentração alta no método final.

\begin{tabular}{cccc}
\hline Compostos & $\begin{array}{c}\text { Concentração } \\
\text { adicionada } \\
\mu g^{-1}\end{array}$ & $\begin{array}{c}\text { Concentração } \\
\text { recuperada } \\
\mu g^{-1}\end{array}$ & $\begin{array}{c}\text { Recuperação } \\
\%\end{array}$ \\
\hline Fenol & 0,1980 & 0,1460 & 74 \\
3-metilfenol & 0,1980 & 0,1803 & 91 \\
2-nitrofenol & 0,1960 & 0,1714 & 87 \\
2,4-diclorofenol & 0,1980 & 0,1853 & 94 \\
4-cloro-3-metilfenol & 0,1980 & 0,1800 & 91 \\
2,4,6-triclorofenol & 0,1960 & 0,1831 & 93 \\
\hline
\end{tabular}

Os valores de recuperação obtidos no método SPE por sua vez, se encontraram na faixa de 10 a $90 \%$ indicando que a recuperação para o método proposto é baixa para alguns dos compostos, principalmente em maiores concentrações. Porém para os compostos 2,4-diclorofenol, 4-cloro-3-metilfenol e 2,4,6-triclorofenol as recuperações estão acima de 50\%, mostrando que o método é adequado para a quantificação destes compostos. Nas TAB. 35, 36, 37, podem ser observados os resultados de recuperação no método SPE para as concentrações baixa, média e alta respectivamente.

Tabela 35. Valores de recuperação obtidos para concentração baixa no método SPE.

\begin{tabular}{cccc}
\hline Compostos & $\begin{array}{c}\text { Concentração } \\
\text { adicionada } \\
\mu g^{-1}\end{array}$ & $\begin{array}{c}\text { Concentração } \\
\text { recuperada } \\
\mu g^{-1}\end{array}$ & $\begin{array}{c}\text { Recuperação } \\
\%\end{array}$ \\
\hline Fenol & 0,05 & 0,0457 & 91 \\
3-metilfenol & 0,05 & 0,0297 & 59 \\
2-nitrofenol & 0,05 & 0,0444 & 88 \\
2,4-diclorofenol & 0,05 & 0,0251 & 50 \\
4-cloro-3-metilfenol & 0,05 & 0,0351 & 70 \\
2,4,6-triclorofenol & 0,05 & 0,0286 & 57 \\
\hline
\end{tabular}


Tabela 36. Valores de recuperação obtidos para concentração média no método SPE.

\begin{tabular}{cccc}
\hline Compostos & $\begin{array}{c}\text { Concentracaão } \\
\text { adicionada } \\
\mu g^{-1}\end{array}$ & $\begin{array}{c}\text { Concentração } \\
\text { recuperada } \\
\mu g^{-1}\end{array}$ & $\begin{array}{c}\text { Recuperação } \\
\%\end{array}$ \\
\hline Fenol & 0,2 & 0,3456 & 34 \\
3-metilfenol & 0,2 & 0,0527 & 26 \\
2-nitrofenol & 0,2 & 0,0678 & 33 \\
2,4-diclorofenol & 0,2 & 0,1312 & 65 \\
4-cloro-3-metilfenol & 0,2 & 0,1342 & 67 \\
2,4,6-triclorofenol & 0,2 & 0,1052 & 52 \\
\hline
\end{tabular}

Tabela 37. Valores de recuperação obtidos para concentração alta no método SPE.

\begin{tabular}{cccc}
\hline Compostos & $\begin{array}{c}\text { Concentração } \\
\text { adicionada } \\
\mu g g^{-1}\end{array}$ & $\begin{array}{c}\text { Concentração } \\
\text { recuperada } \\
\mu g^{-1}\end{array}$ & $\begin{array}{c}\text { Recuperação } \\
\%\end{array}$ \\
\hline Fenol & 0,5 & 0,2178 & 22 \\
3-metilfenol & 0,5 & 0,0827 & 16 \\
2-nitrofenol & 0,5 & 0,1269 & 25 \\
2,4-diclorofenol & 0,5 & 0,2080 & 42 \\
4-cloro-3-metilfenol & 0,5 & 0,2762 & 55 \\
2,4,6-triclorofenol & 0,5 & 0,2856 & 57 \\
\hline
\end{tabular}

Conforme já citado no item 8.6.2 desta dissertação, a partir desse resultado dos ensaios de recuperação, concluiu-se de que a metodologia de extração inicialmente desenvolvida utilizando cartuchos SPE $C_{18}$ não foi satisfatória para os compostos Fenol, 3-metilfenol, 2-nitrofenol e 2,4-diclorofenol. O procedimento experimental foi então reavaliado ao longo de testes sucessivos. Foram feitos novos estudos para purificação do extrato utilizando-se duplo cartucho SPE $C_{18}$, cartuchos Stracta-x e apenas filtração a vácuo da amostra com membrana $0,45 \mu \mathrm{m}$. 
Observou-se que tanto a secagem do extrato sob fluxo contínuo de $\mathrm{N}_{2}$ como a forte adsorção desses compostos no material absorvente dos cartuchos, influenciam na recuperação dos analitos, gerando baixa recuperação nos resultados. Provavelmente a grande volatilidade e baixa sensibilidade destes três compostos pode ter contribuído para esses resultados baixos de recuperação. Após a avaliação de todos os resultados deste estudo, optou-se pela utilização do sistema de filtração a vácuo com membrana PTFE 0,45 $\mu \mathrm{m}$ na etapa de purificação, mesmo gerando um extrato menos puro.

Embora a metodologia final tenha sido definida para todos os compostos, nos casos onde se tenha uma amostra que necessite de uma maior purificação, a metodologia inicialmente proposta com uso de cartuchos SPE pode ser utilizada para os compostos 4-cloro-3-metilfenol e 2,4,6-triclorofenol, com boa seletividade, linearidade, precisão, exatidão e limites de quantificação menores, visto que o extrato é mais puro.

\subsection{Robustez}

O ensaio de robustez foi realizado com auxílio dos cálculos da planilha elaborada por Furusawa (2007), que segue a metodologia proposta por Vander Heyden et al. (2001).

Na FIG. 34 são apresentados os gráficos dos efeitos para os seis compostos estudados no ensaio com matriz no método final, onde é possível avaliar a influência positiva ou negativa que cada parâmetro tem sobre cada composto estudado individualmente. 


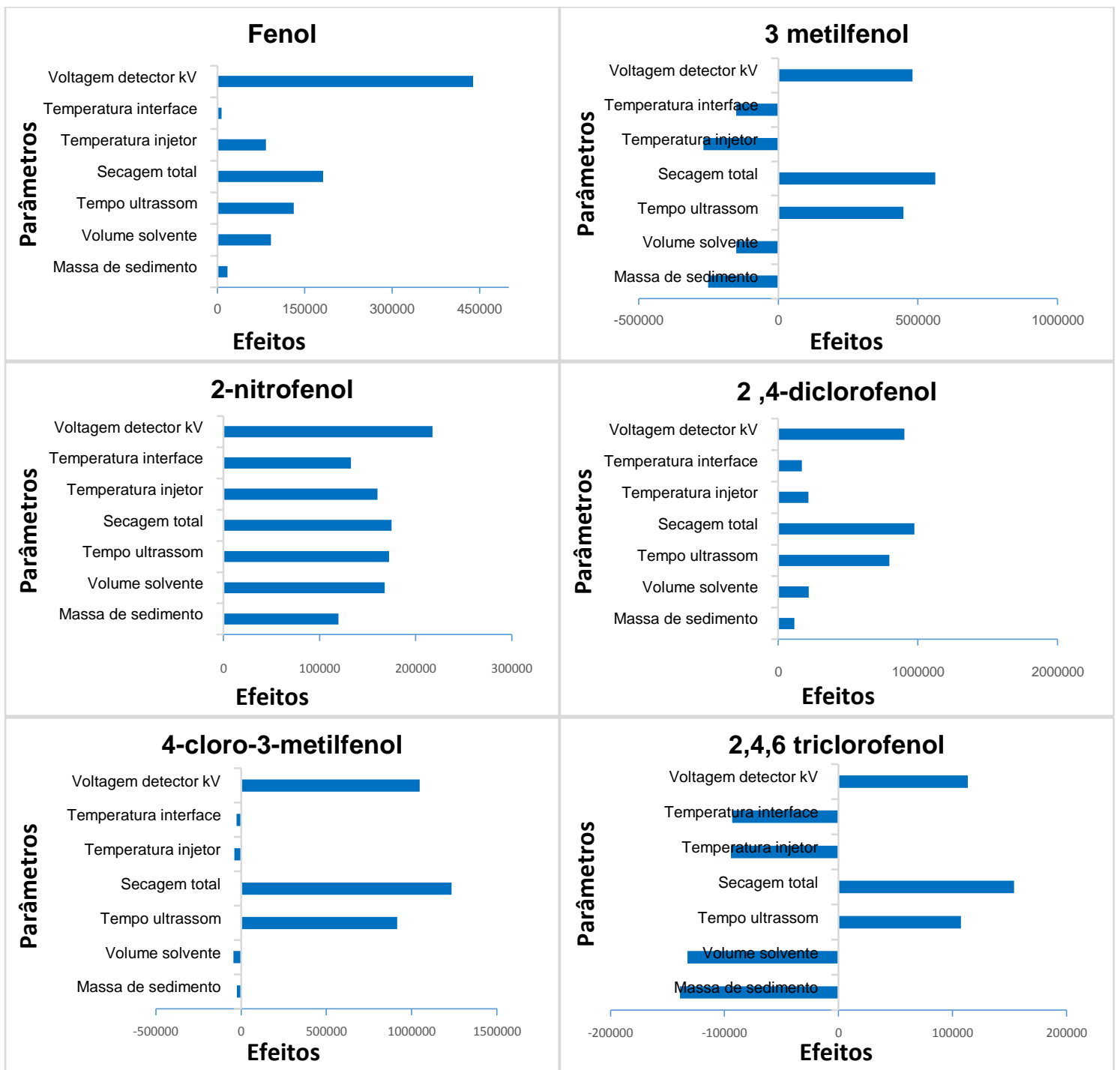

Figura 34. Representação gráfica do teste de verificação de significância dos efeitos no ensaio de robustez em sedimento no método final.

Observou-se que o parâmetro voltagem do detector é o parâmetro com maior efeito positivo no método para praticamente todos os compostos, pois com o aumento da tensão aumenta-se significativamente a intensidade do sinal. É importante observar que a maioria dos parâmetros avaliados no teste favorecem os valores nominais. Esse fato ocorre devido à previa avaliação da metodologia, visto que inicialmente foi estudado um método de extração em ultrassom seguida de purificação e concentração por SPE. Logo, a maioria dos parâmetros já havia sido avaliada, conforme reportado no item 8.6.1 desta dissertação. 
Para os compostos 3-metilfenol e 2,4,6-triclorofenol as variações dos parâmetros temperatura da interface, temperatura do injetor, volume do solvente e massa do sedimento favorecem a determinação, pois apresentam um incremento no sinal, porém observando-se que para todos os compostos estudados, os efeitos destes parâmetros ficaram abaixo do valor ME (margin of error), como pode ser observado nos gráficos de Rankit apresentados nas FIG. 35 e 36 . Usando-se o valor de ME como referência, resultados que não ultrapassem essa margem de erro podem considerar-se não terem efeito significativo sobre o método, porém parâmetros com valores próximos dessa margem necessitam de uma maior atenção durante a execução do método. Pelos resultados obtidos na avaliação da robustez, pode-se concluir que as variações aplicadas não afetam o resultado geral da extração de forma significativa, portanto não se faz necessária nenhuma mudança no método para o 3-metilfenol nem para o 2,4,6-triclorofenol.

Avaliando-se também os gráficos de probabilidade normal, pode-se observar que os valores obtidos no ensaio de robustez estão bem distribuídos no intervalo de -2 e +2 , mostrando que a probabilidade de que haja outliers é baixa. 


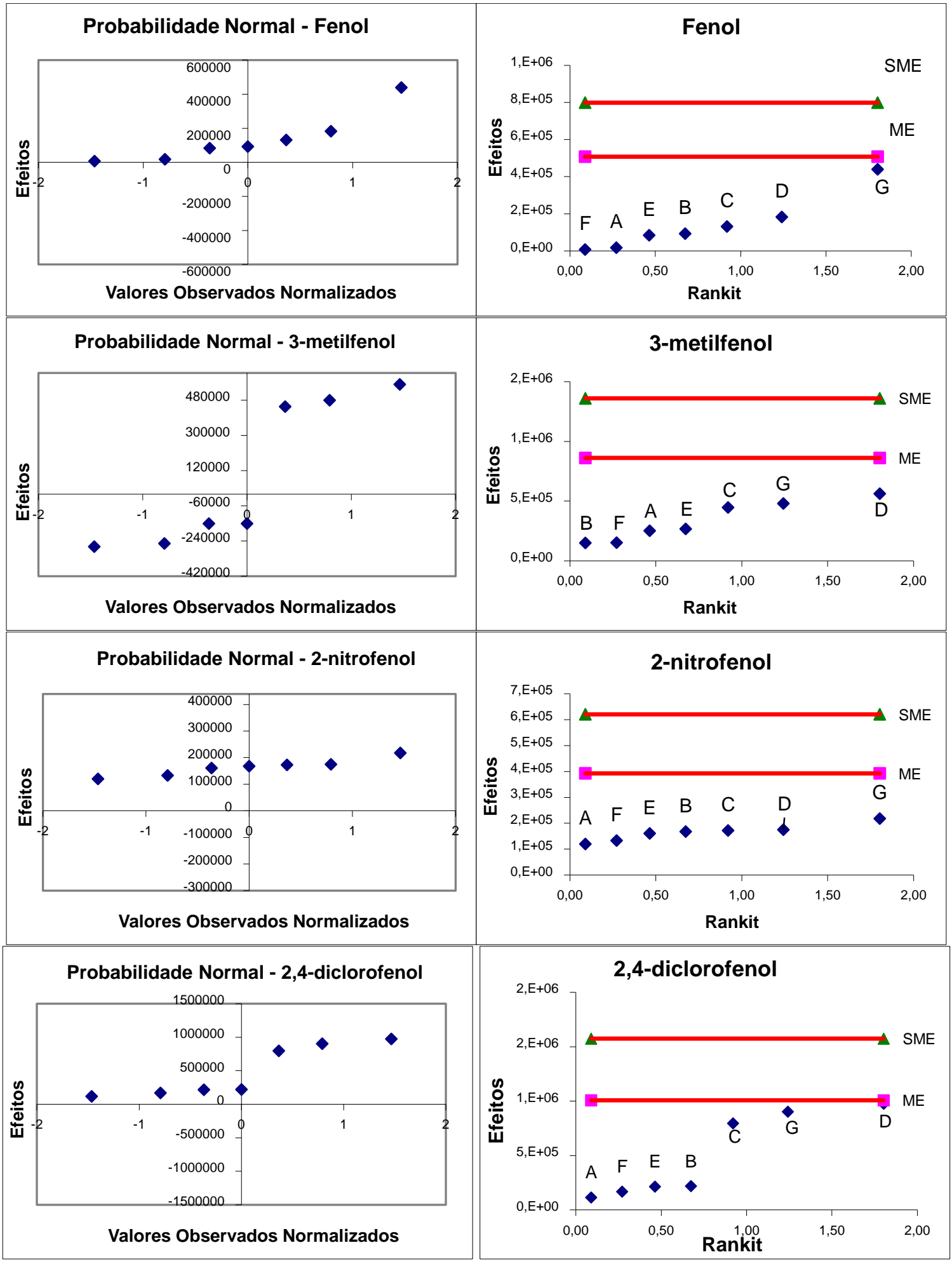

Figura 35. Gráficos de probabilidade normal e Rankit para os compostos fenol, 3-metilfenol, 2-nitrofenol e 2,4-diclorofenol no método final. 


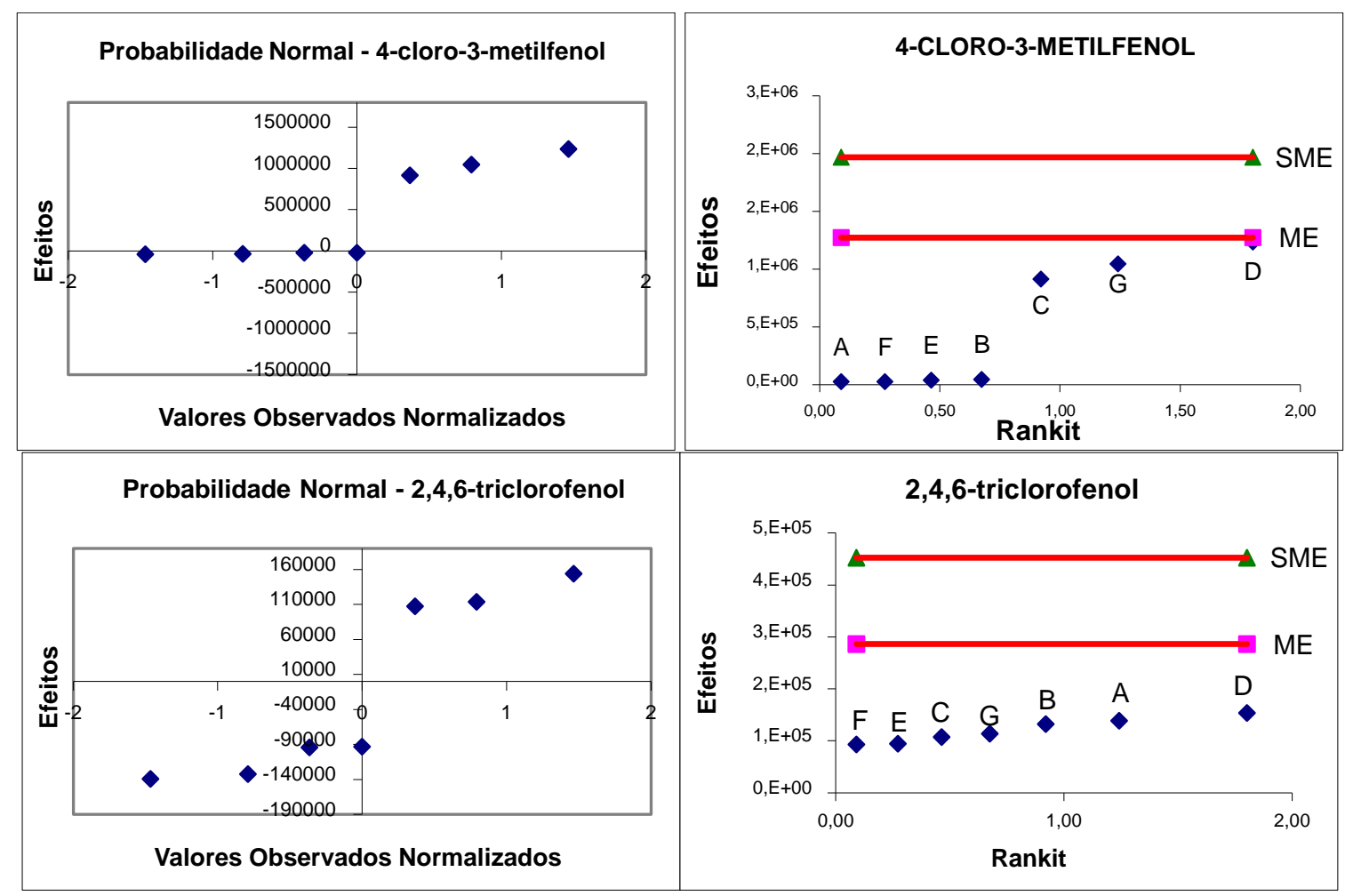

Figura 36. Gráficos de probabilidade normal e Rankit para os compostos 4-cloro-3-metilfenol e 2,4,6-triclorofenol no método final.

Os parâmetros selecionados para o ensaio de robustez do método utilizando cartuchos para extração em fase sólida são apresentados na TAB. 38.

Tabela 38. Parâmetros nominais e suas variações selecionadas para o ensaio de robustez do método SPE.

\begin{tabular}{c|cc|cc}
\hline Parâmetro & \multicolumn{2}{|c|}{ Nominal } & \multicolumn{2}{c}{ Variação } \\
\hline Massa da Amostra & A & $2 \mathrm{~g}$ & $\mathrm{a}$ & $1 \mathrm{~g}$ \\
Tempo Ultrassom & $\mathrm{B}$ & $50 \mathrm{~min}$ & $\mathrm{~b}$ & $30 \mathrm{~min}$ \\
Rotoevaporador & C & Sim & c & Não \\
Acidificação & D & Sim & d & Não \\
Solvente Eluição & E & DCM:MeOH 60:40 & e & DCM:MeOH 1:1 \\
Secagem Total Eluído & F & Sim & f & Não \\
Voltagem Detector $(k V)$ & G & Absolute & g & 0.4 kv \\
\hline
\end{tabular}

Na FIG. 37 são apresentados os gráficos dos efeitos para os seis compostos estudados no ensaio com matriz no método SPE. 


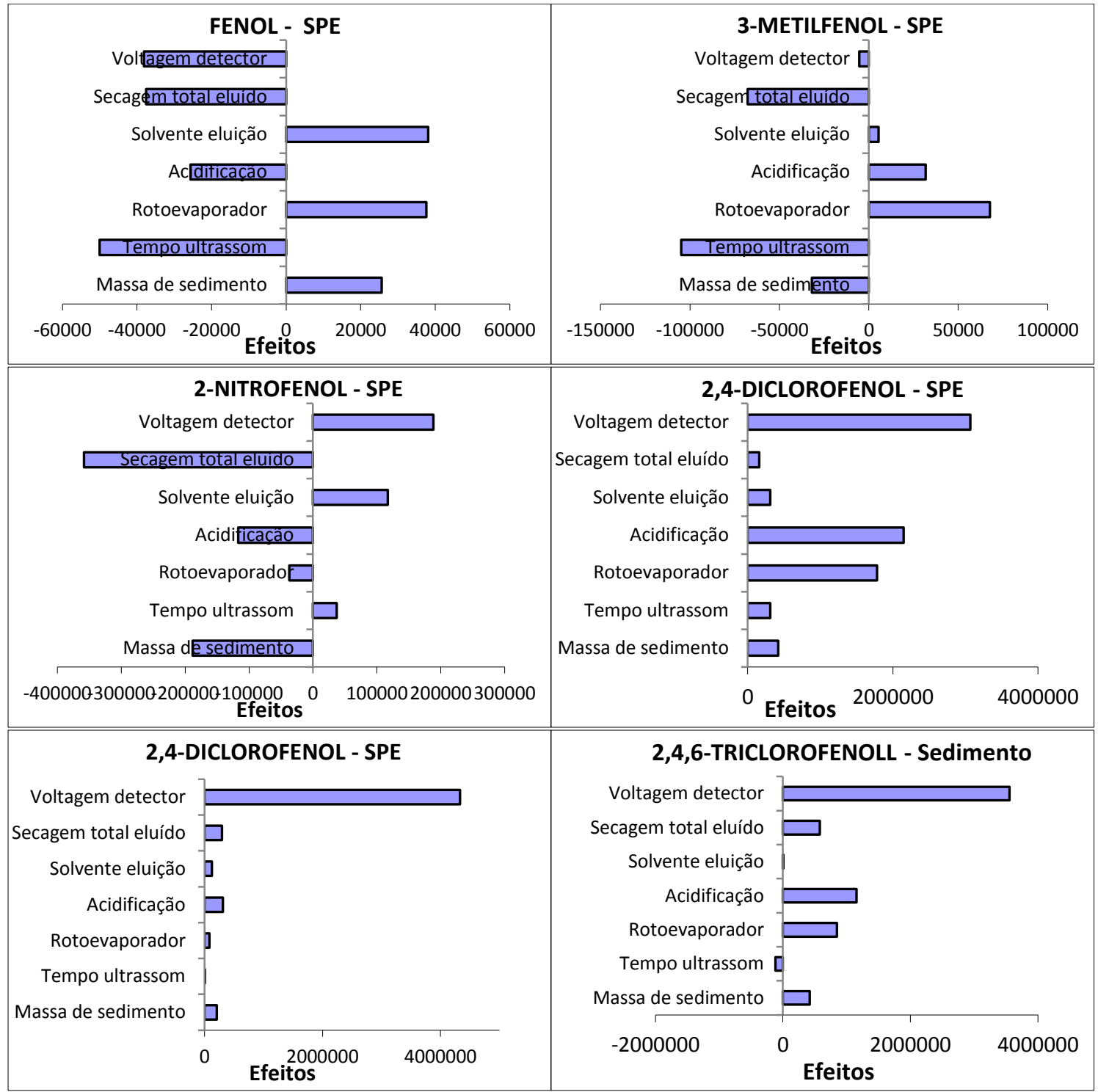

Figura 37. Representação gráfica do teste de verificação de significância dos efeitos no ensaio de robustez em sedimento no método SPE.

Os gráficos de probabilidade normal e Rankit para o ensaio de robustez do método SPE podem ser observados nas FIG. 38 e 39. 


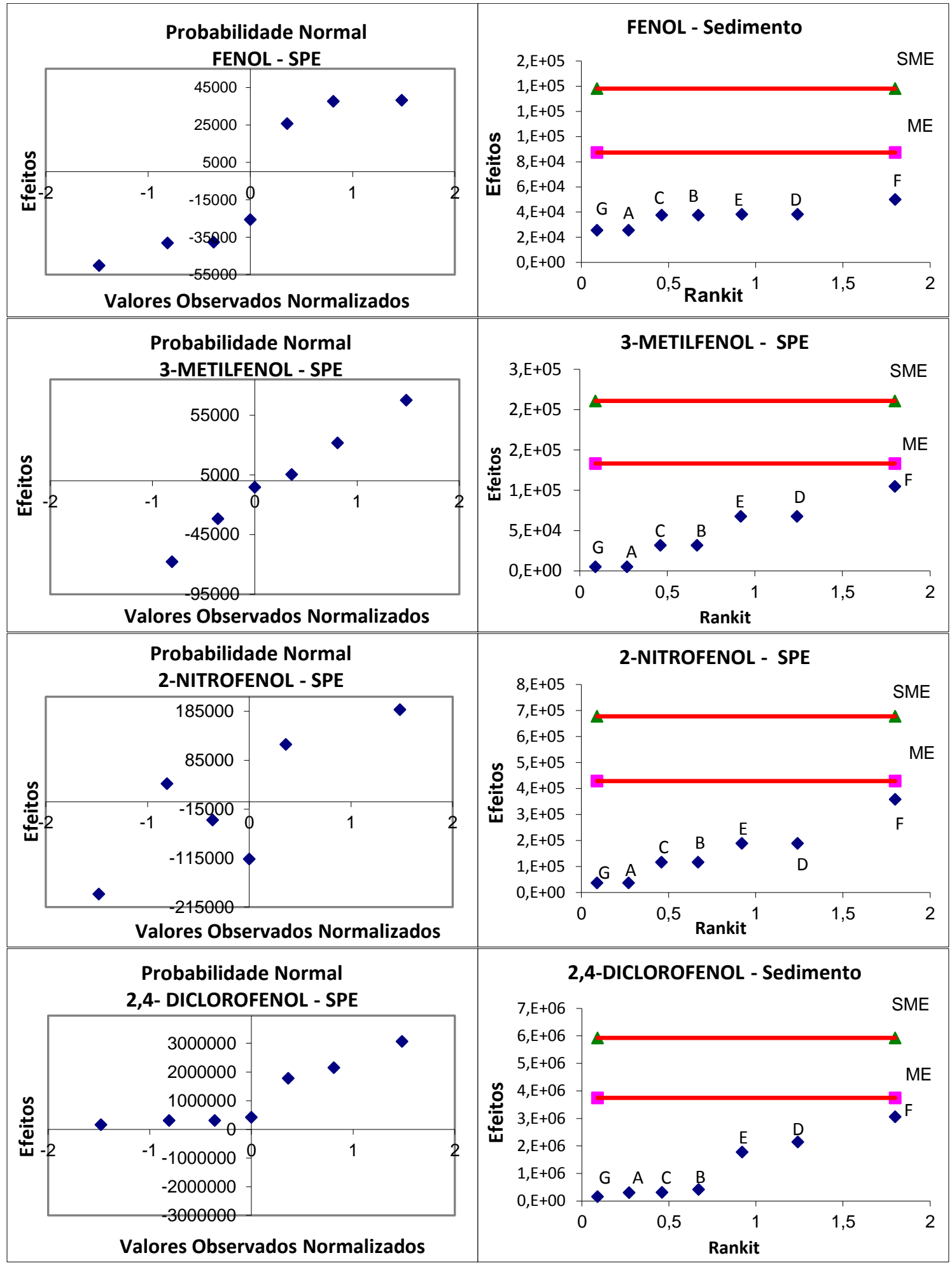

Figura 38. Gráficos de probabilidade normal e Rankit para os compostos fenol, 3-metilfenol, 2-nitrofenol e 2,4-diclorofenol no método SPE. 


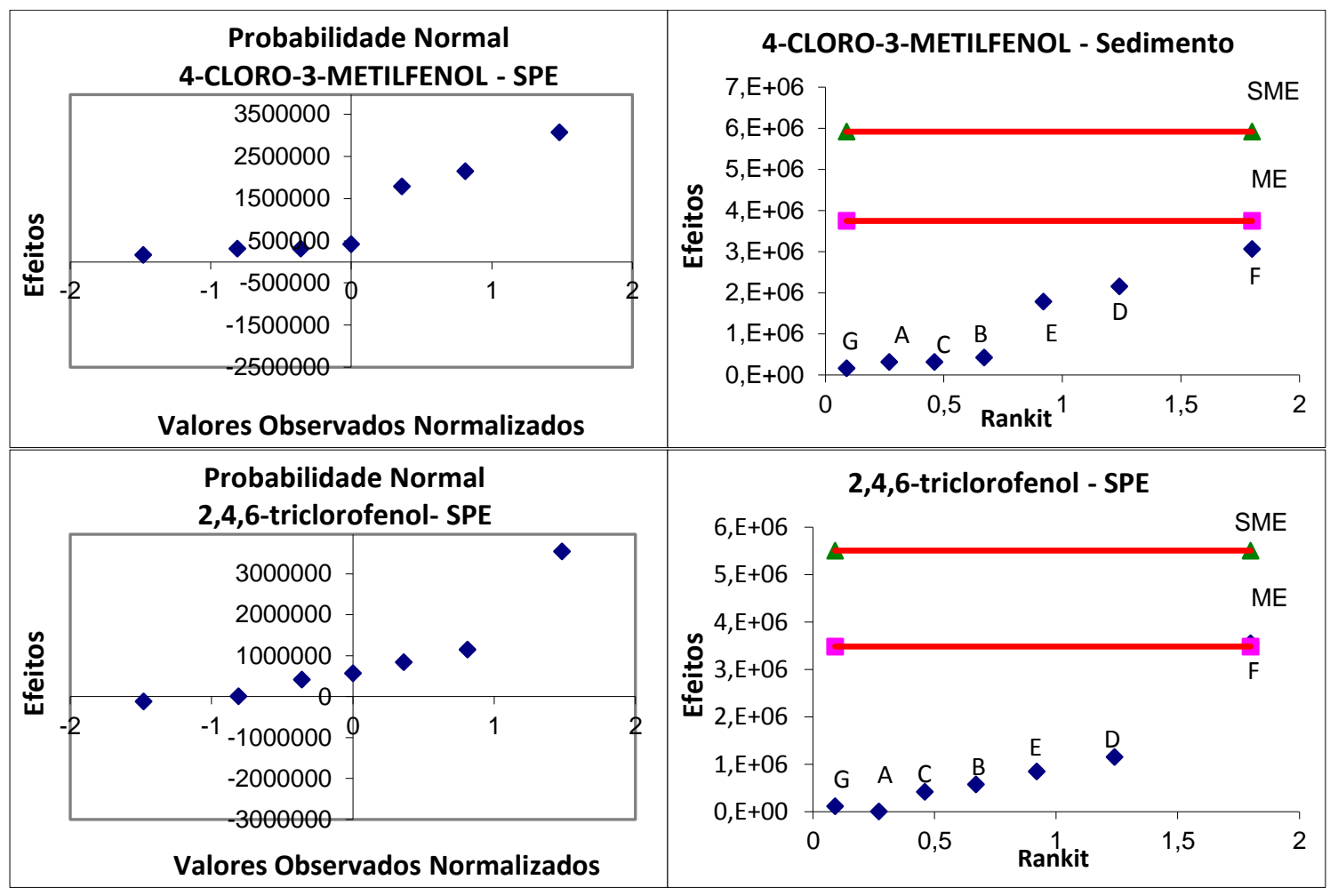

Figura 39. Gráficos de probabilidade normal e Rankit para os compostos 4-cloro-3-metilfenol e 2,4,6-triclorofenol no método SPE.

Observou-se que a voltagem do detector deve permanecer no modo "Absolute", pois favorece a quantificação de praticamente todos os compostos. A secagem total dos extratos eluídos beneficiaria a extração dos compostos fenol, 3-metilfenol e 2-nitrofenol, porém analisando os gráficos de Rankit os efeitos proporcionados por esta alteração encontram-se abaixo do $\mathrm{ME}$, em decorrência disto, normalmente optar-se-ia por manter a secagem total do eluído, mas como definido incialmente no primeiro teste de robustez, reportado no item 8.6.1 desta dissertação e, considerando-se os testes de recuperação, estabeleceu-se a secagem parcial do extrato.

De acordo com os resultados, observa-se que a alteração dos parâmetros massa do sedimento e tempo de ultrassom não afetaria a eficiência do método, portanto com o objetivo de otimizar o tempo de extração os parâmetros foram alterados para $1 \mathrm{~g}$ de sedimento e 30 minutos em banho de ultrassom. 
Pelos resultados obtidos na avaliação da robustez, pode-se concluir que as variações aplicadas não afetam o resultado geral da extração de forma significativa.

\subsection{Estimativa das Incertezas}

Os estudos para a estimativa de incerteza reportados a seguir são referentes apenas ao método final.

Na TAB. 39 são apresentados os resultados dos cálculos de incerteza expandida para os compostos estudados em matriz de extrato de sedimento, considerando-se um ponto intermediário na curva e na TAB. 40, são apresentadas as contribuições individuais de cada grandeza de entrada e a incerteza combinada destas para cada composto relativo ao ponto médio estabelecido. Os cálculos foram realizados com auxílio de uma planilha desenvolvida por Martins (2010).

Tabela 39. Resultados dos cálculos de incertezas expandidas para os compostos estudados em matriz de extrato de sedimento, analisados pelo método final, considerando-se um intervalo de concentração equivalente ao ponto médio da curva $\left(0,2 \mu \mathrm{g} \mathrm{g}^{-1}\right)$.

\begin{tabular}{crrrr}
\hline & \multicolumn{4}{c}{ Matriz } \\
\cline { 2 - 4 } Composto & $\begin{array}{c}\text { Concentração } \\
\left(\mu \mathrm{g} \mathrm{g}^{-1}\right)\end{array}$ & & $\begin{array}{c}\text { Incerteza } \\
\text { Expandida }\end{array}$ & $\%$ \\
\hline Fenol & 0,216 & \pm & 0,025 & 11,4 \\
3-metilfenol & 0,181 & \pm & 0,027 & 15,2 \\
2-nitrofenol & 0,228 & \pm & 0,018 & 7,8 \\
2,4-diclorofenol & 0,223 & \pm & 0,021 & 9,3 \\
4-cloro-3-metilfenol & 0,207 & \pm & 0,042 & 20,1 \\
2,4,6-triclorofenol & 0,214 & \pm & 0,017 & 7,9 \\
\hline
\end{tabular}


Tabela 40. Contribuição da incerteza de cada grandeza de entrada no cálculo do mensurando no ensaio em matriz de sedimento, analisados pelo método final, para todos os compostos estudados, considerando-se intervalo de concentração equivalente ao ponto médio da curva.

\begin{tabular}{|c|c|c|c|c|c|c|}
\hline \multirow[t]{2}{*}{ Composto } & \multirow{2}{*}{$\begin{array}{c}\text { Valor Real } \\
\text { Calculado } \\
\mu \mathrm{g} \mathrm{g}^{-1}\end{array}$} & \multicolumn{5}{|c|}{$\begin{array}{c}\text { Contribuições Individuais de Cada Incerteza em } \\
\text { Matriz }\end{array}$} \\
\hline & & Urel(Curva) & $u_{\text {rel }}(V f)$ & $u_{\text {rel }}\left(m_{\text {sedto }}\right)$ & $u_{\text {rel }}(R)$ & $u_{r[F e n o ́ i s]}$ \\
\hline Fenol & 0,216 & 0,0558 & 0,0041 & 0,0001 & 0,0102 & 0,0123 \\
\hline 3-metilfenol & 0,181 & 0,0683 & 0,0041 & 0,0001 & 0,0330 & 0,0137 \\
\hline 2-nitrofenol & 0,228 & 0,0050 & 0,0041 & 0,0001 & 0,0386 & 0,0089 \\
\hline 2,4-diclorofenol & 0,223 & 0,0453 & 0,0041 & 0,0001 & 0,0097 & 0,0103 \\
\hline 4-cloro-3-metilfenol & 0,207 & 0,0360 & 0,0041 & 0,0001 & 0,0940 & 0,0208 \\
\hline 2,4,6-triclorofenol & 0,214 & 0,0371 & 0,0041 & 0,0001 & 0,0274 & 0,0084 \\
\hline
\end{tabular}

Na FIG. 40 podem ser observadas as representações gráficas das incertezas relativas às grandezas de entrada selecionadas. 


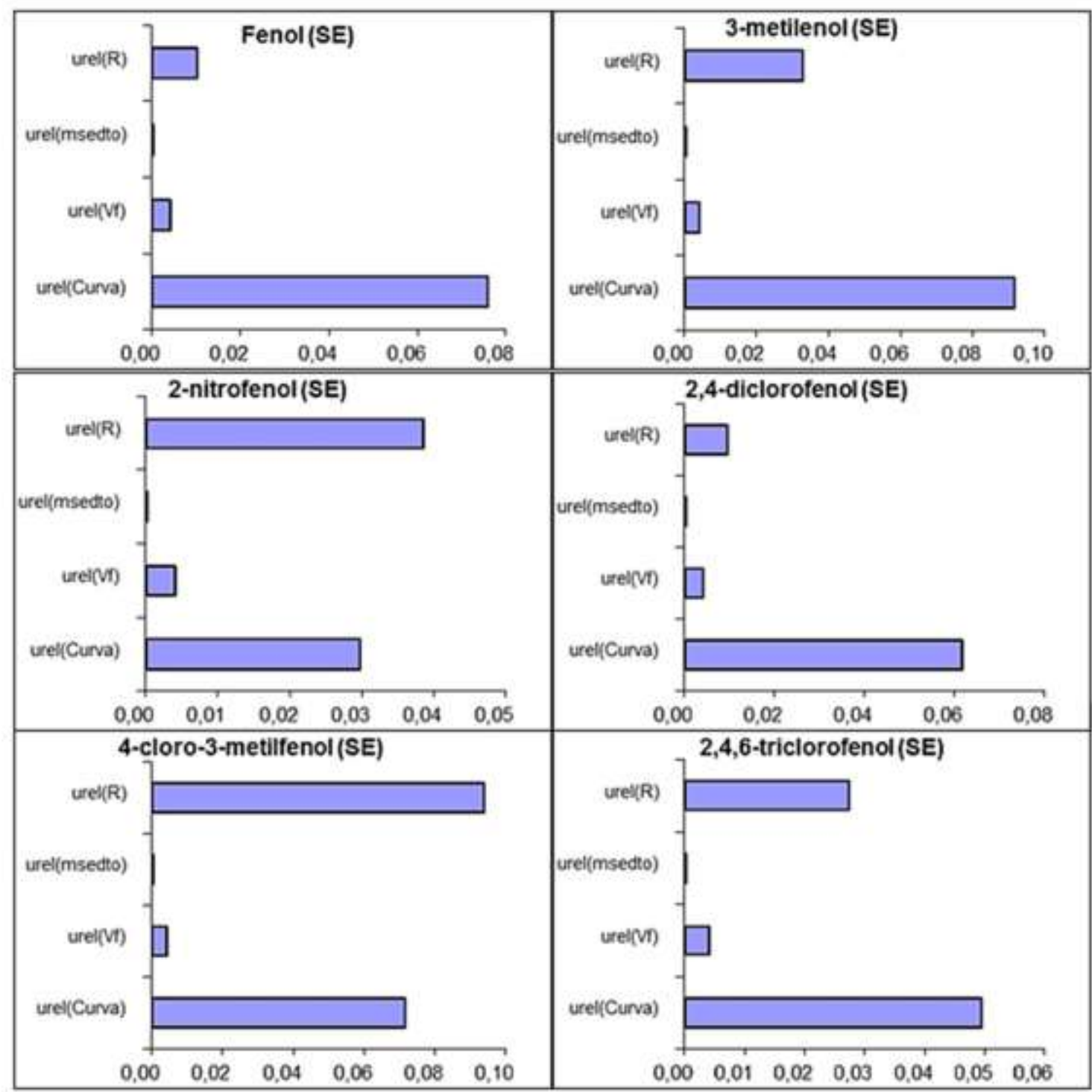

Figura 40. Representações gráficas das incertezas individuais envolvidas na análise dos compostos fenólicos em sedimento no método final.

De acordo com os resultados obtidos pelos cálculos de incertezas dos compostos estudados, pode-se constatar uma maior contribuição para a incerteza associada à recuperação do analito e à curva analítica. Este resultado é coerente, visto que ambas estão relacionadas à concentração, entrada esta que considera todas as incertezas relacionadas às preparações de soluções e suas diluições, e à resposta obtida pelo equipamento. 
Avaliando a FIG. 40, é possível constatar que as incertezas relacionadas à massa da amostra de sedimento e o volume final são desprezíveis em relação à incerteza final. Neste caso, esses cálculos poderiam ser dispensados.

No ANEXO 1, são apresentados os resultados de todas as incertezas parciais envolvidas no Cálculo de Incertezas para todos os compostos estudados.

\subsection{Resultados da avaliação das amostras do Reservatório Guarapiranga}

Com a metodologia validada, foi possível verificar a presença e quantificar as amostras de sedimento coletadas no Reservatório Guarapiranga em relação aos compostos fenólicos estudados. Nas TAB. 41 e 42, estão apresentados os resultados das coletas de 2011 e 2014, onde alguns compostos foram detectados, porém a maioria permaneceu abaixo de seus respectivos limites de quantificação.

Tabela 41. Resultados da análise, em $\mu \mathrm{g} \mathrm{g}^{-1}$, da 1a coleta para os 6 compostos nas amostras de sedimento do Reservatório Guarapiranga.

\begin{tabular}{|c|c|c|c|c|c|c|c|c|}
\hline Compostos & $\begin{array}{l}\text { LQ } \\
\mu g g^{-1}\end{array}$ & $\begin{array}{l}\text { G-01 } \\
2011\end{array}$ & $\begin{array}{l}\text { G-02 } \\
2011\end{array}$ & $\begin{array}{l}\text { G-03 } \\
2011\end{array}$ & $\begin{array}{l}\text { G-04 } \\
2011\end{array}$ & $\begin{array}{l}\text { G-05 } \\
2011\end{array}$ & $\begin{array}{l}\text { G-06 } \\
2011\end{array}$ & $\begin{array}{l}\text { G-07 } \\
2011\end{array}$ \\
\hline Fenol & 0,081 & $<L Q$ & $<L Q$ & $<L Q$ & $<L Q$ & $<L Q$ & $<L Q$ & $<L Q$ \\
\hline 3-metilfenol & 0,069 & $<L Q$ & $<L Q$ & $<L Q$ & $<L Q$ & $<L Q$ & $<L Q$ & $<L Q$ \\
\hline 2-nitrofenol & 0,081 & $<L Q$ & $<L Q$ & $<L Q$ & $<L Q$ & $<L Q$ & $<L Q$ & $<\mathrm{LQ}$ \\
\hline 2,4-diclorofenol & 0,056 & $<L Q$ & $<L Q$ & $<L Q$ & $<L Q$ & $<L Q$ & $<L Q$ & $<L Q$ \\
\hline 4-cloro-3-metilfenol & 0,085 & $<L Q$ & $<L Q$ & $<L Q$ & $<L Q$ & $<L Q$ & $<L Q$ & $<\mathrm{LQ}$ \\
\hline 2,4,6-triclorofenol & 0,049 & $<\mathrm{LQ}$ & $<L Q$ & $<L Q$ & $<L Q$ & $<L Q$ & $<L Q$ & $<\mathrm{LQ}$ \\
\hline Compostos & $\underset{\mu g g^{\prime}}{\operatorname{LQ}}$ & $\begin{array}{l}\text { G-08 } \\
2011\end{array}$ & $\begin{array}{l}\text { G-09 } \\
2011\end{array}$ & $\begin{array}{l}\text { G-10 } \\
2011\end{array}$ & $\begin{array}{l}\text { G-11 } \\
2011\end{array}$ & $\begin{array}{l}\text { G-12 } \\
2011\end{array}$ & $\begin{array}{l}\text { G-13 } \\
2011\end{array}$ & $\begin{array}{c}\text { G-14 } \\
2011\end{array}$ \\
\hline Fenol & 0,081 & $<L Q$ & $0,19 \pm 0,03$ & $0,09 \pm 0,02$ & $0,15 \pm 0,02$ & $<L Q$ & $<L Q$ & $<L Q$ \\
\hline 3-metilfenol & 0,069 & $<L Q$ & $<L Q$ & $<L Q$ & $0,10 \pm 0,03$ & $<L Q$ & $0,19 \pm 0,07$ & $<\mathrm{LQ}$ \\
\hline 2-nitrofenol & 0,081 & $<L Q$ & $<L Q$ & $<L Q$ & $<L Q$ & $<L Q$ & $<L Q$ & $<\mathrm{LQ}$ \\
\hline 2,4-diclorofenol & 0,056 & $<L Q$ & $<L Q$ & $<L Q$ & $<L Q$ & $<L Q$ & $<L Q$ & $<\mathrm{LQ}$ \\
\hline 4-cloro-3-metilfenol & 0,085 & $<L Q$ & $<L Q$ & $<L Q$ & $<L Q$ & $<L Q$ & $<L Q$ & $<L Q$ \\
\hline 2,4,6-triclorofenol & 0,049 & $<L Q$ & $<L Q$ & $<L Q$ & $<L Q$ & $<\mathrm{LQ}$ & $<\mathrm{LQ}$ & $<\mathrm{LQ}$ \\
\hline
\end{tabular}


Tabela 42. Resultados da análise, em $\mu \mathrm{g} \mathrm{g}^{-1}$, da $2^{\text {a }}$ coleta para os 6 compostos nas amostras de sedimento do Reservatório Guarapiranga.

\begin{tabular}{|c|c|c|c|c|c|c|c|c|c|c|}
\hline Compostos & $\underset{\mu \mathrm{g} \mathrm{g}}{\mathrm{LQ}}$ & $\begin{array}{l}\text { G-01 } \\
2014\end{array}$ & $\begin{array}{l}\text { G-02 } \\
2014\end{array}$ & $\begin{array}{c}\text { G-03 } \\
2014\end{array}$ & $\begin{array}{c}\text { G-04 } \\
2014\end{array}$ & $\begin{array}{l}\text { G-07 } \\
2014\end{array}$ & $\begin{array}{l}\text { G-08 } \\
2014\end{array}$ & $\begin{array}{c}\text { G-09 } \\
2014\end{array}$ & $\begin{array}{c}\text { G-10 } \\
2014\end{array}$ & $\begin{array}{l}\text { G-11 } \\
2014\end{array}$ \\
\hline Fenol & 0,081 & $<L Q$ & $<L Q$ & $<L Q$ & $<L Q$ & $<L Q$ & $<L Q$ & $<L Q$ & $<L Q$ & $<\mathrm{LQ}$ \\
\hline 3-metilfenol & 0,069 & $<\mathrm{LQ}$ & $0,07 \pm 0,01$ & $<L Q$ & $<\mathrm{LQ}$ & $0,08 \pm 0,02$ & $<L Q$ & $<L Q$ & $<L Q$ & $<\mathrm{LQ}$ \\
\hline 2-nitrofenol & 0,081 & $<L Q$ & $<L Q$ & $<L Q$ & $<L Q$ & $<L Q$ & $<L Q$ & $<L Q$ & $<L Q$ & $<L Q$ \\
\hline 2,4-diclorofenol & 0,056 & $<L Q$ & $<L Q$ & $<L Q$ & $<L Q$ & $<L Q$ & $<L Q$ & $<L Q$ & $<L Q$ & $<\mathrm{LQ}$ \\
\hline 4-cloro-3-metilfenol & 0,085 & $<L Q$ & $<L Q$ & $<L Q$ & $<L Q$ & $<L Q$ & $<L Q$ & $<L Q$ & $<L Q$ & $<L Q$ \\
\hline 2,4,6-triclorofenol & 0,049 & $<L Q$ & $<L Q$ & $<L Q$ & $<L Q$ & $<L Q$ & $<L Q$ & $<L Q$ & $<L Q$ & $<L Q$ \\
\hline
\end{tabular}

O fenol foi o composto encontrado com maior frequência nas amostras de sedimento de 2011, com alguns resultados acima do LQ, principalmente em pontos com maior influência urbana. Também foi encontrado o 3-metilfenol com resultados acima do LQ em dois pontos de coleta em 2011 (G-11 e G-13). Já na coleta realizada em outubro de 2014, o composto 3-metilfenol foi quantificado em dois pontos de coleta, G-02 e G-07, sendo detectado abaixo do LQ em diversos pontos ao longo do reservatório.

Embora a classificação das bacias segundo o uso e ocupação do solo apresentada na FIG. 13 e os demais estudos realizados na região (Shihomatsu, 2014; Otomo, 2015) aponte o G103-12 como o mais impactado, não foram detectados fenóis em valores acima do LQ para esse ponto em nenhuma das coletas. Porém, os demais pontos com valores quantificados também se encontram na área mais densamente ocupada.

Considerando-se que os compostos em sedimento com o tempo podem ser liberados na coluna d'água e causar contaminação na água de abastecimento, a Resolução CONAMA no 357 (Brasil, 2005) para águas doces classe 1, que diz respeito aos limites de contaminantes em corpos d'água, pode ser utilizada como referência para os limites destes compostos na matriz estudada. Apesar de os valores encontrados para compostos fenólicos neste trabalho estarem abaixo dos limites estabelecidos, a presença destes no sedimento pode indicar uma contaminação decorrente de atividades industriais nas margens do reservatório. 


\section{CONCLUSÕES}

- A metodologia proposta mostrou ser adequada para alcançar o objetivo de avaliar a presença dos 6 compostos orgânicos em sedimento da represa Guarapiranga, o que pode ser evidenciado pelos resultados da validação do método.

- Após a adequação do método inicialmente proposto para a determinação de fenóis em sedimentos da represa Guarapiranga, o processo de validação do mesmo forneceu confiabilidade estatística aos dados, demonstrando a sensibilidade e seletividade do método, além de linearidade satisfatória nas faixas de trabalho consideradas para todos os compostos na matriz avaliada, sendo ainda um método simples de rápida execução que não necessita de concentração e purificação por extração em fase sólida (SPE) como os demais métodos apresentados na literatura.

- Os limites de detecção e quantificação alcançados, são satisfatórios para a análise de compostos orgânicos em níveis traço em amostras ambientais, especialmente para a matriz sedimento.

- A metodologia foi considerada robusta para determinação dos compostos fenólicos em sedimento, porém constatou-se que o parâmetro voltagem do detector é de extrema importância para a análise dos compostos, sugerindo que o mesmo deve estar sob rígido controle durante toda a análise.

- Após avaliação das amostras da área estudada, conclui-se que o reservatório apresenta baixas concentrações de fenol e de 3-metilfenol ao longo de toda a área, com alguns resultados acima do $L Q$, principalmente em pontos com maior influência urbana.

- Embora a legislação não contemple os compostos na matriz sedimento, esses compostos se ressuspendidos no corpo d'água, podem apresentar risco de contaminação, mesmo que tenham sido detectados abaixo dos limites máximos da legislação para águas.

- O trabalho gerou um segundo método que pode ser utilizado para os compostos 4-cloro-3-metilfenol e 2,4,6-triclorofenol com melhores condições de purificação com a utilização de cartuchos para extração em fase sólida. 
ABNT - ASSOCIAÇÃO BRASILEIRA DE NORMAS TÉCNICAS. NBR 10004. Rio de Janeiro, 2004.

ANDRADE, M. R. M.; SALIM, A.; PENTEADO, D. R.; COSTA, J. A.; Alana Almeida de SOUZA5; SAAD, A. R.; OLIVEIRA, A. M. S. Mapeamento de uso da terra para avaliação da qualidade das águas do Reservatório Guarapiranga. Geociências, v. 34, n. 2, p.258-274, 2015.

ATSDR - AGENCY FOR TOXIC SUBSTANCES AND DISEASE REGISTRY. Toxicological Profile for Nitrophenols: 2-Nitrophenol; 4-Nitrophenol. Atlanta, 1992.

BICUDO, C.E.M.; TUNDISI, J.G.; SCHEUENSTUHL, M.C.B. Águas do Brasil: análises estratégicas. São Paulo, SP: Instituto de Botânica, 2010.

BONATO, P. S.; COLLINS, C. H.; BRAGA, G. L. Introdução a Métodos Cromatográficos. 6ª ed., Campinas, SP: Unicamp, 1995.

BORELLI, E. A Bacia do Guarapiranga: ocupação em áreas de mananciais e a legislação ambiental. Revista de Ciências Sociais, v. 25, 2006.

BRASIL. Ministério da Saúde. Portaria no 2914 de 12/12/2011. Disponível em: <http://www.saude.mg.gov.br/index.php?option=com_gmg\&controller=documen $\mathrm{t} \& \mathrm{id}=8014$-portaria-no-2914-de-12-de-dezembro-de-2011-

sesmg\&task=download $>$ Acesso em: 27 de março de 2014c.

BRASIL. Ministério do desenvolvimento urbano e meio ambiente. Conselho nacional do meio ambiente (CONAMA). Resolução n. 357 de 17 de março de 2005. Disponível em:

<http://www.mma.gov.br/port/conama/legiabre.cfm?codlegi=646> Acesso em: 27 de março de 2014a.

BRASIL. Ministério do desenvolvimento urbano e meio ambiente. Conselho nacional do meio ambiente (CONAMA). Resolução n. 430 de 13 maio de 2011. Disponível em:

<http://www.mma.gov.br/port/conama/legiabre.cfm?codlegi=646> Acesso em: 27 de março de 2014b.

BRITO, C.F. Desenvolvimento e validação de metodologia analítica para determinação de hidrocarbonetos policíclicos aromáticos (HPAs) em sedimentos. Avaliação da Represa Parque do Pedroso, Santo André. Dissertação (Mestrado) - Instituto de Pesquisas Energéticas e Nucleares/Universidade de São Paulo, São Paulo, 2009. 
CANADIAN WATER QUALITY GUIDELINES FOR THE PROTECTION OF AQUATIC LIFE. Phenols: mono- and dihydric phenols. Canadian Council of Ministers of the Environment, 1999.

CARDELLICCHIO, N.; CAVALLI, S.; PIANGERELLI, V.; GIANDOMENICO, S.; RAGONE, P. Determination of phenols in environmental samples by liquid chromatography - electrochemistry. Fresenius J Anal Chem., v. 358, p. 749754, 1997.

CHIARADIA, M. C.; COLLINS, H. CAROL; JARDIM, I. C. F. O estado da arte da cromatografia associada à espectrometria de massas acoplada à espectrometria de massas na análise de compostos tóxicos em alimentos. Quim. Nova, v. 31, n. 3, p. 623-636, 2008.

COTTA, J.A.O.; REZENDE, M.O.O.; LANDGRAF, M.D. Avaliação de solventes de extração por ultrassom usando-se cromatografia líquida de alta eficiência para a determinação de hidrocarbonetos policíclicos aromáticos em solos contaminados. Quim. Nova, v. 32, n. 8, p. 2026-2033, 2009.

DHHS - Department of Health and Human Service. Report on Carcinogens 2,4,6-Trichlorophenol. 11를 edition. 2001.

DHHS - Department of Health and Human Service. Toxicological profile for cresols. 2008a.

DHHS - Department of Health and Human Service. Toxicology and Carcinogenesis Studies of 2,4-Dichlorophenol. 1989.

DORNFELD, C.B. Utilização de Chironomussp (Diptera, Chironomidea) para a avaliação da qualidade de sedimentos e contaminação por metais. 2006. Tese (Doutorado) - Escola de Engenharia de São Carlos, São Paulo.

DUPONT, A-L.; EGASSE, C.; MORIN, A.; VASSEUR, F. Comprehensive characterization os cellulose-and lignocellulose-degradation products in aged papers: Capillary zone electrophoresis of low-molar mass organic acids, carbohydrates, and aromatic lignin derivates. Carbohydrates Polimers., v. 68, p. 1-16, 2007.

ESTEVES, F.A. Fundamentos em Limnologia. 2.ed. Rio de Janeiro: Interciência, 1998.

EURACHEM .Quantifying Uncertainty in Analytical Measurement. 3.e.d. 2012.

FALUDI, T.; BALOG, C.; SERFŐZŐ, Z.; MOLNÁR-PERL, I. Analysis of phenolic compounds in the dissolved and suspended phases of Lake Balaton water by gas chromatography-tandem mass spectrometry. Environ Sci Pollut Res, v. 22, p. 11966-11974, 2015. 
FELTRE, R. Química Orgânica: teoria. São Paulo: Moderna. 1974.

FU, L.; MAcCLLUM, S. A.; MIAO, J.; HART, C.; TUDRYN, G.; ZHANG, F.; LINHARDT, R. J. Rapid and accurate determination of the lignin content of lignocellulosic biomass by solid-state NMR. Fuel, v. 141, p. 39-45, 2015.

FURUSAWA, H. A. Validação de Ensaios Químicos. São Paulo, IPENCNEN/SP, 2007 (adaptação eletrônica baseada no documento DOQ-CGCRE008 de 01/03/2003 do INMETRO). São Paulo, 2007.

GAO, P.; FENG, Y.; ZHANG, Z.; LIU, J.; REN, N. Comparison of competitive and synergetic adsorption of three phenolic compounds on river sediment. Environ. Pollut., v. 159, p. 2876-2881, 2011.

GHISELLI, G.; JARDIM, W.F. INTERFERENTES ENDÓCRINOS NO AMBIENTE. Quim. Nova, v. 30, v. 3, p. 695-706, 2007.

GUERRA, R. Ecotoxicological and chemical evaluation of phenolic compounds in industrial effluents. Chemosphere, v. 44, p. 1737-1747, 2001.

HALKET, J. M.; ZAIKIN, V. G. Derivatization in mass spectrometry - 1 .

Silylation. Eur. J. Mass Spectrom.,v. 9, p. 1-21, 2003.

HUANG, B.; SUN, W. W.; LI, X. M.; YANG, X. X.; REN, D.; WANG Y.; PAN, X. J. Simultaneous determination of progestogens, androgens, estrogens and phenols in water, sediment and biological samples by enolisation-silylation with ASE-GPC-SPE-GC/MS. Anal. Methods, v. 7, p. 6139-6151, 2015.

INMETRO - Instituto Nacional de Metrologia, Normalização e Qualidade Industrial. Orientação sobre validação de métodos de ensaios químicos. Rio de Janeiro. DOQ-CGCRE-008. Revisão 01. Mar. 2003.

INMETRO - Instituto Nacional de Metrologia, Normalização e Qualidade Industrial. Orientação sobre validação de métodos de ensaios químicos. Rio de Janeiro. DOQ-CGCRE-008. Revisão 04. Jul. 2011.

INMETRO, Instituto Nacional de Metrologia - 2010. Orientação sobre validação de métodos de ensaios químicos. DOQ-CGCRE-008. Rio de Janeiro, 2010. Vol. Rev. 03.

INMETRO, Instituto Nacional de Metrologia - 2012. Avaliação de dados de medição: Guia para a expressão de incerteza de medição - GUM 2008. $1^{\text {a }}$ Edição Brasileira da 1a Edição do BIPM de 2008: Evaluation of measurement data - Guide to the expression of uncertainty in measurement. Duque de Caxias, RJ: INMETRO/CICMA/SEPIN, 2012.

KLEIBOHMER, W. (Ed.). Environmental Analysis Handbook of Analytical Separations. Elsevier Science B. V., v.3, c.6, 2001. 
KOVACS, A.; KENDE, A.; MORTL, M.; VOLKC, G.; RIKKER, T.; TORKOS, K. Determination of phenols and chlorophenols as trimethylsilyl derivatives using gas chromatography-mass spectrometry. J. Chromatogr. A, v. 1194, p.139142, 2008.

KUBOTA, L.T.; FREIRE, R.S.; DURÁN, N., ROSATTO, S.S. Biossensores amperométricos para determinação de compostos fenólicos em amostras de interesse ambiental. Quím. Nova, v. 24, p. 77-86, 2001.

$\mathrm{KUCH}, \mathrm{M}$; BALLSCHMITER, K. Determination of Endocrine-Disrupting Phenolic Compounds and Estrogens in Surface and Drinking Water by HRGC-(NCI)-MS in the Pico gram per Liter Range. Environ. Sci. Technol., v. 35, p. 3201-3206, 2001.

LANÇAS, F. M. Cromatografia Líquida Moderna e a Espectometria de Massas: Finalmente Compatíveis?. Sci. Chromatogr., v. 1, n. 2, 2009.

LANÇAS, Fernando M. Cromatografia em fase gasosa. São Carlos: Acta, 1993.

LEITE, F. Validação em análise química. 5.ed. Campinas: Átomo, 2008.

LI, B.; LIU, R.; GAO, H.; TAN, R.; ZENG, P.; Song, Y. Spatial distribution and ecological risk assessment of phthalic acid esters and phenols in surface sediment from urban rivers in Northeast China. Environ. Pollut., v. 30, p. 1-7, 2016.

LIBÂNIO, P. A. C.; CHERNICHARO, C. A. L.; NASCIMENTO, N. O. A dimensão da qualidade de água: avaliação da relação entre indicadores sociais, de disponibilidade hídrica, de saneamento e de saúde pública. Eng. Sanit. Ambient., v. 10, n. 3, p. 219-228, 2005.

LOUCHOARN, P.; AMON, R. M. W.; DUAN, S.; PONDELL, C.; SEWARD, S. M.; WHITE, N. Analysis of lignin-derived phenols in standard reference materials and ocean dissolved organic matter by gas chromatography/tandem mass spectrometry. Mar. Chem., v. 118, n. 1/2, p. 85-97, 2010.

LV, J.; LUO, L.; ZHANG, J.; CHRISTIE, P.; ZHANG, S. Adsorption of mercury lignin: Combined surface complexation modeling and $\mathrm{X}$-ray absorption spectroscopy studies. Envirom. Pollut., v.162, p. 255-261, 2012.

MACHADO, V.N.; SETTI, J.A.P.; SOVIERZOSKI, M.A. Metrologia química e suas particularidades no cálculo da incerteza de medição. $7^{\circ}$ Congresso Brasileiro de Metrologia, Ouro Preto/MG, novembro de 2013. Disponível em: <http://www.energiapura.net.br/Trabalhos\%20Publicados/2013/incertezas_na_ mq_versao_final_apos_revisor_290813.pdf>. Acesso em: 25/04/2016. 
MARTINS, E. A. J. Estimativa da incerteza em ensaios químicos. São Paulo, IPEN-CNEN/SP (adaptação eletrônica baseada no documento EURACHEM/CITAC Guide.Second Edition, 2000). 2010.

MARTINS, E. A. J.; FURUSAWA, H. A.; OTOMO, J. I.; SOUZA, R. R.; OLIVEIRA, C. L.; COTRIM, M. E. B.; PIRES, M. A. F. Avaliação de incerteza de medição na determinação de interferentes endócrinos em água superficial por cromatografia gasosa com detecção por espectrometria de massas. In: XIII International Conference on Engineering and Technology Education. Guimarães, Portugal: 2014.

MEDEIROS, C.R. Determinação de compostos fenólicos em extratos aquosos de resíduos sólidos por microextração em fase sólida e cromatografia a gás acoplada à espectrometria de massas. 2013. Dissertação (Mestrado) -Universidade Federal de Santa Catarina, Florianópolis.

MICHALOWICZ, J.; Duda, W. Phenols - Source and Toxicity. Polish Journal of Environ. Stud., v. 16, n. 3, p. 347-362, 2007.

MORALES, S.; CANOSA, P.; RODRIGUEZ, I.; CELA, E.R.R. Microwave assisted extraction followed by gas chromatography with tandem mass spectrometry for the determination of triclosan and two related chlorophenols in sludge and sediments. J.Chromatogr. A., v. 1082, p. 128-135, 2005.

MUKAKA, M.M. "Statistics Corner: A guide to appropriate use of Correlation coefficient in medical research". Malawi Med J., v. 24, n.3, p. 69-71, 2012.

OTOMO, J.I. Contribuição antrópica na qualidade das águas da Represa do Guarapiranga. Um estudo sobre interferentes endócrinos. Tese (Doutorado) - Instituto de Pesquisas Energéticas e Nucleares, IPEN/USP, São Paulo.

OTOMO, J.I. Desenvolvimento e validação de metodologia analítica para determinação de hormônios, considerados disruptores endócrinos, nas águas destinadas ao abastecimento público na região do rio Paraíba do Sul, SP. 2010. Dissertação (Mestrado) - Instituto de Pesquisas Energéticas e Nucleares, IPEN/USP, São Paulo.

PEIXE, T. S.; NASCIMENTO, E. S. Análise de fenol em amostras de urina de trabalhadores e no ar de fundição de metais. Rev. bras. toxicol., v. 21, n.2, p. 60-69, 2008.

PETROVIC, M.; ELJARRAT, E.; Lopez de ALDA, M.J.; BARCELÓ, D.Recent advances in the mass spectrometric analysis related to endocrine disrupting compounds in aquatic environmental samples. J. Chromatogr. A., v.974, p.23$51,2002$.

PINTO, M. Desenvolvimento de metodologia analítica para a determinação de derivados fenólicos de lignina em sedimentos por SPME-GC/FID. 2015. 
Dissertação (Mestrado) - Universidade Federal de Santa Catarina, Florianópolis.

POMPÊO, M.; PADIAL, P.R.; MARIANI, C.F.; SILVA, S.S.; CARLOS, V.M.; SILVA, D.C.V.R.; PAIVA, T.C.B.; BRANDIMARTE, A.C. Biodisponibilidade de metais no sedimento de um reservatório tropical urbano (reservatório Guarapiranga - São Paulo (SP), Brasil): há toxicidade potencial e heterogeneidade espacial?. Geochim. Brasilie., v. 27, n. 2, p. 104-119, 2013.

PORTO, L.C.S; ETHUR, E.M. Elementos traço na água e em vísceras de peixes da Bacia dos Rios Batuí-lcamaquã, Rio Grande do Sul, Brasil. Ciênc. Rural., v.39, n. 9, p. 2512-2518, 2009.

RIBANI, M.; BOTTOLI, C. B. G.; COLLINS, C. H.; JARDIM, I. C. S. F.; MELO, L. F. C. Validação em métodos cromatográficos e eletroforéticos. Quim. Nova, v. 27, n. 5 , p. $771-780,2004$.

RICHARDSON, S. D. Water analysis: Emerging Contaminants and current issues. Anal. Chem., v. 81, p. 4645-4677, 2009.

SABESP - Dossiê - Sistema Guarapiranga. Espaço das Águas. Fundação Patrimônio Histórico da Energia e Saneamento. São Paulo: Companhia de Saneamento Básico do Estado de São Paulo - Sabesp, 2008.

SALIM, A.; LUCHIARI, A. A urbanização e os desafios para a proteção da bacia do reservatório do Guarapiranga. Caderno Prudentino de Geografia, Volume Especial, n.36, p.191-202, 2014.

SANT'ANNA, C.L.; AZEVEDO, M.T.P.; WERNER, W.R.; DOGO, C.R.; RIOS, F.R.; CARVALHO, L.R. Review of toxic species of cyanobacteria in Brazil. Algol. Stud., v. 126, p.249-263, 2008.

SANTANA, C.M.; FERRERA, Z.S.; RODRÍGUEZ, J.J.S. A New and Fast Extraction Method for the Determination of Priority Phenols from Marine Sediments by Liquid Chromatography. J. Chromatogr. Sci., v. 43, 2005.

SANTANA, C.M.; FERRERA, Z.S; PADRÓN, E.T.; RODRIGUEZ, J.J. Methodologies for the extraction of Phenolic Compounds from Environmental Samples: New Approaches. Molecules, v. 14, p. 298-320, 2009.

SARAJI; M; BAKHSHI, M. Determination of phenols in water samples by singledrop microextraction followed by in-syringe derivatization and gas chromatography-mass spectrometric detection. J. Chromatogr. A, v. 1098, p. 30-36, 2005.

SHIHOMATSU, H.M. Desenvolvimento e validação de metodologia SPELC-MS/MS para a determinação de fármacos e droga de abuso nas águas da represa Guarapiranga-São Paulo/SP, Brasil. 2015. Tese (Doutorado) Instituto de Pesquisas Energéticas e nucleares, São Paulo. 
SILVA, D.C.V.R. Toxicidade da água e sedimento dos reservatórios Guarapiranga, Billings e Paiva Castro, na Região Metropolitana de São Paulo. 2013. Dissertação (Mestrado) - Instituto de Biociências da Universidade de São Paulo, São Paulo.

SILVA, L. F. Reconstrução paleolimnológica da eutrofização na represa Guarapiranga com base em multitraçadores biogeoquímicos. 2013. Tese (Doutorado) - Universidade Estadual Paulista Júlio de Mesquita Filho, Instituto de Biociências de Rio Claro.

SILVA, R.A. Desenvolvimento de software como ferramenta de confiabilidade para a análise da água subterrânea do IPEN. 2012. Dissertação de Mestrado - Instituto de Pesquisas Energéticas Nucleares, IPEN/USP, São Paulo.

SILVEIRA, A. L. C. Validação de métodos para a determinação de compostos fenólicos em melancia. 2013. Dissertação (Mestrado) - Instituto Politécnico de Castelo Branco-Escola Superior Agrária, Portugal, 2013

SOLOMONS, T.W.G. Organic chemistry. Craig B. Fryhle. 8.e.d. 2004.

SOUZA, R.R. Desenvolvimento e validação de metodologia analítica para determinação de disruptores endócrinos resultantes de atividades antrópicas nas águas da região do rio Paraíba do Sul, SP. 2011.

Dissertação (Mestrado) - Instituto de Pesquisa Energéticas e Nucleares, São Paulo.

THOMAZELLI, F.F. Composição da matéria orgânica no gradiente estuarino da Baía de Sepetiba. 2010. Tese (Doutorado) - Universidade Federal Fluminense, Rio de Janeiro.

TUNDISI, J.G. Novas perspectivas para a gestão de recursos hídricos. REVISTA USP, n.70, p. 24-35, 2006.

TUNDISI, J.G. Recursos hídricos no futuro: problemas e soluções. Estud. av., v. 22, n. $63,2008$.

USEPA - United States Environmental Protection Agency. Phenol: Ambient Water Quality Criteria. 1978.

USEPA (United States - Environmental Protection Agency). Toxicological review of Phenol. Washington: IRIS (Integrated Risk Information System $\mathrm{n}$. EPA/635/ R-02/006); 2002.

VERMEULEN, A., WELVAERT, K., VERCAMMEN, J.. Evaluation of a dedicated gas chromatography-mass spectrometry method for the analysis of phenols in water. J. Chromatogr. A, v. 1071, p. 41-46, 2005. 
VIDAL, J. L. M.; VEGA, A.B.; FRENICH, A. G.; GONZALEZ; F. J. E.; LIEBANAS, F. J. A. Determination of fifteen priority phenolic compounds in environmental samples from Andalusia (Spain) by liquid chromatography-mass spectrometry. Anal. Bioanal. Chem., v. 379, p. 125-130, 2004.

VIDAL, J.L.M; LIÉBANAS, F.J.A.; GONZÁLES, F.J.E.; LÓPEZ, E.A.; TORRES, M.E.H; RODRIGUEZ, L.C. Assessment of uncertainty in pesticide multiresidue analytical methods: main sources and estimation. Anal. Chim. Acta, v. 454, p. 237-314, 2002.

WANG, B.; DONG, F.; CHEN, S.; CHEN, M.; BAI, Y.; TAN, J.; LI, J.; WANG, Q. Phenolic endocrine disrupting chemical Sinan urban receiving river (Pan long river) of Yunnan-Guizhou plate au: Occurrence, bioaccumulation and sources. Ecotox. Environ. Safe., v. 128, p. 133-142, 2016.

WHATELY, M.; CUNHA, P. Guarapiranga 2006: Como e por que São Paulo está perdendo este manancial: Resultados e diagnóstico. Instituto sócio ambiental. São Paulo, 2006.

WU, A.; YANG, B.; XI, L.; ZHU, Y. Determination of phenols with ion chromatography-online electrochemical derivatization based on porous electrode-fluorescence detection. J. Chromatogr. A, v. 1229, p. 288-292, 2012.

ZHANG, Y.Z.; TANG, C. Y.; SONG, X. F.; DUN, Y.; MENG, W.; ZHANG, Y. Concentrations, potential sources and behavior of organochlorines and phenolic endocrine-disrupting chemicals in surficial sediment of the Shaying River, eastern China. Environ. Earth. Sci., v. 70, p. 2237-2247, 2013.

ZHOU, F.; LI, X.; ZENG, Z. Determination of phenolic compounds in wastewater samples using a novel fiber by solid-phase microextraction coupled to gas chromatography. Anal. Chim. Acta, v. 538, p. 63-70, 2005.

ZHU, Y.; WHU. S; YANG B.; XI L. Determination of phenols with ion chromatography-online electrochemical derivatization based on porous electrode-fluorescence detection. J Chromatogr. A., v. 1229, p. 288-292, 2012.

ZOCATELLI, R.; CECANHO, F.; AMORIM, M.; BERNARDES, M., MOREIRATURCQ, P; TURCQ, B; SIFEDDINE, A.; Cordeiro, R. C.. Uso dos fenóis da lignina no estudo da matéria orgânica na Várzea do Lago Grande Curuái, Pará e no Lago do Caçó, Maranhão, Brasil. Acta Amaz., v. 41, n. 2, p.195 - 204, 2011. 


\section{ANEXO 1}

Resultados das incertezas parciais envolvidas no Cálculo de Incertezas para todos os compostos estudados.

\section{CÁLCULO DE INCERTEZAS PARA FENOL EM SEDIMENTO}

\section{Incerteza da preparação da solução padrão.}

Grandezas de entrada:pureza do padrão e volume final da solução estoque.

Componentes de incertezas

$\mathrm{u}(\mathrm{P})=0,00577 \mu \mathrm{g}$ Coeficiente de sensibilidade $=0,040 \quad \mathrm{u}(\mathrm{P})=0,00023 \mu \mathrm{gL}^{-1}$ $\mathrm{u}(\mathrm{V})=0,04420 \mathrm{~mL}$ Coeficiente de sensibilidade $=0,001 \quad \mathrm{u}(\mathrm{V})=0,00004 \mu \mathrm{gL}^{-1}$

Incerteza combinada

$\mathrm{u}_{\mathrm{c}}($ Fenol $)=0,00023 \mu \mathrm{g} \mathrm{mL}^{-1}$

\section{Incerteza da preparação da solução de trabalho}

Grandezas de entrada: incerteza da solução estoque, volume pipetado da solução estoque individual para preparação da solução mista de trabalho e volume final da solução mista de trabalho.

Componentes de incertezas

$$
\begin{aligned}
& \mathrm{u}\left(\mathrm{C}_{\text {sol.estoque }}\right)=0,23358 \mu \mathrm{g} \mathrm{mL}^{-1} \\
& \mathrm{u}\left(\mathrm{V}_{\text {i_estoque }}\right)=0,00051 \mu \mathrm{gL}^{-1} \\
& \text { fabricante }=0,00006124 \\
& \text { repe }=0,00051031 \\
& \Delta \mathrm{t}=0,00003031 \\
& \mathrm{u}\left(\mathrm{V}_{\text {final }}\right)=0,00884 \mu \mathrm{g} \mathrm{mL}^{-1} \\
& \text { fabricante }=0,00816497 \\
& \text { repe }=0,00316228 \\
& \Delta \mathrm{t}=0,00121244
\end{aligned}
$$




\section{Incerteza combinada}

$\mathrm{U}_{\mathrm{c}}($ Fenol sol_trabalho $)=0,00266 \mu \mathrm{g} \mathrm{mL}-1$

\section{Incerteza da preparação das soluções de calibração para a curva analítica}

Grandezas de entrada: incerteza da solução de trabalho, volume pipetado da solução de trabalho e volume dos balões usados para diluição das soluções.

$$
\begin{aligned}
& \text { Incerteza volume pipetado para cada solução da curva } \\
& \mathrm{u}(\mathrm{V} 1 \text { _sol.trabalho })=0,0000858 \mu \mathrm{g} \mathrm{\textrm {m } ^ { - 1 }} \\
& \text { fabricante }=0,000002 \\
& \text { repe }=0,000086 \\
& \Delta \mathrm{t}=0,000004 \\
& \mathrm{u}(\mathrm{V} 2 \text { _sol.trabalho })=0,0001430 \mu \mathrm{g} \mathrm{mL} \mathrm{m}^{-1} \\
& \text { fabricante }=0,000003 \\
& \text { repe }=0,000143 \\
& \Delta \mathrm{t}=0,000006 \\
& \mathrm{u}(\mathrm{V} 3 \text { _sol.trabalho })=0,0001237 \mu \mathrm{g} \mathrm{mL}-1 \\
& \text { fabricante }=0,000012 \\
& \text { repe }=0,000122 \\
& \Delta \mathrm{t}=0,000012 \\
& \mathrm{u}(\mathrm{V} 4 \text { _sol.trabalho })=0,0001855 \mu \mathrm{g} \mathrm{mL} \mathrm{m}^{-1} \\
& \text { fabricante }=0,000018 \\
& \text { repe }=0,000184 \\
& \Delta \mathrm{t}=0,000018 \\
& \mathrm{u}(\mathrm{V} 5 \text { _sol.trabalho })=0,0001683 \mu \mathrm{g} \mathrm{mL}-1 \\
& \text { fabricante }=0,000033 \\
& \text { repe }=0,000163 \\
& \Delta \mathrm{t}=0,000024
\end{aligned}
$$

Incerteza balão volumétrico $1 \mathrm{~mL}$ (utilizado para cada uma das soluções de calibração)

$$
\begin{gathered}
\mathrm{u}\left(\mathrm{V}_{-} 1 \mathrm{~mL}\right)=\mathbf{0 , 0 0 4 1} \mu \mathrm{g} \mathrm{mL}-1 \\
\text { fabricante }=0,0041 \\
\text { repe }=0 \\
\Delta \mathrm{t}=0,00012
\end{gathered}
$$




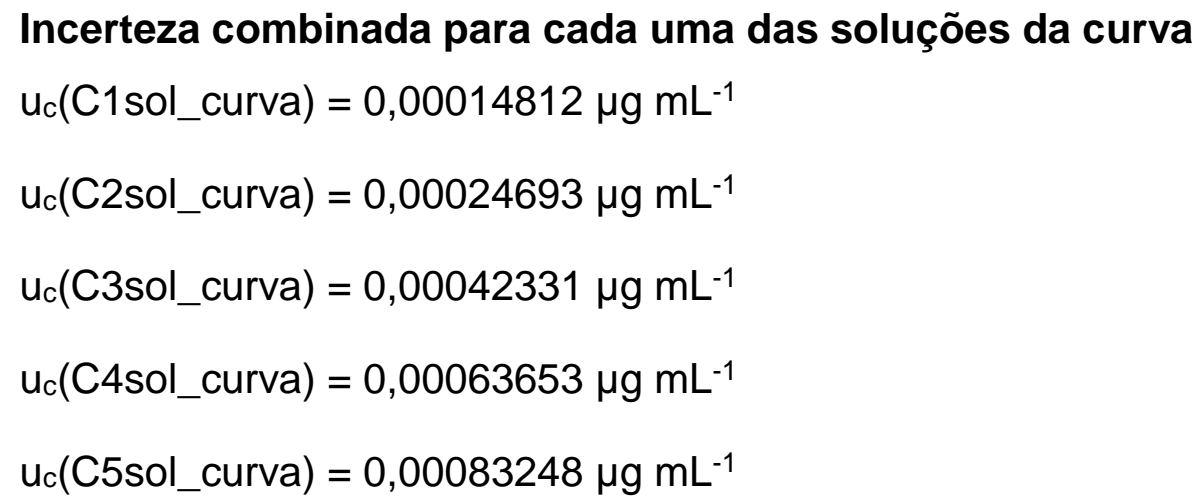

4. Incerteza da curva analítica

Grandezas de entrada: área das amostras, área do branco, soluções da curva (C1 a C5), áreas referentes às soluções da curva. A incerteza combinada da curva foi calculada pelo método dos mínimos quadrados, utilizando a planilha elaborada por Martins (2010), baseada no ISO-GUM (2008) e EURACHEM (2012).

Incerteza combinada da curva analítica

$\mathrm{uc}_{\mathrm{c}}($ Fenolcurva_analítica $)=0,0017 \mu \mathrm{g} \mathrm{mL}-1$

\section{Incerteza da recuperação}

Grandezas de entrada: concentração da solução padrão e resultado da concentração encontrada.

Incerteza combinada da recuperação em três concentrações

$$
\begin{aligned}
& \mathrm{u}_{\mathrm{c}}(\text { Fenolrecuperação_0,05) }=0,032 \mu \mathrm{g} \mathrm{mL}-1 \\
& \mathrm{u}\left(\mathrm{C}_{\text {real }}\right)=0,00133 \mu \mathrm{g} \mathrm{mL}^{-1} \\
& \mathrm{u}\left(\mathrm{C}_{\text {encontrada }}\right)=0,037 \mu \mathrm{g} \mathrm{mL}-1 \\
& \mathrm{u}_{\mathrm{c}}\left(\text { Fenol } \text { recuperação_0,1 }=0,064 \mu \mathrm{g} \mathrm{mL} \mathrm{L}^{-1}\right. \\
& \mathrm{u}\left(\mathrm{C}_{\text {real }}\right)=0,00133 \mu \mathrm{g} \mathrm{mL}-1 \\
& \mathrm{u}\left(\mathrm{C}_{\text {encontrada }}\right)=0,068 \mu \mathrm{g} \mathrm{mL}-1 \\
& \mathrm{Uc}_{\mathrm{c}}\left(\text { Fenolrecuperação_0,2) }=0,008 \mu \mathrm{g} \mathrm{mL} \mathrm{m}^{-1} \text { (equivalente à concentração de } 0,2 \mu \mathrm{g} \mathrm{mL}^{-1}\right. \text { ) } \\
& \mathrm{u}(\text { Creal })=0,00133 \mu \mathrm{g} \mathrm{mL}^{-1} \\
& \mathrm{u}(\text { Cencontrada })=0,010 \mu \mathrm{g} \mathrm{mL}^{-1}
\end{aligned}
$$




\section{CÁLCULO DE INCERTEZAS PARA 3-METILFENOL EM SEDIMENTO}

1. Incerteza da preparação da solução padrão.

Grandezas de entrada:pureza do padrão e volume final da solução estoque.

Componentes de incertezas

$\mathrm{u}(\mathrm{P})=0,00577 \mu \mathrm{g}$ Coeficiente de sensibilidade $=0,040 \quad \mathrm{u}(\mathrm{P})=0,00023 \mu \mathrm{gL}^{-1}$

$\mathrm{u}(\mathrm{V})=0,04420 \mathrm{~mL}$ Coeficiente de sensibilidade $=0,001 \quad \mathrm{u}(\mathrm{V})=0,00004 \mu \mathrm{g} \mathrm{mL}^{-1}$

\section{Incerteza combinada}

$\mathrm{u}_{\mathrm{c}}(3-$ Metilfenol $)=0,00023 \mu \mathrm{g} \mathrm{mL}-1$

\section{Incerteza da preparação da solução de trabalho}

Grandezas de entrada: incerteza da solução estoque, volume pipetado da solução estoque individual para preparação da solução mista de trabalho e volume final da solução mista de trabalho.

Componentes de incertezas

$\mathrm{u}\left(\mathrm{C}_{\text {sol. estoque }}\right)=0,23358 \mu \mathrm{g} \mathrm{mL}^{-1}$

$\mathrm{u}\left(\mathrm{V}_{\text {i_estoque }}\right)=0,00051 \mu \mathrm{g} \mathrm{m}^{-1}$

fabricante $=6,12372 \mathrm{E}-05$

repe $=0,00051031$

$\Delta \mathrm{t}=3,03109 \mathrm{E}-05$

$\mathrm{u}\left(\mathrm{V}_{\text {final }}\right)=0,00884 \mu \mathrm{g} \mathrm{mL}^{-1}$

fabricante $=0,008164966$

repe $=0,003162278$

$\Delta \mathrm{t}=0,001212436$

\section{Incerteza combinada}

$\mathrm{u}_{\mathrm{c}}($ Fenolsol_trabalho $)=0,00266 \mu \mathrm{g} \mathrm{mL}^{-1}$ 


\section{Incerteza da preparação das soluções de calibração para a curva analítica}

Grandezas de entrada: incerteza da solução de trabalho, volume pipetado da solução de trabalho e volume dos balões usados para diluição das soluções.

Incerteza volume pipetado para cada solução da curva

$\mathrm{u}(\mathrm{V} 1$ _sol.trabalho $)=8,58264 \mathrm{E}-05 \mu \mathrm{g} \mathrm{mL}-1$

fabricante $=0,000002$

repe $=0,000086$

$\Delta \mathrm{t}=0,000004$

$\mathrm{u}(\mathrm{V} 2$ sol.trabalho $)=0,000143044 \mu \mathrm{g} \mathrm{mL}-1$

fabricante $=0,000003$

repe $=0,000143$

$\Delta \mathrm{t}=0,000006$

$\mathrm{u}(\mathrm{V} 3$ _sol.trabalho $)=0,000123681 \mu \mathrm{g} \mathrm{mL}^{-1}$

fabricante $=0,000012$

repe $=0,000122$

$\Delta \mathrm{t}=0,000012$

$\mathrm{u}(\mathrm{V} 4$ _sol.trabalho $)=0,000185522 \mu \mathrm{g} \mathrm{mL}^{-1}$

fabricante $=0,000018$

repe $=0,000184$

$\Delta \mathrm{t}=0,000018$

$\mathrm{u}(\mathrm{V} 5$ _sol.trabalho $)=0,000168289 \mu \mathrm{g} \mathrm{mL}^{-1}$

fabricante $=0,000033$

repe $=0,000163$

$\Delta \mathrm{t}=0,000024$

Incerteza balão volumétrico $1 \mathrm{~mL}$ (utilizado para cada uma das soluções de calibração)

$$
\begin{aligned}
\mathrm{u}\left(\mathrm{V}_{-} 1 \mathrm{~mL}\right)=\mathbf{0 , 0 0 4 1} \mu \mathrm{gL}^{-1} & \\
& \text { fabricante }=0,0041 \\
& \text { repe }=0 \\
& \Delta \mathrm{t}=0,00012
\end{aligned}
$$

Incerteza combinada para cada uma das soluções da curva

$\mathrm{u}_{\mathrm{c}}(\mathrm{C} 1$ sol_curva $)=0,000148121 \mathrm{~g} \mathrm{~mL}^{-1}$

$\mathrm{u}_{\mathrm{c}}(\mathrm{C} 2 \mathrm{sol}$ curva $)=0,000246925 \mu \mathrm{g} \mathrm{mL}$ 


$$
\begin{aligned}
& u_{c}(\text { C3sol_curva })=0,000423311 \mu \mathrm{g} \mathrm{mL}^{-1} \\
& u_{c}(\text { C4sol_curva })=0,000636527 \mu \mathrm{g} \mathrm{m}^{-1} \\
& \mathrm{u}_{\mathrm{c}}(\text { C5sol_curva })=0,000832478 \mu \mathrm{g} \mathrm{mL}^{-1}
\end{aligned}
$$

\section{Incerteza da curva analítica}

Grandezas de entrada: área das amostras, área do branco, soluções da curva ( $C 1$ a $C 5)$, áreas referentes às soluções da curva.

A incerteza é calculada pelo método de Kragten, ou método relativo, proposto pelo ISO GUM

Incerteza combinada da curva analítica

$\mathrm{u}_{\mathrm{c}}(3-$ Metilfenol curva_analítica $)=0,0,0107 \mu \mathrm{g} \mathrm{mL}$

\section{Incerteza da recuperação}

Grandezas de entrada: concentração da solução padrão e resultado da concentração encontrada.

Incerteza combinada da recuperação em três concentrações

$u_{c}\left(3-\right.$ Metilfenolrecuperação_o,05) $=0,032 \mu \mathrm{g} \mathrm{mL}^{-1}$

$$
\begin{aligned}
& \mathrm{u}(\text { Creal })=0,00133 \mu \mathrm{g} \mathrm{mL}^{-1} \\
& \mathrm{u}(\text { Cencontrada })=0,037 \mu \mathrm{g} \mathrm{mL}^{-1}
\end{aligned}
$$

$\mathrm{U}_{\mathrm{c}}(3$-Metilfenolrecuperação_ 0,1$)=0,064 \mu \mathrm{g} \mathrm{mL}$

$$
\begin{aligned}
& \mathrm{u}\left(\text { Creal }_{\text {rea }}=0,00133 \mu \mathrm{g} \mathrm{mL}^{-1}\right. \\
& \mathrm{u}(\text { Cencontrada })=0,068 \mu \mathrm{g} \mathrm{mL}^{-1}
\end{aligned}
$$

$\mathrm{U}_{\mathrm{c}}\left(3-\right.$ Metilfenol ecuperação_o,2) $=0,008 \mu \mathrm{g} \mathrm{mL}^{-1}$ (equivalente à concentração de $0,2 \mu \mathrm{g}$ $\left.\mathrm{mL}^{-1}\right)$

$$
\begin{aligned}
& \mathrm{u}(\text { Creal })=0,00133 \mu \mathrm{g} \mathrm{mL}^{-1} \\
& \mathrm{u}(\text { Cencontrada })=0,010 \mu \mathrm{gL}^{-1}
\end{aligned}
$$




\section{CÁLCULO DE INCERTEZAS PARA 2-NITROFENOL EM SEDIMENTO}

1. Incerteza da preparação da solução padrão.

Grandezas de entrada:pureza do padrão e volume final da solução estoque.

Componentes de incertezas

$u(P)=0,01155 \mu \mathrm{g}$ Coeficiente de sensibilidade $=0,040 \quad u(P)=0,00046 \mu \mathrm{gL}^{-1}$

$\mathrm{u}(\mathrm{V})=0,04420 \mathrm{~mL}$ Coeficiente de sensibilidade $=0,001 \quad \mathrm{u}(\mathrm{V})=0,00003 \mu \mathrm{g} \mathrm{mL}^{-1}$

\section{Incerteza combinada}

$\mathrm{uc}_{\mathrm{c}}(2-$ Nitrofenol $)=0,00046 \mu \mathrm{gL}^{-1}$

\section{Incerteza da preparação da solução de trabalho}

Grandezas de entrada: incerteza da solução estoque, volume pipetado da solução estoque individual para preparação da solução mista de trabalho e volume final da solução mista de trabalho.

Componentes de incertezas

$\mathrm{u}\left(\mathrm{C}_{\text {sol.estoque }}\right)=0,46318 \mu \mathrm{g} \mathrm{mL}^{-1}$

$\mathrm{u}\left(\mathrm{V}_{\text {i_estoque }}\right)=0,00051 \mu \mathrm{g} \mathrm{m}^{-1}$

fabricante $=6,12372 \mathrm{E}-05$

repe $=0,00051031$

$\Delta \mathrm{t}=3,03109 \mathrm{E}-05$

$\mathrm{u}\left(\mathrm{V}_{\text {final }}\right)=0,00884 \mu \mathrm{g} \mathrm{mL}^{-1}$

fabricante $=0,008164966$

repe $=0,003162278$

$\Delta \mathrm{t}=0,001212436$

Incerteza combinada

$\mathrm{u}_{\mathrm{c}}(2$-Nitrofenolsol_trabalho $)=0,00363 \mu \mathrm{g} \mathrm{mL}^{-1}$ 


\section{Incerteza da preparação das soluções de calibração para a curva analítica}

Grandezas de entrada: incerteza da solução de trabalho, volume pipetado da solução de trabalho e volume dos balões usados para diluição das soluções.

$$
\begin{aligned}
& \text { Incerteza volume pipetado para cada solução da curva } \\
& \mathrm{u}(\mathrm{V} 1 \text { _sol.trabalho })=8,58264 \mathrm{E}-05 \mu \mathrm{g} \mathrm{mL}-1 \\
& \text { fabricante }=0,000002 \\
& \text { repe }=0,000086 \\
& \Delta \mathrm{t}=0,000004 \\
& \mathrm{u}(\text { V2_sol.trabalho })=0,000143044 \mu \mathrm{g} \mathrm{mL}^{-1} \\
& \text { fabricante }=0,000003 \\
& \text { repe }=0,000143 \\
& \Delta \mathrm{t}=0,000006 \\
& \mathrm{u}(\text { V3_sol.trabalho })=0,000123681 \mu \mathrm{gL}^{-1} \\
& \text { fabricante }=0,000012 \\
& \text { repe }=0,000122 \\
& \Delta \mathrm{t}=0,000012 \\
& \mathrm{u}(\mathrm{V} 4 \text { _sol.trabalho })=0,000185522 \mu \mathrm{g} \mathrm{mL}-1 \\
& \text { fabricante }=0,000018 \\
& \text { repe }=0,000184 \\
& \Delta \mathrm{t}=0,000018 \\
& \mathrm{u}(\text { V5_sol.trabalho })=0,000168289 \mu \mathrm{g} \mathrm{mL}^{-1} \\
& \text { fabricante }=0,000033 \\
& \text { repe }=0,000163 \\
& \Delta \mathrm{t}=0,000024
\end{aligned}
$$

Incerteza balão volumétrico $1 \mathrm{~mL}$ (utilizado para cada uma das soluções de calibração)

$$
\begin{gathered}
\mathrm{u}\left(\mathrm{V}_{-} 1 \mathrm{~mL}\right)=\mathbf{0 , 0 0 4 1 \mu g ~ \mathrm { mL } ^ { - 1 }} \\
\text { fabricante }=0,0041 \\
\text { repe }=0 \\
\Delta \mathrm{t}=0,00012
\end{gathered}
$$


Incerteza combinada para cada uma das soluções da curva

$\mathrm{u}_{\mathrm{c}}(\mathrm{C} 1$ sol_curva $)=0,000148121 \mu \mathrm{g} \mathrm{mL}^{-1}$

$u_{c}($ C2sol_curva $)=0,000246925 \mu \mathrm{g} \mathrm{mL}^{-1}$

$\mathrm{uc}_{\mathrm{c}}($ C3sol_curva $)=0,000423311 \mu \mathrm{g} \mathrm{mL}^{-1}$

$\mathrm{u}_{\mathrm{c}}\left(\mathrm{C} 4 \mathrm{sol} \_\right.$curva $)=0,000636527 \mu \mathrm{g} \mathrm{mL}^{-1}$

$\mathrm{u}_{\mathrm{c}}($ C5sol_curva $)=0,000832478 \mu \mathrm{g} \mathrm{mL}^{-1}$

\section{Incerteza da curva analítica}

Grandezas de entrada: área das amostras, área do branco, soluções da curva ( $\mathrm{C} 1 \mathrm{a} \mathrm{C}$ ), áreas referentes às soluções da curva.

Incerteza combinada da curva analítica

$\mathrm{u}_{\mathrm{c}}\left(2\right.$-Nitrofenol $\left.{ }_{\text {curva_analítica }}\right)=0,0008 \mu \mathrm{g} \mathrm{mL}-1$

\section{Incerteza da recuperação}

Grandezas de entrada: concentração da solução padrão e resultado da concentração encontrada.

\section{Incerteza combinada da recuperação em três concentrações}

$\mathrm{u}_{\mathrm{c}}\left(2\right.$-Nitrofenolrecuperação_o,05) $=0,027 \mu \mathrm{gL}^{-1}$

$$
\begin{aligned}
& \mathrm{u}\left(\text { C }_{\text {real }}\right)=0,00182 \mu \mathrm{g} \mathrm{mL}^{-1} \\
& \mathrm{u}(\text { Cencontrada })=0,031 \mu \mathrm{g} \mathrm{mL}^{-1}
\end{aligned}
$$

$\mathrm{uc}_{\mathrm{c}}(2$-Nitrofenolrecuperação_0,1) $=0,063 \mu \mathrm{g} \mathrm{mL}-1$

$$
\mathrm{u}(\text { Creal })=0,00182 \mathrm{~g} \mathrm{~mL}^{-1}
$$

$\mathrm{u}\left(\mathrm{C}_{\text {encontrada }}\right)=0,075 \mu \mathrm{gL} \mathrm{m}^{-1}$

$\mathrm{u}_{\mathrm{c}}(2$-Nitrofenolrecuperação_0,2) $=0,034 \mu \mathrm{g} \mathrm{mL}-1$

$$
\begin{aligned}
& \mathrm{u}\left(C_{\text {real }}\right)=0,00182 \mu \mathrm{g} \mathrm{mL}^{-1} \\
& \mathrm{u}\left(C_{\text {encontrada }}\right)=0,039 \mu \mathrm{gL}^{-1}
\end{aligned}
$$




\section{CÁLCULO DE INCERTEZAS PARA 2,4-DICLOROFENOL EM SEDIMENTO}

\section{Incerteza da preparação da solução padrão.}

Grandezas de entrada: pureza do padrão e volume final da solução estoque.

Componentes de incertezas

$\mathrm{u}(\mathrm{P})=0,00577 \mu \mathrm{g}$ Coeficiente de sensibilidade $=0,040 \quad \mathrm{u}(\mathrm{P})=0,00023 \mu \mathrm{gL}^{-1}$

$\mathrm{u}(\mathrm{V})=0,04420 \mathrm{~mL}$ Coeficiente de sensibilidade $=0,001 \quad \mathrm{u}(V)=0,00004 \mu \mathrm{g} \mathrm{mL}^{-1}$

\section{Incerteza combinada \\ $\mathrm{u}_{\mathrm{c}}(2,4$-Diclorofenol $)=0,00023 \mu \mathrm{g} \mathrm{mL}^{-1}$}

\section{Incerteza da preparação da solução de trabalho}

Grandezas de entrada: incerteza da solução estoque, volume pipetado da solução estoque individual para preparação da solução mista de trabalho e volume final da solução mista de trabalho.

$$
\begin{aligned}
& \text { Componentes de incertezas } \\
& \mathrm{u}\left(\mathrm{C}_{\text {sol.estoque }}\right)=0,23358 \mu \mathrm{gL}^{-1} \\
& \mathrm{u}\left(\mathrm{V}_{\text {i_estoque }}\right)=0,00051 \mu \mathrm{gL}^{-1} \\
& \text { fabricante }=6,12372 \mathrm{E}-05 \\
& \text { repe }=0,00051031 \\
& \Delta \mathrm{t}=3,03109 \mathrm{E}-05 \\
& \mathrm{u}\left(\mathrm{V}_{\text {final }}\right)=0,00884 \mu \mathrm{g} \mathrm{mL}^{-1} \\
& \text { fabricante }=0,008164966 \\
& \text { repe }=0,003162278 \\
& \Delta \mathrm{t}=0,001212436
\end{aligned}
$$

Incerteza combinada

$\mathrm{u}_{\mathrm{c}}(2,4$-Diclorofenolsol_trabalho $)=0,00266 \mu \mathrm{g} \mathrm{mL}$ 


\section{Incerteza da preparação das soluções de calibração para a curva analítica}

Grandezas de entrada: incerteza da solução de trabalho, volume pipetado da solução de trabalho e volume dos balões usados para diluição das soluções.

Incerteza volume pipetado para cada solução da curva

$$
\begin{aligned}
& \mathrm{u}(\mathrm{V} 1 \text { _sol.trabalho })=8,58264 \mathrm{E}-05 \mu \mathrm{gL}^{-1} \\
& \text { fabricante }=0,000002 \\
& \text { repe }=0,000086 \\
& \Delta \mathrm{t}=0,000004 \\
& \mathrm{u}(\mathrm{V} 2 \text { _sol.trabalho })=0,000143044 \mu \mathrm{g} \mathrm{m}^{-1} \\
& \text { fabricante }=0,000003 \\
& \text { repe }=0,000143 \\
& \Delta \mathrm{t}=0,000006 \\
& \mathrm{u}(\mathrm{V} 3 \text { _sol.trabalho })=0,000123681 \mu \mathrm{gL}^{-1}
\end{aligned}
$$$$
\text { fabricante }=0,000012
$$$$
\text { repe }=0,000122
$$$$
\Delta \mathrm{t}=0,000012
$$$$
\mathrm{u}(\mathrm{V} 4 \text { _sol.trabalho })=0,000185522 \mu \mathrm{g} \mathrm{mL}^{-1}
$$$$
\text { fabricante }=0,000018
$$$$
\text { repe }=0,000184
$$$$
\Delta \mathrm{t}=0,000018
$$

$$
\mathrm{u}(\mathrm{V} 5 \text { _sol.trabalho })=0,000168289 \mu \mathrm{g} \mathrm{mL}^{-1}
$$

fabricante $=0,000033$

$$
\begin{aligned}
& \text { repe }=0,000163 \\
& \Delta \mathrm{t}=0,000024
\end{aligned}
$$

Incerteza balão volumétrico $1 \mathrm{~mL}$ (utilizado para cada uma das soluções de calibração)

$$
\begin{gathered}
\mathrm{u}\left(\mathrm{V}_{-} 1 \mathrm{~mL}\right)=\mathbf{0 , 0 0 4 1 \mu \mathrm { mL } ^ { - 1 }} \\
\text { fabricante }=0,0041 \\
\text { repe }=0 \\
\Delta \mathrm{t}=0,00012
\end{gathered}
$$




$$
\begin{aligned}
& \mathrm{uc}_{c}(\text { C2sol_curva })=0,000246925 \mu \mathrm{g} \mathrm{mL}^{-1} \\
& \mathrm{u}_{c}(\text { C3sol_curva })=0,000423311 \mu \mathrm{g} \mathrm{mL}^{-1} \\
& \mathrm{u}_{c}(\text { C4sol_curva })=0,000636527 \mu \mathrm{g} \mathrm{mL}^{-1} \\
& \mathrm{u}_{c}(\text { C5sol_curva })=0,000832478 \mu \mathrm{g} \mathrm{mL}^{-1}
\end{aligned}
$$

\section{Incerteza da curva analítica}

Grandezas de entrada: área das amostras, área do branco, soluções da curva ( $\mathrm{C} 1 \mathrm{a} \mathrm{C} 5)$, áreas referentes às soluções da curva.

Incerteza combinada da curva analítica

$\mathrm{uc}_{\mathrm{c}}(2,4$-Diclorofenolcurva_analítica $)=0,0009 \mu \mathrm{g} \mathrm{mL}^{-1}$

\section{Incerteza da recuperação}

Grandezas de entrada: concentração da solução padrão e resultado da concentração encontrada.

\section{Incerteza combinada da recuperação em três concentrações}

$\mathrm{uc}_{\mathrm{c}}(2,4$-Diclorofenolrecuperação_ 0,05$)=0,026 \mu \mathrm{g} \mathrm{mL}^{-1}$

$\mathrm{u}($ Creal $)=0,00133 \mu \mathrm{g} \mathrm{mL}^{-1}$

$\mathrm{u}($ Cencontrada $)=0,026 \mu \mathrm{g} \mathrm{mL}^{-1}$

$\mathrm{u}_{\mathrm{c}}\left(2,4\right.$-Diclorofenolrecuperação _0,1) $=0,010 \mu \mathrm{g} \mathrm{mL}^{-1}$

$\mathrm{u}($ Creal $)=0,00133 \mathrm{\mu g} \mathrm{mL}^{-1}$

$\mathrm{u}($ Cencontrada $)=0,010 \mu \mathrm{g} \mathrm{mL}^{-1}$

$\mathrm{uc}_{\mathrm{c}}\left(2,4\right.$-Diclorofenolrecuperação _0,2) $=0,028 \mu \mathrm{g} \mathrm{mL}^{-1}$

$\mathrm{u}($ Creal $)=0,00133 \mu \mathrm{g} \mathrm{mL}^{-1}$

$\mathrm{u}($ Cencontrada $)=0,030 \mu \mathrm{gL}^{-1}$ 


\section{CÁLCULO DE INCERTEZAS PARA 4-CLORO-3-METILFENOL EM SEDIMENTO}

\section{Incerteza da preparação da solução padrão.}

Grandezas de entrada:pureza do padrão e volume final da solução estoque.

Componentes de incertezas

$\mathrm{u}(\mathrm{P})=0,00577 \mu \mathrm{g}$ Coeficiente de sensibilidade $=0,040 \quad \mathrm{u}(\mathrm{P})=0,00023 \mu \mathrm{gL}^{-1}$

$\mathrm{u}(\mathrm{V})=0,04420 \mathrm{~mL}$ Coeficiente de sensibilidade $=0,001 \quad \mathrm{u}(V)=0,00004 \mu \mathrm{g} \mathrm{mL}^{-1}$

\section{Incerteza combinada \\ $\mathrm{u}_{\mathrm{c}}\left(4\right.$-Cloro-3-Metilfenol) $=0,00023 \mu \mathrm{g} \mathrm{mL}^{-1}$}

\section{Incerteza da preparação da solução de trabalho}

Grandezas de entrada: incerteza da solução estoque, volume pipetado da solução estoque individual para preparação da solução mista de trabalho e volume final da solução mista de trabalho.

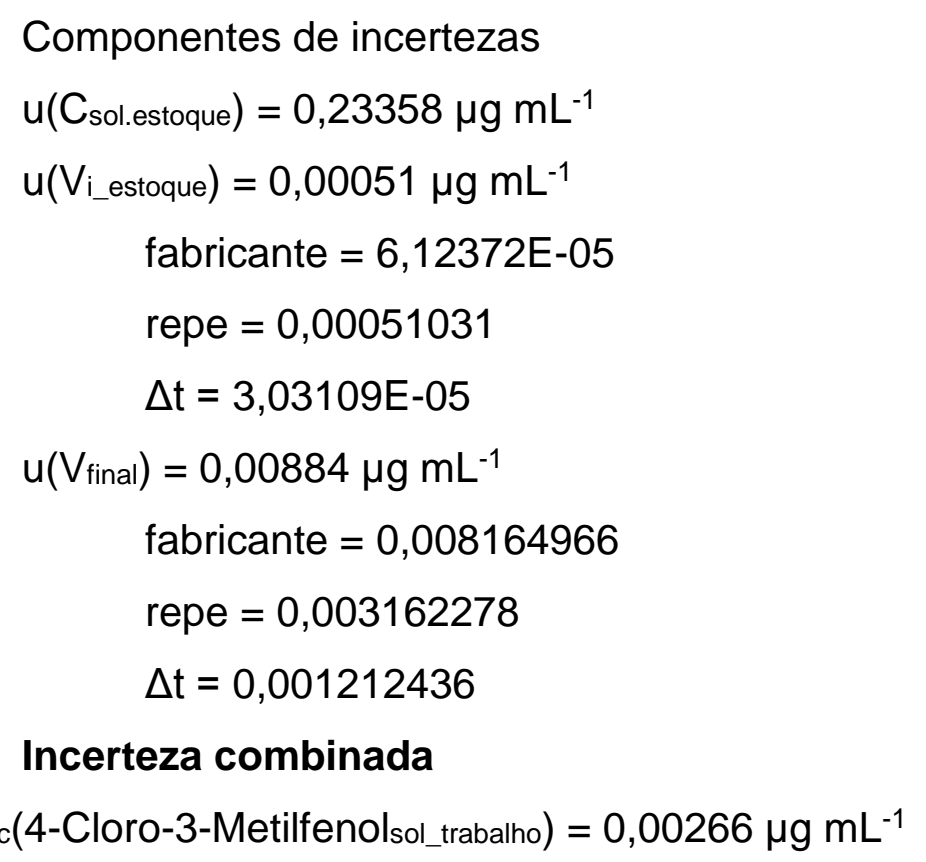




\section{Incerteza da preparação das soluções de calibração para a curva analítica}

Grandezas de entrada: incerteza da solução de trabalho, volume pipetado da solução de trabalho e volume dos balões usados para diluição das soluções.

Incerteza volume pipetado para cada solução da curva

$$
\begin{aligned}
& \mathrm{u}(\mathrm{V} 1 \text { _sol.trabalho })=8,58264 \mathrm{E}-05 \mu \mathrm{gL}^{-1} \\
& \text { fabricante }=0,000002 \\
& \text { repe }=0,000086 \\
& \Delta \mathrm{t}=0,000004 \\
& \mathrm{u}(\mathrm{V} 2 \text { _sol.trabalho })=0,000143044 \mu \mathrm{g} \mathrm{m}^{-1} \\
& \text { fabricante }=0,000003 \\
& \text { repe }=0,000143 \\
& \Delta \mathrm{t}=0,000006 \\
& \mathrm{u}(\mathrm{V} 3 \text { _sol.trabalho })=0,000123681 \mu \mathrm{gL}^{-1}
\end{aligned}
$$

fabricante $=0,000012$

repe $=0,000122$

$\Delta \mathrm{t}=0,000012$

$\mathrm{u}(\mathrm{V} 4$ _sol.trabalho $)=0,000185522 \mu \mathrm{g} \mathrm{mL}^{-1}$

fabricante $=0,000018$

repe $=0,000184$

$\Delta \mathrm{t}=0,000018$

$\mathrm{u}(\mathrm{V} 5$ _sol.trabalho $)=0,000168289 \mu \mathrm{g} \mathrm{mL}^{-1}$

fabricante $=0,000033$

repe $=0,000163$

$\Delta \mathrm{t}=0,000024$

Incerteza balão volumétrico $1 \mathrm{~mL}$ (utilizado para cada uma das soluções de calibração)

$$
\begin{gathered}
\mathrm{u}\left(\mathrm{V}_{-} 1 \mathrm{~mL}\right)=\mathbf{0 , 0 0 4 1 \mu \mathrm { mL } ^ { - 1 }} \\
\text { fabricante }=0,0041 \\
\text { repe }=0 \\
\Delta \mathrm{t}=0,00012
\end{gathered}
$$

Incerteza combinada para cada uma das soluções da curva $\mathrm{uc}_{\mathrm{c}}$ C1sol_curva $)=0,000148121 \mu \mathrm{g} \mathrm{mL}^{-1}$ 


$$
\begin{aligned}
& u_{c}(\text { C2sol_curva })=0,000246925 \mu \mathrm{g} \mathrm{mL}^{-1} \\
& u_{c}(\text { C3sol_curva })=0,000423311 \mu \mathrm{g} \mathrm{mL}^{-1} \\
& u_{c}(\text { C4sol_curva })=0,000636527 \mu \mathrm{g} \mathrm{mL}^{-1} \\
& u_{c}(\text { C5sol_curva })=0,000832478 \mu \mathrm{g} \mathrm{mL}^{-1}
\end{aligned}
$$

\section{Incerteza da curva analítica}

Grandezas de entrada: área das amostras, área do branco, soluções da curva ( $\mathrm{C} 1 \mathrm{a} \mathrm{C} 5)$, áreas referentes às soluções da curva.

Incerteza combinada da curva analítica

$\mathrm{u}_{\mathrm{c}}(4$-Cloro-3-Metilfenolcurva_analítica $)=0,0020 \mathrm{\mu g} \mathrm{mL}^{-1}$

\section{Incerteza da recuperação}

Grandezas de entrada: concentração da solução padrão e resultado da concentração encontrada.

Incerteza combinada da recuperação em três concentrações

$$
\begin{aligned}
& \mathrm{uc}_{\mathrm{c}}(\text { Fenolrecuperação_ } 0,05)=0,014 \mu \mathrm{g} \mathrm{mL}^{-1} \\
& \mathrm{u}\left(\mathrm{C}_{\text {real }}\right)=0,00133 \mu \mathrm{g} \mathrm{mL}^{-1} \\
& \mathrm{u}\left(C_{\text {encontrada }}\right)=0,018 \mathrm{~g} \mathrm{~mL}^{-1} \\
& \left.\mathrm{uc}_{\mathrm{c}} \text { (4-Cloro-3-Metilfenolrecuperação_0,1 }\right)=0,070 \mu \mathrm{g} \mathrm{mL}^{-1} \\
& \mathrm{u}(\text { Creal })=0,00133 \mu \mathrm{g} \mathrm{mL}^{-1} \\
& \mathrm{u}(\text { Cencontrada })=0,076 \mu \mathrm{g} \mathrm{mL}^{-1} \\
& \mathrm{Uc}_{\mathrm{c}} \text { (4-Cloro-3-Metilfenolrecuperação_o,2) }=0,085 \mu \mathrm{g} \mathrm{mL}^{-1} \\
& \mathrm{u}(\text { Creal })=0,00133 \mu \mathrm{g} \mathrm{mL}^{-1} \\
& \mathrm{u}(\text { Cencontrada })=0,094 \mu \mathrm{gL}^{-1}
\end{aligned}
$$




\section{CÁLCULO DE INCERTEZAS PARA 2,4,6-TRICLOROFENOL EM SEDIMENTO}

1. Incerteza da preparação da solução padrão.

Grandezas de entrada:pureza do padrão e volume final da solução estoque.

Componentes de incertezas

$u(P)=0,01155 \mu \mathrm{g} \quad$ Coeficiente de sensibilidade $=0,040 \quad u(P)=0,00046 \mu \mathrm{gL}^{-1}$

$\mathrm{u}(\mathrm{V})=0,04420 \mathrm{~mL}$ Coeficiente de sensibilidade $=0,001 \quad \mathrm{u}(V)=0,00003 \mu \mathrm{g} \mathrm{mL}^{-1}$

\section{Incerteza combinada \\ $\mathrm{uc}_{\mathrm{c}}(2,4,6$-Triclorofenol $)=0,00046 \mu \mathrm{g} \mathrm{mL}^{-1}$}

\section{Incerteza da preparação da solução de trabalho}

Grandezas de entrada: incerteza da solução estoque, volume pipetado da solução estoque individual para preparação da solução mista de trabalho e volume final da solução mista de trabalho.

$$
\begin{aligned}
& \text { Componentes de incertezas } \\
& \mathrm{u}\left(\mathrm{C}_{\text {sol.estoque }}\right)=0,46318 \mu \mathrm{gL} \mathrm{m}^{-1} \\
& \mathrm{u}\left(\mathrm{V}_{\text {i_estoque }}\right)=0,00051 \mu \mathrm{gL}^{-1} \\
& \quad \begin{array}{l}
\text { fabricante }=6,12372 \mathrm{E}-05 \\
\text { repe }=0,00051031 \\
\Delta \mathrm{t}=3,03109 \mathrm{E}-05 \\
\mathrm{u}\left(\mathrm{V}_{\text {final }}\right)=0,00884 \mu \mathrm{g} \mathrm{mL}^{-1} \\
\text { fabricante }=0,008164966 \\
\text { repe }=0,003162278 \\
\Delta \mathrm{t}=0,001212436
\end{array}
\end{aligned}
$$

Incerteza combinada

$\mathrm{u}_{c}(2,4,6$-Triclorofenolsol_trabalho $)=0,00363 \mu \mathrm{g} \mathrm{mL}^{-1}$ 


\section{Incerteza da preparação das soluções de calibração para a curva analítica}

Grandezas de entrada: incerteza da solução de trabalho, volume pipetado da solução de trabalho e volume dos balões usados para diluição das soluções.

Incerteza volume pipetado para cada solução da curva

$$
\begin{aligned}
& \mathrm{u}(\mathrm{V} 1 \text { _sol.trabalho })=8,58264 \mathrm{E}-05 \mu \mathrm{gL}^{-1} \\
& \text { fabricante }=0,000002 \\
& \text { repe }=0,000086 \\
& \Delta \mathrm{t}=0,000004 \\
& \mathrm{u}(\mathrm{V} 2 \text { _sol.trabalho })=0,000143044 \mu \mathrm{g} \mathrm{m}^{-1} \\
& \text { fabricante }=0,000003 \\
& \text { repe }=0,000143 \\
& \Delta \mathrm{t}=0,000006 \\
& \mathrm{u}(\mathrm{V} 3 \text { _sol.trabalho })=0,000123681 \mu \mathrm{gL}^{-1}
\end{aligned}
$$$$
\text { fabricante }=0,000012
$$$$
\text { repe }=0,000122
$$$$
\Delta \mathrm{t}=0,000012
$$$$
\mathrm{u}(\mathrm{V} 4 \text { _sol.trabalho })=0,000185522 \mu \mathrm{g} \mathrm{mL}^{-1}
$$$$
\text { fabricante }=0,000018
$$$$
\text { repe }=0,000184
$$$$
\Delta \mathrm{t}=0,000018
$$

$$
\mathrm{u}(\mathrm{V} 5 \text { _sol.trabalho })=0,000168289 \mu \mathrm{g} \mathrm{mL}^{-1}
$$

fabricante $=0,000033$

$$
\begin{aligned}
& \text { repe }=0,000163 \\
& \Delta \mathrm{t}=0,000024
\end{aligned}
$$

Incerteza balão volumétrico $1 \mathrm{~mL}$ (utilizado para cada uma das soluções de calibração)

$$
\begin{gathered}
\mathrm{u}\left(\mathrm{V}_{-} 1 \mathrm{~mL}\right)=\mathbf{0 , 0 0 4 1 \mu \mathrm { mL } ^ { - 1 }} \\
\text { fabricante }=0,0041 \\
\text { repe }=0 \\
\Delta \mathrm{t}=0,00012
\end{gathered}
$$




$$
\begin{aligned}
& u_{c}(\text { C2sol_curva })=0,000246925 \mu \mathrm{g} \mathrm{mL}^{-1} \\
& u_{c}(\text { C3sol_curva })=0,000423311 \mu \mathrm{g} \mathrm{mL}^{-1} \\
& u_{c}(\text { C4sol_curva })=0,000636527 \mu \mathrm{g} \mathrm{mL}^{-1} \\
& u_{c}(\text { C5sol_curva })=0,000832478 \mu \mathrm{g} \mathrm{mL}^{-1}
\end{aligned}
$$

\section{Incerteza da curva analítica}

Grandezas de entrada: área das amostras, área do branco, soluções da curva ( $\mathrm{C} 1 \mathrm{a} \mathrm{C} 5)$, áreas referentes às soluções da curva.

Incerteza combinada da curva analítica

$\mathrm{u}_{\mathrm{c}}\left(2,4,6\right.$-Triclorofenol ${ }_{\text {curva_analítica })}=0,0011 \mu \mathrm{g} \mathrm{mL}^{-1}$

\section{Incerteza da recuperação}

Grandezas de entrada: concentração da solução padrão e resultado da concentração encontrada.

\section{Incerteza combinada da recuperação em três concentrações}

$\mathrm{u}_{\mathrm{c}}(2,4,6$-Triclorofenolrecuperação_ 0,05$)=0,038 \mu \mathrm{g} \mathrm{mL}^{-1}$

$\mathrm{u}($ Creal $)=0,00182 \mathrm{\mu g} \mathrm{mL}^{-1}$

$\mathrm{u}($ Cencontrada $)=0,046 \mu \mathrm{g} \mathrm{mL}^{-1}$

$\mathrm{uc}_{\mathrm{c}}(2,4,6$-Triclorofenolrecuperação_o, 1$)=0,023 \mu \mathrm{g} \mathrm{mL}^{-1}$

$\mathrm{u}($ Creal $)=0,00182 \mu \mathrm{g} \mathrm{mL}^{-1}$

$\mathrm{u}\left(\mathrm{C}_{\text {encontrada }}\right)=0,023 \mu \mathrm{g} \mathrm{mL}^{-1}$

$\mathrm{u}_{\mathrm{c}}(2,4,6$-Triclorofenolrecuperação_o, 0,2$)=0,026 \mu \mathrm{g} \mathrm{mL}^{-1}$

$$
\begin{aligned}
& \mathrm{u}(\text { Creal })=0,00182 \mu \mathrm{g} \mathrm{mL}^{-1} \\
& \mathrm{u}(\text { Cencontrada })=0,027 \mu \mathrm{g} \mathrm{mL}^{-1}
\end{aligned}
$$

